\title{
Identifizierung schutzvermittelnder Antigene von Aspergillus fumigatus für eine Impfstoffentwicklung zur Verhütung invasiver Aspergillosen bei Leukämie-Patienten
}

\author{
Dissertation \\ zur Erlangung des mathematisch-naturwissenschaftlichen Doktorgrades \\ "Doctor rerum naturalium" \\ der Georg-August-Universität Göttingen
}

im Promotionsprogramm Grundprogramm Biologie
der Georg-August University School of Science (GAUSS)

vorgelegt von

Sahra Herrmann

aus Uslar

Göttingen, 2014 


\section{Betreuungsausschuss}

\section{Prof. Dr. Uwe Groß}

(Universitätsmedizin Göttingen, Institut für Medizinische Mikrobiologie)

Prof. Dr. Gerhard Braus,

(Institut für Mikrobiologie und Genetik, Abteilung Molekulare Mikrobiologie und Genetik)

\section{Mitglieder der Prüfungskommission}

Referent/in: Prof. Dr. Uwe Groß

(Universitätsmedizin Göttingen, Institut für Medizinische Mikrobiologie)

Korreferent/in: Prof. Dr. Gerhard H. Braus

(Institut für Mikrobiologie und Genetik, Abteilung Molekulare Mikrobiologie und Genetik)

Weitere Mitglieder der Prüfungskommission:

\section{Prof. Dr. Ernst Wimmer}

(Johann-Friedrich-Blumenbach-Institut für Zoologie und Anthropologie, Abteilung Entwicklungsbiologie)

Jun.-Prof. Dr. Kai Heimel

(Institut für Mikrobiologie und Genetik, Abteilung Molekulare Mikrobiologie und Genetik)

Prof. Dr. Stefanie Pöggeler

(Institut für Mikrobiologie und Genetik, Abteilung Genetik eukaryotischer Mikroorganismen)

PD Dr. Marko Rohlfs

(Johann-Friedrich-Blumenbach-Institut für Zoologie und Anthropologie, Abteilung Tierökologie)

Tag der mündlichen Prüfung: 30.06.2014 


\section{Danksagung}

Zuallererst möchte ich Herrn Prof. Dr. Utz Reichard dafür danken, dass er mir die Anfertigung dieser sehr interessanten Doktorarbeit ermöglicht hat. Für seine engagierte Betreuung, die vielen Ratschläge und Hilfestellungen, die mühevolle Arbeit des Korrekturlesens und nicht zuletzt den persönlichen Kontakt bin ich sehr dankbar.

Ein großer Dank geht an Herrn Prof. Dr. Uwe Groß für die Möglichkeit der Durchführung meiner Dissertation im Institut für Medizinische Mikrobiologie, die Anregungen während meiner Jahresberichte und die Übernahme des Referats meiner Doktorarbeit.

Bedanken möchte ich mich außerdem bei Herrn Prof. Dr. Gerhard Braus für die Übernahme des Korreferats und die hilfreichen Diskussionen während meiner Fortschrittsberichte.

Herrn Prof. Dr. Ernst Wimmer, Herrn Jun.-Prof. Dr. Kai Heimel, Frau Prof. Dr. Stefanie Pöggeler und Herrn PD Dr. Marko Rohlfs möchte ich für die Bereitschaft, Mitglied meiner Prüfungskommission zu werden, danken.

Bei Iris Iben möchte ich mich für die hervorragende Zusammenarbeit bedanken und dafür, dass wir uns auch privat, fernab des Laborsalltags, so gut verstehen.

Ich bedanke mich bei Herrn Prof. Dr. Axel Brakhage, dass er es mir ermöglicht hat, im Zuge unserer Kooperation, einige Wochen in der Abteilung Molekulare und Angewandte Mikrobiologie am Leibniz-Institut für Naturstoff-Forschung und Infektionsbiologie am Hans Knöll Institut (HKI) in Jena zu arbeiten. Bedanken möchte ich mich außerdem dafür, dass ich währenddessen und einige Zeit darüber hinaus vom HKI finanziert wurde. Vera Pähtz gilt mein Dank für die besonders nette Zusammenarbeit und ihre mir entgegengebrachte Hilfsbereitschaft. Sylke Fricke danke ich für ihre unermüdliche Unterstützung im Labor und Dr. Maria Straßburger für die Durchführung der Mausinfektionsversuche. 
Des Weiteren möchte ich mich bei Herrn Prof. Dr. Sven Krappmann dafür bedanken, dass ich eine Woche in seinem Labor in Würzburg arbeiten durfte und dabei die Technik der Komplementierung erlernen konnte.

Ebenso gilt mein Dank Herrn Prof. Dr. Frank Ebel (München) für die Überlassung einiger rekombinanter Proteine und Herrn Prof. Dr. Michel Monod (Lausanne, Schweiz) für die Bereitstellung einiger Plasmide zur Proteinexpression.

Für die Finanzierung möchte ich mich bei der José-Carreras Leukämie-Stiftung e. V. bedanken (Projektnummer: DJCLS R 10/31f).

Allen Kollegen danke ich für die vielen konstruktiven Gespräche und Vorschläge, für ihre Hilfsbereitschaft, für's Zuhören, Aufmuntern und die schöne gemeinsame Zeit.

Ich bedanke mich an dieser Stelle auch bei meinen Freunden - für die aufmunternden (Telefon-/Skype-) Gespräche, Spaziergänge, Spieleabende, entspannenden Ausritte durch den Solling, die netten Unterhaltungen im Reitstall und die Abende mit dem Kulturticket oder im Kino. Ihr habt versucht, mich zu den richtigen Zeitpunkten zu motivieren, wart für mich da und habt immer an mich geglaubt. Danke!

Bei Katja Reich möchte ich mich außerdem für das sorgfältige Korrekturlesen bedanken.

Schließlich und keineswegs zuletzt, möchte ich meiner Familie - meinen Eltern und meinem Bruder - danken, für ihre großartige Unterstützung, ihren unermüdlichen Zuspruch und ihren Glauben an mich. Ohne euch wäre diese Doktorarbeit nicht möglich gewesen! 


\section{Inhaltsverzeichnis}

Danksagung .........................................................................................................................

Inhaltsverzeichnis ........................................................................................................... III

Abkürzungsverzeichnis ................................................................................................... VII

1 Einleitung........................................................................................................................................... 1

1.1 Taxonomie und Morphologie von Aspergillus fumigatus .................................... 1

1.2 A.fumigatus und seine ökologische Bedeutung ............................................... 2

1.3 A.fumigatus als humanpathogener Erreger ....................................................... 2

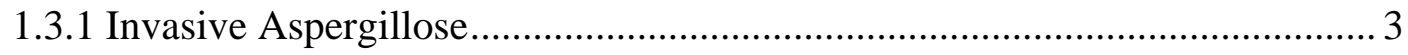

1.3.2 Andere durch A.fumigatus hervorgerufene Erkrankungen ........................... 4

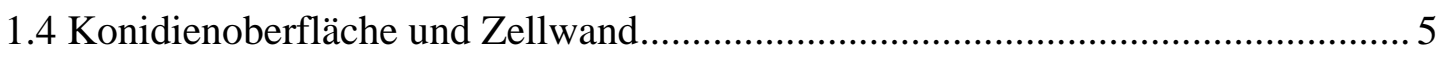

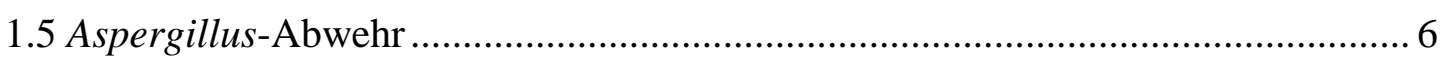

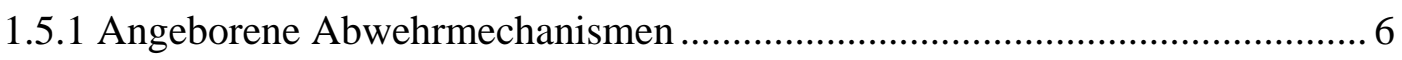

1.5.2 Erworbene Abwehrmechanismen ........................................................... 9

1.6 Vakzinierungsversuche gegen A.fumigatus .................................................. 11

1.7 Screening-Methoden für die Suche nach schützenden Antigenen........................ 12

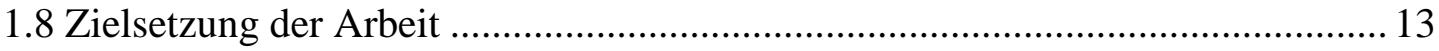

2 Material und Methoden................................................................................................. 15

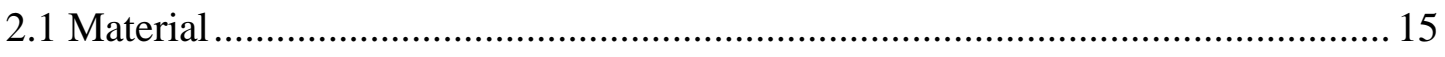

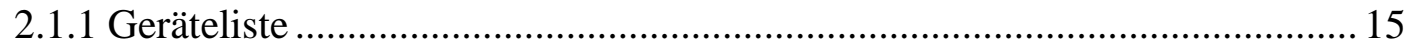

2.1.2 Verwendete Software und Internet-Tools ............................................. 17

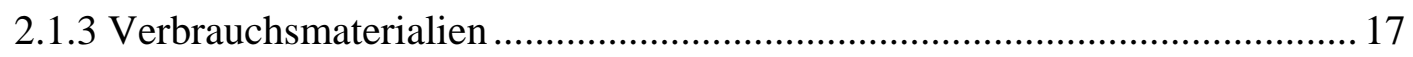

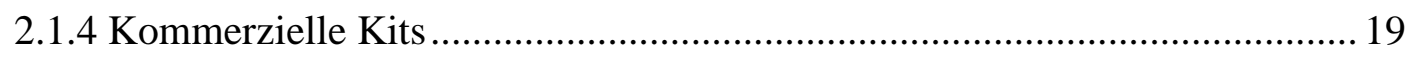

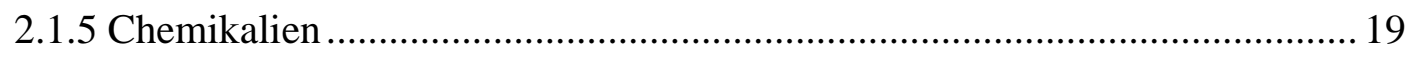

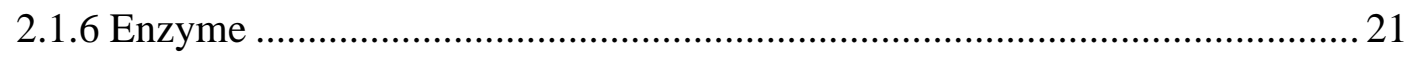

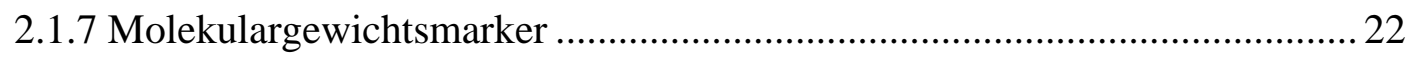




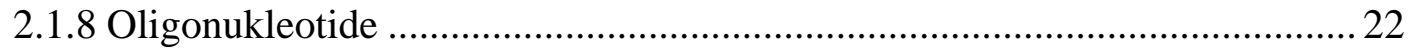

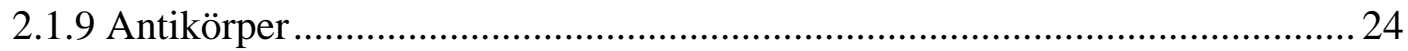

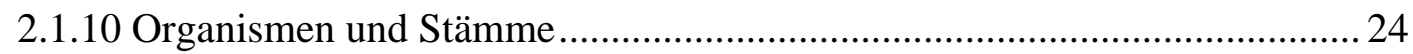

2.1.11 Plasmide und Proteinexpressionsplasmide ............................................ 24

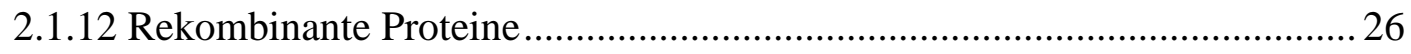

2.1.13 Platten zur Anzucht von Aspergillen ....................................................... 27

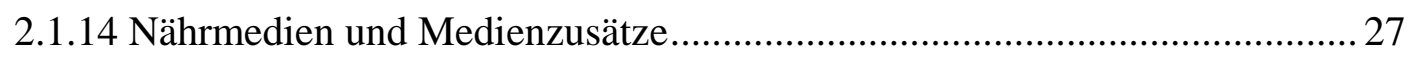

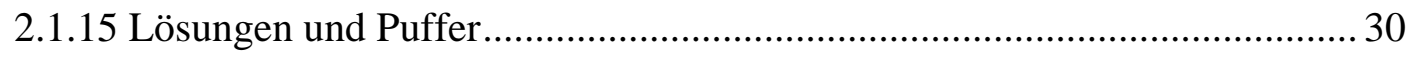

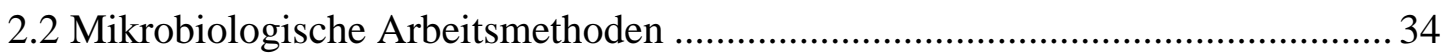

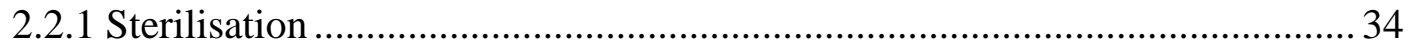

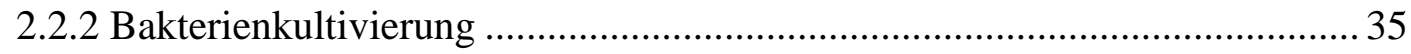

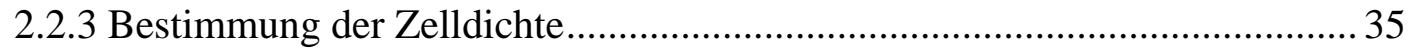

2.2.4 Herstellung elektrokompetenter E.coli ...................................................... 35

2.2.5 Transformation kompetenter E.coli …................................................... 35

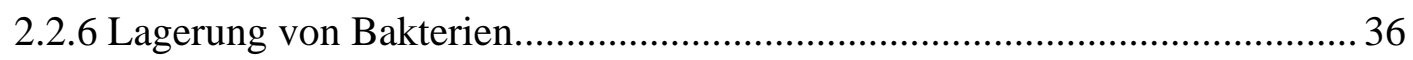

2.2.7 Herstellung einer A.fumigatus-Sporensuspension .................................... 36

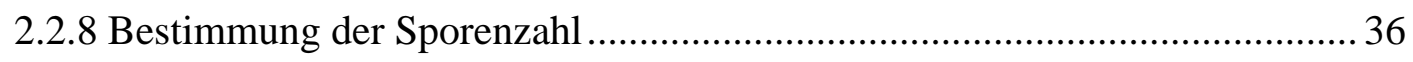

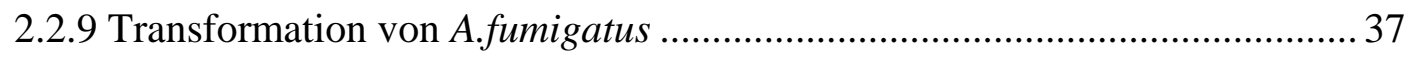

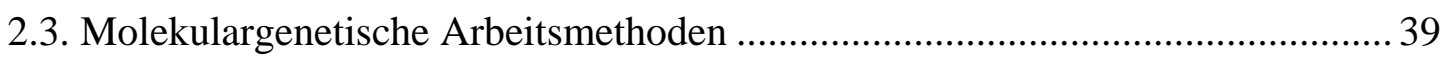

2.3.1 Isolierung von Transformanten-DNA für PCR-Ansatz .............................. 39

2.3.2 Isolierung von genomischer DNA aus A.fumigatus................................... 40

2.3.3 Präparation von Plasmid-DNA aus E.coli .................................................. 41

2.3.4 Bestimmung der Nukleinsäurekonzentration........................................... 41

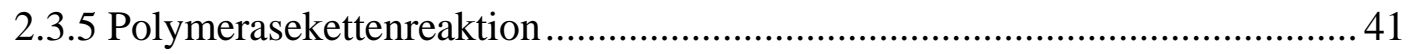

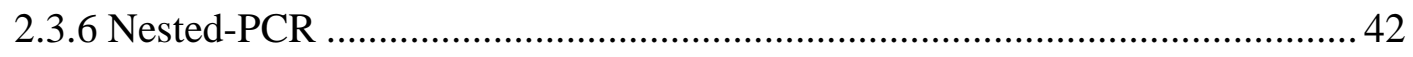

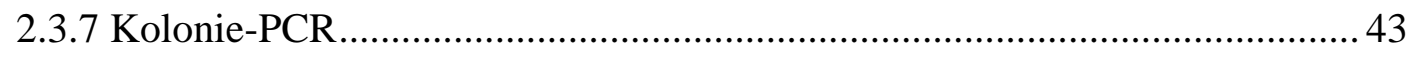

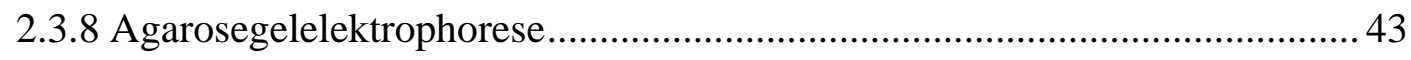




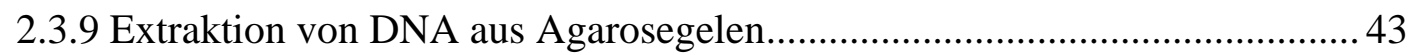

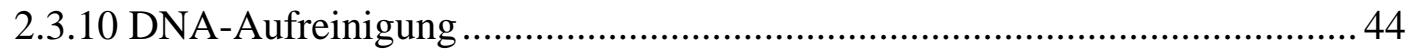

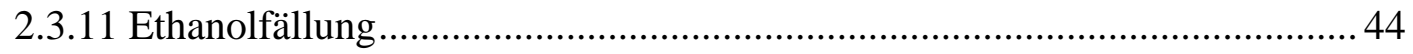

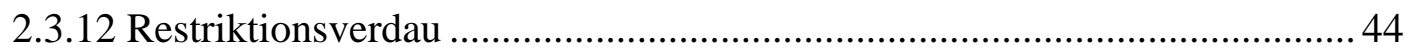

2.3.13 Dephosphorylierung von Plasmid-DNA .............................................. 45

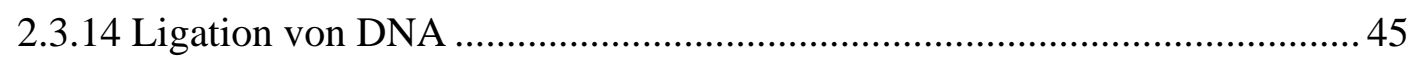

2.3.15 GeneArt ${ }^{\circledR}$ Seamless Cloning and Assembly Kit ..................................... 46

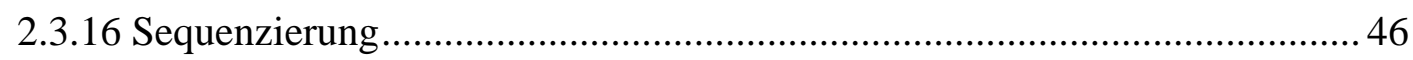

2.3.17 Herstellung einer Digoxigenin-markierten Sonde ................................... 46

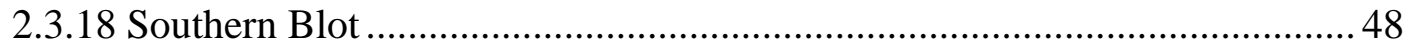

2.4 Proteinanalytische Arbeitsmethoden ............................................................... 50

2.4.1 Produktion und Aufreinigung His-getagter Proteine zur Verimpfung ..........50

2.4.2 Herstellung der HP16-Expressionsplasmide und Test auf rekombinante

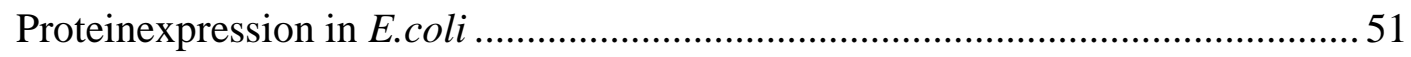

2.4.3 Aufreinigung His-getagter Proteine .......................................................... 52

2.4.4 Diskontinuierliche SDS-Polyacrylamid-Gelelektrophorese ......................... 53

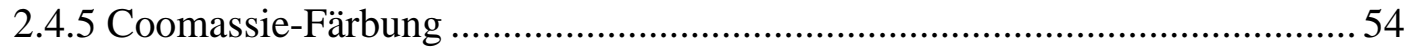

2.5 Charakterisierung der A.fumigatus Aspf3-Deletionsmutante und

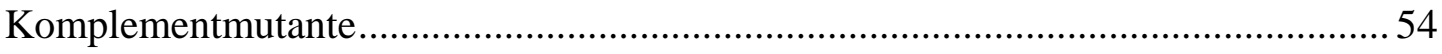

2.5.1 Wachstumskontrolle der Aspf3-Deletions- und Komplementmutante........... 54

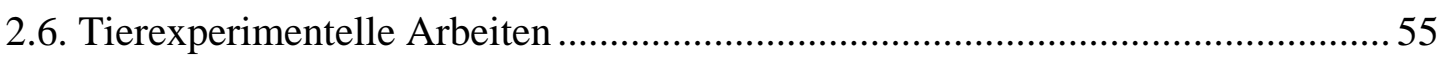

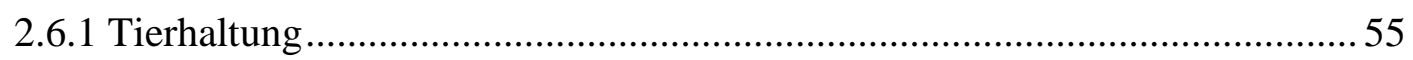

2.6.2 Immunisierung mit rekombinanten A.fumigatus-Proteinen im Mausmodell. 55

2.6.3 Immunsuppression der Mäuse mit A.fumigatus-Konidien ........................... 55

2.6.4 Infektion der Mäuse mit A.fumigatus-Konidien .........................................56

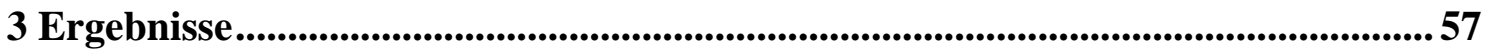

3.1 Herstellung von Gen-Deletionsmutanten und Komplementmutanten in

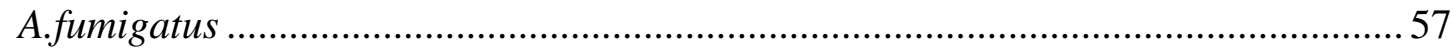




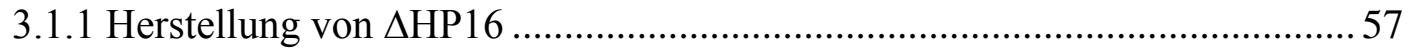

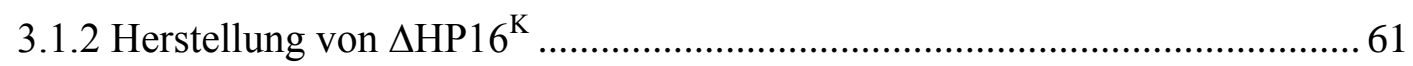

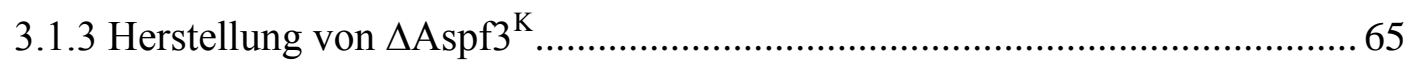

3.2 Biochemische Charakterisierung der Aspf3-Deletionsmutante und -

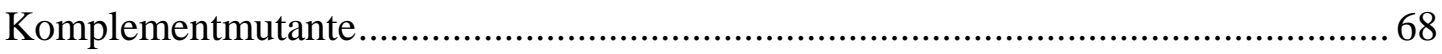

3.3 Herstellung des rekombinanten Proteins HP16 …............................................ 70

3.3.1 Expression von HP16 in E.coli unter Verwendung eines His-Tags .............. 70

3.4. Etablierung eines Mausmodells mit Dosisfindungsstudie ................................. 72

3.5 Immunisierung mit rekombinanten A.fumigatus-Proteinen im Mausmodell........ 73

3.6 Virulenztestung der A.fumigatus-Deletionsmutanten im Vergleich zu ihrer Komplementmutanten und dem Wildtyp D141 .................................................. 80

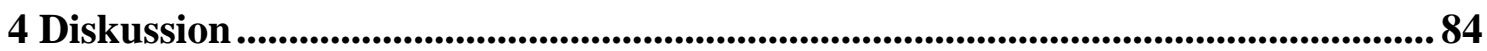

4.1 Deletionsmutante $\Delta$ HP16 eines ausgewählten Konidienoberflächenproteins von

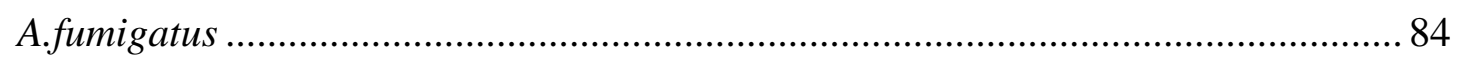

4.2 Untersuchung des hypothetischen Proteins HP16 …........................................ 85

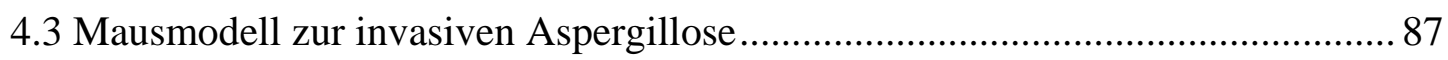

4.4 Virulenzversuche mit dem hypothetischen Protein HP16 …............................... 88

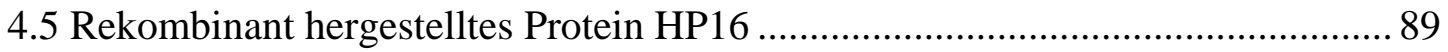

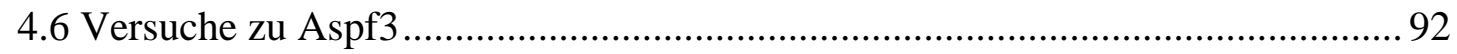

4.7 Immunisierung von Mäusen mit rekombinanten Proteinen................................ 95

4.8 Einschränkungen und Verbesserungen bei der Impfstoffsuche........................... 98

5 Zusammenfassung …....................................................................................................... 101

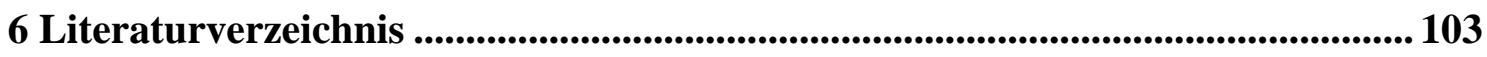

7 Anhang

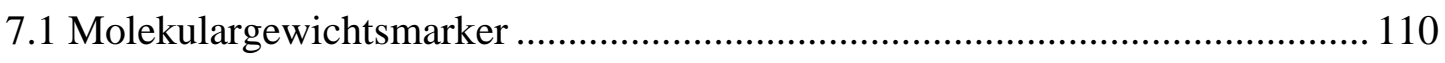

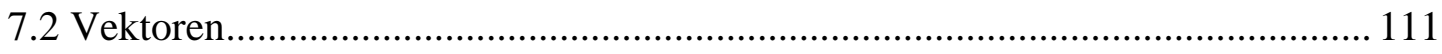

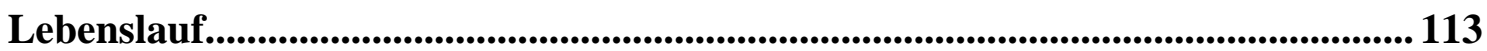




\section{Abkürzungsverzeichnis}

${ }^{\circ} \mathrm{C}$

Abb.

ABPA

A.fumigatus

APS

AS

bp

bzw.

C.albicans

$\mathrm{CF}$

DIG

DNA

dNTP

E.coli

EDTA

et al.

g

$\mathrm{h}$

$\mathrm{HCl}$

IA

IFN

IL

$\mathrm{kDa}$

LB

MHC

$\min$

MM-Medium

$\mathrm{NaCl}$

$\mathrm{NaOH}$

NET
Grad Celsius

Abbildung

allergische bronchopulmonale Aspergillose

Aspergillus fumigatus

Ammoniumperoxosulfat

Aminosäure

Basenpaare

beziehungsweise

Candida albicans

Cystischer Fibrose

Digoxigenin

Desoxyribonukleinsäure (desoxyribonucleic acid)

Desoxyribonukleotid

Escherichia coli

Ethylendiamintetraessigsäure

und andere (et alii)

Erdbeschleunigungskonstante $\left(9,81 \mathrm{~m} / \mathrm{s}^{2}\right)$

Stunde (hora)

Salzsäure

invasive Aspergillose

Interferon

Interleukin

Kilodalton

lysogeny broth

Haupthistokompatibilitätskomplexe

(major histocompatibility complex)

Minute

Minimal-Medium

Natriumchlorid

Natriumhydroxid

neutrophile extrazelluläre Fallen (neutrophil extracellular traps) 
Ni-NTA

NK-Zellen

$\mathrm{OD}_{\lambda}$

$\mathrm{OM}$

PBS

$P f u$

$\mathrm{pH}$

p.i.

rpm

PRR

ROI

s.

s.c.

SDS-PAGE

sec

Tab.

TAE

Taq

TB-Puffer

TB-Medium

TBE

TEMED

TLR

Tween

U

$\mathrm{U} / \mathrm{min}$

usw.

V

$\mathrm{w} / \mathrm{v}$

z.B.
Nickel-Nitrilotriessigsäure (nickel nitrilotriacetic acid)

Natürlichen Killer-Zellen

optische Dichte der Wellenlänge $\lambda$ (in nm)

osmotisches Medium

Phosphatgepufferte Salzlösung (phosphate buffered saline)

Pyrococcus furiosus

negativer dekadischer Logarithmus der

Wasserstoffionenkonzentration

nach einer Infektion (post infectionem)

Umdrehung pro Minute (rounds per minute)

Pathogen-Erkennungsrezeptoren (pathogen recognition receptor)

reaktiven Sauerstoffspezies (reactive oxidant intermediates)

siehe

unter der Haut (subkutan)

Natriumdodecylsulfat-Polyacrylamidgelelektrophorese (sodium

dodecyl sulfate polyacrylamide gel electrophoresis)

Sekunde

Tabelle

Tris-Acetat-EDTA-Puffer

Thermus aquaticus

trapping buffer

terrific broth

Tris-Borat-EDTA-Puffer

$\mathrm{N}, \mathrm{N}, \mathrm{N}^{\prime}, \mathrm{N}^{\prime}-$ Tetramethylethylendiamin

Toll-ähnlicher Rezeptor (toll-like receptor)

Polyoxyethylensorbitanmonolaurat

Unit

Umdrehungen pro Minute

und so weiter

Volt

Masse pro Volumen (weight per volume)

zum Beispiel 


\section{Einleitung}

\subsection{Taxonomie und Morphologie von Aspergillus fumigatus}

Die Spezies Aspergillus fumigatus (A.fumigatus) wurde zuerst 1863 von Johann Baptist Georg Wolfgang Fresenius beschrieben. Der Name des Schimmelpilzes A.fumigatus lässt sich von lat. fumus (der Rauch) ableiten und bezieht sich auf die rauchgrüne Farbe des Pilzes.

Die effiziente Verbreitung von A.fumigatus wird durch die Produktion einer großen Zahl asexueller Sporen, so genannter Konidien, gewährleistet. Dabei bildet jedes Konidiophor (Konidienträger) tausende Konidien, die an basipeptalen Ketten aus Phialiden verankert sind (Abb. 1). Diese Konidien werden in die Atmosphäre freigesetzt, haben einen Durchmesser von nur 2-3 $\mu \mathrm{m}$ und sind klein genug, um nach dem Einatmen bis in die Lungenbläschen (Alveolen) zu gelangen [1].

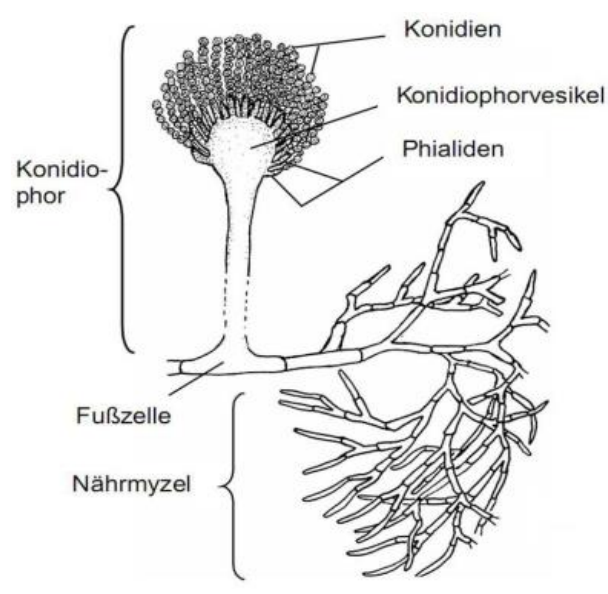

Abb. 1: Morphologie von A.fumigatus in schematischer Darstellung (modifiziert nach [2]).

In feuchter Umgebung und wärmeren Temperaturen kommt es zur Auskeimung ruhender Konidien. Die charakteristische, echinulate Morphologie ruhender Sporen beginnt sich mit der Zeit zu verändern. So zeigen geschwollene Konidien eine deutlich geschnürte Oberflächenstruktur [3]. Der Übergang von der Keimung hin zum vegetativen Wachstum wird von der Ausbildung von Keimschläuchen gekennzeichnet. Es bilden sich Hyphen, aus denen sich dann das Myzel entwickelt. Die Basis des Konidophor wird durch eine Fußzelle gebildet, die senkrecht dem Nährmyzel 
entspringt. Am distalen Ende des Konidiophors findet sich ein Vesikel, welchem wiederum zu allen Seiten Phialiden aufsitzen.

A.fumigatus wurde lange Zeit zu den Vertretern der Deuteromycota gezählt, da nur sein asexueller Lebenszyklus beobachtet werden konnte. Neuere Erkenntnisse wiesen jedoch auch auf eine sexuelle Reproduktion bei A.fumigatus hin. So konnte durch Genomanalysen das Vorhandensein von 215 Genen belegt werden, die in die sexuelle Entwicklung involviert sind, darunter die kreuzungstypspezifischen Gene MAT1-1 und MAT1-2, sowie Gene für Pheromonsynthese und deren entsprechende Rezeptoren [4,5]. Den endgültigen Nachweis erbrachten O'Gorman et al. [6], die im Jahr 2009 einen vollfunktionellen Fortpflanzungszyklus nachwiesen. Sie beobachteten auch die Bildung von Ascosporen in für Ascomyceten typischen Cleistothecien sowie sein Teleomorph Neosartorya fumigata.

\subsection{A.fumigatus und seine ökologische Bedeutung}

Pilze sind eukaryontische Lebewesen mit einer ausgeprägten Zellwand, die anders als bei Pflanzen oft aus relativ hohen Chitinanteilen besteht. Ihren Energiebedarf decken Pilze durch den Abbau organischer Substanzen; ein Vorgang, der als Heterotrophie bezeichnet wird. A.fumigatus spielt als ein Vertreter saprophytischer Pilze eine wichtige Rolle bei der Aufbereitung von Kohlenstoff und Stickstoff in der Umwelt [7]. Seine natürliche ökologische Nische ist der Boden. A.fumigatus ist eine thermophile Spezies, sein Wachstum wurde bei Temperaturen von bis $\mathrm{zu} 55^{\circ} \mathrm{C}$, sein Überleben sogar bei zu $70^{\circ} \mathrm{C}$ nachgewiesen (zur Übersicht [1]).

\subsection{A.fumigatus als humanpathogener Erreger}

Obwohl A.fumigatus nur einen geringen Anteil der Schimmelpilzisolate in der Luft eines Krankenhauses ausmacht $(0,3 \%)$, findet sich der Pilz bei ca. $44 \%$ der Patientenisolate [8]. Zudem verursacht A.fumigatus etwa $90 \%$ aller invasiven Aspergillosen [9]. Auf Grund seiner enormen Kapazität zur Sporulierung ist die Konzentration mit 1-100 Konidien pro Kubikmeter in der Luft sowohl in Innenräumen als auch im Freien sehr hoch [10]. Bei immunkompetenten Menschen verursachen diese Konidien normalerweise keine invasiven Erkrankungen. Sie werden effizient von den 
Abwehrmechanismen innerhalb der Lunge eliminiert [11]. Dennoch kann das Zusammentreffen zwischen Aspergillus und dem Wirt mit einem breiten Spektrum an Krankheiten einhergehen. Die Krankheiten, die von A.fumigatus verursacht werden, sind vielfältig und können in drei Kategorien unterteilt werden, welche in Abhängigkeit zur Immunreaktion des Wirtes stehen: (I) invasive Infektionen, die durch das Wachstum von Hyphen in Geweben gekennzeichnet sind; (II) Infektionen, die durch die Besiedlung der Schleimhäute ohne Invasion in das Gewebe einhergehen; und (III) Hypersensitivitätserkrankungen, die durch die Immunantwort des Wirtes hervorgerufen werden (Abb. 2) [12].

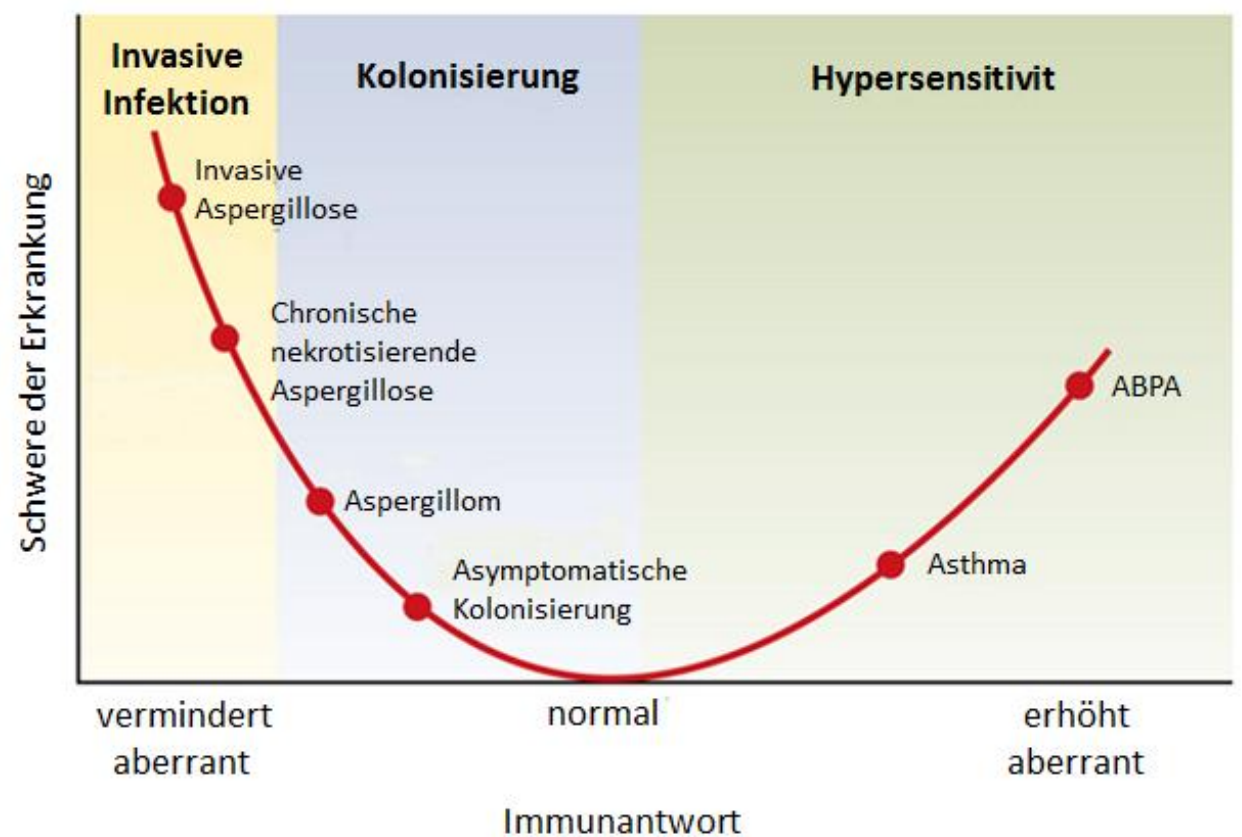

Abb. 2: Schematische Darstellung von Krankheiten, die Aspergillus-Arten zugeschrieben werden, resultierend aus unterschiedlichen Wirt-Immunantworten (verändert nach Park 2009 [12]).

\subsubsection{Invasive Aspergillose}

Anders als bei gesunden Personen, bei denen Konidien durch die pulmonale Abwehr beseitigt werden, werden bei immunsupprimierten Patienten die eingeatmeten Aspergillus-Konidien nicht oder nur unzureichend phagozytiert. So keimen diese innerhalb weniger Stunden aus, und ihre Hyphen wachsen invasiv in das Lungengewebe ein [13]. Die dabei im Vordergrund stehende Eigenschaft des invasiven AspergillusHyphenwachstums hat auch zur Namensgebung der Erkrankung als invasive Aspergillose (IA) geführt. 
Allgemein hat die Häufigkeit von invasiven, oft tödlich verlaufenden Mykosen in den letzten beiden Jahrzehnten erheblich zugenommen (zur Übersicht [14]). Dies wird auf die steigende Anzahl von Patienten mit einem Risiko für die Entwicklung schwerer Pilzinfektionen zurückgeführt. Im Vordergrund stehen die Durchführung von Organtransplantationen, Blut- und Knochenmarkstransplantationen, größere Operationen, Infektionskrankheiten wie HIV, Tumorerkrankungen, immunsuppressive Therapie, erhöhtes Alter und Frühgeburten (zur Übersicht [15]). Patienten mit dem höchsten Risiko für eine invasive Aspergillose sind diejenigen mit einer signifikanten Reduktion in der Anzahl oder Funktion ihrer Granulozyten, etwa Leukämiepatienten, die sich einer Chemotherapie unterziehen. Auch Patienten unter Langzeittherapie mit Immunsuppressiva, vor allem bei Behandlung mit Cortison (z.B. Patienten nach Organtransplantation), sind mit einem erhöhten Risiko konfrontiert [16,17]. Trotz der Entwicklung neuer Behandlungen liegt die Sterblichkeit bei Patienten mit IA bei $50 \%$, in bestimmten Situationen bei bis zu $95 \%[11,18]$.

\subsubsection{Andere durch A.fumigatus hervorgerufene Erkrankungen}

Neben der beschriebenen IA bei immunsupprimierten Patienten kann A.fumigatus noch eine Reihe weiterer Erkrankungen bei immunkompetenten Patienten auslösen. Hierzu zählen Asthma, allergische Sinusitis und allergische Alveolitis. Sie finden sich vor allem nach wiederholter Exposition gegen Konidien oder Antigene von Aspergillus, wobei eine Kolonisierung des Wirtes ausbleibt. In den meisten Fällen reicht oft die Vermeidung des Kontakts mit dem Agens aus, um den Erkrankungen vorzubeugen.

Die allergische bronchopulmonale Aspergillose (ABPA) hingegen ist hiervon abzutrennen, da sie zusätzlich mit einer Besiedlung des Bronchialsystems mit dem Pilz einhergeht. Die Erkrankung manifestiert sich als Asthma bronchiale mit transienten Lungeninfiltraten, wobei die chronische Entzündung oft terminal in einer Lungenfibrose mündet (zur Übersicht [1]). ABPA tritt meist bei Personen auf, die an atopischem Asthma oder Cystischer Fibrose (CF) leiden. Es wird angenommen, dass die Prävalenz von ABPA bei etwa 1-2 \% bei Patienten mit Asthma und bei 2-15\% bei Patienten mit CF liegt [19]. 
Auch beim Aspergillom steht eine Kolonisierung des Wirtes im Vordergrund, jedoch im sind Gegensatz zur ABPA kaum allergische Reaktionen zu beobachten. Das Aspergillom, das auf Grund seiner Erscheinung auch als „Pilzball“ bezeichnet wird [20], ist die häufigste und bekannteste Form des Lungenbefalls durch Aspergillus. Es besteht aus Pilzmyzel, entzündlichen Zellen, Fibrin, Schleim und Gewebetrümmer, wobei die Entwicklung in der Regel in einem Hohlraum der Lunge stattfindet [21]. Eine Vorerkrankung durch Tuberkulose kann als der häufigste prädisponierende Faktor angesehen werden [21,22]. Dabei bildet sich der Ball in der präformierten Höhle, der Kaverne, aus.

\subsection{Konidienoberfläche und Zellwand}

Die wichtigste Aufgabe der Zellwand ist ihre Schutzfunktion als äußere Barriere, aber ihr wird auch die Vermittlung von pathogenen Eigenschaften zugeschrieben. So steht die Pilzzellwand in direktem Kontakt mit der Umgebung, wobei es Strukturen gibt, die wiederum als Ziele für das Immunsystem des Wirtes agieren [23]. Die wichtigsten Bestandteile der A.fumigatus-Zellwand sind Polysaccharide (mindestens $90 \%$ ) [24], die auf Grund ihres Löslichkeitverhaltens in heißen Basen in zwei Gruppen eingeteilt werden können. Dabei besteht die lösliche Fraktion hauptsächlich aus $\alpha$-(1,3)-Glukan mit einem geringen Anteil an Galaktomannan. Im Gegensatz dazu besteht die unlösliche Fraktion, die für die Rigidität der Zellwand verantwortlich ist, hauptsächlich aus $\beta$ $(1,3)$ - und $\beta$-(1,6)-Glukanen. Diese Polysaccharide dienen der Verankerung anderer Polysaccharide, wie Chitin und Galaktomannan [25,26].

Während der Keimphase erfolgt ein kontinuierlicher Umbau der Zellwand [27]. In den ersten Phasen der Keimung (Aufblähung) verursacht die Hydrolyse der Polysaccharide das Weichmachen und Verdünnen der ursprünglichen Wand, der eine de novo-Synthese einer neuen Innenschicht folgt. Die wachsenden Hyphen haben nur eine einzige Zellwandschicht. Die Konidien von A.fumigatus mit ihrer Funktion als Dauer- und Verbreitungsform haben eine doppelschichtige Zellwand. Im Gegensatz zum Myzel sind Konidien von Hydrophobinen, sogenannten Rodlets, bedeckt. Dies bewahrt sie vor der Erkennung durch Immunzellen und macht die Konidien somit immunologisch inert [28]. Dabei enthält die äußere Zellwandschicht zwei Hydrophobine, RodA und RodB, die als wasserunlösliche Komplexe vorliegen [29]. Konidien einer $\Delta$ RodA- 
Deletionsmutante bilden keine Rodlet-Schicht aus [30]. Die Deletion des rodB-Gens hat hingegen keinen Einfluss auf die Ausbildung der Rodlet-Schicht [29].

Glycosylphosphatidylinositol (GPI)-verankerte Proteine spielen eine wichtige Rolle in der Morphogenese des Pilzes und der Zellwandorganisation [31]. GPI-Anker sind konservierte Modifikationen in Eukaryoten, mit deren Hilfe viele Zelloberflächenproteine, wie Zelloberflächenenzyme, Rezeptoren und Adhesionsmoleküle, in der Zellmembran verankert sind [32]. In einer Arbeit von Cao et al. [33] wurden durch Zuhilfenahme des Tools „GPI-SVM+SignalP-Vote“ 115 potentielle GPIverankerte Proteine für A.fumigatus vorhergesagt. Untersuchungen bei A.fumigatus legen nahe, dass mindestens neun GPI-verankerte Proteine orthologe Korrelate in Hefen besitzen [32]. In einer Arbeit von Li et al. konnte durch die Analyse von Mutanten gezeigt werden, dass eine komplette Blockierung der GPI-Anker-Synthese in A.fumigatus zu Zellwanddefekten, abnormalem Hyphenwachstum und schneller Konidienkeimung bei insgesamt abnormaler Konidiation führt. In vivo-Tests zeigten eine reduzierte Virulenz dieser Mutanten in Mäusen. Die GPI-Verankerung von Proteinen ist damit nicht notwendig für die Lebensfähigkeit von A.fumigatus, aber für Zellwandintegrität, Morphogenese und Virulenz [32].

\subsection{Aspergillus-Abwehr}

Die angeborene Immunität (,,innate immunity“) wird als die erste Verteidigungslinie betrachtet. Diese aktiviert ihrerseits aber auch erworbene Immunmechanismen (,adaptive immunity“) mittels spezifischer Signale. Angeborene und erworbene Immunität sind deshalb eng miteinander verknüpft [34].

\subsubsection{Angeborene Abwehrmechanismen}

\section{Mechanische Abwehr}

Die Abwehr eingeatmeter Konidien beginnt mit Hilfe der physikalischen Barrieren der Atemwege. Dazu gehören die Nasenmuscheln und die Verzweigungsstruktur der Bronchien. Es kommt zu einem turbulenten Luftstrom, so dass sich die meisten Konidien auf der Atemwegs-Oberflächenflüssigkeit absetzen. Anschließend werden die 
Konidien durch die ziliare Wirkung des respiratorischen Epithels beseitigt. Ist diese mechanische Abwehr allerdings gestört, können die Konidien in tiefer gelegene Lungenabschnitte gelangen und finden sich dann jenseits der Bronchioli in den Alveolen wieder. Nun müssen komplexere Mechanismen der Eliminierung von A.fumigatus greifen. Diese beinhalten die antimikrobiellen Mechanismen der ansässigen Lungen-Leukozyten, wie Alveolarmakrophagen und dendritische Zellen, Rekrutierung anderer Leukozyten und die Aktivierung der rekrutierten Leukozyten nach ihrer Ankunft am Ort der Infektion [12].

\section{Makrophagen}

Alveolarmakrophagen sind die primären phagozytierenden Zellen innerhalb der Atemwege und somit eine wichtige Abwehrkomponente. Allerdings können die Makrophagen nur kurz vor der Aussprossung (Germination) stehende, metabolisch aktive Konidien abtöten [35]. Dieser Zustand wird von den Konidien erst einige Stunden nach Inhalation erreicht, entweder in den terminalen Luftwegen oder noch später in den Phagosomen der Makrophagen. Aspergillus-Sporen werden in einer aktinabhängigen Weise phagozytiert, ein Mechanismus, der mit Hilfe der pathogenassoziierten Erkennungsrezeptoren (PRR; ,pathogen recognition receptor") der Wirtszellen einhergeht [36]. PRR-Bindung von Aspergillus-Liganden erzeugt eine proinflammatorische Reaktion, die durch die Produktion von Zytokinen und Chemokinen gekennzeichnet ist. Der Toll-ähnliche Rezeptor 2 (TLR; „toll-like receptor"), TLR4 und der Dektin-1-Rezeptor sind die am besten charakterisierten PRRs bei der Erkennung von A.fumigatus und der Aktivierung der Wirtszellen [36]. In vitroStudien haben ergeben, dass Konidien und Hyphen Makrophagen über TLR2 und TLR4 aktivieren, wobei TLR2 sowohl Konidien- als auch Hyphen-Stadien erkennt; TLR4 allerdings nur das Hyphenstadium [37]. Dektin-1 ist der spezifische Rezeptor für das $\beta$ (1,3)-Glukan der Pilzzellwand, welches sich allerdings normalerweise nicht auf der Oberfläche von ruhenden Konidien befindet. Aber nach Schwellung der Konidien und dem daraus resultierenden Verlust der hydrophoben proteinösen Zellwand wird $\beta-(1,3)-$ Glukan nach oberflächlich exponiert [38]. An Glukan gebundenes Dektin-1, unter Mitwirkung der TLRs, aktiviert die Zellen des angeborenen Immunsystems zum Phagozytieren, eliminiert Konidien und löst proinflammatorische Reaktionen aus [36]. 


\section{Phagozytose durch Makrophagen}

Damit Konidien von Alveolarmakrophagen phagozytiert werden können, wird nach Bindung an einen wie oben erwähnten Rezeptor zuerst die Bildung von Aktinabhängigen Membranerweiterungen und Plasmaausstülpungen um die Konidien erzeugt [39]. Sind die Konidien komplett umschlossen und damit internalisiert, spricht man von einem Phagosom. Dieses verschmilzt anschließend mit einem oder mehreren Lysosomen zum so genannten Phagolysosom [40]. Die Abtötung von A.fumigatusKonidien durch Alveolarmakrophagen beginnt ca. sechs Stunden nach der Phagozytose. Dabei ist das Anschwellen der Konidien die Bedingung für ihre Tötung [41]. Zum Phagozytieren geschwollener Konidien sind außerdem reaktive Sauerstoff-Metabolite (ROI; „reactive oxidant intermediates“) und die phagolysosome Ansäuerung Voraussetzung [41]. Nach dem Phagozytieren findet in den Makrophagen eine Reihe von Stoffwechselreaktionen statt, die mit einer massiven Freisetzung von reaktiven Sauerstoffspezies einhergeht. Dieser Prozess wird als respiratorische Entladung (,respiratory burst") bezeichnet [42].

\section{Neutrophile Granulozyten}

Als zweite Abwehrlinie gegen die Aspergillus-Infektion gelten neutrophile Granulozyten; sie nutzen auch verschiedene PRRs, einschließlich TLRs und Dektin-1, um A.fumigatus zu erkennen und auf den Pilz zu reagieren [36]. Wie Makrophagen sind Neutrophile erst dann in der Lage Aspergillus-Konidien abzutöten, wenn diese bereits metabolisch aktiv und im Auskeimen begriffen sind [35]. Neutrophile können ganze Pilzelemente auf Grund ihrer Größe nicht mehr phagozytieren. Sie nutzen deshalb neutrophile extrazelluläre Fallen (NET; ,neutrophil extracellular traps“), um wachsende Hyphen zu zerstören. Diese setzen sich aus DNA-Fasern, die überzogen sind von Granulat und zytosolischen Proteinen, zusammen [43]. Der Pilz wird von den NETs eingefasst; diese verhindern dessen weitere Ausbreitung und helfen bei der Rekrutierung von Neutrophilen und anderen Immunzellen an den Ort der Infektion [44].

\section{$\underline{\text { Natürliche Killer-Zellen }}$}

Die Natürlichen Killer-Zellen (NK-Zellen) bilden zusammen mit den B- und T-Zellen die Gruppe der Lymphozyten. Auf Grund der fehlenden Antigen-spezifischen Rezeptoren gehören sie zur angeborenen Immunantwort und haben eine Lebensspanne 
von ungefähr zwei Wochen [45]. Im Gegensatz zu den klassischen B- und T-Zellen benötigen NK-Zellen keine klonale Vermehrung, bevor sie effektiv auf Antigene ansprechen können [34,46]. Die meisten NK-Zellen befinden sich in den vaskulären und interstitiellen Kompartimenten der Lungen und damit auch in unmittelbarer Nähe zu eingeatmeten Aspergillen [47]. Untersuchungen zur Interaktion zwischen NK-Zellen und A.fumigatus ergaben, dass NK-Zellen den Pilz direkt durch die Freisetzung von Interferon- $\gamma(\mathrm{IFN}-\gamma)$ schädigen, wobei IFN- $\gamma$ eine dosisabhängige fungizide Wirkung hat [48].

\subsubsection{Erworbene Abwehrmechanismen}

Entscheidend für die Abwehr von systemischen Pilzinfektionen sind die angeborenen Abwehrmechanismen in erster Linie durch Granulozyten und Makrophagen. Die Rolle der erworbenen Immunität beim Menschen ist unklar. Im Tierversuch ließ sich jedoch eine erworbene, schützende Immunität gegen systemische Pilzinfektionen erzeugen (zur Übersicht [49]). So entsteht erworbene Immunität im Tier gegen A.fumigatus sowohl nach einer überlebten Infektion mit dem Pilz, als auch durch eine Verimpfung von A.fumigatus-Kulturüberstand [50-52]. Wenn das Immunsystem nicht erfolgreich gegen die Konidien und die ersten Hyphenstadien angehen konnte, führte die andauernde Antigen-Präsentation und klonale Vermehrung von Aspergillus-antigenspezifischen TZell-Klonen in den darauffolgenden Tagen zur Ausbildung der erworbenen Immunität [12].

Hierbei erkennen die T-Zell-Rezeptoren auf der Th0-Zelle das von Makrophagen oder dendritischen Zellen über den Haupthistokompatibilitätskomplex II (MHCII, „major histocompatibility complex“) präsentierte Antigen (MHCII-Restriktion). Je nach Antigen kommt es in der Folge zu einer Differenzierung der Th0-Zelle in eine Th1oder Th2-Zelle (zur Übersicht [10]). Th1-Zellen aktivieren (nach klonaler Proliferation) nun ihrerseits Makrophagen, welche dann in die Lage versetzt werden, Aspergillus effizienter abzutöten (zelluläre Immunität). Th2-Zellen führen zu einer klonalen Vermehrung spezifischer B-Zellen, die ihrerseits Aspergillus-Antigen-spezifische Antikörper freisetzen (humorale Immunität). Wie bei anderen Pilzen scheint die Produktion von Th1-Zytokinen schützend zu sein, dagegen die Th2-Reaktionen nicht [53]. 


\section{Zelluläre Immunität}

In vivo-Studien haben gezeigt, dass dendritische Zellen sowohl Aspergillus-Hyphen als auch Konidien internalisieren und sie von den Atemwegen $\mathrm{zu}$ den drainierenden Lymphknoten transportieren [54]. Phagozytose von Konidien induziert die Interleukin12-(IL-12)-Produktion, während die Phagozytose von Hyphen IL-4 und IL-10 induziert. Nach der Phagozytose wandern die dendritischen Zellen der Lunge zu den drainierenden Lymphknoten und der Milz, durchlaufen eine funktionelle Reifung und stimulieren durch oben genannte Interleukine nä̈ve CD4+-T-Zellen [11]. Diese vorbereiteten und differenzierten $\mathrm{CD}^{+}$-T-Zellen kehren dann (nach klonaler Proliferation) zurück an den Ort der Infektion, wo sie ihre Zytokine TNF und IFN- $\gamma$ abgeben, die wiederum die Eliminierung von Konidien und Hyphen durch Aktivierung von Makrophagen und Neutrophile stimulieren [55].

Neben MHCII-vermittelten Immunreaktionen kann auch eine MHCI-vermittelte Reaktion eintreten, wobei MHCI von den meisten menschlichen Zellen exprimiert werden kann und zusammen mit dem Antigen an den T-Zell-Rezeptor vom CD8 ${ }^{+}-$ Zellen bindet (MHCI-Restriktion). Zytotoxische T-Zellen werden aktiviert. Bei der Aspergillus-Abwehr gibt es bis jetzt nur wenige Hinweise für eine MHCI-vermittelte Immunaktivierung. Sun et al. konnten jedoch durch immunologische Untersuchungen zeigen, dass verschiedene eingesetzte Impfpeptide eine wirksame zytotoxische T-ZellAntwort in $\mathrm{CD}^{+}$-Zellen induzieren konnten und so eine Beschädigung von Konidien und Hyphen bewirkten [56].

Daneben existieren offensichtlich andere T-Zell-Linien, die die Immunantwort auf A.fumigatus beeinflussen [55]. Th17-Zellen sind eine Untergruppe der CD4+-T-Zellen und unterscheiden sich von Th1- und Th2-Zellen. Sie werden während einer Immunantwort zu einem frühen Zeitpunkt gefunden und sind sowohl bei Th1- als auch Th2-Typ-Antworten beteiligt [53]. Neuere Untersuchungen konnten den Th17-Zellen eine mögliche Rolle bei der immunologischen Abwehr des Hyphenwachstums zuschreiben [57]. 


\subsection{Vakzinierungsversuche gegen A.fumigatus}

Bereits im Jahr 1976 wurde nachgewiesen, dass sich eine protektive Immunreaktion gegen Infektionen mit A.fumigatus ausbilden kann. In Mäusen, die nur einmal mit Konidien, bei gleichzeitiger Gabe von Cortison, infiziert wurden, ließ sich eine systemische Infektion mit Beteiligung von Nieren, Leber und Herz beobachten. Wurden den Mäusen hingegen Konidien intravenös (i.v.) in subletaler Dosis verabreicht, konnte nach überstandener Infektion nach einer späteren zweiten Gabe von Konidien und gleichzeitiger Gabe von Cortison lediglich ein lokalisiertes Wachstum des Pilzes in den Nieren beobachten werden. [50]. Etwa zur gleichen Zeit konnten Corbel und Eades zeigen, dass ältere Mäuse eine deutlich höhere Resistenz gegenüber A.fumigatusInfektionen aufweisen als junge Mäuse des gleichen Stamms [51]. Auch hier müssen mit dem Alter erworbene Immunmechanismen eine Rolle spielen. Da die Aussichten einen wirksamen Impfstoff zu entwickeln dann besonders hoch sind, wenn bereits eine natürliche Infektion eine protektive Immunreaktion induziert, führten die Ergebnisse dieser beiden Versuche $\mathrm{zu}$ mehreren Impfstoff-Studien und eingehenderen immunologischen Untersuchungen [58]. Im Jahr 1993 erbrachte eine subletale i.v. induzierte Infektion eine Immunität in Mäusen, die nicht durch Serum übertragbar war, jedoch durch Makrophagen. Dies wurde durch den Transfer einer Milzzellfraktion von einem immunen auf ein naïves Tier erreicht [59]. Die Rolle der zellulären Immunität konnte durch ein weiteres Experiment belegt werden, bei dem, nach einer im Vorfeld durchgeführten nasalen Impfung, entweder mit A.fumigatus-Konidien oder aufbereitetem Kulturfiltrat, Schutz induziert werden konnte. Die aus diesen Mäusen gewonnenen CD4+-T-Zellen wurden auf naïve Mäuse übertragen, welche daraufhin ebenfalls als geschützt imponierten [52]. Ito et al. erzeugten eine Corticosteroidunabhängige Immunität in Mäusen, indem sie den Mäusen vor der abschließenden nasalen Infektion mit Aspergillus-Konidien zuvor schon einmal Konidien als Impfung verabreichten. Der größte Erfolg stellte sich dabei ein, wenn die Hyphenmasse zuvor Ultraschall-behandelt wurde und die Impfung subkutan statt intranasal erfolgte [60]. Im Jahr 2002 veröffentlichten Bozza et al. die erste Impfstudie, in deren Verlauf Mäuse ein definiertes Impf-Antigen von A.fumigatus erhielten. Dadurch konnte eine protektive Immunantwort gegen IA induziert werden. Als Antigen wurde Aspf16 (AFUA_1G16190, auch als Aspf9 oder Crf1 beschrieben) verwendet (s. unten) [61]. Im Jahr 2009 untersuchte dieselbe Arbeitsgruppe eine Vielzahl von rekombinanten 
A.fumigatus-Proteinen auf ihre Fähigkeit in vitro T-Zellen $\mathrm{zu}$ aktivieren, welche anschließend auf Knochenmark-transplantierte Mäuse übertragen wurden. Bei einer nachfolgenden Infektion imponierten diese Mäuse zum Teil als geschützt (s. unten) [62].

Bislang konnte eine protektive Immunantwort nur mit vier verschiedenen A.fumigatus Einzel-Antigenen erfolgreich erzeugt werden [58]. So gelang bis jetzt eine Immunisierung mit Aspf3 (AFUA_6G02280; auch als AHP1 beschrieben), Aspf16, Gel1 (AFUA_2G01170) und Pep2 (AFUA_3G11400) [61-63]. Von diesen vier Antigenen wurde insbesondere das Aspf3 bereits mehrfach auf seine Potenz zur Etablierung einer protektiven Immunreaktion getestet [63-65]. Sequenzanalysen legen nahe, dass Aspf3 eine Peroxireduktase ist. Es wurde auf der Konidienoberfläche gefunden und wird ebenso im Hyphenstadium exprimiert [15].

\subsection{Screening-Methoden für die Suche nach schützenden Antigenen}

Trotz Fortschritten in der antimykotischen Therapie bleibt die IA eine lebensbedrohliche Erkrankung für immunsupprimierte Patienten. Daher würden alternative prophylaktische oder therapeutische Optionen von großem Nutzen sein. Insbesondere die Entwicklung eines Impfstoffes wäre ein alternativer Ansatz. Der erste Schritt hierfür ist die Identifikation schutz-vermittelnder Antigene. Gegen Infektionen, die durch A.fumigatus verursacht werden, kann eine erworbene schützende Immunantwort im Tiermodell induziert werden (s. 1.6).

In einer Arbeit von Denikus et al. [66] wurden systematische Versuche unternommen, mögliche Impfstoffkandidaten zu identifizieren. Zehn Kaninchen wurden i.v. mit A.fumigatus-Konidien in subletalen Dosen infiziert. Einige von ihnen entwickelten eine schützende Immunantwort gegen weitere systemische Infektionen. Blut der Kaninchen wurde vor Beginn der Versuche entnommen und währenddessen. Anschließend wurde eine cDNA-Expressionsbank auf der Basis von jungen keimenden Konidien mit den rekonvaleszenten Seren der Tiere untersucht. Da die allermeisten Proteine sowohl T- als auch B-Zell-Epitope tragen, bestand die Hoffnung, durch dieses „AntikörperScreening“ (auf B-Zell-Epitope) auch protektive Antigene $\mathrm{zu}$ identifizieren [67], wenngleich die eigentliche protektive Reaktion wahrscheinlich auf T-Zell-Epitope zurückzuführen ist [62]. Insgesamt wurden 36 Proteine mit Hilfe dieser Methode 
identifiziert. Unter ihnen waren die Allergene Aspf16 und Aspf3, für die schutzvermittelnde Eigenschaften gegen eine IA kurz vorher bzw. etwas später von anderen Arbeitsgruppen gezeigt werden konnten (s. oben) [61,63].

Dieselbe Arbeitsgruppe verwendete die Kaninchenseren für ein 2D-Western BlotScreening auf Basis von Proteinextrakten aus keimenden A.fumigatus-Konidien [2]. Reagierende Spots wurden mit Massenspektrometrie analysiert, dabei konnte eine Liste von 59 verschiedenen Proteinen erstellt werden. Unter diesen Proteinen fand sich wiederum das Allergen Aspf3, jedoch zusätzlich eine 1,3-Glucanosyltransferase (Gel1). Rekombinantes Gel1 wurde als Impfstoff in Mäusen kurz vorher getestet und erbrachte dabei eine schutzvermittelnde Immunreaktion (s. oben) [62].

Basierend auf der Annahme, dass das Immunsystem zuerst in Kontakt mit Oberflächenantigenen, insbesondere A.fumigatus-Konidien, kommt, wurden in einer Arbeit von Asif et al. Konidienoberflächenproteine extrahiert [15]. Insgesamt wurden 26 verschiedene Proteine identifiziert. Unter ihnen war auch die Protease Pep2, welche später auch als Protektions-vermittelnd identifiziert wurde [62]. Auch wurde ein weiteres Mal das Aspf3 unter den identifizierten Proteinen gefunden [15]. Bisher konnte eine protektive Immunantwort nur mit vier verschiedenen A.fumigatus-Antigenen erfolgreich durchgeführt werden (s. 1.6).

\subsection{Zielsetzung der Arbeit}

A.fumigatus-Konidien werden von jedem Menschen eingeatmet. Ihre Konzentration ist mit 1-100 Konidien pro Kubikmeter sowohl in Innenräumen als auch im Freien variabel, aber zum Teil hoch [10]. Bei immunkompetenten Menschen verursachen diese eingeatmeten Konidien normalerweise keine invasiven Erkrankungen. Sie werden effizient von den Abwehrmechanismen innerhalb der Lunge eliminiert [11]. Bei immunsupprimierten Patienten werden die eingeatmeten Aspergillus-Konidien nicht oder nur unzureichend phagozytiert und es kann sich eine IA manifestieren. Dabei ist A.fumigatus der häufigste Erreger solch invasiver, meist tödlich verlaufender Schimmelpilzmykosen bei Leukämiepatienten. Nach einer subletalen Infektion mit dem Pilz lässt sich im Tierversuch eine protektive Immunreaktion gegenüber einer folgenden, an sich letalen Infektion nachweisen [66,68]. Es wird daher davon ausgegangen, dass Aspergillen während der Infektion Antigene exprimieren, die eine 
solche schützende Immunantwort induzieren. Die Identifizierung dieser Antigene könnte die Basis für die Entwicklung eines Impfstoffes sein. Zur Immunisierung von Mäusen mit rekombinanten Proteinen standen entsprechende Kandidaten aus Vorarbeiten zur Verfügung bzw. sollten selbst hergestellt werden.

In einer Arbeit von Asif et al. [15] wurden verschiedene Konidienoberflächenproteine identifiziert. Da die Konidienoberfläche den ersten Kontakt mit dem Wirtsorganismus vermittelt, stellen diese Antigene sowohl vielversprechende Impfstoffkandidaten als auch mögliche Virulenzfaktoren dar. Durch die Generation korrespondierender Knockout- und Komplementmutanten mit anschließender Testung im Tierversuch sollte hier eine Überprüfung erfolgen. 


\section{Material und Methoden}

\subsection{Material}

\subsubsection{Geräteliste}

Tab. 1: Auflistung der verwendeten Geräte mit Angabe von Modell und Hersteller

\begin{tabular}{|c|c|c|}
\hline Gerät & Modell & Hersteller \\
\hline $\begin{array}{l}\text { Agarosegel- } \\
\text { Elektrophoresekammer }\end{array}$ & $\begin{array}{l}\text { Flachgel-Elektrophorese- } \\
\text { kammer "Mini" }\end{array}$ & $\begin{array}{l}\text { Keutz Labortechnik, } \\
\text { Reiskirchen }\end{array}$ \\
\hline Destillierapparat & Destamat $^{\circledR}$ & $\begin{array}{l}\text { Heraeus Quarzglas, } \\
\text { Kleinostheim }\end{array}$ \\
\hline Digitaler Graphikdrucker & UP-D890 & Biometra, Göttingen \\
\hline Elektroporationsapparatur & $\begin{array}{l}\left.\text { Electro Cell Manipulator }{ }^{(}\right) \\
600\end{array}$ & $\begin{array}{l}\text { BTX Instrument Division, } \\
\text { Holliston, USA }\end{array}$ \\
\hline Fluoreszenzmikroskop & Axiostar plus & ZEISS, Göttingen \\
\hline Gasbrenner & Gasprofi 1 & WLD-TEC, Göttingen \\
\hline Geldokumentationsstation & BioDoc II ${ }^{\mathrm{TM}}$ & Biometra, Göttingen \\
\hline Geltrocknungsapparatur & $\begin{array}{l}\text { DryEase }{ }^{\mathrm{TM}} \text { Mini-Gel } \\
\text { Drying System }\end{array}$ & $\begin{array}{l}\text { Novel Experimental } \\
\text { Technology,San } \\
\text { Diego,USA }\end{array}$ \\
\hline Glaswaren, diverse & & SCHOTT AG, Mainz \\
\hline Hochdruckhomogenisator & EmulsiFlex-C5 & $\begin{array}{l}\text { AVESTIN, Inc., } \\
\text { Ontario, Kanada }\end{array}$ \\
\hline $\begin{array}{l}\text { Hoefer-Kammer zum } \\
\text { Gießen von SDS-Gelen }\end{array}$ & $\begin{array}{l}\text { Multiple Gel Caster SE200 } \\
\text { Serie }\end{array}$ & $\begin{array}{l}\text { Hoefer Inc., Holliston, } \\
\text { USA }\end{array}$ \\
\hline $\begin{array}{l}\text { Homogenisatorgefäß mit } \\
\text { Glaskolben }\end{array}$ & Volumen $5 \mathrm{ml}$ & Sartorius, Göttingen \\
\hline Inkubator & MIR-153 & SANYO, Wiesloch \\
\hline Kompakt-Kältethermostat & RM 6 & Lauda, Lauda-Königshofen \\
\hline Kreisschüttler & KS 260 basic & $\begin{array}{l}\text { IKA }{ }^{\circledR} \text {-Werke GmbH \& Co. } \\
\text { KG, Staufen }\end{array}$ \\
\hline Leuchttisch & Typ 101391 & $\begin{array}{l}\text { Waldmann, Villingen- } \\
\text { Schwenningen }\end{array}$ \\
\hline $\begin{array}{l}\text { Lumineszenz Image } \\
\text { Reader }\end{array}$ & LAS 4000 & Fujifilm, Düsseldorf \\
\hline Magnetrührer & RCT basic IKAMAG $^{\circledR}$ & $\begin{array}{l}\text { IKA }^{\circledR} \text {-Werke GmbH \& Co. } \\
\text { KG, Staufen }\end{array}$ \\
\hline Magnetrührer & REO IKAMAG $^{\circledR}$ & $\begin{array}{l}\mathrm{IKA}^{\circledR}-\text { Werke } \mathrm{GmbH} \& \mathrm{Co} . \\
\text { KG, Staufen }\end{array}$ \\
\hline Mikrowelle & Micromat 5.8 & AEG, Frankfurt \\
\hline Mikroskop & Axoskop 50 & ZEISS, Göttingen \\
\hline NanoDrop & ND-1000 & $\begin{array}{l}\text { Thermo Scientific, } \\
\text { Waltham, USA }\end{array}$ \\
\hline pH-Meter & MP 225 & Mettler-Toledo, Gießen \\
\hline Photometer & Ultrospec 1000 & Biometra, Göttingen \\
\hline
\end{tabular}




\begin{tabular}{|c|c|c|}
\hline Gerät & Modell & Hersteller \\
\hline Pipette & Pipetman P5000 & GILSON, Middleton, USA \\
\hline Pipetten & $\begin{array}{l}\text { Research } \\
2,5 / 10 / 20 / 100 / 200 / 1000\end{array}$ & Eppendorf, Hamburg \\
\hline Pipettierhilfe & Accu-jet & $\begin{array}{l}\text { BRAND GmbH + Co KG, } \\
\text { Wertheim }\end{array}$ \\
\hline Plattformschüttler & Duomax 1030 & $\begin{array}{l}\text { Heidolph Instruments } \\
\text { GmbH \& Co. KG, } \\
\text { Schwabach }\end{array}$ \\
\hline Röntgenfilmkassette & IEC 60406 & $\begin{array}{l}\text { rego Gollwitzer GmbH \& } \\
\text { Co. KG, Augsburg }\end{array}$ \\
\hline Schüttelwasserbad & GFL-1012 & $\begin{array}{l}\text { GFL Gesselschaft für } \\
\text { Labortechnik mbH, } \\
\text { Burgwedel }\end{array}$ \\
\hline $\begin{array}{l}\text { Schüttler mit } \\
\text { Inkubationshaube }\end{array}$ & SM 30 und TH30 & $\begin{array}{l}\text { Edmund Bühler } \mathrm{GmbH} \text {, } \\
\text { Hechingen }\end{array}$ \\
\hline Schüttler im Wärmeraum & HAT Tischschüttler & Infors GmbH, Einsbach \\
\hline SDS-PAGE-System & & Hoeffer, Holliston, USA \\
\hline Sicherheitswerkbank & HERA Safe 09/2 & Heraeus GmbH, Hanau \\
\hline Spannungsgerät & $\begin{array}{l}\text { Biometra Standard Power } \\
\text { Pack } 25\end{array}$ & Biometra, Göttingen \\
\hline Spannungsgerät & $\begin{array}{l}\text { Electrophoresis Constant } \\
\text { Power Supply ECPS } \\
3000 / 150\end{array}$ & $\begin{array}{l}\text { Pharmacia, Uppsala, } \\
\text { Schweden }\end{array}$ \\
\hline Stab-Ultraschallgerät & Branson Sonifer 250 & $\begin{array}{l}\text { G.HEINEMANN, } \\
\text { Schwäbisch Gmünd }\end{array}$ \\
\hline Thermocycler & $\mathrm{T} 3$ & Biometra, Göttingen \\
\hline Thermomixer & 5436 & Eppendorf, Hamburg \\
\hline Überkopfdreher & Test-tube-rotator 34528 & $\begin{array}{l}\text { Snijders, Tilburg, } \\
\text { Niederlande }\end{array}$ \\
\hline $\begin{array}{l}\text { UV/Weißlicht- } \\
\text { Transilluminator }\end{array}$ & TFP-L/WL, $365 \mathrm{~nm}$ & $\begin{array}{l}\text { Vilber Lourmat, } \\
\text { Eberhardzell }\end{array}$ \\
\hline Vakuumofen mit Pumpe & RUT 220 & Heraeus GmbH, Hanau \\
\hline Vortexer & Genie 2 & $\begin{array}{l}\text { Scientific Industries, New } \\
\text { York, USA }\end{array}$ \\
\hline Vortexer & RFAX 1DR & Heidolph, Schwabach \\
\hline Waage & SBC33 & Scaltec, Heiligenstadt \\
\hline Waage & SBC52 & Scaltec, Heiligenstadt \\
\hline Wasserbad & GFL-1083 & $\begin{array}{l}\text { GFL Gesselschaft für } \\
\text { Labortechnik mbH, } \\
\text { Burgwedel }\end{array}$ \\
\hline Western Blot-Kammer & $\begin{array}{l}\text { TE Series Transphor } \\
\text { Electrophoresis Unit }\end{array}$ & Hoeffer, Holliston, USA \\
\hline Zählkammer & Thoma $0,100 \mathrm{~mm}$ Tiefe & $\begin{array}{l}\text { Assistent, Sondheim / } \\
\text { Rhön }\end{array}$ \\
\hline Zentrifuge & $5415 \mathrm{D}$ & Eppendorf, Hamburg \\
\hline Zentrifuge & Beckman Avanti J25 & $\begin{array}{l}\text { Beckman Coulter } \mathrm{GmbH} \text {, } \\
\text { Krefeld }\end{array}$ \\
\hline Zentrifuge & Megafuge 1.0 & Heraeus GmbH, Hanau \\
\hline
\end{tabular}




\begin{tabular}{|l|l|l|}
\hline Gerät & Modell & Hersteller \\
\hline Zentrifuge & Universal 30RF & $\begin{array}{l}\text { A.Hettrich GmbH\&CoKG, } \\
\text { Tuttlingen }\end{array}$ \\
\hline Zentrifuge & Z 233 MK-2 & $\begin{array}{l}\text { Hermle Labortechnik, } \\
\text { Wehingen }\end{array}$ \\
\hline
\end{tabular}

\subsubsection{Verwendete Software und Internet-Tools}

Die Software SimVector 3 (Premier Biosoft International, Palo Alto, USA) wurde für die Erstellung der Vektor-Karten verwendet. Die Berechnung der Signifikanz-Werte (Log-rank-Test) wurde mit Hilfe des Programms GraphPad Prism (Version 5, GraphPad Software Inc., San Diego CA, USA) vorgenommen.

Zum Übersetzen von DNA in Aminosäure-Sequenzen wurde das Internet-Tool http://web.expasy.org/translate genutzt. Zum Berechnen der molekularen Proteinmasse wurde der „Protein Molecular Weight Calculator“ der Internetseite von Science Gateway, http://www.sciencegateway.org/tools/proteinmw.htm, verwendet.

\subsubsection{Verbrauchsmaterialien}

Tab. 2: Auflistung der verwendeten Verbrauchsmaterialien

\begin{tabular}{|c|c|c|}
\hline & Beschreibung & Hersteller \\
\hline Deckgläser & $18 \mathrm{x} 18 \mathrm{~mm} \mathrm{Nr} .1$ & $\begin{array}{l}\text { Gerhard Menzel GmbH, } \\
\text { Braunschweig }\end{array}$ \\
\hline Einmal-Küvetten & $1,5 \mathrm{ml} \mathrm{PS}$ & Brand GmbH, Wertheim \\
\hline Entsorgungsbeutel & $300 \times 200 \mathrm{~mm}$ & Labor-Brand, Gießen \\
\hline Einmal-Injektions-Kanüle & $\begin{array}{l}100 \text { Sterican, Gr. } 1 \text {, gelb, } \varnothing \\
0.90 \mathrm{~mm} \times 40 \mathrm{~mm}, \mathrm{G} 20 \times 1 \frac{11}{2}\end{array}$ & B. Braun, Melsungen \\
\hline Einmal-Injektions-Kanüle & $\begin{array}{l}\text { BD Microlance }{ }^{\mathrm{TM}}, 3 \mathrm{rosa} \text {, } \\
1,2 \mathrm{~mm} \times 40 \mathrm{~mm}, \mathrm{G} 18 \times 1 \frac{1}{2}\end{array}$ & BD, Heidelberg \\
\hline Einweg-Impfschlinge & $1 \mu 1,10 \mu 1$ & Sarstedt, Nürmbrecht \\
\hline Elektroporationsküvette & $1 \mathrm{~mm}$ & $\begin{array}{l}\text { peqlab Biotechnologie } \\
\text { GmbH, Erlangen }\end{array}$ \\
\hline Filtrierpapier & Type $713,58 \times 58 \mathrm{~cm}$ & Machery-Nagel, Düren \\
\hline Flächendesinfektionsmittel & Biguacid Liquid & $\begin{array}{l}\text { Antiseptica chem. pharm. } \\
\text { Produkte GmbH, Pulheim }\end{array}$ \\
\hline Gewebekulturschale & $35,0 / 10 \mathrm{~mm}$ & $\begin{array}{l}\text { Greiner bio-one } \mathrm{GmbH} \text {, } \\
\text { Frickenhausen }\end{array}$ \\
\hline His GraviTrap & & $\begin{array}{l}\text { GE Healthcare Europe } \\
\text { GmbH, Freiburg }\end{array}$ \\
\hline
\end{tabular}




\begin{tabular}{|c|c|c|}
\hline & Beschreibung & Hersteller \\
\hline Kryoröhrchen & Microbank $^{\mathrm{TM}}$ & $\begin{array}{l}\text { Pro-Lab, Richmond, } \\
\text { Kanada }\end{array}$ \\
\hline Labortücher & Kimtech Science & Kimberly-Clark, Mainz \\
\hline Mikro-Schraubröhre & $1,5 \mathrm{ml}, 2 \mathrm{ml}$ & Sarstedt, Nürmbrecht \\
\hline Nitrilhandschuhe & Nitril NextGen & $\begin{array}{l}\text { Rösner-Mautby Meditrade } \\
\text { GmbH, Kiefersfelden }\end{array}$ \\
\hline Nitrozellulosemembran & Optitran BA-S 83 & $\begin{array}{l}\text { Schleicher\&Schuell, } \\
\text { Dassel }\end{array}$ \\
\hline Objektträger & $\begin{array}{l}\text { Menzel-Gläser, } \\
\text { Superfrost }{ }^{\circledR}\end{array}$ & $\begin{array}{l}\text { Gerhard Menzel GmbH, } \\
\text { Braunschweig }\end{array}$ \\
\hline Parafilm $^{\circledR}$ & „M“" & $\begin{array}{l}\text { Pechiney Plastic Packaging } \\
\text { Company, Chicago, USA }\end{array}$ \\
\hline Pasteurpipetten & $230 \mathrm{~mm}$ & WU Mainz, Bamberg \\
\hline PCR-Reaktionsgefäß & 0,2 ml, Flachdeckel & $\begin{array}{l}\text { Biozym Scientific GmbH, } \\
\text { Hess. Oldendorf }\end{array}$ \\
\hline PD10-Säule & Desalting Column & $\begin{array}{l}\text { GE Healthcare Europe } \\
\text { GmbH, Freiburg }\end{array}$ \\
\hline Petrischale & $94 / 16 \mathrm{~mm}, 145 / 20 \mathrm{~mm}$ & $\begin{array}{l}\text { Greiner bio-one } \mathrm{GmbH} \text {, } \\
\text { Frickenhausen }\end{array}$ \\
\hline Pipettenspitzen & $20 \mu \mathrm{l}, 200 \mu \mathrm{l}, 1000 \mu \mathrm{l}$ & Sarstedt, Nürnbrecht \\
\hline Polyacrylamid-Gel & $\begin{array}{l}\text { NuPAGE }^{\circledR} \text { Novex }{ }^{\circledR} 4-12 \% \\
\text { Bis-Tris Protein Gel }\end{array}$ & $\begin{array}{l}\text { Invitrogen, Life } \\
\text { Technologies GmbH, } \\
\text { Darmstadt }\end{array}$ \\
\hline Reaktionsgefäß & $0,5 \mathrm{ml}$ & Eppendorf, Hamburg \\
\hline Reaktionsgefäß & $1,5 \mathrm{ml}, 2,0 \mathrm{ml}$ & Sarstedt, Nürmbrecht \\
\hline Röntgenfilm & $\begin{array}{l}\text { Kodak BioMax }{ }^{\circledR} \text { light film } \\
\text { size } 13 \mathrm{~cm} \times 18 \mathrm{~cm}\end{array}$ & $\begin{array}{l}\text { Eastman Kodak Company, } \\
\text { Rochester, USA }\end{array}$ \\
\hline Schutzhandschuhe & Diamond Grip Plus & $\begin{array}{l}\text { Microflex Corporation, } \\
\text { Reno, USA } \\
\end{array}$ \\
\hline Skalpelle & Dahlhausen präzisa & $\begin{array}{l}\text { P.J. Dahlhausen \& Co. } \\
\text { GmbH, Köln }\end{array}$ \\
\hline Spritze & BD Discardit $^{\mathrm{TM}} \mathrm{II}, 2 \mathrm{ml}$ & BD, Heidelberg \\
\hline Spritze & BD Plastipak $^{\mathrm{TM},} 1 \mathrm{ml}$ & BD, Heidelberg \\
\hline Spritzenfilter & Filtropur S $0,2 \mu \mathrm{m}$ & Sarstedt, Nürmbrecht \\
\hline Thermopapier & K65HM-Rolle & $\begin{array}{l}\text { Mitsubishi HiTec Paper } \\
\text { GmbH, Bielefeld }\end{array}$ \\
\hline $\begin{array}{l}\text { Vakuumfiltrationseinheit } \\
\text { als Flaschenaussatz } \\
\text { (Bottle-Top-Filter) }\end{array}$ & $\begin{array}{l}500 \mathrm{ml} \text { Bottle top Filter, } \\
45 \mathrm{~mm} \text { Neck, 0,22 } \mu \mathrm{m} \text { PES }\end{array}$ & Corning, Corning, USA \\
\hline $\begin{array}{l}\text { Vakuumfiltrationseinheit } \\
\text { als Flaschenaussatz } \\
\text { (Bottle-Top-Filter) }\end{array}$ & $\begin{array}{l}500 \mathrm{ml} \text { Bottle top Filter, } \\
45 \mathrm{~mm} \text { Neck, 0,45 } \mu \mathrm{m} \mathrm{CA}\end{array}$ & Corning, Corning, USA \\
\hline Vivaspin & $\begin{array}{l}\text { 2, 5000 MWCO PES; } \\
\text { 20,5000 MWCO PES }\end{array}$ & $\begin{array}{l}\text { sartorius stedim Biotech } \\
\text { GmbH, Göttingrn }\end{array}$ \\
\hline Whatman-Papier & GB005, 580x580 mm & Whatman GmbH, Dassel \\
\hline Zellkulturröhrchen & CELLSTAR $^{\circledR} 12 \mathrm{ml}$, & $\begin{array}{l}\text { Greiner bio-one } \mathrm{GmbH}, \\
\text { Frickenhausen }\end{array}$ \\
\hline
\end{tabular}




\begin{tabular}{|l|l|l|}
\hline & Beschreibung & Hersteller \\
\hline Zentrifugenröhrchen & Cellstar $^{\circledR}$ Tubes, $15 \mathrm{ml}$ & $\begin{array}{l}\text { Greiner bio-one GmbH, } \\
\text { Frickenhausen }\end{array}$ \\
\hline Zentrifugenröhrchen & $50 \mathrm{ml}$ & Sarstedt, Nürmbrecht \\
\hline
\end{tabular}

\subsubsection{Kommerzielle Kits}

Tab. 3: Auflistung der verwendeten Kits

\begin{tabular}{|c|c|}
\hline Bezeichnung & Hersteller \\
\hline $\begin{array}{l}\text { GeneArt }{ }^{\circledR} \text { Seamless Cloning and } \\
\text { Assembly Kit }\end{array}$ & Invitrogen $\mathrm{GmbH}$, Karlsruhe \\
\hline QIAEX $^{\circledR}$ II Gel Extraction Kit & Qiagen, Hilden \\
\hline QIAprep ${ }^{\circledR}$ Spin Miniprep Kit & Qiagen, Hilden \\
\hline QIAquick ${ }^{\circledR}$ PCR Purification Kit & Qiagen, Hilden \\
\hline
\end{tabular}

\subsubsection{Chemikalien}

Tab. 4: Auflistung der verwendeten Chemikalien

\begin{tabular}{|l|l|}
\hline Bezeichnung & Hersteller \\
\hline Aceton & Merck KGaA, Darmstadt \\
\hline Agarose peqGOLD & peqlab Biotechnologie GmbH, Erlangen \\
\hline Ammoniumpersulfat (APS) & Sigma-Aldrich, St. Louis, USA \\
\hline Ammoniumtartrat & Sigma-Aldrich, St. Louis, USA \\
\hline Ampicillin & Sigma-Aldrich, St. Louis, USA \\
\hline Anti-Digoxigenin-POD, Fab fragments & Roche, Mannheim \\
\hline Antifoam 204 & Sigma-Aldrich, St. Louis, USA \\
\hline Bacto ${ }^{\text {TM }}$-Agar & $\begin{array}{l}\text { BD (Becton, Dickinson and Company), } \\
\text { Heidelberg }\end{array}$ \\
\hline Bacto ${ }^{\text {TM }}$-Hefeextrakt & $\begin{array}{l}\text { BD (Becton, Dickinson and Company), } \\
\text { Heidelberg }\end{array}$ \\
\hline Bacto ${ }^{\text {TM }}$-Hefestickstoff-Basismedium & $\begin{array}{l}\text { BD (Becton, Dickinson and Company), } \\
\text { Heidelberg }\end{array}$ \\
\hline Bacto ${ }^{\text {TM }- \text { Trypton }}$ & BD (Becton, Dickinson and Company), \\
& Heidelberg \\
\hline Blankophor-P, flüssig & Bayer AG, Leverkusen \\
\hline Borsäure & Merck KGaA, Darmstadt \\
\hline Bovines Serum Albumin (BSA) & Sigma-Aldrich, St. Louis, USA \\
\hline $\begin{array}{l}\text { Bovines Serum Albumin (BSA) für } \\
\text { Restriktionsverdau }\end{array}$ & New England Biolabs, Frankfurt \\
\hline Bromphenolblau & Pharmacia, Uppsala, Schweden \\
\hline 1-Butanol & Merck KGaA, Darmstadt \\
\hline Chloramphenicol & Sigma-Aldrich, St. Louis, USA \\
\hline Chloroform & Merck KGaA, Darmstadt \\
\hline Coomassie ${ }^{\circledR}$ Brillant Blue R250 & Merck KGaA, Darmstadt \\
\hline & \\
\hline
\end{tabular}




\begin{tabular}{|c|c|}
\hline Bezeichnung & Hersteller \\
\hline Cortisonacetat & Sigma-Aldrich, St. Louis, USA \\
\hline Cotrim K- ratiopharm $^{\circledR} 240 \mathrm{mg} / 5 \mathrm{ml} \mathrm{Saft}$ & ratiopharm $\mathrm{GmbH}, \mathrm{Ulm}$ \\
\hline Diethanolamin & Merck KGaA, Darmstadt \\
\hline Diethylpyrocarbonat & Sigma-Aldrich, St. Louis, USA \\
\hline Digoxigenin-11-UTP-Nukleotide & Boehringer Mannheim GmbH, Mannheim \\
\hline Dinatriumhydrogenphosphat & Merck KGaA, Darmstadt \\
\hline DNA Probenpuffer 6x (Loading Dye) & Fermentas GmbH, St.Leon-Rot \\
\hline ECL $^{\mathrm{TM}}$ Western Blotting Analysis System & GE Healthcare Europe GmbH, Freiburg \\
\hline Entwickler GBX & $\begin{array}{l}\text { Eastman Kodak Company, Rochester, } \\
\text { USA }\end{array}$ \\
\hline Essigsäure (Eisessig) & Merck KGaA, Darmstadt \\
\hline Ethanol & Merck KGaA, Darmstadt \\
\hline $\begin{array}{l}\text { Ethidiumbromid - Lösung 0,07 \% } \\
\text { "dropper-bottle" }\end{array}$ & AppliChem GmbH, Darmstadt \\
\hline Ethylendiamintetraacetat (EDTA) & Paesel + Lorei GmbH \& Co., Duisburg \\
\hline Ficoll $^{\circledR}$ Typ 400 & Pharmacia, Uppsala, Schweden \\
\hline Fixierer GBX & $\begin{array}{l}\text { Eastman Kodak Company, Rochester, } \\
\text { USA }\end{array}$ \\
\hline Fleischextrakt (trocken) & Merck KGaA, Darmstadt \\
\hline Formamid & Merck KGaA, Darmstadt \\
\hline D-(+)-Glucose-Monohydrat & Merck KGaA, Darmstadt \\
\hline Glycerol & Merck KGaA, Darmstadt \\
\hline Glycin & Carl Roth, Karlsruhe \\
\hline Glykogen & Boehringer Mannheim GmbH, Mannheim \\
\hline Guanidine-Hydrochlorid & Carl Roth, Karlsruhe \\
\hline Harnstoff & Carl Roth, Karlsruhe \\
\hline Heringsperma-DNA & Invitrogen $\mathrm{GmbH}$, Karlsruhe \\
\hline 8-Hydroxychinolin & Sigma-Aldrich, St. Louis, USA \\
\hline Hygromycin B & Sigma-Aldrich, St. Louis, USA \\
\hline Isoamylalkohol & Merck KGaA, Darmstadt \\
\hline Isopropanol & Merck KGaA, Darmstadt \\
\hline Isopropyl- $\beta$-D-thiogalactoside (IPTG) & peqlab Biotechnologie $\mathrm{GmbH}$, Erlangen \\
\hline Kaliumchlorid & Merck KGaA, Darmstadt \\
\hline Kaliumdihydrogenphosphat & Merck KGaA, Darmstadt \\
\hline Kanamycin & Carl Roth, Karlsruhe \\
\hline Kohlenstoffdioxid & $\begin{array}{l}\text { AIR LIQUIDE Medical GmbH, } \\
\text { Düsseldorf }\end{array}$ \\
\hline Magermilchpulver (Sucofin) & TSI GmbH \& Co. KG, Zeven \\
\hline Magnesiumchlorid-Hexahydrat & Merck KGaA, Darmstadt \\
\hline Magnesiumsulfat-Heptahydrat & Carl Roth, Karlsruhe \\
\hline$\beta$-Mercaptoethanol & Sigma-Aldrich, St. Louis, USA \\
\hline MOPS & Sigma-Aldrich, St. Louis, USA \\
\hline Natriumacetat & Merck KGaA, Darmstadt \\
\hline Natriumchlorid & Carl Roth, Karlsruhe \\
\hline Natriumcitrat & Carl Roth, Karlsruhe \\
\hline Natriumdihydrogenphosphat & Merck KGaA, Darmstadt \\
\hline Natriumdihydrogenphosphat-Monohydrat & Natriumdihydrogenphosphat \\
\hline
\end{tabular}




\begin{tabular}{|l|l|}
\hline Bezeichnung & Hersteller \\
\hline Natriumdodecylsulfat (SDS) & Sigma-Aldrich, St. Louis, USA \\
\hline Natriumhydroxid Plätzchen & Merck KGaA, Darmstadt \\
\hline Natriumnitrat & Carl Roth, Karlsruhe \\
\hline Ni-NTA-Agarose & Qiagen, Hilden \\
\hline Nucleotide (dGTP, dATP, dCTP, dTTP) & Boehringer Mannheim GmbH, Mannheim \\
\hline $\begin{array}{l}\text { NuPAGE } \\
\text { (20X) }{ }^{\circledR} \text { MES SDS Running Buffer }\end{array}$ & $\begin{array}{l}\text { Invitrogen, Life Technologies GmbH, } \\
\text { Darmstadt }\end{array}$ \\
\hline NuPAGE ${ }^{\circledR}$ Sample Buffer (4X) & Invitrogen, Life Technologies GmbH, \\
& Darmstadt \\
\hline Methanol & Carl Roth, Karlsruhe \\
\hline Overnight Express ${ }^{\text {TM }}$ Instant TB medium & Merck KGaA, Darmstadt \\
\hline PCR Nukleotide (dNTP Mix) & Roche, Mannheim \\
\hline Pepton aus Fleisch & Merck KGaA, Darmstadt \\
\hline Phenol & Carl Roth, Karlsruhe \\
\hline Polyethylenglykol (PEG) & Sigma-Aldrich, St. Louis, USA \\
\hline Polyvinylpyrrolidon & Sigma-Aldrich, St. Louis, USA \\
\hline $\begin{array}{l}\text { Protease-Inhibitortabletten, cOmplete, } \\
\text { Mini, EDTA-free }\end{array}$ & Roche, Mannheim \\
\hline Proteinase K & Roche, Mannheim \\
\hline Pyrithiamin hydrobromide & Sigma-Aldrich, St. Louis, USA \\
\hline Rotiphorese ${ }^{\circledR}$ Gel 30 & Carl Roth, Karlsruhe \\
\hline D-(+)-Saccharose & Roche, Mannheim \\
\hline Salzsäure & Merck KGaA, Darmstadt \\
\hline Sorbit & Sigma-Aldrich, St. Louis, USA \\
\hline Stickstoff, flüssig & $\begin{array}{l}\text { AIR LIQUIDE Medical GmbH, } \\
\text { Düsseldorf }\end{array}$ \\
\hline Temed & Merck KGaA, Darmstadt \\
\hline Tetracyclin & Sigma-Aldrich, St. Louis, USA \\
\hline TiterMax ${ }^{\circledR}$ Classic & TiterMax, Norcross, USA \\
\hline Tris & Carl Roth, Karlsruhe \\
\hline Tris-Cl & Paesel + Lorei GmbH \& Co., Duisburg \\
\hline Tween20 & Sigma-Aldrich, St. Louis, USA \\
\hline Tween80 & Sigma-Aldrich, St. Louis, USA \\
\hline Wasserstoffperoxid & Carl Roth, Karlsruhe \\
\hline & \\
\hline
\end{tabular}

\subsubsection{Enzyme}

Tab. 5: Verwendete Enzyme (die entsprechend benötigten Puffer wurden von demselben Hersteller bezogen wie die Enzyme)

\begin{tabular}{|l|l|}
\hline Bezeichnung & Hersteller \\
\hline Antarctic Phosphatase & New England Biolabs, Frankfurt \\
\hline Glucanex $^{\circledR}$ & Novozymes A/S, Bagsværd, Dänemark \\
\hline PfuUltra DNA Polymerase AD & Agilent Technologies, Böblingen \\
\hline Phusion Flash II DNA Polymerase & Thermo Scientific, Waltham, USA \\
\hline Restriktionsendonukleasen & New England Biolabs, Frankfurt \\
\hline
\end{tabular}




\begin{tabular}{|l|l|}
\hline Bezeichnung & Hersteller \\
\hline RNase Typ XII & Sigma-Aldrich, St. Louis, USA \\
\hline T4 DNA Ligase & New England Biolabs, Frankfurt \\
\hline Taq DNA Polymerase & Roche, Mannheim \\
\hline
\end{tabular}

\subsubsection{Molekulargewichtsmarker}

Tab. 6: Verwendete Molekulargewichtsmarker

\begin{tabular}{|c|c|}
\hline Bezeichnung & Hersteller \\
\hline BenchMark $^{\mathrm{TM}}$ & $\begin{array}{l}\text { Invitrogen, Life Technologies } \mathrm{GmbH} \text {, } \\
\text { Darmstadt }\end{array}$ \\
\hline $\begin{array}{l}\text { DNA molecular-weight marker II } \\
\text { digoxigenin-labeled }\end{array}$ & Boehringer Mannheim GmbH, Mannheim \\
\hline GeneRuler $^{\mathrm{TM}}$ 100bp DNA Ladder & Fermentas GmbH, St.Leon-Rot \\
\hline MassRuler ${ }^{\mathrm{TM}}$ DNA Ladder Mix & Fermentas GmbH, St.Leon-Rot \\
\hline $\begin{array}{l}\text { Prestained SDS-PAGE Standards Low } \\
\text { Range }\end{array}$ & Bio-Rad, Hercules, USA \\
\hline
\end{tabular}

\subsubsection{Oligonukleotide}

Tab.7: Auflistung der verwendeten Oligonukleotide. Die Restriktionsschnittstellen sind unterstrichen: gestrichelter Unterstrich- SfiI-Schnittstellen; durchgezogener Unterstrichunterschiedliche Schnittstellen

\begin{tabular}{|l|l|}
\hline Name des Primers & Sequenz 5'- \\
\hline \multicolumn{2}{|l|}{ Primer zur Erstellung von Deletionsplasmiden } \\
\hline HP16-1 & TATATGCGGCCGCTGGTGTAAGTCCATTTTCAAAGC \\
\hline HP16-2 & $\begin{array}{l}\text { ATATTACCCGGGGGCCTGAGTGGCTCATATGAGGACAACAAT } \\
\text { TCAACG }\end{array}$ \\
\hline HP16-3 & GAGTAGCCAGGCATGATTGC \\
\hline HP16-4 & CATCCTCAGGGACAGAGACC \\
\hline HP16-5 & $\begin{array}{l}\text { ATATTAGAATTCGGCCATCTAGGCCAGTACTAAGCAGGACGCT } \\
\text { CAACAG }\end{array}$ \\
\hline HP16-6 & TATCGTTAATTAACCCTCAGTTACTAGACCCGAAAG \\
\hline HP16-7 & TCTCGTTCCAGCTTGATTGC \\
\hline HP16-8 & AGTTCGCAGGAAGAGAGACG \\
\hline Primer zur Erstellung von Plasmiden zur Herstellung der Komplementmutanten \\
\hline sv831 (HP16) & $\begin{array}{l}\text { AATTCGAGCTCGGTACGTTAACTTGGTGTAAGTCCATTTTCAA } \\
\text { AG }\end{array}$ \\
\hline sv832 (HP16) & ATCCCGTAATCAATTAGAATACAAGACTGTGCGTATG \\
\hline sv833 (HP16) & AACAAAGATGCAAGATTAATAAGCACTTTTCCTTGACATG \\
\hline sv834 (HP16) & $\begin{array}{l}\text { GCCAAGCTTGCATGCCGTTAACCAAGAGAAGATACCCTACAA } \\
\text { CC }\end{array}$ \\
\hline sv197 (HP16) & AATTGATTACGGGATCCCATTGG \\
\hline sv198 (HP16) & CATATTATGTTTGTTTCTACGTTCT \\
\hline
\end{tabular}




\begin{tabular}{|c|c|}
\hline Name des Primers & Sequenz $5^{6}-3^{6}$ \\
\hline Asp3-nested_1 & GTGCTATGGGCAAGATTCGT \\
\hline Asp3-nested_2 & GCTCTGACCGGTTGTTGATT \\
\hline Asp3-nested_3 & GAATCAAGGGAGGCATGAAA \\
\hline Asp3-nested_4 & GAGTGCCGGGATACCACTAA \\
\hline Asp3-nested_5 & CTCACAAAGGTGCTCGGTTT \\
\hline Asp3-nested_6 & CCCATACTGGCGACGATACT \\
\hline Aspf3-Rekom_1 & ATTCGAGCTCGGTACGTTAACCCACGAGGGAATGGTGTGCTCG \\
\hline Aspf3-Rekom_2 & TCGTTACCAATGGGAGACATCATACGGTTTGATAGGGCG \\
\hline Aspf3-Rekom_3 & TCCCATTGGTAACGAAATGTAAAAGC \\
\hline Aspf3-Rekom_4 & TCTTGCATCTTTGTTTGTATTATAC \\
\hline Aspf3-Rekom_5 & AACAAAGATGCAAGAAGGTAGGAACTACGTCTTAAGTAC \\
\hline Aspf3-Rekom_6 & CCAAGCTTGCATGCCGTTAACAGCCTGCTGTTCGGCATCACTC \\
\hline \multicolumn{2}{|c|}{ Primer zur Herstellung rekombinanter Proteine } \\
\hline $\begin{array}{l}\text { Afu1g13670_23_ } \\
\text { BamHI }\end{array}$ & AACTGGGATCCCGTCAGGGTGCAGCAGCATTTGTTA \\
\hline $\begin{array}{l}\text { Afu1g13670_218_ } \\
\text { HindIII }\end{array}$ & ACTGAAGCTTTTAATTGCTTGCTTTTTTTTCCGGTGCGGC \\
\hline $\begin{array}{l}\text { Afu1g13670_182_ } \\
\text { HindIII }\end{array}$ & ACTGAAGCTTTTAGCTATTCTGAACTTCTTGACCCTGATGG \\
\hline HP16_rekom_1 & CTCGCGCTGGCGCCTACCGC \\
\hline HP16_rekom_2 & TCACCGGAAACCGAGCACCT \\
\hline HP16_rekom_3 & AAATTTGCATGCGCCTTCGTCACAGTGAACTCG \\
\hline HP16_rekom_4 & ATAATAGTCGACTCAGCGAGCCTCCTGCTTAGG \\
\hline \multicolumn{2}{|c|}{ Primer für Kolonie-PCR bei der Herstellung rekombinanter Proteine } \\
\hline HP16-Kolonie-PCR_1 & GGGTGAGCAAAAACAGGAAG \\
\hline HP16-Kolonie-PCR_2 & AGACCTTGAGAGCCTTGCAG \\
\hline \multicolumn{2}{|c|}{ Primer zur Herstellung einer DIG-markierten Sonde } \\
\hline Phle-Pro1 & TGCTTTGCCCGGTGTATGAAACC \\
\hline Phle-Pro2 & AAGGGATGGGAAGGATGGAGTATGG \\
\hline Phle-Pro3 & TCTGTAGGGCGTCCAAATATCGTGC \\
\hline Phle-Pro4 & CATGGTGATGTCTGCTCAAGCGG \\
\hline RekomHP16_Sonde1 & GATCCCATTGGTAACGAAATGT \\
\hline RekomHP16_Sonde2 & ACGCCAAAGACGTTACCTAAGA \\
\hline RekomHP16_Sonde3 & GCCGATGTCAGGATGATTTC \\
\hline RekomHP16_Sonde4 & TTGTGAGAGTCCAGCCAAAA \\
\hline \multicolumn{2}{|c|}{ Kontrollprimer der Deletionsmutanten } \\
\hline Primer HP16_screen_1 & TACGGGCATTGTATCTCCAG \\
\hline Primer HP16_screen_2 & GTTTCATACACCGGGCAAAG \\
\hline Primer HP16_screen_3 & CTCCGTAACACCCAATACGC \\
\hline Primer HP16_screen_4 & CAATGCGATGCTGTCAGAGT \\
\hline \multicolumn{2}{|c|}{ Kontrollprimer der Komplementmutanten } \\
\hline HP16_ReplacTrafo_1 & CAGATATCGCCTGATGACGA \\
\hline HP16_ReplacTrafo_2 & GTTCTTGGGAGGATGCAAAA \\
\hline HP16_ReplacTrafo_3 & TGGCTGTGTCCCGTATGTAA \\
\hline HP16_ReplacTrafo_4 & ATCAATTTGGCCTTCGTCAC \\
\hline Aspf3_ReplacTrafo_3 & GACAGGTGGCAATGACACAA \\
\hline Aspf3_ReplacTrafo_4 & GTGGGGTGATTTATTATGGAAC \\
\hline
\end{tabular}




\begin{tabular}{|l|l|}
\hline Name des Primers & Sequenz 5'- $\mathbf{3}^{\mathbf{6}}$ \\
\hline Aspf3_ReplacTrafo_5 & ATGGCTGTGTCCCGTATGTAA \\
\hline Aspf3_ReplacTrafo_6 & CCAAGCTTGCATGCCGTTA \\
\hline
\end{tabular}

\subsubsection{Antikörper}

Tab. 8: Verwendete Antikörper

\begin{tabular}{|l|l|}
\hline Bezeichnung & Hersteller \\
\hline Anti-Digoxigenin-POD, Fab fragments & Roche, Mannheim \\
\hline
\end{tabular}

\subsubsection{Organismen und Stämme}

Tab. 9: Verwendete Organismen und Stämme

\begin{tabular}{|l|l|}
\hline Aspergillus fumigatus & Wildtyp/ Klinisches Isolat \\
\hline D141 & Herstellung durch Utz Reichard \\
\hline D141 delAspf3-5 & eigene Herstellung \\
\hline D141 delAspf3-5 komplementiert & eigene Herstellung \\
\hline D141 delHP16-8 & eigene Herstellung \\
\hline D141 delHP16-8 komplementiert & Bioline GmbH, Luckenwalde \\
\hline Escherichia coli & Stratagene, La Jolla, USA \\
\hline$\alpha$-Select & Agilent Technologies, Böblingen \\
\hline BL21-CodonPlus ${ }^{\circledR}$ (DE3)-R|L & Invitrogen GmbH, Karlsruhe \\
\hline BL21(DE3) & Stratagene, La Jolla, USA \\
\hline DH5 $\alpha$ & Invitrogen GmbH, Karlsruhe \\
\hline SURE & $\begin{array}{l}\text { Herstellung durch Martin Rosenow und } \\
\text { eigene Herstellung }\end{array}$ \\
\hline Top10 & Harlan Laboratories, Horst, Niederlande \\
\hline E. coli mit Expressionsplasmiden & Harlan Laboratories, Horst, Niederlande \\
\hline Versuchstiere &
\end{tabular}

\subsubsection{Plasmide und Proteinexpressionsplasmide}

Tab. 10: Plasmide zur Herstellung von Deletions- und Komplementmutanten sowie Plasmide zur Proteinexpression

\begin{tabular}{|l|l|l|}
\hline Name & $\begin{array}{l}\text { Beschreibung/ relevante } \\
\text { Merkmale }\end{array}$ & Hersteller \\
\hline Herstellung von Deletions- und Komplementmutanten & \\
\hline pAN7-1 & A.nidulans-Promotor & \\
& gpdA & P. J. Punt [69] \\
\hline
\end{tabular}




\begin{tabular}{|c|c|c|}
\hline Name & $\begin{array}{l}\text { Beschreibung/ relevante } \\
\text { Merkmale }\end{array}$ & Hersteller \\
\hline pBlueskript II SK+ PacI & $\begin{array}{l}\text { pBluescript SK+ mit zusätzlicher } \\
\text { PacI- Schnittstelle zu Beginn der } \\
\text { Multiple Cloning Site }\end{array}$ & Utz Reichard \\
\hline pAspf3-del komplementiert & $\begin{array}{l}\text { Plasmid zur Herstellung der } \\
\text { Komplementmutante: Aspf3-Gen } \\
\text { nebst den C- und N-terminal } \\
\text { flankierenden Bereichen, ptrA }{ }^{\mathrm{R}} \text {, } \\
\text { pptrA, tptrA }\end{array}$ & $\begin{array}{l}\text { eigene } \\
\text { Herstellung }\end{array}$ \\
\hline pHP16-del & $\begin{array}{l}\text { Plasmid zur Herstellung der } \\
\text { Deletionsmutante HP16: C- und } \\
\text { N-terminal flankierende Bereiche } \\
\text { des Gens, loxP, pgpdA, hph }{ }^{\mathrm{R}} \text {, } \\
\text { HSV1 TK, ttrpC, amp }\end{array}$ & $\begin{array}{l}\text { eigene } \\
\text { Herstellung }\end{array}$ \\
\hline pHP16-del komplementiert & $\begin{array}{l}\text { Plasmid zur Herstellung der } \\
\text { Komplementmutante: HP16-Gen } \\
\text { nebst den C- und N-terminal } \\
\text { flankierenden Bereichen, ptrA }{ }^{\mathrm{R}} \text {, } \\
\text { pptrA, tptrA }\end{array}$ & $\begin{array}{l}\text { eigene } \\
\text { Herstellung }\end{array}$ \\
\hline pSK275 & $\begin{array}{l}\text { Insert für Komplementierungs- } \\
\text { plasmid, } p \operatorname{tr} \mathrm{A}^{\mathrm{R}}\end{array}$ & $\begin{array}{l}\text { Sven Krappmann } \\
\text { (Erlangen) }\end{array}$ \\
\hline pSK397 & $\begin{array}{l}\text { Insert für Deletionsplasmide } \\
\text { SfiI, loxP, pgpdA, hph }{ }^{\mathrm{R}}, \operatorname{amp}^{\mathrm{R}} \text {, } \\
\text { HSV1 TK, ttrpC }\end{array}$ & $\begin{array}{l}\text { Sven Krappmann } \\
\text { (Erlangen) }\end{array}$ \\
\hline pUC19L & $\begin{array}{l}\text { linearisierter pUC19-Vektor zur } \\
\text { Herstellung der Komplemen- } \\
\text { tierungsplasmide, } \mathrm{Amp}^{\mathrm{R}}, 2659 \mathrm{bp}\end{array}$ & $\begin{array}{l}\text { Invitrogen } \\
\text { GmbH, Karlsruhe }\end{array}$ \\
\hline \multicolumn{3}{|c|}{ Herstellung von Proteinexpressionsplasmiden } \\
\hline $\begin{array}{l}\text { pET28aHT_Afu1g13670_ } \\
23-182\end{array}$ & $\begin{array}{l}\text { HP16 (AS 23-182) in pET28a- } \\
\text { Derivat kloniert, 6x His-tag, TEV } \\
\text { site, } \operatorname{Kan}^{\mathrm{R}}\end{array}$ & $\begin{array}{l}\text { zusammen mit } \\
\text { Vera Pähtz (HKI, } \\
\text { Jena) }\end{array}$ \\
\hline $\begin{array}{l}\text { pET28aHT_Afu1g13670_ } \\
\text { 23-218 }\end{array}$ & $\begin{array}{l}\text { HP16 (AS 23-218) in pET28a- } \\
\text { Derivat kloniert, 6x His-tag, TEV } \\
\text { site, } \operatorname{Kan}^{\mathrm{R}}\end{array}$ & $\begin{array}{l}\text { zusammen mit } \\
\text { Vera Pähtz (HKI, } \\
\text { Jena) }\end{array}$ \\
\hline pET-BL874 & $\begin{array}{l}\text { Aspf3 (AHP1)- vollständig } \\
\text { rekombinant in pET-Vektor (His- } \\
\text { tag) }\end{array}$ & $\begin{array}{l}\text { Michel Monod } \\
\text { (Lausanne, } \\
\text { Schweiz) }\end{array}$ \\
\hline pET-BL875 & $\begin{array}{l}\text { HSP90-C-Terminus rekombinant } \\
\text { in pET-Vektor (His-tag) }\end{array}$ & $\begin{array}{l}\text { Michel Monod } \\
\text { (Lausanne, } \\
\text { Schweiz) }\end{array}$ \\
\hline pET-BL876 & $\begin{array}{l}\text { Enolase (Aspf22)- vollständig } \\
\text { rekombinant in pET-Vektor (His- } \\
\text { tag) }\end{array}$ & $\begin{array}{l}\text { Michel Monod } \\
\text { (Lausanne, } \\
\text { Schweiz) }\end{array}$ \\
\hline pMA-T_Afu1g13670_23-218 & $\begin{array}{l}\text { Synthetisches Gen HP16 in } \\
\text { pMA-T-Derivat, Amp }^{\mathrm{R}}\end{array}$ & $\begin{array}{l}\text { Invitrogen } \\
\text { GmbH, Karlsruhe }\end{array}$ \\
\hline
\end{tabular}




\subsubsection{Rekombinante Proteine}

Die in der nachfolgenden Tabelle aufgeführten Proteine wurden, wenn nicht selbst produziert, von Martin Rosenow (Göttingen) hergestellt. Alle Proteine sollten in dieser Arbeit als Vakzine im Mausmodell auf ihre Protektion geprüft werden.

Tab. 11: Rekombinante Proteine aus E.coli. Wurden zwei Proteine mit dem gleichen Namen, aber zwei verschiedenen Aminosäure (AS)-Bereichen angegeben, wurde das Protein in zwei Fragmenten exprimiert

\begin{tabular}{|c|c|c|c|}
\hline Abkürzung & Name & $\begin{array}{l}\text { Accession } \\
\text { Nummer }\end{array}$ & Hersteller \\
\hline AAT & $\begin{array}{l}\text { Aspartat-Aminotransferase (AS 69- } \\
\text { 261) }\end{array}$ & AFUA_4G10410 & M.Rosenow \\
\hline $\mathrm{ADH}$ & Alkohol-Dehydrogenase (AS 29-200) & AFUA_5G06240 & M.Rosenow \\
\hline ADMA & $\begin{array}{l}\text { Metalloprotease ADM-A (AS 116- } \\
435 \text { ) }\end{array}$ & AFUA_6G14420 & M.Rosenow \\
\hline ALAD & $\begin{array}{l}\text { Aldolase ClassII/ Adducin-Domain- } \\
\text { Protein (AS8-294) }\end{array}$ & AFUA_3G09800 & M.Rosenow \\
\hline AP & Aminopeptidase (AS 285-609) & AFUA_4G09030 & M.Rosenow \\
\hline AP5/6 & Aminopeptidase (AS 661-849) & AFUA_4G09030 & M.Rosenow \\
\hline Aspf3 & $\begin{array}{l}\text { Peroxireduktase, vollständig } \\
\text { rekombinant (s. Plasmide; 2.1.11) }\end{array}$ & AFUA_6G02280 & $\begin{array}{l}\text { eigene } \\
\text { Herstellung }\end{array}$ \\
\hline BGT & $\begin{array}{l}\text { 1,3-beta-Glucanosyltransferase Gel1 } \\
\text { (AS 25-188) }\end{array}$ & AFUA_2G01170 & M.Rosenow \\
\hline BGT3/4 & $\begin{array}{l}\text { 1,3-beta-Glucanosyltransferase Gel1 } \\
\text { (AS 219-398) }\end{array}$ & AFUA_2G01170 & M.Rosenow \\
\hline $\mathrm{COA}$ & $\begin{array}{l}\text { Coatomer, Delta-Untereinheit } \\
\text { (AS 86-406) }\end{array}$ & AFUA_1G15860 & M.Rosenow \\
\hline DI & Disulfid-Isomerase Pdi1 (AS 26-220) & AFUA_2G06150 & M.Rosenow \\
\hline $\mathrm{DI} 3 / 4$ & Disulfid-Isomerase Pdi1 (AS 255-424) & AFUA_2G06150 & M.Rosenow \\
\hline Enolase & $\begin{array}{l}\text { Enolase, vollständig rekombinant } \\
\text { (s. Plasmide; 2.1.11) }\end{array}$ & AFUA_6G06770 & $\begin{array}{l}\text { eigene } \\
\text { Herstellung }\end{array}$ \\
\hline FBA & $\begin{array}{l}\text { Fructosebisphosphataldolase, classII } \\
\text { (AS 251-420) }\end{array}$ & AFUA_3G11690 & M.Rosenow \\
\hline GAPD & $\begin{array}{l}\text { Glyceraldehyd-3-Phosphat- } \\
\text { Dehydrogenase (AS 63-240) }\end{array}$ & AFUA_5G01970 & M.Rosenow \\
\hline HP10 & $\begin{array}{l}\text { Konserviertes hypothetisches Protein } \\
\text { (AS 578-742) }\end{array}$ & AFUA_6G07410 & M.Rosenow \\
\hline HP90 & $\begin{array}{l}\text { Konserviertes hypothetisches Protein } \\
\text { (AS 2-95) }\end{array}$ & AFUA_1G02290 & M.Rosenow \\
\hline HSP30 & $\begin{array}{l}\text { Hitzeschockprotein Hsp30 } \\
\text { (AS 4-519) }\end{array}$ & AFUA_3G14540 & M.Rosenow \\
\hline HSP90 & $\begin{array}{l}\text { Hitzeschockprotein Hsp90, C-terminal } \\
\text { (s. Plasmide; 2.1.11) }\end{array}$ & AFUA_5G04170 & $\begin{array}{l}\text { eigene } \\
\text { Herstellung }\end{array}$ \\
\hline HSP70 & $\begin{array}{l}\text { Hitzeschockprotein Hsp70 } \\
\text { (AS 212-533) }\end{array}$ & AFUA_1G12610 & M.Rosenow \\
\hline
\end{tabular}




\begin{tabular}{|l|l|l|l|}
\hline Abkürzung & Name & $\begin{array}{l}\text { Accession } \\
\text { Nummer }\end{array}$ & Hersteller \\
\hline INVO3/4 & $\begin{array}{l}\text { Involucrin-Repeat-Protein (AS 650- } \\
887)\end{array}$ & AFUA_4G11410 & M.Rosenow \\
\hline MIPS & $\begin{array}{l}\text { Myo-Inositol-Phosphat-Synthase } \\
\text { (AS 4-210) }\end{array}$ & AFUA_2G01010 & M.Rosenow \\
\hline MPRO5/6 & M-Repeatprotein (AS 818-1137) & AFUA_6G08660 & M.Rosenow \\
\hline NDGD & $\begin{array}{l}\text { NAD+-abhängigen Glutamat- } \\
\text { Dehydrogenase (AS 413-699) }\end{array}$ & AFUA_2G06000 & M.Rosenow \\
\hline PG & $\begin{array}{l}\text { Phosphoglucomutase PgmA } \\
(\text { AS 49-369) }\end{array}$ & AFUA_3G11830 & M.Rosenow \\
\hline PG3/4 & $\begin{array}{l}\text { Phosphoglucomutase PgmA } \\
(\text { AS 385-548) }\end{array}$ & AFUA_3G11830 & M.Rosenow \\
\hline PGM & Phosphoglyceratmutase (AS 22-248) & AFUA_3G09290 & M.Rosenow \\
\hline PGM3/4 & Phosphoglyceratmutase (AS 385-548) & AFUA_3G09290 & M.Rosenow \\
\hline SHMT & $\begin{array}{l}\text { Serine-Hydroxymethyltransferase } \\
(\text { AS 248-439) }\end{array}$ & AFUA_3G09320 & M.Rosenow \\
\hline TBP & $\begin{array}{l}\text { Thiamin-Biosynthese-Protein Nmt1 } \\
(\text { AS 131-342) }\end{array}$ & AFUA_5G02470 & M.Rosenow \\
\hline TK & Transketolase TktA (AS 157-393) & AFUA_1G13500 & M.Rosenow \\
\hline
\end{tabular}

\subsubsection{Platten zur Anzucht von Aspergillen}

Zum Ausplattieren von A.fumigatus wurden Fertigagarplatten der Firma Oxoid GmbH verwendet (PO5096A). Der Sarbouraud-Glucose-Agar enthielt Chloramphenicol (50 $\mu \mathrm{g} / \mathrm{ml})$ und Gentamicin $(100 \mu \mathrm{g} / \mathrm{ml})$. Sollten beim Ausplattieren der A.fumigatusStämme diese speziell auf eine Antibiotikaresistenz (Hygromycin oder Pyrithiamin) gescreent werden, wurden diese auf selbst angesetzten MM-Agarplatten, denen das jeweilige Antibiotikum beigesetzt wurde, ausplattiert.

\subsubsection{Nährmedien und Medienzusätze}

Wenn nicht anders angegeben, wurden die Lösungen und Puffer in $\mathrm{H}_{2} \mathrm{O}$ angesetzt, gelöst und der $\mathrm{pH}$-Wert mit $\mathrm{HCl}$ bzw. $\mathrm{NaOH}$ eingestellt. Die Prozentzahlen entsprechen, wenn nicht anders angegeben, w/v-Angaben. 
$\underline{\text { Glucosebouillon }}$

$\underline{\text { LB-Agar }}$

LB-Medium:

$\underline{\text { MM-Agar }}{ }^{\text {Hygromycin }}$

$\underline{\text { MM-Agar }}{ }^{\text {Pyrithimain }}$

$\underline{\text { MM-Medium }}$

$\underline{\text { MM-Top-Agar }}{ }^{\text {Hygromycin }}$
$0,5 \% \mathrm{NaCl}$

$1 \%$ Glucose

$1 \%$ Pepton (aus Fleisch)

$1 \%$ Fleischextrakt trocken

in $\mathrm{H}_{2} \mathrm{O}$ ansetzen, titrieren auf $\mathrm{pH} 7,2$

und autoklavieren

2,0\% Agar

in LB-Medium ansetzen und autoklavieren

1,0\% Bacto-Trypton

$0,5 \%$ Bacto-Hefeextrakt

$1,0 \% \mathrm{NaCl}$

in $\mathrm{H}_{2} \mathrm{O}$ ansetzen, titrieren auf $\mathrm{pH} 7,0$

und autoklavieren

1 M Saccharose

$2 \%$ Agar

in MM-Medium ansetzen und autoklavieren

für $20 \mathrm{~min}$ bei $105^{\circ} \mathrm{C}$

$1 \%$ Glucose

1x AspA

$1 \mathrm{mM} \mathrm{MgSO}_{4} \times \mathrm{H}_{2} \mathrm{O}$

$0,1 \%$ Spurenelement-Lösung

$\mathrm{H}_{2} \mathrm{O}$ ad $10 \mathrm{ml}$

1,2 M Sorbit (einzeln autoklariert)

$2 \%$ Agar (einzeln autoklaviert)

$1 \%$ Glucose

$0,092 \%$ Ammoniumtartrat

$0,052 \% \mathrm{KCl}$

$0,052 \% \mathrm{MgSO}_{4} \times 7 \mathrm{H}_{2} \mathrm{O}$

$0,152 \% \mathrm{KH}_{2} \mathrm{PO}_{4}$

$0,1 \%$ Spurenelement-Lösung

in $\mathrm{H}_{2} \mathrm{O}$ ansetzen, titrieren auf $\mathrm{pH} 6,8$

und autoklavieren

1 M Saccharose

$0,7 \%$ Agar

in MM-Medium ansetzen und autoklavieren

für $20 \mathrm{~min}$ bei $105^{\circ} \mathrm{C}$ 
$\underline{\text { MM-Top-Agar }}$ Pyrithiamin

$\underline{\text { PEG-Lösung }}$

$\underline{\text { SOC-Medium }}$

$\underline{\text { TB-Medium }}$

$\underline{\text { YNB-Medium }}$
$1 \%$ Glucose

1x AspA

$1 \mathrm{mM} \mathrm{MgSO}_{4} \times \mathrm{H}_{2} \mathrm{O}$

$0,1 \%$ Spurenelement-Lösung

$\mathrm{H}_{2} \mathrm{O}$ ad $10 \mathrm{ml}$

1,2 M Sorbit (einzeln autoklariert)

$0,7 \%$ Agar (einzeln autoklaviert)

$60 \%$ Polyethylenglykol PEG3350

in MSC lösen und sterilfiltrieren

$0,5 \%$ Bacto-Hefeextract

$2 \%$ Bacto-Trypton

$0,05 \% \mathrm{NaCl}$

in $\mathrm{H}_{2} \mathrm{O}$ ansetzen und autoklavieren

$+0,1 \% 1 \mathrm{M} \mathrm{MgCl}_{2}$-Lösung (steril)

$+0,1 \% 1 \mathrm{M} \mathrm{MgSO}_{4}$-Lösung (steril)

$+0,1 \% 2 \mathrm{M}$ Glucose-Lösung (steril)

$6 \% \mathrm{~TB}$

$1,26 \%$ Glycerol

$30 \mathrm{sec}$ in der Mikrowelle aufkochen

0,67\% Hefestickstoff-Basismedium in $\mathrm{H}_{2} \mathrm{O}$ ansetzen, titrieren auf $\mathrm{pH} 6,8$ und autoklavieren

\section{$\underline{\text { Antibiotikazusätze }}$}

Die verwendeten Antibiotika wurden als Stammlösung angesetzt, steril filtriert und bei $-20^{\circ} \mathrm{C}$ gelagert. Sie wurden dem autoklavierten Medium bzw. Agar nach Abkühlen auf etwa $55^{\circ} \mathrm{C}$ unter sterilen Bedingungen zugesetzt. Dabei wurden folgende Endkonzentrationen verwendet:

$\begin{array}{lr}\text { Ampicillin } & 100 \mu \mathrm{g} / \mathrm{ml} \\ \text { Chloramphenicol } & 50 \mu \mathrm{g} / \mathrm{ml} \\ \text { Hygromycin B } & 200 \mu \mathrm{g} / \mathrm{ml} \\ \text { Kanamycin } & 50 \mu \mathrm{g} / \mathrm{ml} \\ \text { Pyrithiamin } & 2 \mu \mathrm{g} / \mathrm{ml} \\ \text { Tetracyclin } & 12,5 \mu \mathrm{g} / \mathrm{ml}\end{array}$




\title{
2.1.15 Lösungen und Puffer
}

Wenn nicht anders angegeben, wurden die Lösungen und Puffer in $\mathrm{H}_{2} \mathrm{O}$ angesetzt und der $\mathrm{pH}-\mathrm{Wert}$ mit $\mathrm{HCl}$ bzw. $\mathrm{NaOH}$ eingestellt. Die Prozentzahlen entsprechen, wenn nicht anders angegeben, w/v-Angaben.

$\underline{\operatorname{AspA} 50 \mathrm{x}}$

\author{
$3,5 \mathrm{M} \mathrm{NaNO}_{3}$ \\ $350 \mathrm{mM} \mathrm{KCl}$ \\ $550 \mathrm{mM} \mathrm{KH}_{2} \mathrm{PO}_{4}$ \\ titrieren auf $\mathrm{pH}$ 5,5 und autoklavieren
}

Denhardts Reagenz

1,0\% Ficoll Typ 400

$1,0 \%$ Polyvinylpyrrolidon

$1,0 \%$ BSA

sterilfiltrieren

$\underline{\operatorname{EDTA}(0,5 \mathrm{M})}$

0,5 M Na-EDTA

titrieren auf $\mathrm{pH} 8,0$ und autoklavieren

Lysispuffer für die Aufarbeitung genomischer Aspergillus-DNA

0,1 M NaEDTA

0,2 $\mathrm{m}$ TrisCl

$1 \%$ SDS

titieren auf $\mathrm{pH} 8,5$

Lysispuffer für Transformation $\quad 0,4 \mathrm{M} \mathrm{NaCl}$

0,2 M Tris-Cl pH 8.0

$0,4 \%$ SDS

$10 \mathrm{mM}$ EDTA

$\underline{\mathrm{MS}}$

$10 \mathrm{mM}$ MOPS

1 M Sorbit

titrieren auff $\mathrm{pH}$ 6,5 und sterilfiltrieren

$\underline{\mathrm{MSC}}$

$10 \mathrm{mM}$ MOPS

$1 \mathrm{M}$ Sorbit

$20 \mathrm{mM} \mathrm{CaCl}_{2}$

titrieren auf $\mathrm{pH}$ 6,5 und sterilfiltrieren

$\underline{\text { Na-Acetat-Lösung (3 M) }}$

$3 \mathrm{M} \mathrm{Na}$-Acetat

titrieren auf $\mathrm{pH}$ 5,2 
$\underline{\text { Na-Acetat-Lösung (8 M) }}$

$\underline{\mathrm{NaCl} \text {-Lösung (2 M) }}$

$\underline{\mathrm{NaCl}-\mathrm{Tween}}$

$\underline{\mathrm{Na}}_{2} \underline{\text { EDTA-SDS-Lösung }}$

$\underline{\text { OM-Puffer }}$

$\underline{\text { PBS 10x }}$
17,4 M Eisessig

titrieren auf $\mathrm{pH} 4,2$

$2 \mathrm{M} \mathrm{NaCl}$

autoklavieren

$0,9 \% \mathrm{NaCl}$

$0,1 \%$ Tween 80

$50 \mathrm{mM} \mathrm{Na} 2$ EDTA

$0,25 \%$ SDS

$10 \mathrm{mM} \mathrm{Na}_{3} \mathrm{PO}_{4}$

$1.2 \mathrm{M} \mathrm{MgSO}_{4} \times \mathrm{H}_{2} \mathrm{O}$

titrieren auf $\mathrm{pH} 8,5$ und sterilfiltrieren

$8 \% \mathrm{NaCl}$

$0,2 \% \mathrm{KCl}$

$1,44 \% \mathrm{Na}_{2} \mathrm{HPO}_{4}$

$0,24 \% \mathrm{KH}_{2} \mathrm{PO}_{4}$

titrieren auf $\mathrm{pH} 7,4$ und autoklavieren

Phenol-Chloroform-Isoamylalkohol 1 Volumen Phenol-Lösung

1 Volumen Chloroform-Isoamylalkohol (24:1)

gut mischen und Phasentrennung abwarten

Phenol-Lösung

$500 \mathrm{~g}$ Phenol (fest)

$0,5 \mathrm{~g} 8$-Hydroxychinolin

im $65^{\circ} \mathrm{C}$ Wasserbad erwärmen

+1 Volumen $1 \mathrm{M}$ TrisCl $(\mathrm{pH} 8,0)$

schütteln und mischen, Phasentrennung abwarten,

obere Phase verwerfen

+1 Volumen $1 \mathrm{M}$ TrisCl $(\mathrm{pH} 8,0)$

schütteln und mischen, Phasentrennung abwarten, obere Phase verwerfen, $\mathrm{pH}$ 7,8 soll vorliegen, sonst Vorgang wiederholen

wie folgt aliquotieren:

$40 \mathrm{ml}$ Phenol

$8 \mathrm{ml} \mathrm{0,1} \mathrm{M} \mathrm{TrisCl}$

$8 \mu \mathrm{l} \beta$-Mercaptoethanol 
Prähybridisierungslösung

$\underline{\text { Protein-Produktion-Puffer A }}$

$\underline{\text { Protein-Produktion-Puffer B }}$

$\underline{\text { Protein-Produktion-Puffer C }}$

$\underline{\text { Protein-Produktion-Puffer E }}$

$\underline{\operatorname{SDS} 10 \%}$

$\underline{\text { SDS-Entfärbelösung }}$

SDS-Färbelösung

$\underline{\text { SDS-Laufpuffer }}$

$\underline{\text { SDS- Probenpuffer }}$
$50 \%$ Formamid, 6x SSC

5x Denhardts Reagenz

$0,5 \%$ SDS

$100 \mu \mathrm{g} / \mathrm{ml}$ Heringsperma-DNA

6 M Guanidine-Hydrochlorid

$0,1 \mathrm{M} \mathrm{NaH}_{2} \mathrm{PO}_{4}$

$10 \mathrm{mM}$ Tris

titrieren auf $\mathrm{pH} 8,0$

8 M Harnstoff

$0,1 \mathrm{M} \mathrm{NaH}_{2} \mathrm{PO}_{4}$

$10 \mathrm{mM}$ Tris

titrieren auf $\mathrm{pH} 8,0$

8 M Harnstoff

$0,1 \mathrm{M} \mathrm{NaH}_{2} \mathrm{PO}_{4}$

$10 \mathrm{mM}$ Tris

titrieren auf $\mathrm{pH}$ 6,3

8 M Harnstoff

$0,1 \mathrm{M} \mathrm{NaH}_{2} \mathrm{PO}_{4}$

$10 \mathrm{mM}$ Tris

titrieren auf $\mathrm{pH} 4,5$

$10 \%$ SDS (Natriumdodecylsulfat)

7,5 \% Essigsäure

0,17 \% Coomassie Brillant Blue R250

$6,7 \%$ Essigsäure

$33,3 \%$ Methanol

$0,3 \%$ Tris

$1,44 \%$ Glycin

$1 \% \operatorname{SDS} 10 \%$

$20 \%$ Glycerol

$50 \%$ SDS $10 \%$

$30 \%$ SDS-Sammelgelpuffer

0,01\% Bromphenolblau 
$\underline{\text { SDS-Sammelgelpuffer }}$

$\underline{\text { SDS-Trenngelpuffer }}$

$\underline{\text { SDS-Trocknungslösung }}$

$\underline{\text { Southern Blot-Blockpuffer }}$

Southern Blot-Blockpuffer

$5 \%$ Milchpulver
$0,1 \%$ Tween 20
in $1 \mathrm{x}$ PBS ansetzen, titrieren auf $\mathrm{pH} 7,4$

1 M Trís

titrieren auf $\mathrm{pH} 8,8$

$20 \%$ Methanol

$5 \%$ Glycerol

Southern Blot-Denaturierungslsg. $\quad 1,5 \mathrm{M} \mathrm{NaCl}$

$0,5 \mathrm{M} \mathrm{NaOH}$

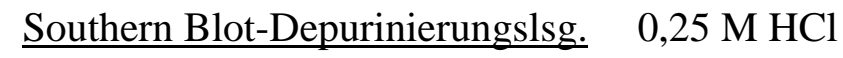

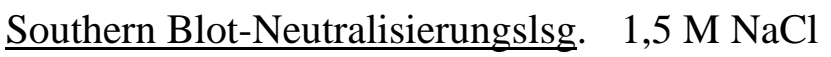

$0,5 \mathrm{M}$ Tris- $\mathrm{Cl}$

$\underline{\text { Southern Blot-Waschpuffer I } \quad 2 x \text { SSC }}$

$0,5 \%$ SDS

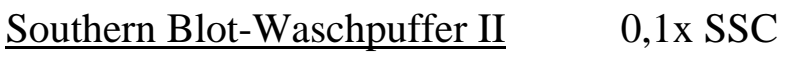

$0,5 \%$ SDS

$\underline{\text { Spurenelemente-Lösung }}$

$\underline{\text { SSC 20x }}$

$0,004 \% \mathrm{Na}_{2} \mathrm{~B}_{4} \mathrm{O}_{7} \times 10 \mathrm{H}_{2} \mathrm{O}$

$0,04 \% \mathrm{CuSO}_{4} \times 5 \mathrm{H}_{2} \mathrm{O}$

$0,08 \% \mathrm{FePO}_{4} \times 2 \mathrm{H}_{2} \mathrm{O}$

$0,08 \% \mathrm{MnSO}_{4} \times 2 \mathrm{H}_{2} \mathrm{O}$

$0,08 \% \mathrm{Na}_{2} \mathrm{MoO}_{4} \times 2 \mathrm{H}_{2} \mathrm{O}$

$0,8 \% \mathrm{ZnSO}_{4} \times 7 \mathrm{H}_{2} \mathrm{O}$

sterilfiltrieren

$3 \mathrm{M} \mathrm{NaCl}$

0,3 M Natriumcitrat

Titrieren auf $\mathrm{pH} 7,0$ 
$\underline{\text { TAE } 6 x}$

$\underline{\mathrm{TB}}$

$\underline{\operatorname{TBE} 5 \mathrm{x}}$

$\underline{\text { TE-Puffer }}$

$\underline{\text { Tris-EDTA-Puffer }}$

$\underline{\text { Western Blot- Blockpuffer }}$

$\underline{\text { Western Blot-Substratpuffer }}$

$\underline{\text { Western Blot- Transferpuffer }}$
$2,90 \%$ Tris

$0,69 \%$ Essigsäure

$1,20 \%$ 0,5 M EDTA (pH 8,0)

$100 \mathrm{mM}$ MOPS

0,6 M Sorbit

titrieren auf $\mathrm{pH}$ 7,5 und sterilfiltrieren

5,4\% Tris

2,75\% Borsäure

$2 \%$ 0,5 M EDTA (pH 8,0)

$10 \mathrm{mM}$ Tris- $\mathrm{Cl}$

$1 \mathrm{mM}$ EDTA

titrieren auf $\mathrm{pH}$ 8,0 und autoklavieren

0,1 M EDTA

mit festem Tris (etwa 1,25\%) auf $\mathrm{pH} 7,4$ titrieren

$10 \%$ Milchpulver

$0,1 \%$ Tween 20

in $1 \mathrm{x}$ PBS ansetzen

$80 \% 0,9 \% \mathrm{NaCl}$

$2 \%$ Diethanolamin

$0,02 \% 4,9 \mathrm{M} \mathrm{MgCl}_{2}$

$0,3 \%$ Tris

$1,44 \%$ Glycin

$15 \%$ Methanol

\subsection{Mikrobiologische Arbeitsmethoden}

\subsubsection{Sterilisation}

Wenn nicht anders angegeben, wurden alle verwendeten Medien, Puffer, Glas- und Plastikgefäße für $20 \mathrm{~min}$ bei $121^{\circ} \mathrm{C}$ dampfsterilisiert. Temperaturempfindliche Lösungen wurden mit Hilfe eines Sterilfilters mit einer Porengröße von 0,2 $\mu \mathrm{m}$ filtriert. 


\subsubsection{Bakterienkultivierung}

Für flüssige Bakterienkulturen wurden 2,5 ml LB-Medium in einem $15 \mathrm{ml}$ Zentrifugenröhrchen mit entsprechenden Antibiotikazusätzen angesetzt. Die Animpfung erfolgte entweder aus einer Glycerolkultur oder mit einer Einzelkolonie von einer LBAgar-Platte mit einer sterilen Impföse. Die Kultur wurde über Nacht bei $37^{\circ} \mathrm{C}$ und 200 rpm auf einem Schüttler inkubiert. Für die Kultivierung von Bakterien auf festem Medium wurde LB-Agar verwendet, dem, wenn nötig, entsprechende Antibiotika zugesetzt wurden.

\subsubsection{Bestimmung der Zelldichte}

Die Zelldichte der Bakterienkulturen wurde durch Messung der OD bei $600 \mathrm{~nm}$ im Photometer bestimmt. Eine OD600 von 1 entspricht hierbei einer Zellzahl von etwa $1 \times 10^{9}$ Zellen pro ml Kultur.

\subsubsection{Herstellung elektrokompetenter E.coli}

Zur Herstellung elektrokompetenter E.coli-Zellen wurden $220 \mathrm{ml}$ vorgewärmtes LBMedium mit 4-5 E.coli-Kolonien angeimpft und bis $\mathrm{zu}$ einer $\mathrm{OD}_{600}$ von $0,35-0,4$ inkubiert. Direkt danach wurde die Kultur für 20 Minuten in ein Eiswasserbad gestellt und während dieser Zeit gelegentlich leicht geschüttelt. Es folgten mehrere Zentrifugationsschritte $\left(4^{\circ} \mathrm{C}, 4000 \times \mathrm{g}, 15 \mathrm{~min}\right)$ und anschließendes Resuspensieren des Pellets in eiskaltem, sterilem $\mathrm{H}_{2} \mathrm{O}$. Nach dem letzten Waschschritt wurde das Pellet in eiskaltem $10 \%$-igem Glycerol aufgenommen. Die so resuspendierten Zellen wurden zu $50 \mu \mathrm{l}$ aliquotiert, in flüssigem Stickstoff schnellst möglich gefroren und bei $-80^{\circ} \mathrm{C}$ gelagert.

\subsubsection{Transformation kompetenter E.coli}

Nach dem Auftauen eines Aliquots elektrokompetenter E.coli auf Eis wurden davon $40 \mu 1$ mit 1,5 $\mu$ l Ligationsansatz (bzw. 1,2 $\mu$ l Plasmid-DNA; 1-100 ng/ $\mu$ l) gemischt. Der Transformationsansatz wurde in eine vorgekühlte Elektroporationsküvette gegeben und mit folgenden Einstellungen transformiert: 


$\begin{array}{ll}\text { Kapazität C: } & 50 \mu \mathrm{F} \\ \text { Widerstand R: } & \text { R5 }(129 \mathrm{Ohm}) \\ \text { Spannung S: } & 1,3-1,5 \mathrm{kV} \\ \text { Pulsdauer t: } & 5-6 \mathrm{msec}\end{array}$

Anschließend wurden $500 \mu 1$ SOC-Medium dazugegeben, vorsichtig gemischt, und der Transformationsansatz wurde in ein Zentrifugenröhrchen überführt. Es folgte die Inkubation bei $37^{\circ} \mathrm{C}$ für $1 \mathrm{~h}$ unter Schütteln. Von dem Ansatz wurden verschiedene Volumina (meinst $10 \mu \mathrm{l}$ und $100 \mu \mathrm{l}$ ) auf die zuvor vorbereiteten LB-Agar-Platten gegeben. Die Platten wurden über Nacht bei $37^{\circ} \mathrm{C}$ inkubiert.

\subsubsection{Lagerung von Bakterien}

Zur längerfristigen Lagerung von Bakterien wurden diese über Nacht in LB-Medium wachsen gelassen. Von dieser Über-Nacht-Kultur wurden $20 \mu \mathrm{lu}$ 2,5 ml LB-Medium gegeben. Diese Subkultur wurde nach 2-3 h gestoppt und $828 \mu$ l wurden entnommen und zu $172 \mu$ s sterilem Glycerol (87 \%) gegeben. Die Lagerung der Dauerkulturen erfolgt bei $-80^{\circ} \mathrm{C}$. Eine kurzfristige Lagerung von bis zu 2 Wochen erfolgte bei $4^{\circ} \mathrm{C}$ auf LB-Agar-Platten.

\subsubsection{Herstellung einer A.fumigatus-Sporensuspension}

Um Sporen von A.fumigatus zu gewinnen, wurden Sabouraud- oder selbst hergestellte MM-Agarplatten beimpft und für mindestens 2 Tage bei $37^{\circ} \mathrm{C}$ inkubiert. Sporen wurden mit etwa 7-15 ml sterilem MM-Medium oder steriler 0,9 \%-iger $\mathrm{NaCl}$-Lösung (jeweils $0,1 \%$ Tween80 zugesetzt) überschichtet und mit Hilfe einer Impföse vorsichtig resuspendiert. Die Suspension wurde bei $4^{\circ} \mathrm{C}$ bis zur weiteren Verwendung aufbewahrt.

\subsubsection{Bestimmung der Sporenzahl}

Die Sporenzahl wurde mit Hilfe einer Thoma-Zählkammer bestimmt. Dazu wurde aus der Sporen-Stammsuspension eine 1:200-Verdünnung in sterilem PBS hergestellt und $10 \mu 1$ davon wurden in die Zählkammer eingebracht. Es wurden jeweils 6 Großquadrate 
(ein Großquadrat besteht aus 16 Kleinstquadraten) ausgezählt. Die Zahl der Sporen pro $\mathrm{ml}$ errechnet sich nach folgender Formel:

Sporen/ml: [Mittelwert aus den Großquadraten/16] x [4 x 10 ${ }^{6}$ ]

\subsubsection{Transformation von A.fumigatus}

Pro Transformation wurden zwei Ansätze $250 \mathrm{ml}$ gekühltes MM-Medium in jeweils 2-Liter-Schikanekolben gegeben und mit der Sporenmenge von zwei Agarplatten beimpft. Die Kolben wurden bei $4^{\circ} \mathrm{C}$ zwischengelagert und abends bei $30,5^{\circ} \mathrm{C}$ und $80 \mathrm{U} / \mathrm{min}$ über Nacht für ca. $10 \mathrm{~h}$ in den Inkubator gegeben. Am nächsten Morgen erfolgte eine mikroskopische Kontrolle; die Konidien sollten aufgebläht und kurz vor der Aussprossung sein. Das Kulturmedium wurde mit einem Bottle-Top-Filter (0,45 $\mu \mathrm{m})$ abfiltriert, die Aspergillen anschließend mit $10 \mathrm{ml}$ eiskaltem OM-Puffer gewaschen. Etwa 1,0-2,0 g gewaschene Pilzmasse wurde in ein $50 \mathrm{ml}$ Zentrifugenröhrchen gewogen und anschließend in $10 \mathrm{ml}$ OM-Puffer resuspendiert. Es folgte ein Zentrifugationsschritt bei $5 \mathrm{~min}$ bei $4000 \mathrm{x} g$ und $4^{\circ} \mathrm{C}$. Die Waschung in OMPuffer wurde zweimal wiederholt. Das Pellet wurde dann in 8,5 ml OM-Puffer resuspendiert und gründlich gevortext. Inkubation für 5 min auf Eis nach Zugabe von $1 \mathrm{ml}$ Glucanex ${ }^{\circledR}(50 \mathrm{mg} / \mathrm{ml}$ in OM). Für ein Gesamtvolumen von $10 \mathrm{ml}$ wurden $0,5 \mathrm{ml}$ BSA-Lösung ( $3 \mathrm{mg} \mathrm{BSA} / \mathrm{ml}$ in $\mathrm{OM}$ ) hinzugegeben und für $3 \mathrm{~h}$ bei $30-33^{\circ} \mathrm{C}$ im Schüttelwasserbad inkubiert. Die Lösung wurde vorsichtig mit $10 \mathrm{ml}$ TB-Puffer überschichtet und für $15 \mathrm{~min}$ bei $4000 \mathrm{x} g$ und $4^{\circ} \mathrm{C}$ zentrifugiert. Die Sphäroplasten befanden sich dann als eher unscharfe Bande im Interface der Lösungen, die vorsichtig abpipettiert wurden (etwa 4-5 ml). Zu 1 Volumen Sphäroplasten-Suspension wurden 9 Volumen MS hinzugemischt. Es folgte eine Zentrifugation für 15 min bei 1000 x $g$ und $4^{\circ} \mathrm{C}$, gefolgt von zweimaligem Waschen des Pellets mit $20 \mathrm{ml}$ MSC und anschließendem Zentrifugieren für $7 \mathrm{~min}$ bei 1000 x $g$ und $4^{\circ} \mathrm{C}$. Abschließend wurde das Pellet in $110 \mu \mathrm{l}$ MSC resuspendiert. 
Für die Transformation wurden folgende Ansätze pipettiert und vorsichtig gemischt:

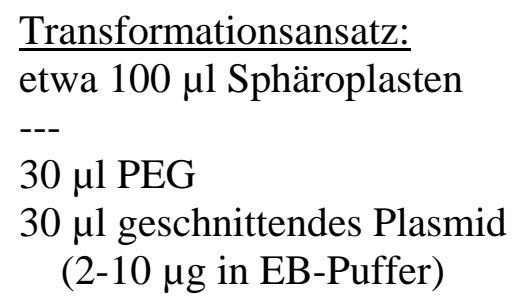

Negativkontrolle:

$10 \mu 1$ Sphäroplasten

$90 \mu \mathrm{l}$ MSC

$30 \mu 1$ PEG

$30 \mu \mathrm{l}$ EB-Puffer

Beide Ansätze wurden für 20-30 min auf Eis inkubiert. Es wurden jeweils $900 \mu 1$ PEG hinzugefügt und gemischt. Es folgte eine Inkubation für 30 min bei Raumtemperatur auf dem Drehrad. Im Anschluss wurden die Ansätze für 15 min bei 5000 x $g$ zentrifugiert. Der Überstand vom Sphäroplasten-Pellet wurde komplett entfernt. Der Transformationsansatz wurde in $500 \mu \mathrm{l}$ MSC und die Negativkontrolle in $50 \mu \mathrm{l}$ MSC resuspendiert.

\section{$\underline{\text { Transformanten mit Hygromycin B-Resistenz }}$}

Für die Transformanten mit Hygromycin B-Resistenz wurden 2,0 ml-Reaktionsgefäße bereitgestellt und 16-mal mit einem Ansatz mit jeweils $30 \mu 1$ Sphäroplasten befüllt. Als Negativkontrolle wurden einmal $25 \mu \mathrm{l}$ und einmal $30 \mu \mathrm{l}$ der Sphäroplasten vorgelegt. $1,6 \mathrm{ml}$ MM-Top-Agar ${ }^{\text {Hygromycin }}$ wurden jeweils hinzugegeben, gemischt, auf vorgewärmte $\left(37^{\circ} \mathrm{C}\right) \mathrm{MM}$-Agarplatten ${ }^{\text {Hygromycin }}$ gegeben und sorgfältig verteilt. Nach Erstarren des Top-Agars wurden die Platten für $20 \mathrm{~h}$ bei Raumtemperatur bebrütet. Am nächsten Tag wurden die Platten mit MM-Top-Agar überschichtet, in den $20 \mu 1$ Hygromycin B (50 mg/ml) je ml Agar gemischt wurden. Nach Erstarren dieser zweiten Top-Agar-Schicht wurden die Platten bei $21^{\circ} \mathrm{C}$ in den Inkubator gestellt. Wurden Einzelkolonien an der Agaroberfläche sichtbar, wurden die Platten für weitere $16 \mathrm{~h}$ bei $42^{\circ} \mathrm{C}$ inkubiert. Nach der Inkubation wurden die Transformanten ausgehend von mononukleären Sporen zwei weitere Male erneut auf MM-Hygromycin-Platten ausplattiert.

\section{$\underline{\text { Transformanten mit Pyrithiamin-Resistenz }}$}

Für die Transformanten mit Pyrithiamin-Resistenz wurden 50 ml-Zentrifugenröhrchen bereitgestellt und nacheinander mit jeweils $5 \mathrm{ml} \mathrm{MM-Top-Agar}{ }^{\text {Pyrithiamin }}$ befüllt. Es wurden jeweils unterschiedliche Volumina Transformations-Ansatz (1x $10 \mu 1,1 \times 25 \mu 1$, 1x $50 \mu 1,1 x 100 \mu l$ und der restliche Ansatz) und Negativkontrolle (1x $25 \mu 1$ und 1x $30 \mu \mathrm{l})$ hinzugeben, gemischt, auf vorgewärmte $\left(37^{\circ} \mathrm{C}\right) \mathrm{MM}$-Agarplatten ${ }^{\text {Pyrithimamin }}$ 
gegeben und sorgfältig verteilt. Nach Erstarren des Top-Agars wurden die Platten für 2-3 Tage bei $30^{\circ} \mathrm{C}$ im Inkubator bebrütet. Nach Inkubation wurden Transformanten erneut auf MM-Pyrithiamin-Platten ausplattiert und anschließend noch ein weiteres Mal neu überimpft.

\subsection{Molekulargenetische Arbeitsmethoden}

\subsubsection{Isolierung von Transformanten-DNA für PCR-Ansatz}

Zur Aufarbeitung von Aspergillus-DNA wurden $15 \mathrm{ml}$-Zentrifugenröhrchen mit $2 \mathrm{ml}$ YNB $+1 \%$ Glucose bereitgestellt und jeweils mit den Sporen einer Transformante angeimpft. Die Kulturen wurden bei $37^{\circ} \mathrm{C}$ über Nacht als Schüttelkultur inkubiert.

Am nächsten Morgen wurden die Kulturen aufgeschüttelt und $500 \mu \mathrm{l}$ der Übernachtkultur in ein 1,5 ml-Schraub-Reaktionsgefäß überführt. Die Kultur wurde für 5 Minuten bei maximaler Drehzahl (13.200 rpm; 16.100 x $g$ ) zentrifugiert, der Überstand abgenommen und $75 \mu l$ TE-Puffer auf das Pilzpellet pipettiert. Die Pilzsuspension wurde zehnmal in flüssigem Stickstoff eingefroren und wiederaufgetaut. Es erfolgte eine Zugabe von $100 \mu$ l Lysispuffer und $16 \mu 1$ Proteinase K-Lösung (25 $\mathrm{mg} / \mathrm{ml}$ ). Die Ansätze wurden über Nacht bei $56^{\circ} \mathrm{C}$ inkubiert.

Am nächsten Tag wurden die Ansätze für 10 Minuten bei $95^{\circ} \mathrm{C}$ in den Thermomixer gegeben. Die Suspensionen wurden 5 Minuten bei höchster Drehzahl zentrifugiert und der Überstand (ca. $180 \mu \mathrm{l}$ ) in ein frisches 1,5 ml-Reaktionsgefäß überführt. Die Ansätze wurden mit $180 \mu \mathrm{l}$ Phenol-Chloroform-Isoamyl-Alkohol-Gemisch versetzt, $15 \mathrm{~s}$ gevortext und 5 Minuten bei maximaler Drehzahl zentrifugiert. Die obere Phase (ca. $100 \mu \mathrm{l}$ ) wurde abgezogen und in vorbereitete Reaktionsgefäße mit $100 \mu \mathrm{l}$ Chloroform gegeben. Das Ganze wurde 15 s gevortext, 1 Minute zentrifugiert, der Überstand (ca. $95 \mu \mathrm{l})$ abgezogen und $2 \mu \mathrm{l}$ Glykogen $(5 \mathrm{mg} / \mathrm{ml})$ zugegeben. Anschließend wurde der Ansatz mit zwei Volumen $(190 \mu \mathrm{l})$ Ethanol $100 \%$ gefällt, gevortext und für $10 \mathrm{~min}$ bei $-20^{\circ} \mathrm{C}$ gefroren. Die Proben wurden für 15 min bei höchster Drehzahl und $4^{\circ} \mathrm{C}$ zentrifugiert. Der Überstand wurde komplett abpipettiert und das Pellet im Thermomixer bei $37^{\circ} \mathrm{C}$ vollständig getrocknet. Abschließend wurde das Pellet in $50 \mu 1$ TE gelöst. Das Screening auf homologe Rekombination der Transformanten erfolgte mit jeweils 2,5 $\mu 1$ der jeweiligen Transformanten-DNA. 


\subsubsection{Isolierung von genomischer DNA aus A.fumigatus}

Von einer gut bewachsenen Sabourand-Platte wurden mit 3-4 ml 0,9\% NaCL + 0,1\% Tween80 die Konidien aufgeschwemmt. Die Suspension wurde zu zwei gleichen Teilen zu jeweils $200 \mathrm{ml}$ vorgewärmter Glucosebouillon (in 2 L-Flaschen) gegeben und für ca. $20 \mathrm{~h}$ bei $41^{\circ} \mathrm{C}$ und etwa $90 \mathrm{U} / \mathrm{min}$ inkubiert.

Nach Filtrierung des Myzels erfolgte dessen Waschung mit Tris-EDTA-Puffer. Zur Weiterverarbeitung wurden 5-6 g des Myzels verwendet und in flüssigem Stickstoff mit einem Mörser und einem Pistill fein zerrieben. Das Pulver wurde mit $70 \mu 1$ Diethylpyrocarbonat und $20 \mathrm{ml}$ auf $68^{\circ} \mathrm{C}$ vorgewärmter $\mathrm{Na}_{2}$ EDTA-SDS-Lösung gemischt und bei $68^{\circ} \mathrm{C}$ für $45 \mathrm{~min}$ im Schüttelwasserbad inkubiert. Das gesamte Gemisch wurde mit $2 \mathrm{ml} 8 \mathrm{M}$ Na-Acetat-Lösung (pH 4,2) versetzt, um Proteine auszufällen. Nach Inkubation des Gemisches für 10 Minuten auf Eis erfolgte ein Zentrifugationsschritt $\left(10 \mathrm{~min} ; 4000 \mathrm{x} g ; 4^{\circ} \mathrm{C}\right)$. Der Überstand wurde in ein neues Zentrifugenröhrchen überführt, 1:1 mit Isopropanol überschichtet und etwa zehnmal über Kopf geschüttelt. Die gefällte DNA wurde durch kurzes Zentrifugieren für 2 min pelletiert. Der Überstand wurde verworfen und das Zentrifugenröhrchen invertiert für 2 min auf ein Zellulosetuch gestellt. Die DNA wurde in $10 \mathrm{ml}$ Lysispuffer gelöst und mit $140 \mu \mathrm{l}$ Proteinase $\mathrm{K}(50 \mathrm{mg} / \mathrm{ml})$ versetzt. Es folgte eine Inkubation bei $56-60^{\circ} \mathrm{C} \mathrm{im}$ Schüttelwasserbad über Nacht.

Die in Lysispuffer gelöste DNA wurde in ein neues Zentrifugenröhrchen überführt, 1:1 mit Phenol-Chloroform-Isoamylalkohol überschichtet, gemischt und für $30 \mathrm{~min}$ bei 4000 x $g$ zentrifugiert. Die obere, wässrige Phase wurde abgenommen und mit 1/10 Volumen $2 \mathrm{M} \mathrm{NaCl}$ und 2 Volumen $100 \%$-igem Ethanol gemischt. Nach kurzem Zentrifugieren für 1 min bei 150 x $g$ wurde das Pellet drainiert. Das Pellet wurde dann in $4 \mathrm{ml} \mathrm{TE}$-Puffer bei $60^{\circ} \mathrm{C}$ gelöst. $\mathrm{Zu}$ der gelösten DNA wurden $100 \mu \mathrm{l}$ RNAse $\left(10 \mathrm{mg} / \mathrm{ml}\right.$ ) hinzugegeben. Anschließend Inkubation für $90 \mathrm{~min}$ bei $37^{\circ} \mathrm{C}$ im Schüttelwasserbad. Es folgten mehrere Phenol-Chloroform-IsoamylalkoholWaschungen und Ethanolfällungen. Die DNA wurde ein weiteres Mal in $4 \mathrm{ml}$ TE gelöst, später zweimal in $0,5 \mathrm{ml}$ TE. Danach wurde die Ethanolfällung zweimal mit 1/10 Volumen $3 \mathrm{M} \mathrm{NaAc}(\mathrm{pH}$ 5,2) und 2 Volumen $100 \%$-igem Ethanol, gefolgt vom Lösen der DNA in $450 \mu 1 \mathrm{TE}$, durchgeführt. Die DNA wurde anschließend durch kaltes $70 \%$-iges Ethanol $\left(4^{\circ} \mathrm{C}\right)$ gezogen und bei $60^{\circ} \mathrm{C}$ für $30 \mathrm{~min}$ auf dem Thermomixer 
getrocknet. Im Anschluss wurde das DNA-Pellet in 100-200 $\mu 1$ TE gelöst. Die so isolierte DNA wurde für Southern Blots und PCR verwendet.

\subsubsection{Präparation von Plasmid-DNA aus E.coli}

Zur Isolierung bzw. Kontrolle von Plasmiden aus E.coli wurde eine Über-NachtSchüttelkultur der Transformanten in 2,5 ml LB-Medium angesetzt. Am folgenden Tag wurde die Kultur bei 3500 x $g$ über 5 min zentrifugiert und der Überstand verworfen. Die Plasmidisolierung erfolgte mit dem QIAprep ${ }^{\circledR}$ Spin Miniprep Kit nach Angaben des Herstellers.

\subsubsection{Bestimmung der Nukleinsäurekonzentration}

Die Konzentration von DNA wurde mit Hilfe des Spektrophotometers NanoDrop ND1000 gemessen. Für die Messung genügt bereits $1 \mu \mathrm{l}$ der zu messenden DNA. Die Messung erfolgte gegen den jeweiligen Elutionspuffer als Referenzwert.

\subsubsection{Polymerasekettenreaktion}

Die Polymerasekettenreaktion (PCR) wurde eingesetzt, um DNA-Abschnitte zu vervielfältigen. Ihr Prinzip ist die zyklische Wiederholung von drei verschiedenen Reaktionsschritten: Denaturierung der Template-DNA, Anlagerung sequenzspezifischer Oligonukleotide (Annealing) und Synthese einer komplementären DNA-Kopie durch eine thermostabile DNA-Polymerase (Elongation). Durch die Verwendung von Oligonukleotiden, die mit zuvor festgelegten Bereichen der DNA-Stränge hybridisieren, wird der zu amplifizierende DNA-Abschnitt definiert. Folgende Bedingungen wurden gewählt:

10-100 ng DNA

$2,5 \mu 1$ 10x PCR-Puffer (optional additiv $2,5 \mu 1 \mathrm{MgCl}_{2} 15 \mathrm{mM}$ )

$0,5 \mu 1$ Nukleotid-Mix (dNTPs jeweils $10 \mathrm{mM}$ )

$2,5 \mu \mathrm{l}$ Primer $1(5 \mathrm{pmol} / \mu \mathrm{l})$

$2,5 \mu 1$ Primer $2(5 \mathrm{pmol} / \mu \mathrm{l})$

1 U Polymerase (z. B. Taq-Polymerase)

mit $\mathrm{H}_{2} \mathrm{O}$ ad $25 \mu \mathrm{l}$ 
Alle durchgeführten Polymerasekettenreaktionen wurden in PCR-Cyklern mit Deckelheizung $\left(105^{\circ} \mathrm{C}\right)$ durchgeführt. Das verwendete PCR-Programm wurde je nach Amplifikatlänge und Oligonukleotid-Schmelztemperatur modifiziert:

Tab. 12: PCR-Programm zur Amplifikation von DNA-Fragmenten (beispielhaft für die Verwendung von Taq-Polymerase)

\begin{tabular}{|c|c|c|l|}
\hline Temperatur & \multicolumn{2}{|l|}{ Zeit } & Funktion \\
\hline $95^{\circ} \mathrm{C}$ & $2 \mathrm{~min}$ & & Denaturierung \\
\hline $95^{\circ} \mathrm{C}$ & $30 \mathrm{sec}$ & \multirow{3}{*}{$\begin{array}{c}25-35 \\
\text { Zyklen }\end{array}$} & Denaturierung \\
\cline { 1 - 2 } $\mathbf{X}^{\circ} \mathrm{C}$ & $30 \mathrm{sec}$ & Annealing \\
\cline { 1 - 2 } $72^{\circ} \mathrm{C}$ & $\mathbf{Y ~ s e c}$ & Elongation \\
\cline { 1 - 2 } $72^{\circ} \mathrm{C}$ & $7-10 \mathrm{~min}$ & finale Elongation \\
\hline $4^{\circ} \mathrm{C}$ & $\infty$ & & Kühlung \\
\hline
\end{tabular}

Die Temperatur zur Anlagerung der Oligonukleotide wurde ausgehend von der Schmelztemperatur der Oligonukleotide $\left(\mathrm{t}_{\mathrm{m}}\right)$ berechnet. Dazu wird die Anzahl der Adenosine (A) und Thymidine (T) bzw. der Guanosine (G) und Cytidine (C) bestimmt. Die Anzahl von $(\mathrm{A}+\mathrm{T})$ wird mit 2, die von $(\mathrm{G}+\mathrm{C})$ mit 4 multipliziert. Die Addition ergibt die Schmelztemperatur in ${ }^{\circ} \mathrm{C}$ :

$$
\text { Schmelztemperatur in }{ }^{\circ} \mathrm{C}=(\mathrm{A}+\mathrm{T})^{*} 2+(\mathrm{G}+\mathrm{C}) * 4
$$

Die verwendete Annealing-Temperatur $(\mathbf{X})$ wurde $5^{\circ} \mathrm{C}$ unter der niedrigsten errechneten Schmelztemperatur der Oligonukleotide-Paare gewählt. Die verwendeten Oligonukleotide sind in Tab.7 aufgeführt. Primer Nummer 1 wurde stets mit 2 gepaart, 3 mit 4, 5 mit 6 und 7 mit 8 usw. Die Elongationszeit (Y) richtete sich nach der Länge des Fragments und betrug als Richtwert etwa 1 min pro 1000 bp.

\subsubsection{Nested-PCR}

Die nested-PCR wurde wie zuvor beschrieben (s. 2.3.5) angesetzt, jedoch wurde anstelle genomischer DNA, etc. das PCR-Produkt der ersten PCR als Template-DNA (1:4 verdünnt) eingesetzt. 


\subsubsection{Kolonie-PCR}

Zur schnellen Überprüfung auf Plasmid-Konstruktion und Transformation wurde mit den E.coli-Klonen eine Kolonie-PCR durchgeführt. Von der Einzelkolonie wurde mit einem sterilen Zahnstocher ein kleiner Teil abgenommen und in ein 1,5 mlReaktionsgefäß abgestrichen. Die E.coli-Kolonie wurde mit $30 \mu 1 \mathrm{H}_{2} \mathrm{O}$ für 2 min bei $98^{\circ} \mathrm{C}$ erhitzt. Davon wurden dann 2-3 $\mu \mathrm{l}$ als Template in den PCR-Ansatz pipettiert.

\subsubsection{Agarosegelelektrophorese}

Bei der Agarosegelelektrophorese lassen sich PCR-Produkte oder Restriktionsansätze im elektrischen Feld auftrennen und ihre Größe und Menge durch den Vergleich mit DNA-Molekülen bekannter Größe und Menge abschätzen.

Die Agarose wurde in 1x TAE in der Mikrowelle zu einer klaren Lösung aufgekocht und nach dem Abkühlen der Lösung wurden zwei Tropfen Ethidiumbromid-Lösung $(0,7 \mathrm{mg} / \mathrm{ml})$ zugegeben. Die Agarose wurde in eine Gelgießkammer gegossen und ein Kamm zur Formung der Probentaschen eingesetzt. Nach Erstarren des Gels wurde es in die Elektrophoresekammer gegeben, die Gelkammer mit 1x TAE gefüllt und der Kamm vorsichtig entfernt. Die DNA-Proben wurden mit 6x Probenpuffer versetzt und in die Taschen im Gel pipettiert. Um die Größe der DNA-Fragmente bestimmen zu können, wurde außerdem ein geeigneter Molekulargewichtsmarker ins Gel pipettiert. Die Gelelektrophorese erfolgte in der Regel bei einer konstanten Spannung von $120 \mathrm{~V}$, wobei die Laufzeit ungefähr 35-45 min betrug. Die DNA-Banden wurden bei einer Wellenlänge von $312 \mathrm{~nm}$ durch Fluoreszenz des interkalierenden Ethidiumbromids dargestellt, fotographisch dokumentiert oder gegebenenfalls zusätzlich als Datei gespeichert.

\subsubsection{Extraktion von DNA aus Agarosegelen}

Im Agarosegel aufgetrennte DNA wurde unter UV-Licht $(365 \mathrm{~nm})$ ausgeschnitten. Zur Isolierung der DNA aus dem Gelstück wurde das QIAEX ${ }^{\circledR}$ II Gel Extraction Kit nach den Angaben des Herstellers verwendet. 


\subsubsection{DNA-Aufreinigung}

Die DNA-Aufreinigung wurde mittels QIAquick ${ }^{\circledR}$ PCR Purification Kit nach Angaben des Herstellers durchgeführt.

\subsubsection{Ethanolfällung}

Bei komplizierten Klonierungen folgte auf die DNA-Extraktion aus Agarosegelen oder der DNA-Aufreinigung mittels QIAquick ${ }^{\circledR}$ PCR Purification Kit eine Ethanolfällung. Hierzu wurden zu $50 \mu$ l Eluat, $2 \mu$ l Glykogen $(5 \mathrm{mg} / \mathrm{ml}), 1 / 10$ Volumen $3 \mathrm{M} \mathrm{NaAc} \mathrm{pH}$ 5,2 und 2 Volumen Ethanol $100 \%$ gegeben. Der Ansatz wurde bei $-20^{\circ} \mathrm{C}$ für 20 min belassen und anschließend bei höchster Drehzahl $(16.100 \times \mathrm{g})$ und $4^{\circ} \mathrm{C}$ für $20 \mathrm{~min}$ zentrifugiert. Der Überstand wurde verworfen und das Pellet bei $40^{\circ} \mathrm{C}$ für $5 \mathrm{~min}$ abgedampft. Abschließend erfolgte die Aufnahme der DNA in EB.

\subsubsection{Restriktionsverdau}

Für einen Restriktionsverdau wurde die entsprechende Restriktionsendonuklease mit dem entsprechenden Puffer, BSA (optional), $\mathrm{H}_{2} \mathrm{O}$ und der $\mathrm{zu}$ verdauenden DNA zusammengefügt und je nach Temperaturoptimum der Restriktionsendonuklease für $4 \mathrm{~h}$ inkubiert (beispielhafter Ansatz):
$1 \mu \mathrm{g}$ DNA
1/10 Volumen Restriktionspuffer
$1 / 10$ Volumen BSA 10x
5 U Restriktionsendonuklease
optional zweite Restriktionsendonuklease
mit $\mathrm{H}_{2} \mathrm{O}$ ad $40 \mu \mathrm{l}$

Restriktionsendonukleasen, die nicht zum Doppelverdau geeignet waren, wurden einzeln nacheinander verwendet. Dabei wurde ein Inaktivierungsschritt für die erste Restriktionsendonuklease eingeschoben. Gegebenfalls erfolgte eine DNAZwischenreinigung mit dem QIAquick $^{\circledR}$ PCR Purification Kit und ein zweiter Inkubationsansatz mit passendem Puffer.

Die Restriktionsendonukleasen wurden, falls möglich, durch Erhitzen z.B. bei $65^{\circ} \mathrm{C}$ für 20 min inaktiviert. Zur Entfernung der Restriktionsendonukleasen aus dem 
Restriktionsansatz wurde anschließend eine Reinigung mit dem QIAquick ${ }^{\circledR} \quad$ PCR Purification Kit durchgeführt. Die Größe der geschnitten Vektoren und Inserts wurde auf einem Agarosegel durch Vergleich mit einem DNA-Standard abgeschätzt.

Um zu prüfen, ob ein Insert in einen Vektor einkloniert wurde, wurde ein Kontrollrestriktionsverdau mit einem Gesamtvolumen von $10 \mu \mathrm{l}$ angesetzt, wobei für die DNA, unter Anpassung der Mengenverhältnisse, eine Konzentration von 0,2 $\mu \mathrm{g}$ gewählt wurde.

\subsubsection{Dephosphorylierung von Plasmid-DNA}

Um die Religation eines Vektors bei der Ligation $\mathrm{zu}$ verhindern, erfolgte eine Dephosphorylierung der 5'-Phosphatenden des zuvor mit Restriktionsendonukleasen geschnittenen Vektors. Hierzu wurde Antarktische Phosphatase wie folgt verwendet:

linearisierte Vektor-DNA $(1-1,5 \mu \mathrm{g})$

$+1 / 10$ Volumen Antarktische Phosphatase (5 U/ $\mu$ l pro $\mu$ g DNA)

$+1 \mu 1$ Phosphatase-Puffer $10 \mathrm{x}$

mit $\mathrm{H}_{2} \mathrm{O}$ ad $10 \mu \mathrm{l}$

Der $10 \mu$ l-Ansatz wurde für $2 \mathrm{~h}$ bei $37^{\circ} \mathrm{C}$ inkubiert und anschließend die Phosphatase für 10 min bei $65^{\circ} \mathrm{C}$ inaktiviert. Die Vektor-DNA wurde mit dem QIAquick ${ }^{\circledR}$ PCR Purification Kit gereinigt und konnte dann für die Ligation eingesetzt werden.

\subsubsection{Ligation von DNA}

Die Ligation von dephosporyliertem Vektor und Insert wurde mit Hilfe der T4 DNA Ligase durchgeführt. In der Regel wurden 100 ng Vektor und die äquimolare Menge Insert verwendet. Dazu wurden folgende Komponenten zusammenfügt:

$$
\begin{aligned}
& 100 \text { ng geschnitter Vektor } \\
& \text { x ng geschnittenes Insert } \\
& \text { mit } \mathrm{H}_{2} \mathrm{O} \text { ad } 8 \mu 1 \\
& \text { Inkubation für } 5 \text { min bei } 45^{\circ} \mathrm{C} \\
& +1 \mu 1 \text { Ligase-Puffer (inkl. ATP) } \\
& +1 \mu 1 \mathrm{~T} 4 \text { DNA Ligase }(4 \mathrm{U} / \mu 1 \text { ) } \\
& \text { Inkubation über Nacht bei } 16^{\circ} \mathrm{C}
\end{aligned}
$$

Zur Negativkontrolle wurde ein Ansatz ohne Insert mitgeführt. 


\subsubsection{GeneArt ${ }^{\circledR}$ Seamless Cloning and Assembly Kit}

Zur Herstellung der A.fumigatus-Komplementmutanten wurde das GeneArt ${ }^{\circledR}$ Seamless Cloning and Assembly Kit nach Angaben des Herstellers verwendet. Dabei wurden jeweils drei DNA-Fragmente gleichzeitig ohne Subklonierungen in den linearen pUC19-Vektor (2659 bp) eingebracht. Die entsprechende Menge an PCR-Amplifikaten wurde nach folgender Formel berechnet:

$\mathrm{X}$ ng PCR-Produkt $=[2 \mathrm{x}(\mathrm{bp}$ PCR-Produkt $) \mathrm{x}(100 \mathrm{ng}$ linearisierter Vektor $)] /[\mathrm{bp}$ Vektor $]$

Für die Klonierung wurden folgende Komponenten zusammengefügt:

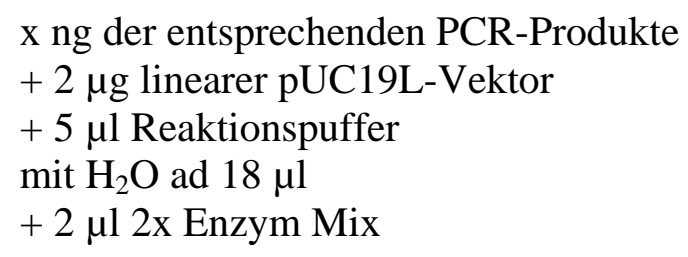

Von dem Ansatz wurden $7 \mu \mathrm{l}$ in den mit dem Kit gelieferten E.coli-Top10-Stamm transformiert und die Plasmide anschließend über Restriktionsanalysen im Agarosegel kontrolliert.

\subsubsection{Sequenzierung}

Die Sequenzierungen wurden von der Firma SeqLab (Göttingen) durchgeführt. Dabei wurden in einem Volumen von $7 \mu 1$, 500-700 ng DNA mit 20 pmol Sequenzierprimer versetzt.

\subsubsection{Herstellung einer Digoxigenin-markierten Sonde}

Für die Herstellung der DIG-markierten Sonde wurde zunächst der folgende NukleotidMix angesetzt:

$\begin{array}{ll}\text { dGTP } & 2,0 \mathrm{mM} \\ \text { dATP } & 2,0 \mathrm{mM} \\ \text { dCTP } & 2,0 \mathrm{mM} \\ \text { dCTP } & 1,3 \mathrm{mM} \\ \text { Dig-11-dUTP } & 0,7 \mathrm{mM}\end{array}$

Es wurden zwei verschiedene Sonden (Sonde I und Sonde II) verwendet: 


\section{$\underline{\text { Sonde I: Southern Blot (Deletionsmutanten) }}$}

Ausgehend von dem Plasmid pAN7-1 als Template wurde die erste PCR für die Sondenherstellung angesetzt:

5 ng Plasmid pAN7-1

2,5 $\mu 1$ 10x Taq Puffer

$0,5 \mu$ l Nukleotid-Mix (dNTPs jeweils $10 \mathrm{mM}$ )

2,5 $\mu$ l Primer Phle-Pro3 (5 pmol/ $\mu \mathrm{l})$

2,5 $\mu$ l Primer Phle-Pro4 (5 pmol/ $\mu \mathrm{l})$

$0,25 \mu 1$ Taq Polymerase

mit $\mathrm{H}_{2} \mathrm{O}$ ad $25 \mu \mathrm{l}$

Tab. 13: Erstes PCR-Programm zur Herstellung der DIG-markierten Sonde

\begin{tabular}{|c|c|c|}
\hline Temperatur & Zeit & \\
\hline $94^{\circ} \mathrm{C}$ & $2 \min$ & \\
\hline $94^{\circ} \mathrm{C}$ & $30 \mathrm{sec}$ & \multirow{4}{*}{$\begin{array}{c}35 \\
\text { Zyklen }\end{array}$} \\
\hline $59^{\circ} \mathrm{C}$ & $30 \mathrm{sec}$ & \\
\hline $72^{\circ} \mathrm{C}$ & $30 \mathrm{sec}$ & \\
\hline $72^{\circ} \mathrm{C}$ & $7 \mathrm{~min}$ & \\
\hline $4^{\circ} \mathrm{C}$ & $\infty$ & \\
\hline
\end{tabular}

Im Anschluss wurde eine nested-PCR mit dem verdünnten PCR-Produkt aus der ersten PCR gefahren:

2,5 $\mu 1$ PCR-Produkt aus der ersten PCR (s. oben) 1:1000 verdünnt

2,5 $\mu 1$ 10x Taq Puffer

2,5 $\mu 1$ Digoxigenin-Mix

$2,5 \mu 1$ Primer Phle-Pro1 (5 pmol/ $\mu \mathrm{l})$

2,5 $\mu 1$ Primer Phle-Pro2 (5 pmol/ $\mu \mathrm{l})$

$0,25 \mu 1$ Taq Polymerase

mit $\mathrm{H}_{2} \mathrm{O}$ ad $25 \mu \mathrm{l}$

Das zweite PCR-Programm entsprach den Bedingungen bei der ersten PCR (s. oben).

\section{Sonde II: Southern Blot (Komplementierung der Deletionsmutante)}

Die Sonde für den Southern Blot wurde auf das ptrA-Gen (Selektionsmarker) generiert.

Dafür wurde das Komplementierungsplasmid pHP16-del-komplementiert verwendet, das, mit HpaI geschnitten, zuvor für die Transformation zur Komplementierung der Deletionsmutante genutzt wurde: 
2,0 $\mu 1$ Plasmid pHP16-del-komplementiert 1:200 verdünnt

2,5 $\mu 1$ 10x Taq Puffer

$0,5 \mu$ l Nukleotid-Mix (dNTPs jeweils $10 \mathrm{mM}$ )

2,5 $\mu$ l Primer RekomHP16_Sonde1 (5 pmol/ $\mu \mathrm{l})$

2,5 $\mu 1$ Primer RekomHP16_Sonde2 (5 pmol/ $\mu \mathrm{l})$

$0,25 \mu 1$ Taq Polymerase

mit $\mathrm{H}_{2} \mathrm{O}$ ad $25 \mu \mathrm{l}$

Im Anschluss wurde eine nested-PCR mit dem verdünnten PCR-Produkt aus der ersten PCR gefahren:

5,0 $\mu$ l PCR-Produkt aus der ersten PCR (s. oben) 1:1000 verdünnt

2,5 $\mu 1$ 10x Taq Puffer

2,5 $\mu$ l Digoxigenin-Mix

$2,5 \mu 1$ Primer RekomHP16_Sonde3 (5 pmol/ $\mu \mathrm{l})$

$2,5 \mu 1$ Primer RekomHP16_Sonde4 (5 pmol/ $\mu \mathrm{l})$

$0,25 \mu \mathrm{T}$ Taq Polymerase

mit $\mathrm{H}_{2} \mathrm{O}$ ad $25 \mu \mathrm{l}$

Die PCR-Programme entsprachen den Bedingungen bei der Herstellung der Sonde für den Southern Blot zur Testung der Deletionsmutanten (s. oben).

\subsubsection{Southern Blot}

Genomische DNA wurde mit Restriktionsenzymen verdaut, mit Phenolchloroformextraktion gereinigt und anschließend gelelektrophoretisch getrennt. Hierfür wurde ein 0,7 \%-iges Agarosegel in 0,5x TBE verwendet und eine Spannung von 0,5-1,0 V/cm angelegt (Dauer etwa $8 \mathrm{~h}$ ). Anschließend wurde das Gel für $10 \mathrm{~min}$ mit Depurinierungslösung, zweimal für 20 min mit Denaturierungslösung und zweimal für $20 \mathrm{~min}$ mit Neutralisierungslösung gewaschen. Der DNA-Transfer auf eine Nitrozellulosemembran erfolgte für 16-24 h mit Hilfe eines Kapillarblots (Abb. 3).

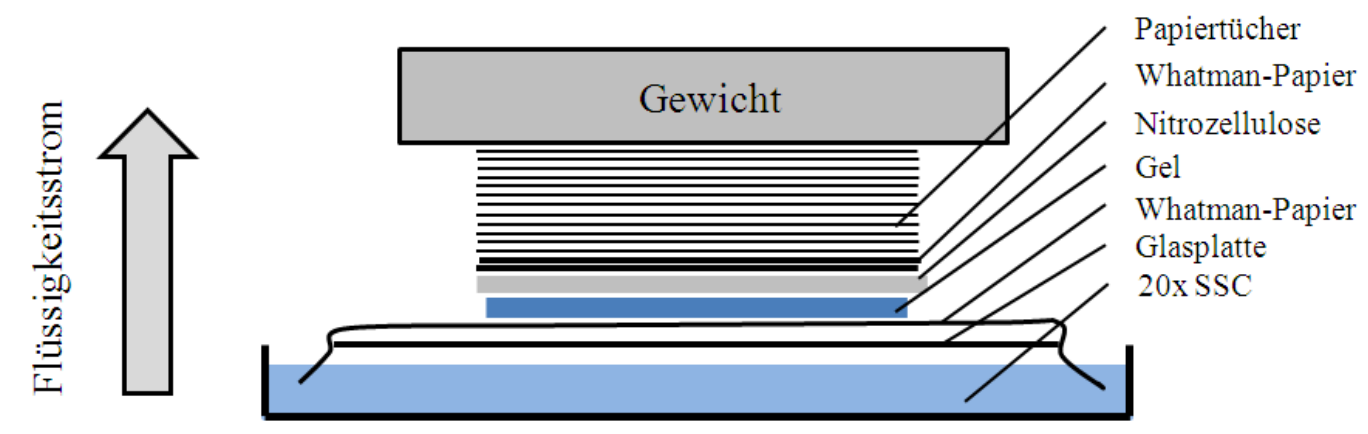

Abb. 3: Schematischer Aufbau des Kapillarblots. 
Beim Kapillarblot wird ein Flüssigkeitsstrom (Kapillareffekt) genutzt, der, ausgehend von einem Reservoir an Pufferlösung (20 x SSC), über das Gel und die Membran bis hin zu einem Stapel von Papiertüchern läuft. Die DNA wird dabei mitgeführt und bleibt auf der Oberfläche der Nitrozellulosemembran hängen. Nach dem Blot wurde die Membran für 5 min in 6x SSC gewaschen, für 30 min luftgetrocknet und anschließend zwischen zwei Lagen Whatman-Papier für 1-2 h im Vakuumofen getrocknet.

\section{Prähybridisierung und Hybridisierung}

Die Prähybridisierung der Membran erfolgte mit $20 \mathrm{ml}$ Prähybridisierungslösung in einer kleinen Glasschale für $2 \mathrm{~h}$. Kurz vor Ablauf der $2 \mathrm{~h}$ wurden $3 \mu$ l DIG-markierte Sonde in $100 \mu \mathrm{H}_{2} \mathrm{O}$ aufgenommen und für 5 min bei $95^{\circ} \mathrm{C}$ denaturiert, anschließend sofort mit $100 \mu$ l Formamid versetzt und der Ansatz für 5 min auf Eis inkubiert. Der Ansatz wurde zu der Prähybridisierungslösung geben und es folgte eine Inkubation für $18-24 \mathrm{~h}$ bei $42^{\circ} \mathrm{C}$ im Schüttler (Hybrisierung).

Am nächsten Morgen wurde die Membran zweimal für jeweils 15 min mit Waschpuffer I bei $37^{\circ} \mathrm{C}$ im Wärmeraum gewaschen, und anschließend folgten zwei weitere Waschschritte mit Waschpuffer II, jeweils 30 Minuten bei $68^{\circ} \mathrm{C}$ im Schüttelwasserbad.

\section{Detektion von Digoxigenin-markierten DNA-Proben}

Die Membran wurde anschließend für 1 min bei Raumtemperatur in PBS äquilibriert und mittels eines Blockpuffers für 60 min unter Schütteln bei Raumtemperatur geblockt. Der POD-markierte Antikörper gegen DIG wurde verdünnt $(30 \mathrm{ml}$ Blockpuffer + 22,5 $\mu$ l POD-markierter AK gegen DIG) und die Membran darin für $2 \mathrm{~h}$ bei Raumtemperatur auf dem Kreisschüttler inkubiert. Die Membran wurde daraufhin dreimal mit PBS $+0,1 \%$ Tween 20 für jeweils 7-10 min gewaschen. In der Dunkelkammer wurden die ECL-Reagenzien 1 und $2 \mathrm{zu}$ gleichen Teilen (jeweils $1 \mathrm{ml}$ ) gemischt und die Membran zwischen zwei Kopierfolien mit den ECL-Reagenzien inkubiert. Es folgte die Belichtung des Röntgenfilms in einer Röntgenfilmkassette für $1 \mathrm{~min}$ bis mehrere Stunden. Der Film wurde für 2 Minuten entwickelt, wobei diese Reaktion durch ein Bad für 20 Sekunden in Essigsäure (5\%) gestoppt wurde. Danach wurde der Film für 2-5 min in Fixierer geschwenkt und abschließend für etwa 5 min in Leitungswasser gewässert und bei Raumtemperatur getrocknet. 


\subsection{Proteinanalytische Arbeitsmethoden}

\subsubsection{Produktion und Aufreinigung His-getagter Proteine zur Verimpfung}

Nach Transformation der Expressionsplasmide in E.coli wurden Über-NachtSchüttelkulturen der jeweiligen Stämme in 2,5 ml LB-Medium mit den entsprechenden Antibiotikazusätzen angesetzt. Diese Über-Nacht-Kulturen wurden am nächsten Morgen zu $250 \mathrm{ml} \mathrm{LB}-M e d i u m$ (mit Antibiotikazusatz) gegeben und bei $37^{\circ} \mathrm{C}$ bis $\mathrm{zu}$ einer OD600 von 0,6-0,8 angezogen. Ein 1 ml-Aliquot wurde von der Kultur entnommen und für 5 min bei 6000 x $g$ zentrifugiert. Der Überstand wurde verworfen und das Pellet (Negativkontrolle ohne IPTG) zur späteren Analyse im SDS-Gel weggefroren. Zu den Kulturen wurden jeweils $0,5 \mathrm{ml}$ 0,5 M IPTG hinzugefügt. Inkubation für weitere $4 \mathrm{~h}$ bei $37^{\circ} \mathrm{C}$. Die Kulturen wurden anschließend bei $4^{\circ} \mathrm{C}$ für $20 \mathrm{~min}$ bei $1500 \mathrm{x} g$ zentrifugiert. Das Pellet konnte bis zur weiteren Verarbeitung bei $-20^{\circ} \mathrm{C}$ zwischengelagert werden.

Nach dem Auftauen des Pellets wurde das induzierte Protein gereinigt. Das Pellet wurde hierfür in $25 \mathrm{ml}$ Puffer A resuspendiert, mit 2 Protease-Inhibitortabletten versetzt und mindestens über 1 min gevortext. Es folgte eine Inkubation für $2 \mathrm{~h}$ auf dem Drehrad. Während der Inkubation wurde die Ni-NTA-Agarose vorbereitet, indem sie auf eine PD10-Säule gegeben wurde und nach dem Sedimentieren nacheinander mit $25 \mathrm{ml}$ $30 \%$-igem Ethanol, $25 \mathrm{ml} \mathrm{H}_{2} \mathrm{O}$ und $25 \mathrm{ml}$ Puffer A gespült wurde. Die Kultur wurde nach Ablauf der $2 \mathrm{~h}$ für $10 \mathrm{~min}$ bei 4000 x $g$ zentrifugiert und der Überstand zu der vorbereiteten Ni-NTA-Agarose gegeben. Es folgte eine Inkubation bei $4^{\circ} \mathrm{C}$ über Nacht auf dem Drehrad.

Am nächsten Morgen wurde die Über-Nacht-Kultur für 5 min bei 500 x $g$ zentrifugiert und der Überstand verworfen. Die Ni-NTA-Agarose wurde wieder auf die PD10-Säule gegeben und nacheinander mit $5 \mathrm{ml}$ Puffer A, $25 \mathrm{ml}$ Puffer B und $25 \mathrm{ml}$ Puffer C gewaschen. Die Elution des Proteins erfolgte mit $20 \mathrm{ml}$ Puffer E. Nach Entsalzung und Volumeneinengung durch Zentrifugation mittels Vivaspin 20- bzw. 2-Säulen bei 4000 x $g$ bei $17^{\circ} \mathrm{C}$ folgte die Analyse der Proben „vor“ und „nach“ IPTG-Zugabe in einem SDS-Gel. 


\subsubsection{Herstellung der HP16-Expressionsplasmide und Test auf rekombinante Proteinexpression in E.coli}

\section{Herstellung der HP16-Expressionsplasmide}

Der unter Punkt 2.4.2 beschriebene Versuch wurde in Zusammenarbeit mit Frau Pähtz, Doktorandin in der Abteilung Molekulare und Angewandte Mikrobiologie unter der Leitung von Herrn Prof. Dr. Axel Brakhage am Leibniz-Institut für NaturstoffForschung und Infektionsbiologie, Hans Knöll Institut (HKI, Jena) durchgeführt.

Das in Auftrag gegebene synthetisch hergestellte Gen HP16 mit optimiertem „CodonUsage“ für E.coli wurde aus dem Vektor Afu1g13670_23-218 mit dem Primerpaar Afu1g13670_23BamHIf/ Afu1g13670_182HindIIIr für eine kurze Version des Proteins (AS 23-182) bzw. mit dem Primerpaar Afu1g13670_23BamHIf/ Afu1g13670_218HindIIIr für eine lange Version des Proteins (AS 23-218) mittels PCR mit einer Phusion Flash II High-Fidelety Polymerase amplifiziert. Die so erhaltenen PCR-Produkte wurden nach Elektrophorese aus dem Gel ausgeschnitten und gereinigt. Sowohl die gereinigten PCR-Produkte als auch der Vektor, der die Fusion des Proteins mit dem His-Tag ermöglichen sollte, wurde mit den Restriktionsendonukleasen BamHI und HindIII geschnitten. Nach Dephosphorylierung des Vektors erfolgte die Ligation mit jeweils der kurzen bzw. der langen Version des Proteins. Nach Transformation in E.coli $\alpha$-Select wurden einzelne Klone gepickt und nach Plasmidisolierung durch Restriktionsverdaue und anschließender Gelelektrophorese kontrolliert. Nach Transformation des Expressionsplasmids in E.coli BL(DE3) wurde im Weiteren mit einem Mini-Expressionsversuch getestet, ob das Protein exprimiert wurde.

\section{$\underline{\text { Mini-Expressionsversuch }}$}

Dafür wurde eine Über-Nacht-Schüttelkultur des Stammes in $3 \mathrm{ml} \mathrm{LB-Medium} \mathrm{mit} \mathrm{den}$ entsprechenden Antibiotikazusätzen angesetzt und bei $37^{\circ} \mathrm{C}$ und $200 \mathrm{rpm}$ geschüttelt. Von diesen Kulturen wurden am nächsten Morgen $400 \mu \mathrm{l}$ in jeweils $10 \mathrm{ml}$ TB-Medium (Autoinduktionsmedium) gegeben. Parallel dazu erfolgte die Beimpfung von $10 \mathrm{ml}$ LBMedium mit $400 \mu 1$ der Vorkultur als Kontrolle. Die Hauptkulturen wurden bei $25^{\circ} \mathrm{C}$ für 24 h bei 200 rpm geschüttelt. Am nächsten Tag wurde die $\mathrm{OD}_{550}$ gemessen, von jedem Ansatz eine OD von 10 berechnet und die entsprechenden Kulturmengen in jeweils 2 ml-Reaktionsgefäßen bei 18.188 x $g$ für 10 min zentrifugiert. Die Pellets wurden für 
mindestens 20 min bei $-20^{\circ} \mathrm{C}$ weggefroren. Anschließend wurden die Pellets in $1 \mathrm{ml}$ Lysepuffer (20 mM NaH $\mathrm{PO}_{4}, 150 \mathrm{mM} \mathrm{NaCl}, 1 \mathrm{mM}$ AEBSF) durch Auf- und Abpipettieren gelöst und die E.colis mit einer Ultraschallsonde aufgeschlossen. Es folgte ein Zentrifugationsschritt für $15 \mathrm{~min}$ bei $15.682 \times \mathrm{g}$ und $4^{\circ} \mathrm{C}$. Die Überstände (lösliche Fraktionen) wurden in ein neues Reaktionsgefäß überführt und zusätzlich wurden die Pellets der TB-Kulturen in $1 \mathrm{ml}$ Lysepuffer gelöst (unlösliche Fraktionen). Jeweils $30 \mu \mathrm{l}$ der LB- (nur lösliche Fraktionen) und TB-Kulturen (lösliche und unlösliche Fraktionen) wurden zusammen mit jeweils $10 \mu$ l Ladepuffer und $2 \mu 1$ Dithiothreitol versetzt. Zur elektrophoretischen Trennung der kurzen und langen Version des Proteins wurden NuPAGE Bis-Tris-Gradientengele (4-12 \% Polyacrylamid) der Firma Invitrogen nach Angaben des Herstellers verwendet.

\subsubsection{Aufreinigung His-getagter Proteine}

Auch dieser Versuch wurde in Zusammenarbeit mit Frau Pähtz durchgeführt.

Über-Nacht-Schüttelkulturen der entsprechenden Stämme wurden in $3 \mathrm{ml}$ LB-Medium mit den entsprechenden Antibiotikazusätzen angesetzt und bei $37^{\circ} \mathrm{C}$ und $200 \mathrm{rpm}$ geschüttelt. Von diesen Kulturen wurde am nächsten Morgen jeweils $1 \mathrm{ml}$ in jeweils $100 \mathrm{ml}$ TB-Medium in einen 2-L-Schikanekolben gegeben. Um das Schäumen der Kulturen über Nacht zu verhindern, wurde den Ansätzen noch zusätzlich jeweils ein Tropfen Antifoam 204 zugesetzt. Diese Hauptkulturen wurden bei $25^{\circ} \mathrm{C}$ für $24 \mathrm{~h}$ bei $200 \mathrm{rpm}$ geschüttelt. Am nächsten Tag wurde die $\mathrm{OD}_{550}$ gemessen. Es folgte ein Zentrifugationsschritt von jeweils $50 \mathrm{ml}$-Kulturmenge bei $3890 \mathrm{rpm}$ für $10 \mathrm{~min}$ bei $4^{\circ} \mathrm{C}$. Der Überstand wurde verworfen und die Pellets wurden bei $-80^{\circ} \mathrm{C}$ weggefroren. Die Pellets wurden in $35 \mathrm{ml}$ Puffer A $\left(20 \mathrm{mM} \mathrm{NaH}_{2} \mathrm{PO}_{4}, 500 \mathrm{mM} \mathrm{NaCl}, 10 \mathrm{mM}\right.$ Imidiazol mit $1 \mathrm{mM}$ AEBSF) resuspendiert, gefolgt von einem Zellaufschluss mit der EmulsiFlex EFC5, einem Hochdruckhomogenisator. Unlösliche Bestandteile wurden bei $14.310 \mathrm{x} g$ über $20 \mathrm{~min}$ bei $4^{\circ} \mathrm{C}$ abgetrennt. Der Überstand wurde abgenommen und durch einen 1,2 $\mu \mathrm{m}$ Spritzenfilter gepresst.

Der zellfreie Extrakt wurde über eine His GraviTrap aufgereinigt. Dazu wurde die Säule mit $5 \mathrm{ml}$ Puffer A äquilibriert und dann beladen. Die Säule wurde folgend mit $5 \mathrm{ml}$ Puffer A, $4 \mathrm{ml}$ Puffer B (20mM NaH $2 \mathrm{PO}_{4}, 500 \mathrm{mM} \mathrm{NaCl}, 50 \mathrm{mM}$ Imidiazol) und $1 \mathrm{ml}$ 
Puffer $\mathrm{C}\left(20 \mathrm{mM} \mathrm{NaH}{ }_{2} \mathrm{PO}_{4}, 500 \mathrm{mM} \mathrm{NaCl}, 250 \mathrm{mM}\right.$ Imidiazol) gewaschen und mit $3 \mathrm{ml}$ Puffer C eluiert. Die einzelnen Fraktionen wurden separat gesammelt, um sie anschließend in einer SDS-PAGE (NuPAGE) zu analysieren.

\subsubsection{Diskontinuierliche SDS-Polyacrylamid-Gelelektrophorese}

Rekombinant hergestellte Proteine wurden mit der SDS-PAGE getrennt und durch Coomassie Färbung weiter analysiert. Verwendet wurden 12,5 \%-ige SDS-Trenngele (7-8 $\mathrm{ml}$ pro Gel). Die in der folgenden Tabelle angegebenen Komponenten (Tab. 14) des Trenngels wurden gemischt und in die vorbereitete Höfer-Kammer zum Gießen von SDS-Gelen pipettiert, wobei immer zwei Gele parallel gegossen wurden. Jedes Gel wurde anschließend mit $200 \mu$ 1-Butanol überschichtet. Nach Erstarren des Trenngels wurde das 1-Butanol abgegossen, mit $\mathrm{H}_{2} \mathrm{O}$ gespült und eventuelle Reste mit Filterpapier abgesaugt. Im Anschluss wurde das Sammelgel gegossen. Die Polyacrylamidkonzentration in den verwendeten Sammelgelen betrug $4 \%$. Die entsprechenden Volumina sind ebenfalls der folgenden Tabelle zu entnehmen.

Für die Probenvorbereitung wurden $180 \mu \mathrm{l}$ SDS-Probenpuffer in ein Reaktionsgefäß pipettiert und mit $20 \mu 1 \beta$-Mercaptoethanol versetzt. 1-10 $\mu \mathrm{l}$ des zu testenden Proteins wurden mit PBS auf ein Gesamtvolumen von $10 \mu 1$ gebracht und anschließend mit $5 \mu 1$ des mit $\beta$-Mercaptoethanol versetzten SDS-Probenpuffers gemischt. Es folgte eine Inkubation über $5 \mathrm{~min}$ bei $95^{\circ} \mathrm{C}$ im Thermomixer. Sollte eine Probe z.B. ,vor IPTGZugabe“ kontrolliert werden, wurden dem Pellet stattdessen $100 \mu \mathrm{l}$ mit $\beta$ Mercaptoethanol versetzter SDS-Probenpuffer zugesetzt und hiervon $15 \mu$ l einpipettiert.

Nach kurzer Zentrifugation wurden die Proben in die Probentaschen des SDS-Gels einpipettiert. Die Elektrophorese fand in einer mit SDS-Laufpuffer gefluteten Kammer bei $120 \mathrm{~V}$ statt und wurde gestoppt, wenn die Bromphenolblau-Front den unteren Gelrand erreichte. Anschließend wurde das Gel gefärbt oder in einem Western Blot eingesetzt. 
Tab. 14 Komponenten für SDS-Gele

\begin{tabular}{|l|c|c|}
\hline & SDS-Trenngel 12,5 \% & SDS-Sammelgel 4,0 \% \\
\hline $30 \%$ Bisacrylamid & $8,0 \mathrm{ml}$ & $1067 \mu \mathrm{l}$ \\
\hline SDS Trenngelpuffer & $7,5 \mathrm{ml}$ & --- \\
\hline SDS Sammelgelpuffer & --- & $1,0 \mathrm{ml}$ \\
\hline $10 \%$ SDS & $200 \mu \mathrm{l}$ & $80 \mu \mathrm{l}$ \\
\hline $\mathrm{H}_{2} \mathrm{O}$ & $4,2 \mathrm{ml}$ & $5,7 \mathrm{ml}$ \\
\hline $1 \%$ Bromphenolblau & --- & $20 \mu \mathrm{l}$ \\
\hline $10 \%$ APS & $170 \mu \mathrm{l}$ & $80 \mu \mathrm{l}$ \\
\hline Temed & $20 \mu \mathrm{l}$ & $10 \mu \mathrm{l}$ \\
\hline
\end{tabular}

\subsubsection{Coomassie-Färbung}

Um die getrennten Proteine in einem SDS-Gel dazustellen, eignet sich die Färbung mit Coomassie Brilliant Blue. Dazu wurde das Gel nach der SDS-PolyacrylamidElektrophorese für $1 \mathrm{~h}$ in die SDS-Coomassie-Färbelösung gelegt. Danach wurde es solange in SDS-Entfärbelösung geschwenkt (meist über Nacht), bis der Hintergrund vollständig entfärbte und die Proteinbanden deutlich sichtbar wurden. Um das Gel zu trocknen, wurde es zuerst für etwa $1 \mathrm{~h}$ in einer Trocknungslösung gebadet, luftblasenfrei zwischen zwei in Trocknungslösung getauchte Zellophanfolien gelegt und abschließend über Nacht in einen Rahmen eingespannt.

\subsection{Charakterisierung der A.fumigatus Aspf3-Deletionsmutante und} Komplementmutante

\subsubsection{Wachstumskontrolle der Aspf3-Deletions- und Komplementmutante}

Die Aspf3-Deletionsmutante und ihre -Komplementmutante wurden im Vergleich zum A.fumigatus-Wildtyp D141 auf ihr Wachstum unter oxidativen Stress getestet. Zu diesem Zweck wurden die Stämme auf MM-Agar (Petrischale, 94/16 mm) ausplattiert. Auf den MM-Agarplatten wurden jeweils $1 \times 10^{5}$ Konidien ausplattiert. Dazu wurden $100 \mu \mathrm{l}$ einer Sporensuspension mit der Konzentration $1 \times 10^{6}$ Konidien/ml verwendet. Anschließend wurden mit einer umgedrehten $10 \mu$ l-Pipettenspitze Löcher in die Plattenmitten gestanzt. In diese Löcher wurden $20 \mu 1$ verschiedener Konzentrationen der zu testenden $\mathrm{H}_{2} \mathrm{O}_{2}$-Lösung pipettiert. Nach Inkubation der Platten über $48 \mathrm{~h}$ bei $30^{\circ} \mathrm{C}$ wurden die Hemmhofdurchmesser verglichen. 


\subsection{Tierexperimentelle Arbeiten}

\subsubsection{Tierhaltung}

Für die Immunisierungs- bzw. Infektionsversuche wurden weibliche, ca. 6-8 Wochen alte BALB/c-Mäuse verwendet. Die Tiere wurden auf Sägespäneeinstreu in Standardkäfigen gehalten, ad libitum mit einem pelletierten, kommerziellen Alleinfuttermittel gefüttert und über Flaschentränken mit Wasser versorgt.

\subsubsection{Immunisierung mit rekombinanten A.fumigatus-Proteinen im Mausmodell}

Mehrere Proteine von A.fumigatus, in E.coli rekombinant exprimiert, wurden aufbereitet und an Mäuse verimpft. Die Impfstoffe (Gesamtvolumen der Impfdosis: $25 \mu 1$ Impfstoff $+25 \mu$ l Adjuvans TiterMax ${ }^{\circledR}$ ) bestanden jeweils aus insgesamt drei unterschiedlichen Proteinen (Kombinationsimpfstoff). Jedes Protein lag dabei in einer absoluten Menge von $15 \mu \mathrm{g}$ vor $(45 \mu \mathrm{g}$ insgesamt pro Impfdosis $)$.

Die Antigene für mehrere Mäuse wurden mit einer 2 ml-Spritze und einer 18 GaugeNadel aufgezogen. In einem Reaktionsgefäß erfolgte die Vermischung der Antigene mit dem TiterMax ${ }^{\circledR}$ durch wiederholtes Aufziehen der Spritze. Zur Verimpfung wurde die milchige Suspension mit einer $1 \mathrm{ml}-$ Spritze aufgezogen, und $50 \mu 1$ der entsprechenden Suspension wurden an Mäuse s.c. (subkutan, unter die Haut) in die Rückenfalte verimpft. Die Kontrollgruppe bekam TiterMax ${ }^{\circledR} 1: 1$ mit 1x PBS gemischt gespritzt. Die Immunisierung wurde nach 14 Tagen einmal wiederholt. Weitere 21 Tage später erfolgt die Immunsuppression, weitere drei Tage später eine weitere Immunsuppression und die Infizierung der Mäuse.

\subsubsection{Immunsuppression der Mäuse mit A.fumigatus-Konidien}

An den Tagen der Immunsuppression (Tag -3 und 0) wurden die Mäuse gewogen (alle Mäuse zwischen 20 und 23 Gramm, leichtere Mäuse wurden aussortiert) und die Cortisonacetat-Lösung hergestellt. Dazu wurde die Lösung in 1x PBS (125 mg/ml) in ein 12 ml-Zellkulturröhrchen (mit rundem Boden) angesetzt. Anschließend erfolgte eine Ultraschallbehandlung mit dem Stab-Ultraschallgerät auf Eis über 5 min auf Output Stufe 2,5 bei einem Unterbrechungszyklus von $30 \%$. Die Suspension wurde vor 
Verabreichung für mindestens 30 min auf dem Drehrad gemischt. Die Mäuse wurden drei Tage vor der Infektion und am Tag der Infektion mit 25 mg Cortisonacetat-Lösung immunsupprimiert (Abb. 4). Pro Maus wurden $200 \mu \mathrm{l}$ der Cortisonacetat-Lösung intraperitoneal (i.p.) gespritzt.

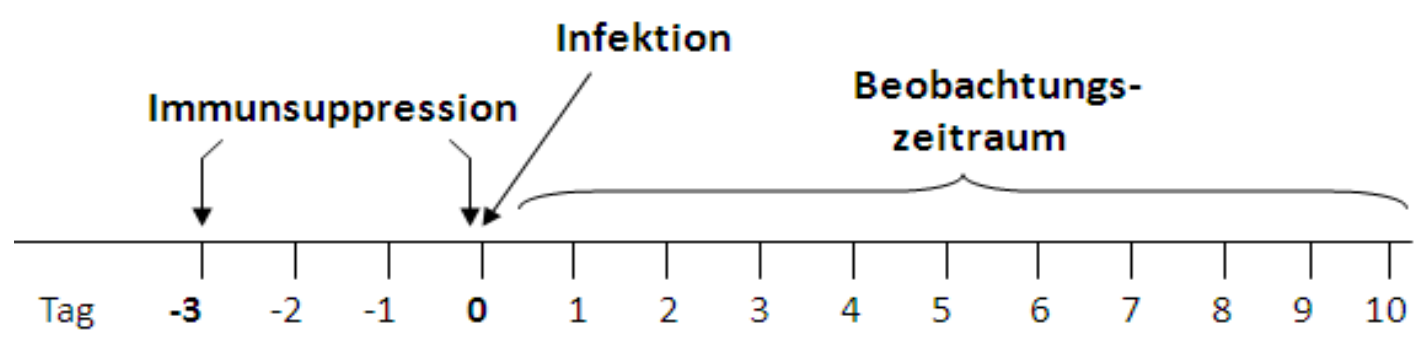

Abb. 4: Zeitschema zur Immunsuppression und Infektion der Mäuse.

\subsubsection{Infektion der Mäuse mit A.fumigatus-Konidien}

Am Tag der Infektion wurde eine A.fumigatus-Sporensuspension hergestellt (s. 2.2.7). Für die Induktion einer IA mit A.fumigatus wurden die in $\mathrm{CO}_{2}$-Atmosphäre betäubten, auf dem Rücken liegenden Mäuse mit $35 \mu 1$ Konidiensuspension $\left(3 \times 10^{6}\right)$ nasal infiziert. Um eine bakterielle Infektion zu vermeiden, wurde dem Trinkwasser CotrimK zugesetzt (0,8 $\mathrm{mg} / \mathrm{ml}$ Sulfamethoxazol und $0,16 \mathrm{mg} / \mathrm{ml}$ Trimethoprim) [64]. Die Tiere wurden zehn Tagen nach Infektion, oder aber beim Auftreten schwerer Krankheitszeichen auch vorzeitig, in $\mathrm{CO}_{2}$-Atmosphäre getötet. Zur Ermittlung der Belastung dienten neben der regelmäßigen Beurteilung von Allgemeinzustand und Spontanverhalten das Auftreten einer Atemnot, sowie die tägliche Gewichtskontrolle. Bei ca. $20 \%$ Gewichtsverlust (innerhalb von 48 h) wurden die Tiere getötet. Getötete Tiere wurden seziert, die Lungen homogenisiert und die Extrakte auf die Anzahl der Kolonie-formenden Einheiten (CFU) untersucht. Dazu wurden Verdünnungsreihen mit physiologischer $\mathrm{NaCl}$ in $1: 10$-Stufen hergestellt $\left(10^{-1}, 10^{-2}, 10^{-3}\right)$. Von diesen Verdünnungsreihen wurden auf drei Sabouraud-Platten jeweils $100 \mu$ l ausgestrichen. Die Platten wurden bei $37^{\circ} \mathrm{C}$ über Nacht bebrütet. 


\section{Ergebnisse}

\subsection{Herstellung von Gen-Deletionsmutanten und}

Komplementmutanten in A.fumigatus

\subsubsection{Herstellung von $\triangle \mathrm{HP16}$}

\section{Deletionsplasmid}

Für die prominentesten Spots aus der Proteomanalyse (diese konnten einem einzelnen Protein (HP16) zugeordnet werden) ([15]; s. Einleitung 1.7) wurde eine Single-Knockout Mutante generiert. Dazu wurde das kodierende Gen AFUA_1G13670 (hier bezeichnet als HP16) des hypothetischen Proteins HP16 mit Hilfe einer GenReplacement-Strategie selektiv durch homologe Rekombination aus dem Genom von A.fumigatus entfernt (Abb. 5).

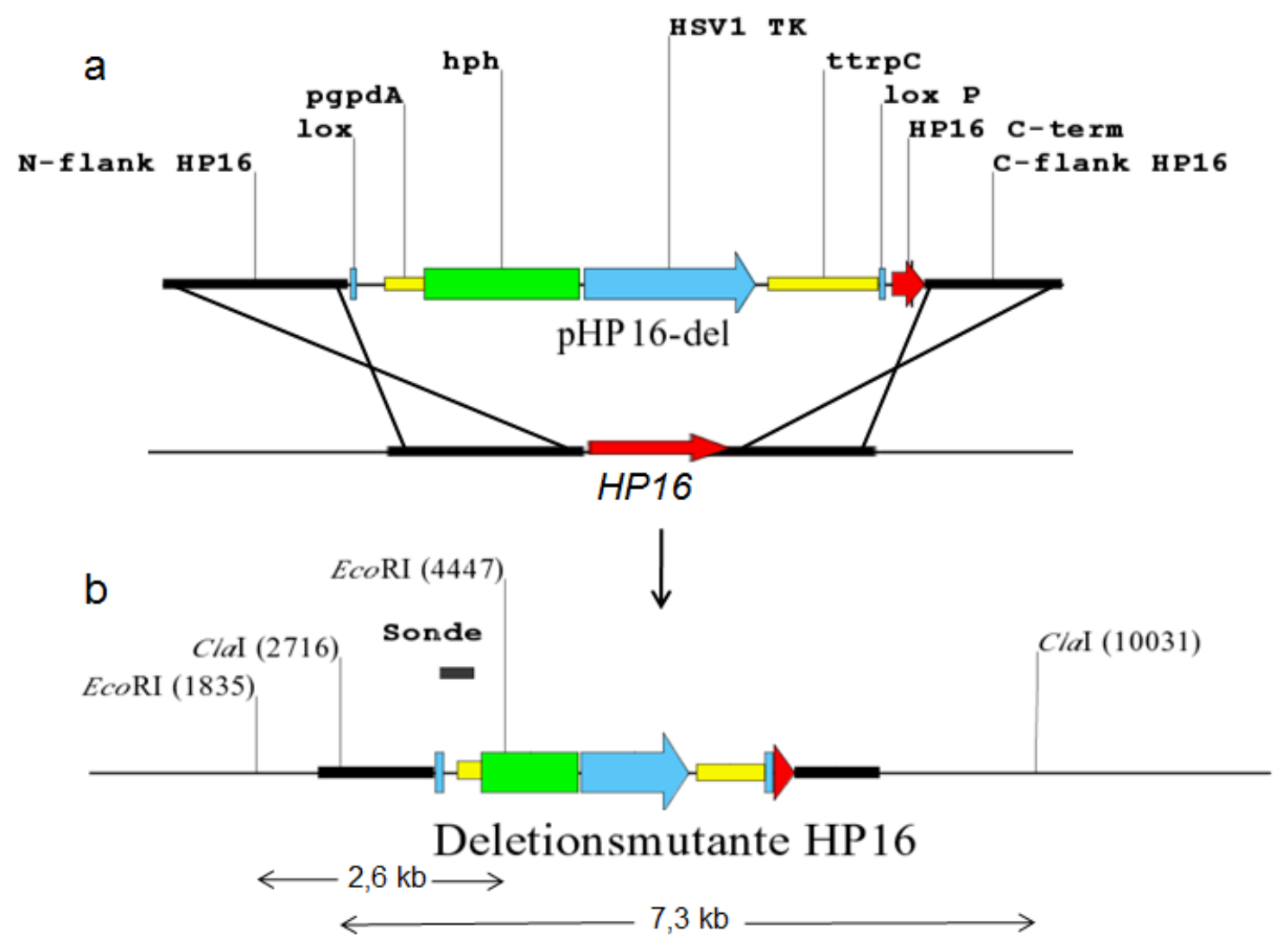

Abb. 5: a) Verwendete Cross-over Strategie bei der homologen Rekombination zur Generierung der Deletionsmutante HP16. b) $\triangle$ HP16-Genom mit den Schnittstellen für die Restriktionsendonukleasen (ClaI und EcoRI), mit denen der Verdau für den Southern Blot durchgeführt wurde. 
Die beiden flankierenden Bereiche des Gens, an denen das Cross-over stattfinden sollte, wurden mittels nested-PCR amplifiziert (Tab.7: Primer HP16-1 bis HP16-8). Eine Zwischenklonierung der Amplifikate erfolgte in den pBlueskript II SK+PacI-Vektor (Abb. 6a, s. Anhang; Abb. 41). Im folgenden Schritt wurde dieser Vektor mit SfiI geschnitten. Ebenso wurde der Vektor psk397 (s. Anhang Abb. 42) mit SfiI verdaut. Zwischen die beiden flankierenden Sequenzen wurde das Resistenz-liefernde Insert aus pSK397 kloniert. Das Insert enthält als Selektionsmarker das $h p h-G e n$, wodurch eine Resistenz gegenüber dem Antibiotikum Hygromycin B vermittelt wird. Das so erstellte Deletionsplasmid pHP16-del (Abb. 6b) wurde über Restriktionsanalysen im Agarosegel kontrolliert. Die erwarteten Fragmentgrößen nach einem Restriktionsverdau mit SalI lagen bei 1198 bp, 3385 bp und 4222 bp (Abb. 6c).

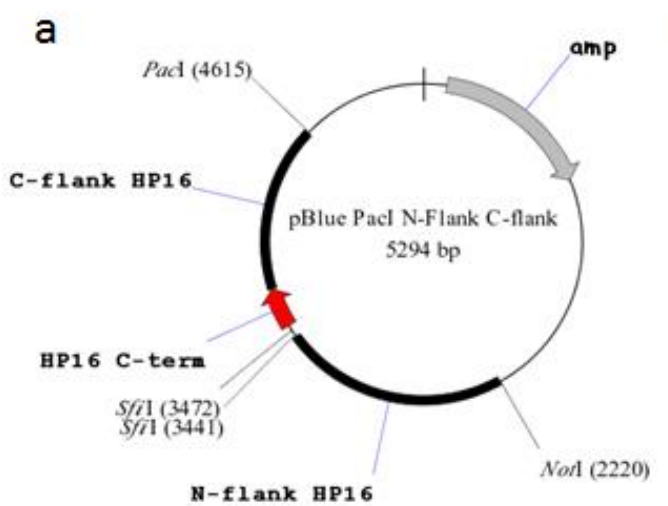

C

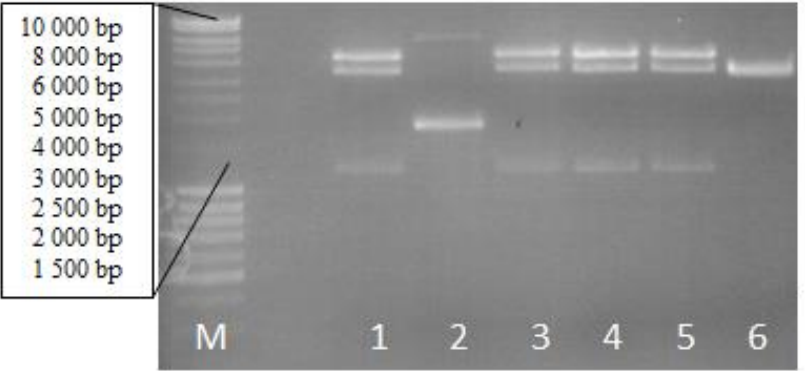

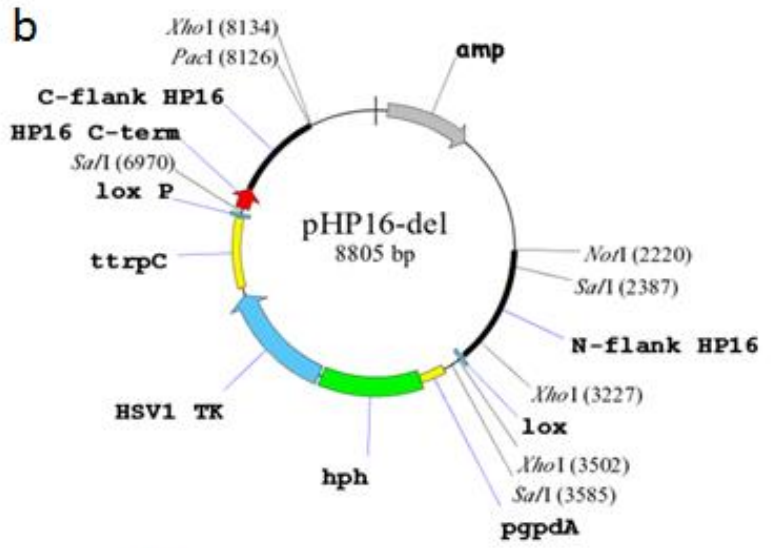

d

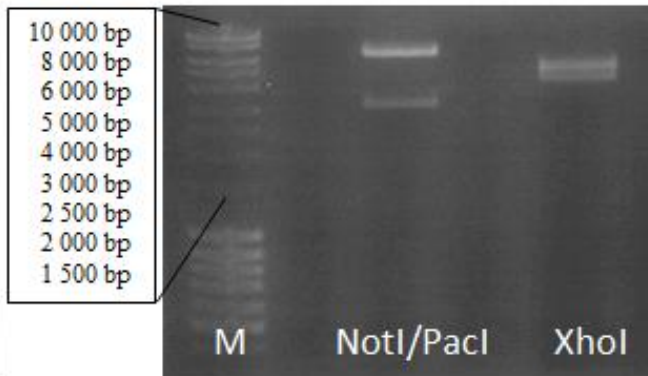

Abb. 6: a) pBlueskript II SK+PacI-Vektor mit einklonierten flankierenden Bereichen des Gens. b) Deletionsplamid pHP16-del mit den Restriktionsschnittstellen SalI, NotI/PacI bzw. XhoI. Das Deletionsplasmid hatte eine Größe von 8805 bp. c) Kontrolle der extrahierten Plasmide 1-6 aus verschiedenen E.coli-Kulturen nach SalI-Verdau. d) Kontrolle des Deletionsplasmids 1 nach einem NotI/PacI-Doppelverdau bzw. einem Verdau mit XhoI. Als Molekulargewichtsmarker (M) wurde der MassRuler ${ }^{\mathrm{TM}}$ DNA Ladder Mix verwendet. 
Das Deletionsplasmid pHP16-del/1 wurde, zur zusätzlichen Kontrolle, noch in einem Doppelverdau mit den beiden Restriktionsendonukleasen NotI und PacI und des Weiteren noch mit XhoI verdaut. Die erwarteten Fragmentgrößen von 2899 bp und 5906 bp, nach dem Verdau mit NotI und PacI, und auch die Fragmentgrößen von 275 bp (hier nicht sichtbar dargestellt), 3898 bp und 4632 bp für den Restriktionsverdau mit XhoI konnten bestätigt werden (Abb. 6d).

Transformation von A.fumigatus-Sphäroplasten mit dem Deletionsplasmid pHP16-del

Das Deletionsplasmid pHP16-del wurde mit NotI und PacI verdaut (Abb. 6b), wodurch die Transformationskassette ausgeschnitten wurde. Um die Kassette in das Genom von A.fumigatus einschleusen zu können, wurden zunächst Sphäroplasten des AspergillusStammes D141 gewonnen (s. 2.2.9). Nach der Transformation konnten die hygromycinresistenten Transformanten durch ihr Wachstum auf hygromycinhaltigen Agarplatten selektiert werden. Hierzu wurde außerdem der Wildtyp als Negativkontrolle mitgeführt. Da Sphäroplasten von A.fumigatus multinukleär sind, waren aller Wahrscheinlichkeit nach die produzierten Transformanten heterokaryotisch. A.fumigatus bildet uninukleäre Konidien, so dass, um genetisch reine Transformanten zu erhalten, der zweimalige Transfer von Kolonien via Konidien auf Selektivagar erfolgte. Die Transformanten wurden mit den Primern HP16_screen_1 bis HP16_screen_4 (Tab.7) zunächst mittels PCR auf das gewünschte Replacementereignis gescreent (Abb. 7).

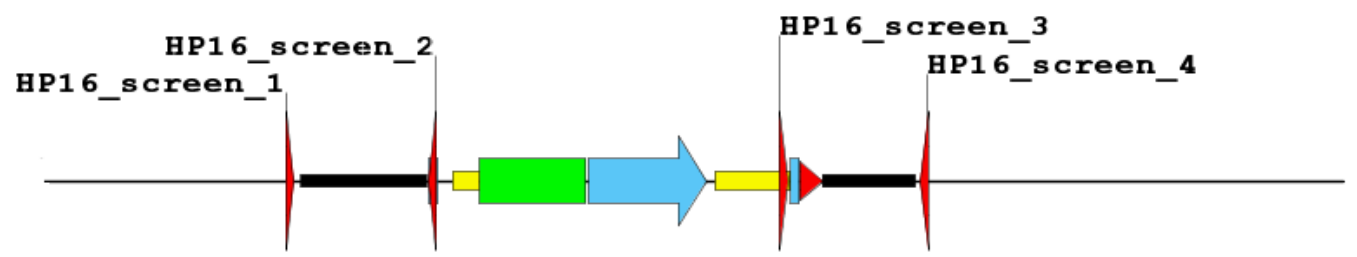

Abb. 7: Schema der Lage der Kontrollprimer HP16_screen_1 bis HP16_screen_4 nach Deletion des HP16-Gens.

Anhand der Abb. 8 ließ sich erkennen, dass nach der PCR-Kontrolle der Transformanten mit dem Primerpaar HP16_screen_1/2 bzw. HP16_screen_3/4 die Klone 4, 8, 10, 20 und 28 als positiv anzusehen waren. 


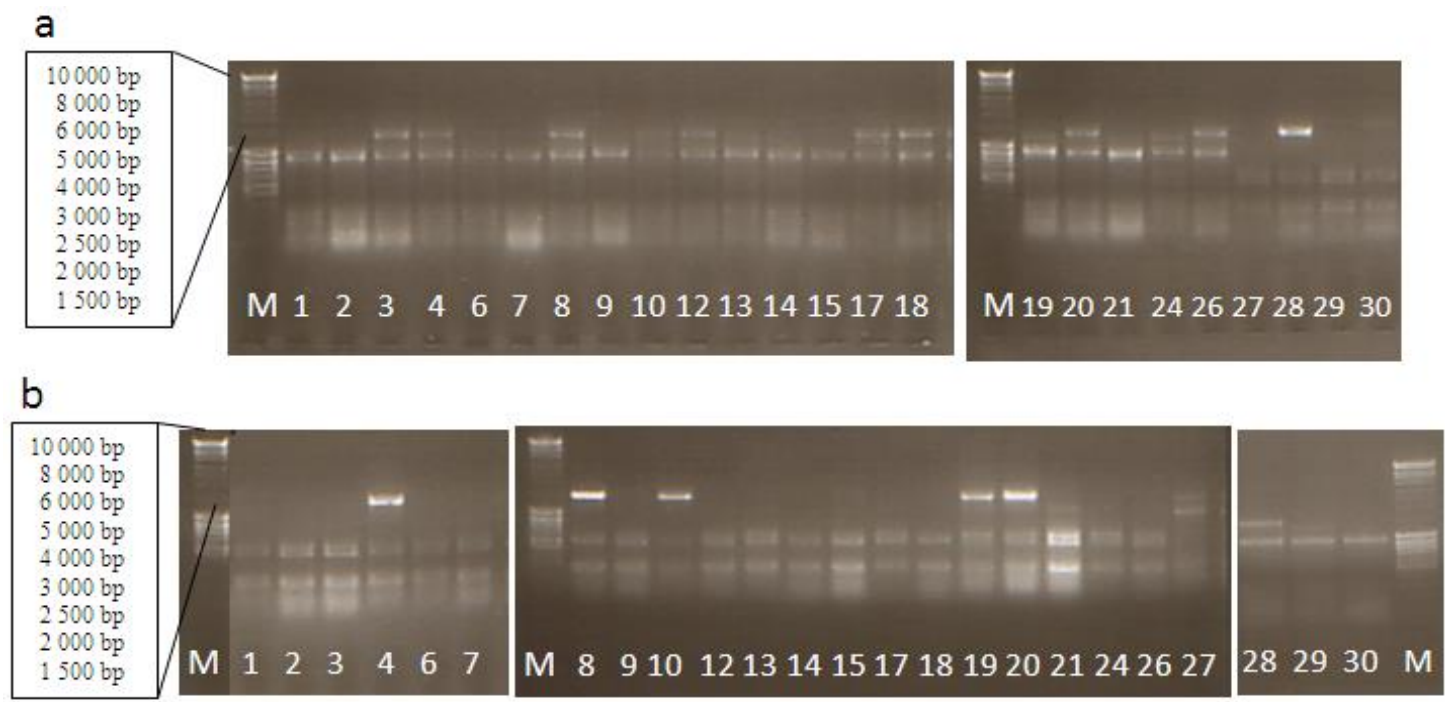

Abb. 8: a) PCR auf Mutanten-DNA nach Deletion von HP16 mit Primerpaar HP16_screen_1 und HP16_screen_2. Die erwartete Bandengröße betrug 1446 bp. b) PCR auf Mutanten-DNA nach Deletion von HP16 mit Primerpaar HP16_screen_3 und HP16_screen_4. Die erwartete Bandengröße betrug 1430 bp. Als Molekulargewichtsmarker (M) wurde der MassRuler ${ }^{\text {TM }}$ DNA Ladder Mix verwendet.

$\underline{\text { Kontrolle mittels Southern Blot }}$

Von den fünf mittels PCR identifizierten Transformanten, mit wahrscheinlich homologer Integration der Replacementkassette, wurden die beiden Transformanten 8 und 28 zur weiteren Analyse im Southern Blot ausgewählt. Die extrahierte und gereinigte DNA der Transformanten wurde mit den Restriktionsenzymen ClaI bzw. EcoRI geschnitten (Abb. 5 b) und im Agarosegel getrennt. Nach dem Blotten der DNA auf Nitrozellulose erfolgte die Hybridisierung mit einer digoxigenierten Sonde, die mit dem A.nidulans-Promotor pgpdA des Resistenz-liefernden Gens hybridisierte. Beide Transformanten 8 und 28 zeigten die erwarteten Bandengrößen von 2,6 kb für die Restriktionsendonuklease EcoRI und 7,3 kb für ClaI (Abb. 9). 


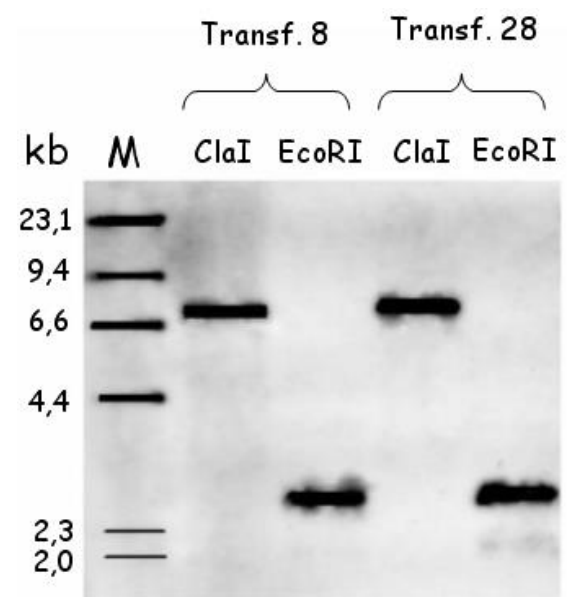

Abb. 9: Southern Blot auf $\Delta$ HP16-Transformanten 8 und 28 jeweils geschnitten mit den Restriktionsendonukleasen ClaI bzw. EcoRI. Als Molekulargewichtsmarker (M) wurde der DIGmarkierte DNA Marker II verwendet.

\subsubsection{Herstellung von $\Delta \mathrm{HP}^{\mathrm{K}}$}

\section{$\underline{\text { Herstellung des Komplementierungsplasmids }}$}

Für die Komplementierung der Deletionsmutante $\Delta$ HP16 (Abb. 13 a) wurden das HP16-Gen und seine flankierenden Bereiche durch PCR mit den Primerpaaren sv831/sv832 bzw. sv833/sv834 (Tab.7) amplifiziert. Ebenso wurde das ptA-Gen, das die Resistenz gegenüber dem Antibiotikum Pyrithiamin vermittelt, durch PCR (Primer sv197 und sv198) aus dem psk275-Vektor gewonnen (s. Anhang; Abb. 43). Alle PCRAmplifikate wurden mit Hilfe des GeneArt ${ }^{\circledR}$ Seamless Cloning and Assembly Kits mit dem linearen pUC19L (s. Anhang Abb. 44) zu einem Komplementierungsplasmid zusammenkloniert. Das so erstellte Plasmid (Abb. 10) wurde über Restriktionsanalysen im Agarosegel verifiziert. 


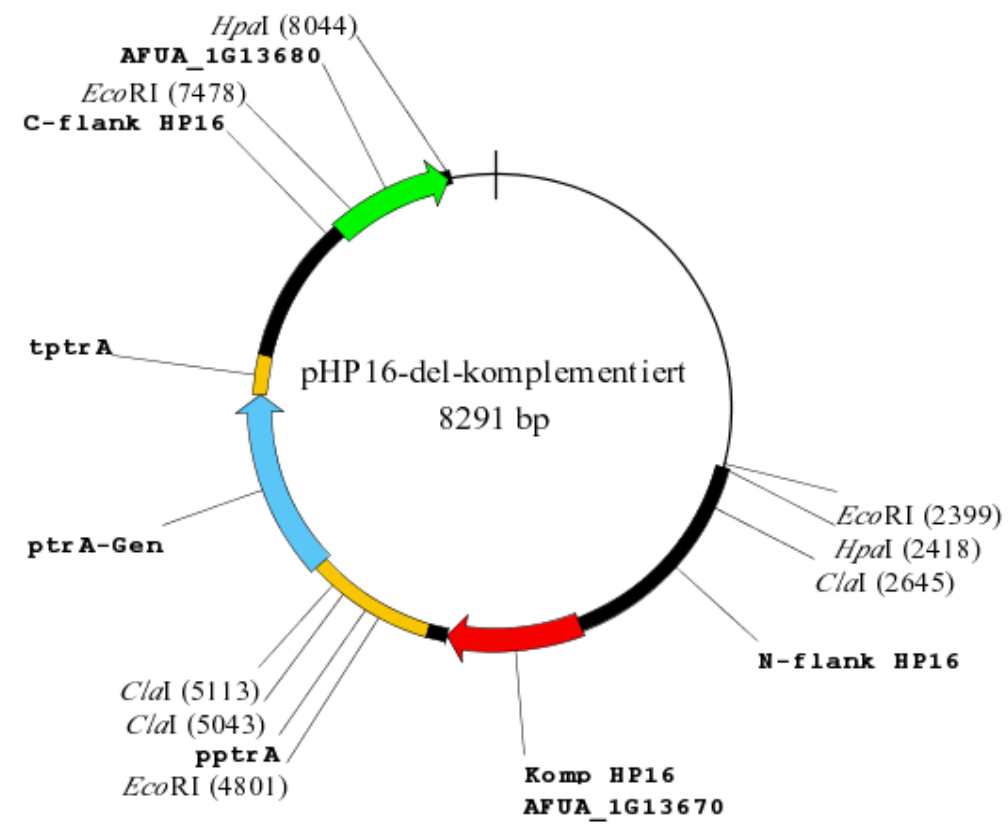

Abb. 10: Komplementierungsplasmid pHP16-del-komplementiert mit den Restriktionsschnittstellen ClaI, EcoRI, bzw. HpaI. Das Komplementierungsplasmid hatte eine Größe von 8291 bp.

Die erwarteten Fragmentgrößen nach einem Restriktionsverdau mit ClaI lagen bei 70 bp, 2398 bp und 5823 bp. Nach einem Restriktionsverdau mit EcoRI wurden Fragmente von 2402 bp, 2677 bp und 3212 bp erwartet. Dies traf auf das Komplementierungsplasmid $17 \mathrm{zu}$ (Abb. 11).

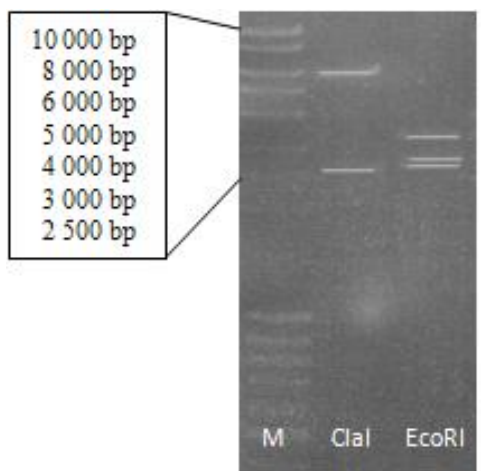

Abb. 11: Kontrolle des Komplementierungsplasmids 17 nach ClaI- bzw. EcoRI- Verdau. Als Molekulargewichtsmarker (M) wurde der MassRuler ${ }^{\mathrm{TM}}$ DNA Ladder Mix verwendet. 
$\underline{\text { Transformation von A.fumigatus-Sphäroplasten mit dem Komplementierungsplasmid }}$

Das Komplemtierungsplasmid pHP16-del-komplementiert wurde mit der Restriktionsendonuklease HpaI verdaut (Abb. 10), um das Plasmid zu linearisieren und die Transformationskassette auszuschneiden. Durch anschließende homologe Rekombination wurde es im Zuge der Transformation in die Deletionsmutante $\triangle$ HP16 (Transformante 8) eingebracht. Um die Kassette in das Genom von A.fumigatus einzuschleusen, wurden zunächst Sphäroplasten der Aspergillus-Knockoutmutante $\triangle$ HP16 generiert. Nach der Transformation konnten die pyrithiaminresistenten Transformanten durch ihr Wachstum auf pyrithiaminhaltigen Agarplatten selektiert werden. Hierzu wurde außerdem der Wildtyp D141 als Negativkontrolle mitgeführt. Die Transformanten wurden mit den Primern HP16_ReplacTrafo_1 bis HP16_ReplacTrafo_4 (Tab.7) mittels PCR auf das gewünschte Replacementereignis gescreent. Anhand der Abb. 12 lässt sich erkennen, dass nach der PCR-Kontrolle der Transformanten mit dem Primerpaar HP16_ReplacTrafo_1/2 bzw. HP16_ReplacTrafo_3/4 die Klone 11,13,14,18,19 und 30 als positiv anzusehen waren.

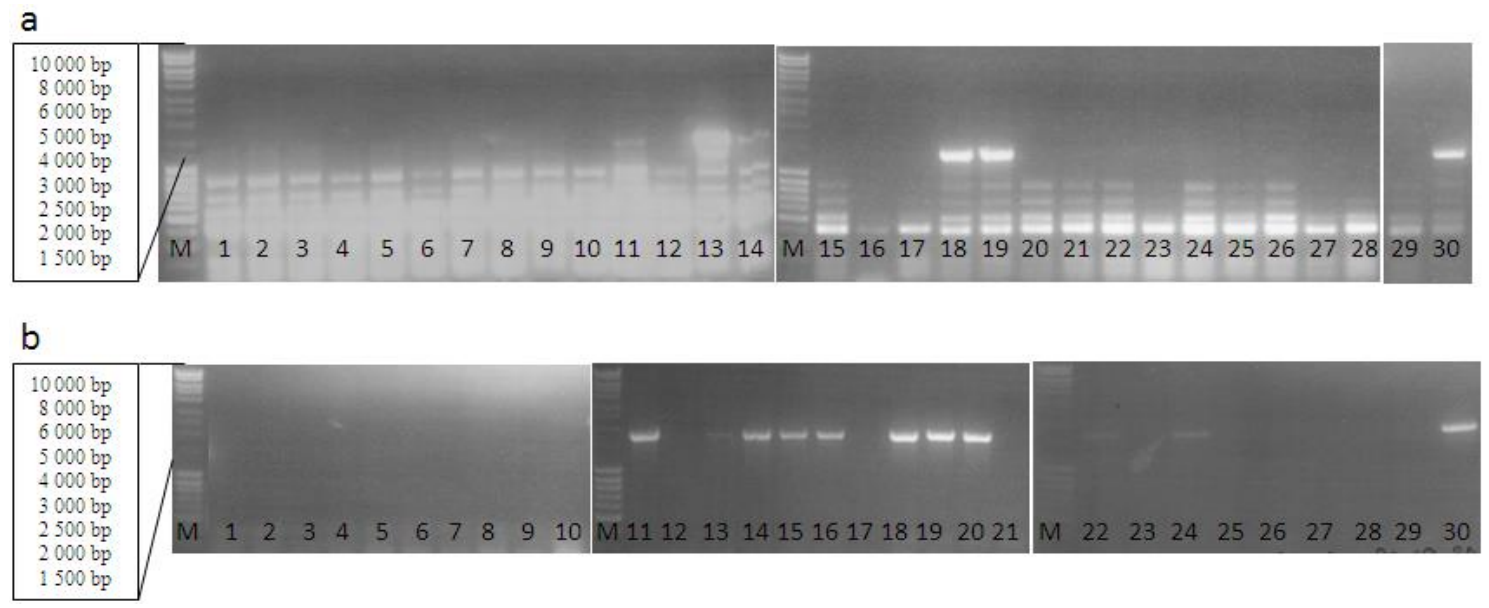

Abb. 12: a) PCR auf Mutanten-DNA nach Komplementierung von $\triangle \mathrm{HP16}$ mit Primerpaar HP16_ReplacTrafo_1 und HP16_ReplacTrafo_2. Die erwartete Bandengröße betrug 1403 bp. b) PCR auf Mutanten-DNA nach Komplementierung von $\triangle$ HP16 mit Primerpaar HP16_ReplacTrafo_3 und HP16_ReplacTrafo_4. Die erwartete Bandengröße betrug 1695 bp. Als Molekulargewichtsmarker (M) wurde der MassRuler ${ }^{\mathrm{TM}}$ DNA Ladder Mix verwendet. 
$\underline{\text { Kontrolle mittels Southern Blot }}$

Von den sechs durch PCR identifizierten Transformanten mit wahrscheinlich homologer Integration wurden die Transformanten 11, 18 und 30 zur weiteren Analyse im Southern Blot ausgewählt. Die extrahierte und gereinigte DNA der Transformanten wurde mit den Restriktionsenzymen EcoRV bzw. StuI geschnitten (Abb. 13 b) und im Agarosegel getrennt. Nach dem Blotten der DNA auf Nitrozellulose erfolgte die Hybridisierung mit einer digoxigenierten Sonde, die den A.oryzae-Promotor pptrA des Resistenz-liefernden Gens als Ziel hatte. Die Transformante 18 erbrachte die erwarteten Bandengrößen von 4,6 kb für die Restriktionsendonuklease EcoRV und 5,5 kb für StuI (Abb. 14).

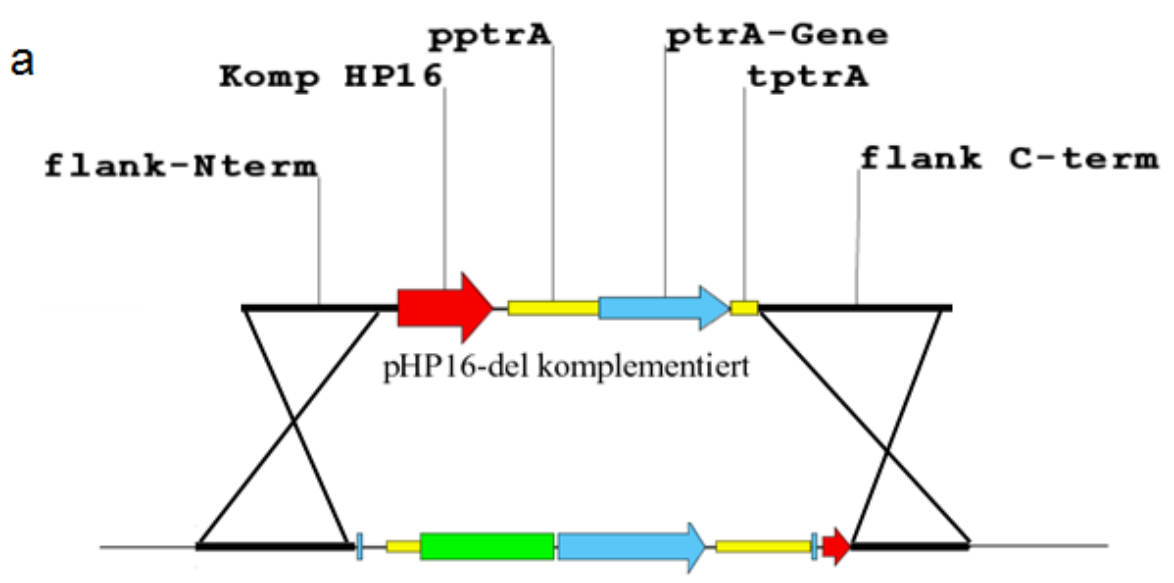

Deletionsmutante HP 16

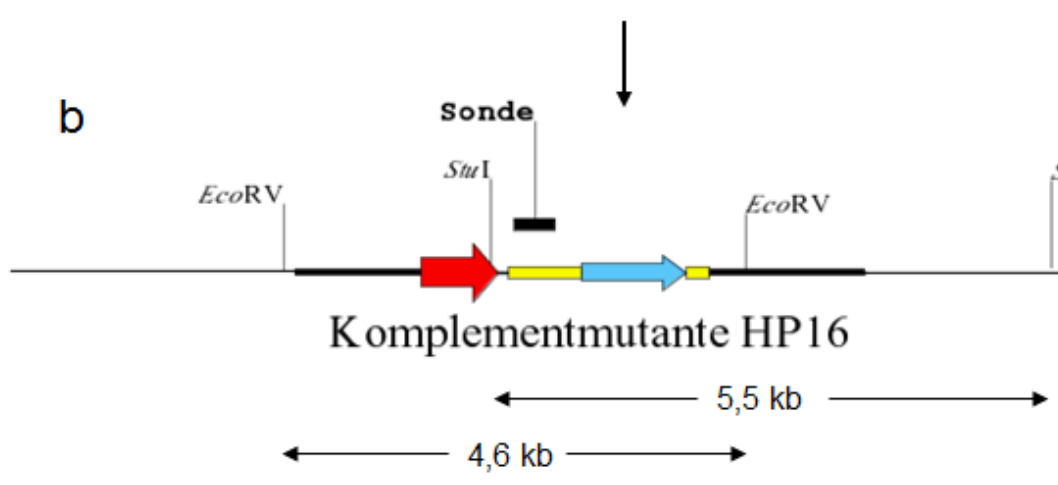

Abb. 13: a) Verwendete Cross-over Strategie bei der homologen Rekombination zur Generierung der HP16-Komplementmutante. b) Genom der Komplementmutante mit den Schnittstellen für die Restriktionsendonukleasen (EcoRV und StuI), mit denen der Verdau für den Southern Blot durchgeführt wurde. 


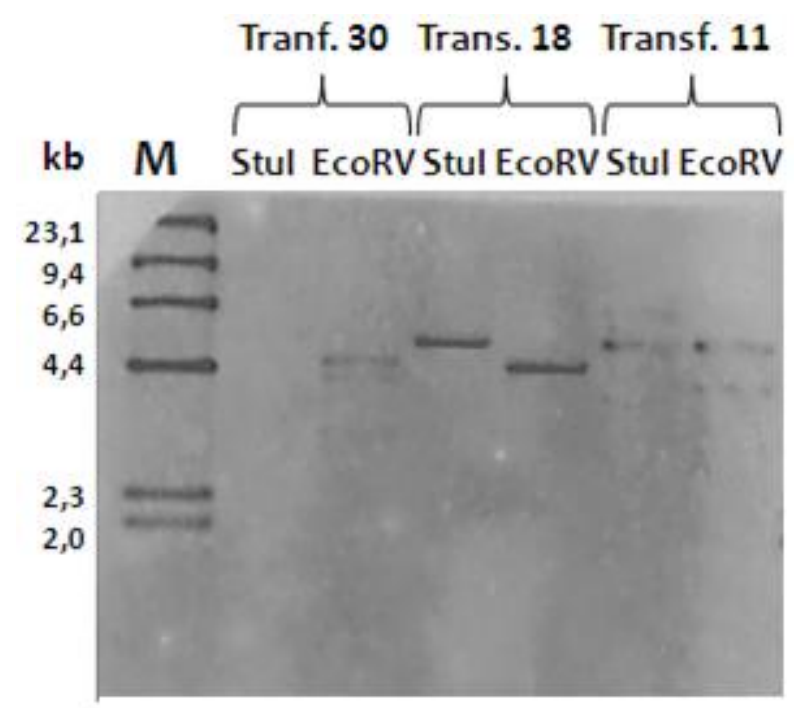

Abb. 14: Southern Blot auf HP16-Komplementmutante. Transformanten 11, 18 und 30, jeweils geschnitten mit den Restriktionsendonukleasen EcoRV bzw. StuI. Als Molekulargewichtsmarker (M) wurde der DIG-markierte DNA Marker II verwendet.

\subsubsection{Herstellung von $\Delta \operatorname{Aspf3}^{\mathrm{K}}$}

$\underline{\text { Herstellung des Komplementierungsplamids }}$

Für die Komplementierung der Deletionsmutante $\Delta$ Aspf3 (Abb. 15) wurden das Aspf3Gen und die flankierenden Bereiche durch nested-PCR auf der genomischen DNA des A.fumigatus Wildtyps D141 mit den Primerpaaren Aspf3-Rekom_5/Aspf3-Rekom_6 (1.PCR: Aspf3-nested_1/Aspf3-nested_2) bzw. Aspf3-Rekom_1/Aspf3-Rekom_2 (1.PCR: Aspf3-nested_3/Aspf3-nested_4) amplifiziert. Siehe dazu auch die Tab.7. Außerdem wurde das $p t A-G e n$, das die Resistenz gegenüber dem Antibiotikum Pyrithiamin vermittelte, mittels PCR mit den Primern Aspf3-Rekom_3 und Aspf3Rekom_4 (1. PCR: Aspf3-nested_5/Aspf3-nested_6) amplifiziert. 


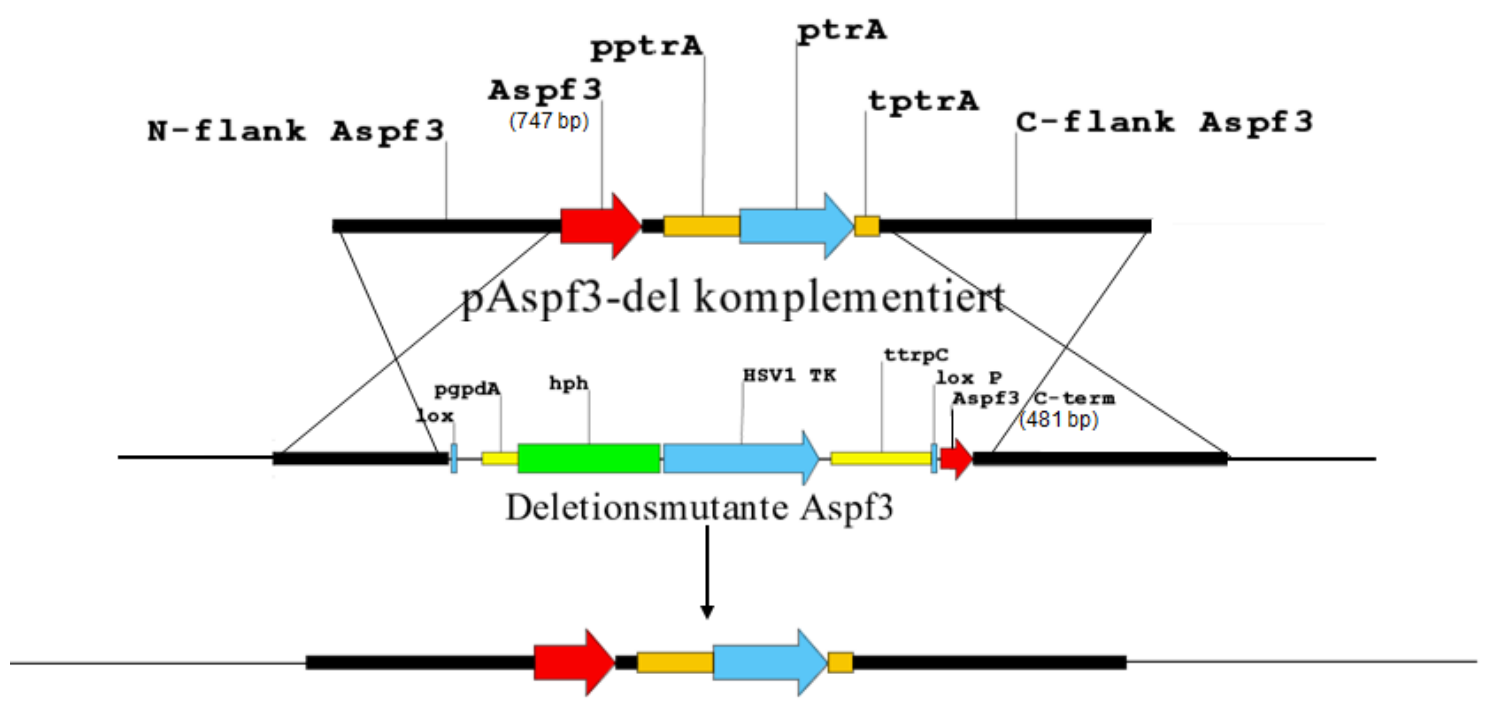

Komplementmutante Aspf3

Abb. 15: Verwendete Cross-over Strategie bei der homologen Rekombination zur Generierung der Komplementmutante Aspf3.

Alle PCR-Amplifikate wurden mit Hilfe des GeneArt@ Seamless Cloning and Assembly Kits mit dem linearen pUC19L (s. Anhang Abb. 44) zu einem Komplementierungsplasmid zusammenkloniert. Das so erstellte Plasmid Aspf3-delkomplementiert (Abb. 16) wurde über Restriktionsanalysen im Agarosegel kontrolliert.

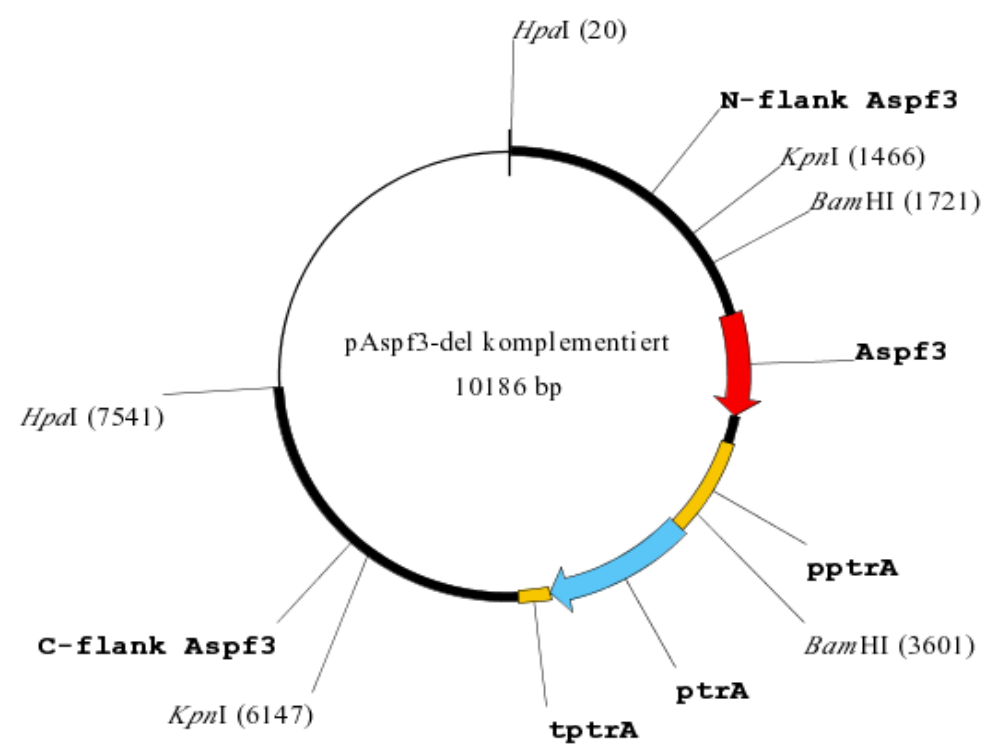

Abb. 16: Komplementierungsplasmid pAspf3-del-komplementiert mit den Restriktionsschnittstellen BamHI, KpnI bzw. HpaI. Das Komplementierungsplasmid hatte eine Größe von 10186 bp. 
Die erwarteten Fragmentgrößen nach Restriktionsverdau mit BamHI lagen bei 1880 bp und 8306 bp. Nach Restriktionsverdau mit KpnI wurden Fragmente von 4681 bp und 5505 bp erwartet. Dies traf auf das Komplementierungsplasmid 11 zu (Abb. 17). Dieses Plasmid wurde dann mit der Restriktionsendonuklease HpaI linearisiert und abschließend durch homologe Rekombination im Zuge der Transformation in die Deletionsmutante $\Delta$ Aspf3 (Transformante 5) eingebracht.

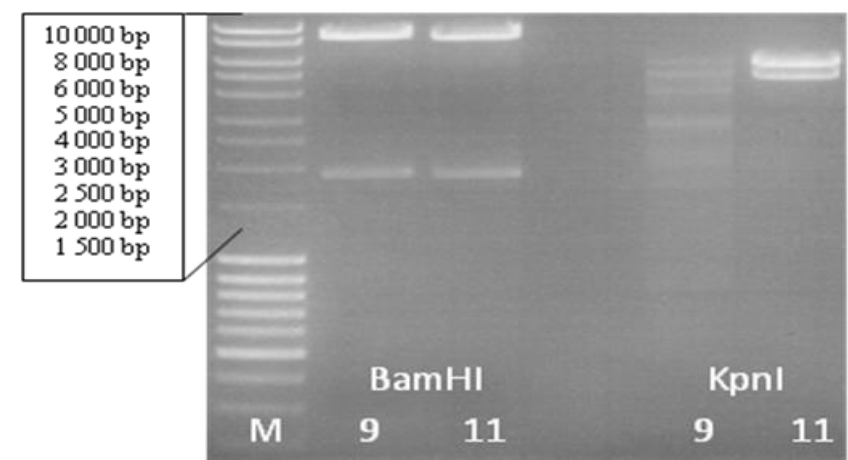

Abb. 17: Kontrolle der Komplementierungsplasmide 9 und 11 nach einem BamHI-, bzw. KpnIVerdau. Als Molekulargewichtsmarker (M) wurde der MassRuler ${ }^{\mathrm{TM}}$ DNA Ladder Mix verwendet.

$\underline{\text { Transformation von A.fumigatus-Sphäroplasten mit Aspf3-Komplemtierungsplasmid }}$

Das Komplementierungsplasmid pAspf3-del-komplementiert wurde mit $\mathrm{HpaI}$ verdaut (Abb. 16), um das Plasmid $\mathrm{zu}$ linearisieren und die Transformationskassette auszuschneiden. Um die Kassette in das Genom von A.fumigatus einschleusen zu können, wurden zunächst Sphäroplasten der Aspergillus-Knockoutmutante $\Delta$ Aspf3 gewonnen. Nach der Transformation konnten die pyrithiaminresistenten Transformanten durch ihr Wachstum auf pyrithiaminhaltigen Agarplatten selektiert werden. Hierzu wurde außerdem der Wildtyp D141 als Negativkontrolle mitgeführt. Die Transformanten wurden mit den Primern Aspf3_ReplacTrafo_3 bis Aspf3_ReplacTrafo_6 (Tab.7) mittels PCR auf das gewünschte Replacementereignis gescreent (Abb. 18). 


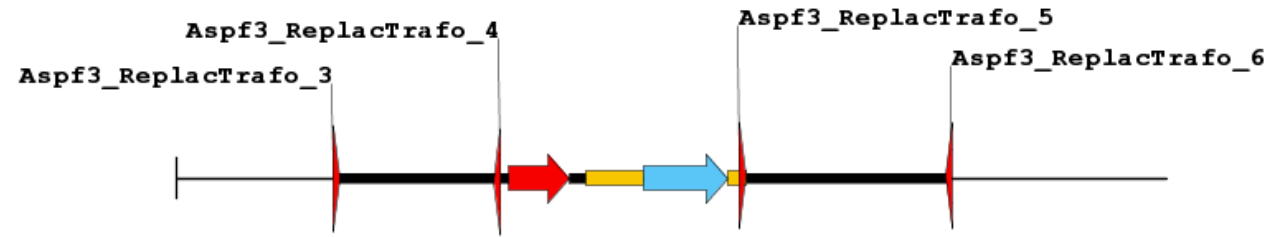

Abb. 18: Schema der Lage der Kontrollprimer Aspf3_ReplacTrafo_3 bis Aspf3_ReplacTrafo_6 nach erfolgter Transformation.

Anhand der Abb. 19 ließ sich erkennen, dass nach der PCR-Kontrolle der Transformanten mit dem Primerpaar Aspf3_ReplacTrafo_3/4 bzw. Aspf3_ReplacTrafo_5/6 die Klone 8,18 und 30 als positiv anzusehen waren.

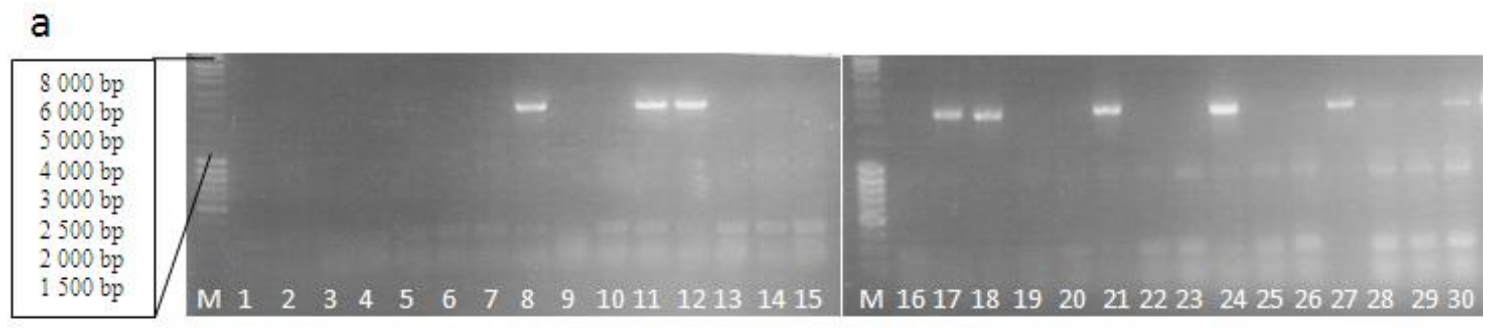

b

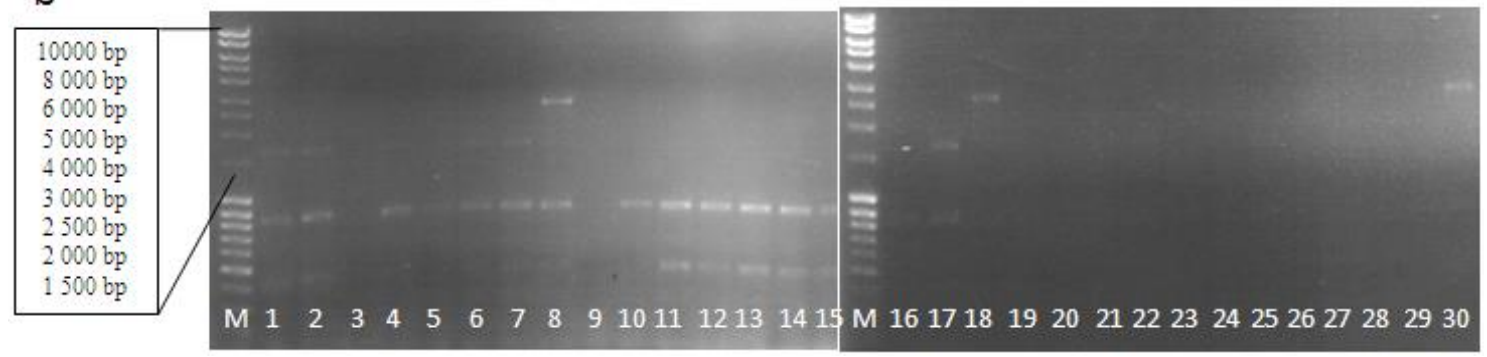

Abb. 19: a) PCR auf Mutanten-DNA nach Komplementierung von $\triangle A s p f 3$ mit Primerpaar Aspf3_ReplacTrafo_3/4. Die erwartete Bandengröße betrug 2060 bp. b) PCR auf Mutanten-DNA nach Komplementierung von Aspf3 mit Primerpaar Aspf3_ReplacTrafo_5/6. Die erwartete Bandengröße betrug 2620 bp. Als Molekulargewichtsmarker (M) wurde der MassRuler ${ }^{\text {TM }}$ DNA Ladder Mix verwendet.

\subsection{Biochemische Charakterisierung der Aspf3-Deletionsmutante und -}

\section{Komplementmutante}

Die Aspf3-Deletionsmutante wurde im Vergleich mit der Komplementmutante und dem Wildtyp D141 auf ihr Wachstum unter oxidativem Stress getestet. Dies wurde mit einem Agar-Diffusionstests unter Verwendung verschiedener Konzentrationen an $\mathrm{H}_{2} \mathrm{O}_{2}$ 
untersucht. Bei der Deletionsmutante konnte ein deutlich größerer Hemmhof festgestellt werden als bei den beiden anderen ausplattierten Stämmen. Bei einem Vergleich des Wachstums der Komplementmutante und des Wildtyps konnte kein Unterschied in der Größe des Hemmhofdurchmessers ausgemacht werden (Abb. 20), allerdings sporulierte die Komplementmutante nicht so stark wie der Wildtyp (Abb. 21).

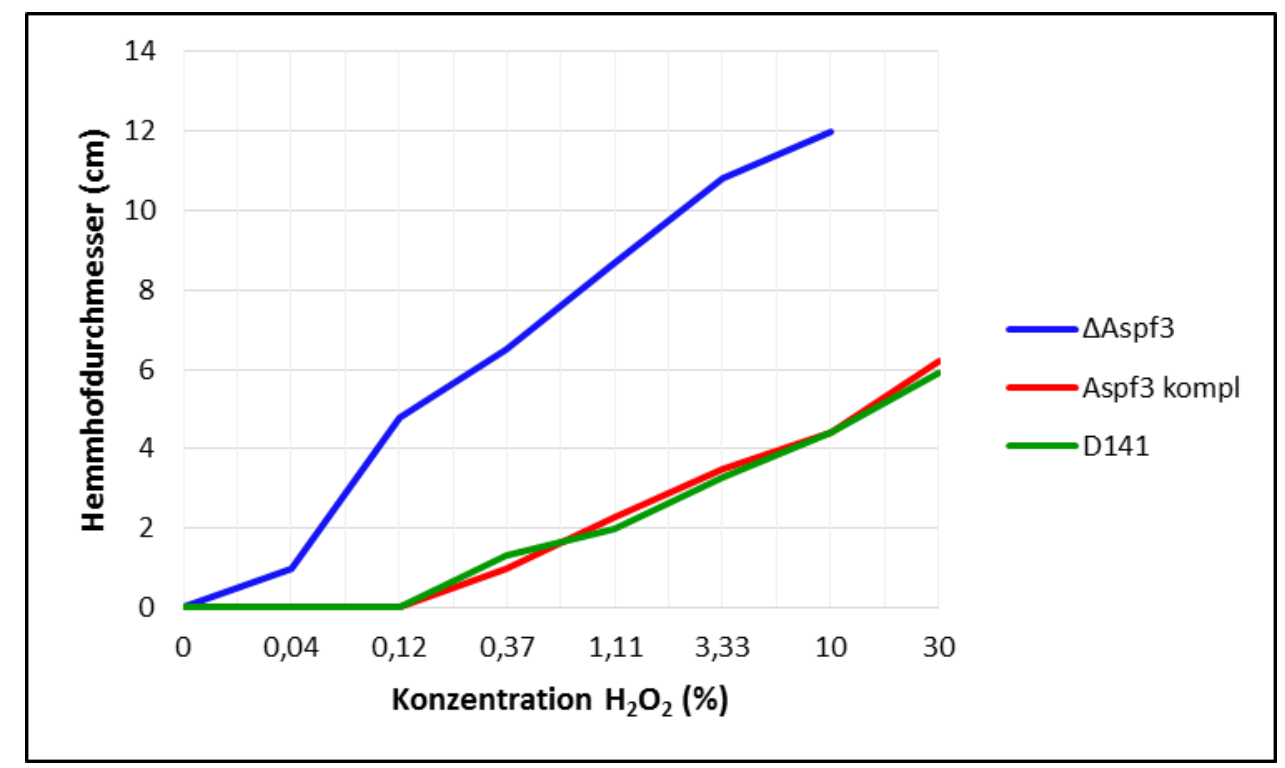

Abb. 20: Auswertung des Agardiffussionstests, dabei ist der Hemmhofdurchmesser gegen die jeweilige Konzentration an $\mathrm{H}_{2} \mathrm{O}_{2}$ aufgetragen.

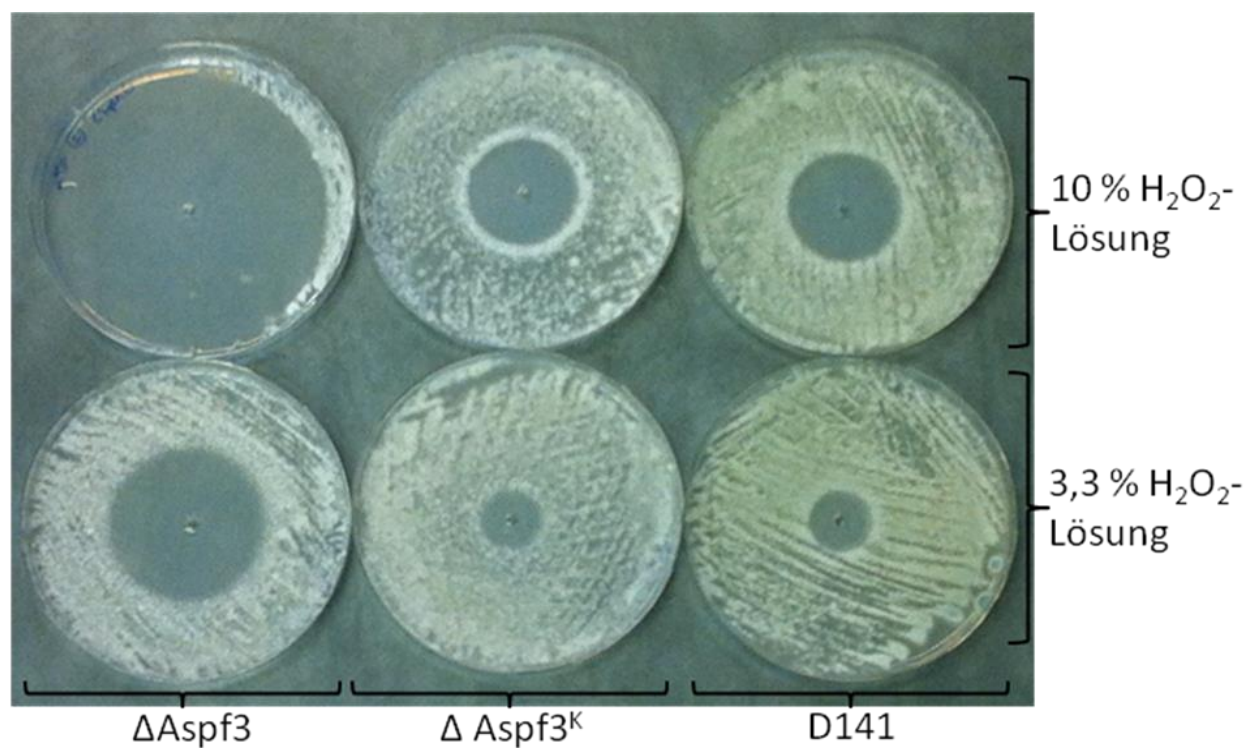

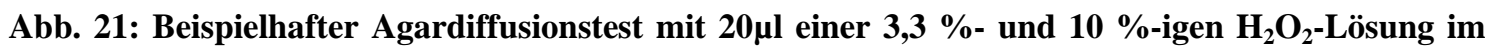
Vergleich mit $\Delta$ Aspf, $\Delta \operatorname{Aspf3}^{\mathrm{K}}$ und dem Wildtyp D141 


\subsection{Herstellung des rekombinanten Proteins HP16}

\subsubsection{Expression von HP16 in E.coli unter Verwendung eines His-Tags}

Die unter diesem Punkt 3.3.2 beschriebenen Ergebnisse wurden in Zusammenarbeit mit Frau Pähtz, Doktorandin in der Abteilung Molekulare und Angewandte Mikrobiologie, unter der Leitung von Herrn Prof. Dr. Axel Brakhage am Leibniz-Institut für NaturstoffForschung und Infektionsbiologie, Hans Knöll Institut (HKI, Jena) durchgeführt.

Der Vektor pMA-T_Afu1g13670_23-218 (HP16), mit dem synthetisch hergestellten Genabschnitt, wurde mit dem Primerpaar Afu1g13670_23BamHIf/ Afu1g13670_182HindIIIr für eine kurze Version des Proteins (AS 23-182), bzw. dem Primerpaar Afu1g13670_23BamHIf/ Afu1g13670_218HindIIIr (Primer s. Tab.7), für eine lange Version des Proteins (AS 23-218) mittels PCR amplifiziert (Abb. 22). Die so erhaltenen PCR-Produkte wurden in den pET28aHT-Vektor kloniert, der eine N-terminale Fusion mit dem His-Tag erlaubte. (s. Anhang, Abb. 45 a und b).

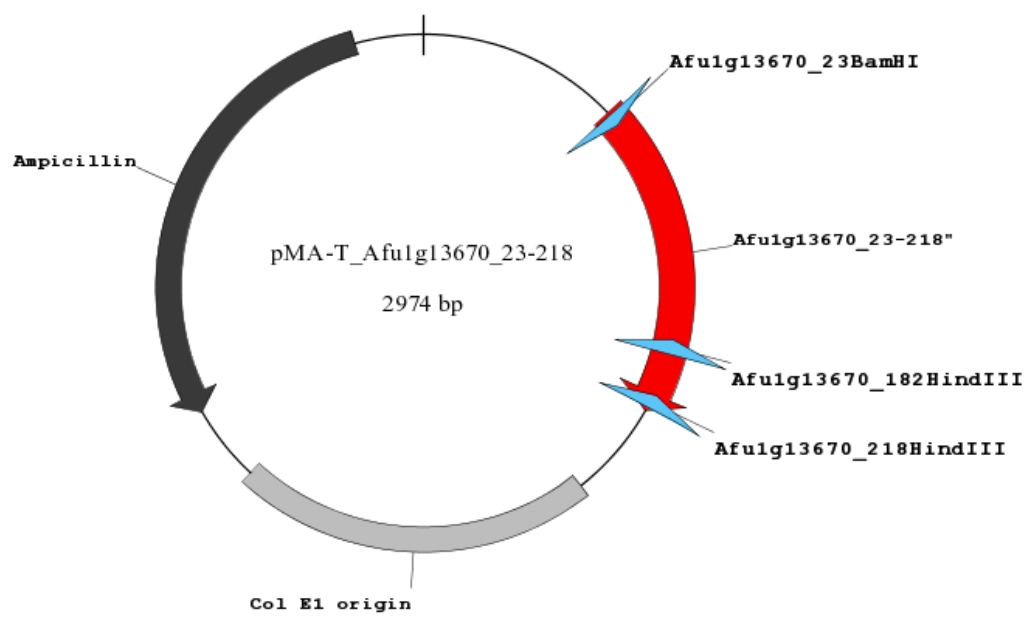

Abb. 22: Vektor pMA-T_Afu1g13670_23-218 mit synthetisch hergestellter kodierender Nukleotidsequenz (AS 23-218) und Schema der Lage der Primer Afu1g13670_23BamHI, Afu1g13670_182HindIII und Afu1g13670_218HindIII.

Die transformierten BL21(DE3)-Expressionsstämme wurden in einem MiniExpressionsversuch getestet. Die SDS-PAGE (Abb. 23, durch rote Markierungen gekennzeichnet) zeigt deutlich die kurze $(22,37 \mathrm{kDa})$ als auch lange Version $(26,2 \mathrm{kDa})$ des Proteins. 


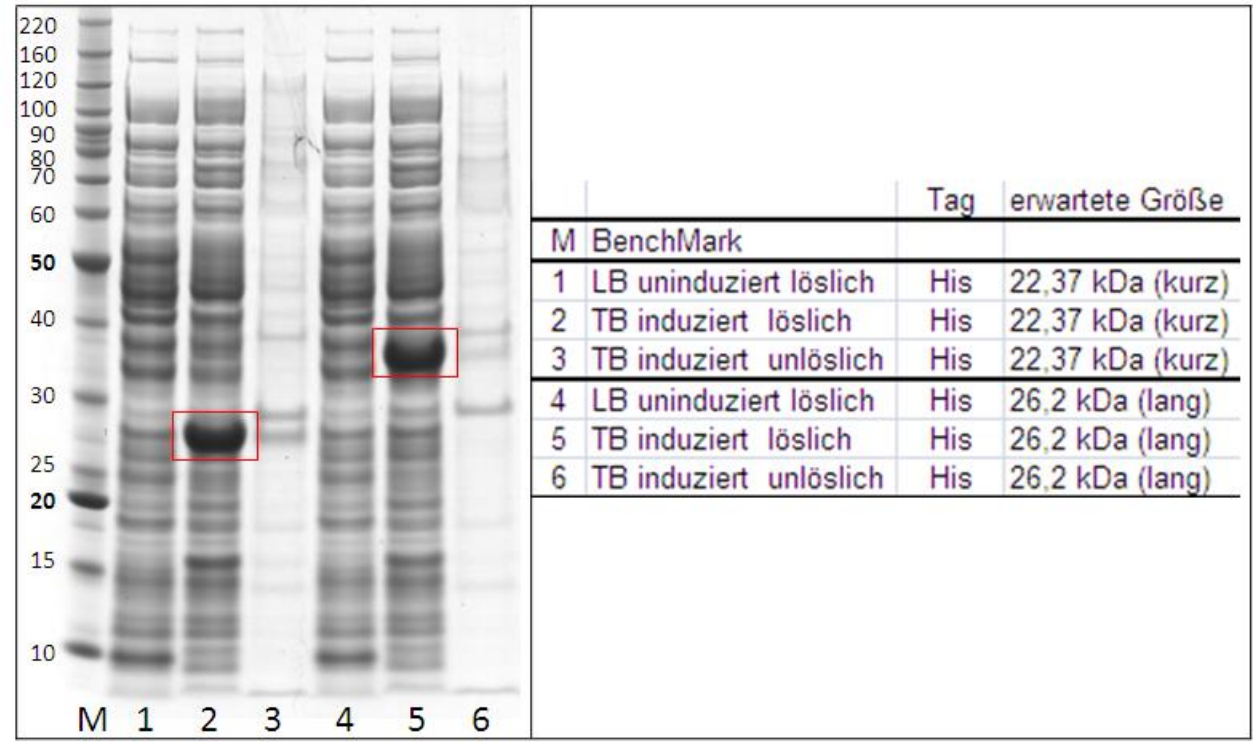

Abb. 23: SDS-PAGE des Mini-Expressionsversuchs unter Verwendung des His-Tags. Lösliche und unlösliche Proteinfraktionen wurden dabei getrennt.

Sowohl die kurze als auch lange Version des Proteins konnten im MiniExpressionsversuch erzeugt werden. Die SDS-PAGE (Abb. 23) zeigte, dass das Protein sich in der löslichen Zellfraktion befindet. Es folgte eine Reinigung des rekombinanten Proteins über Ni-Sepharose mit Hilfe einer His GraviTrap-Säule. Dafür wurde sowohl die kurze als auch die lange Version des Proteins mit dem fusionierten His-Tag genutzt (Abb. 24).

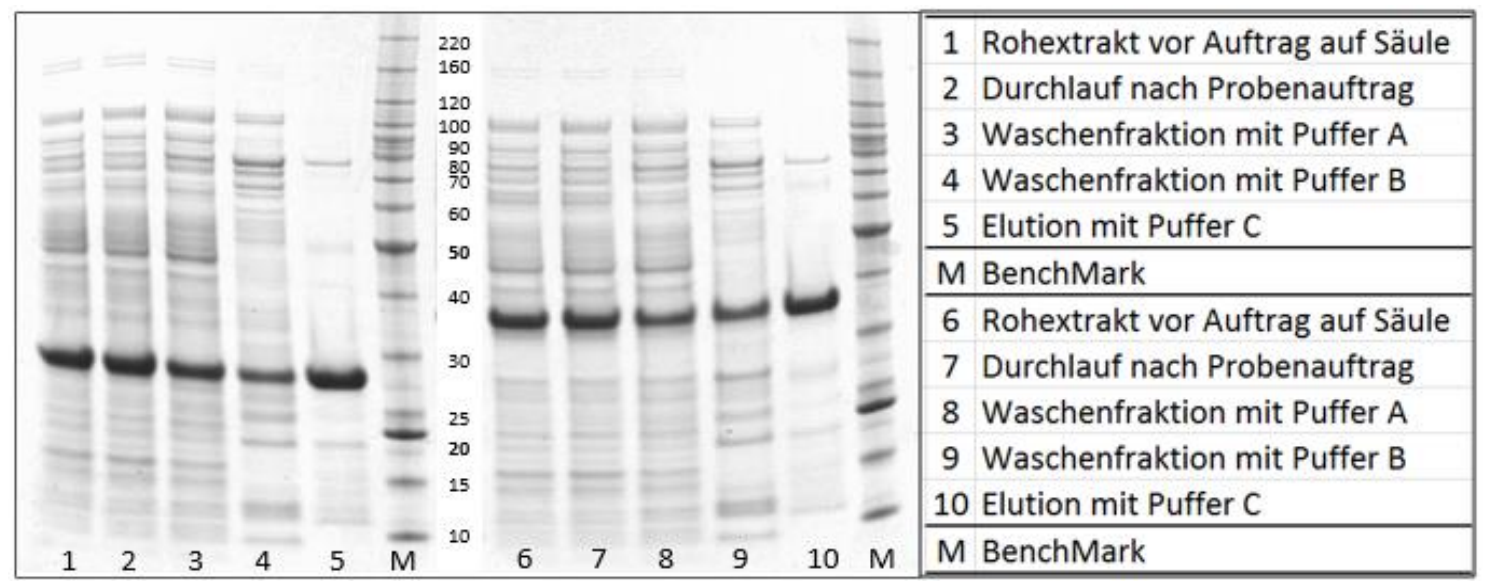

Abb. 24 SDS-PAGE des exprimierten rekombinanten HP16-Proteins (mit His-Tag) nach der NiAffinitätschromatographie. Alle Proben stammen aus löslichem Zellextrakt und nach vorhergehender Anzucht in TB-Medium. Proben 1-5 für die verkürzte Version und 7-10 für die längere Version des Proteins. 


\subsection{Etablierung eines Mausmodells mit Dosisfindungsstudie}

Zur Etablierung eines Mausmodells für die invasive Aspergillose wurden die ersten Vorversuche in Anlehnung an Veröffentlichungen anderer Arbeitsgruppen durchgeführt. Nach weiteren Optimierungen wurde ein eigenes modifiziertes Mausmodell etabliert.

Für den ersten Vorversuch wurden NMRI Mäuse verwendet, die mit unterschiedlichen Mengen an Konidien nasal infiziert wurden. Die Mengen beliefen sich auf $5 \times 10^{6}$, $3,33 \times 10^{5}$ bzw. $2,22 \times 10^{4}$ Konidien. Das Cortisonacetat wurde, um es einfacher in die Maus injizieren zu können, in einem Ultraschallbad vorbehandelt. Stellt man den prozentualen Anteil überlebender Mäuse nach einer Infektion (p.i.; post infectionem) in den drei Gruppen gegenüber (Abb. 25), wird deutlich, dass die Mäuse der Gruppe 1 spätestens an Tag 3 verstarben bzw. getötet werden mussten, dabei waren acht von zehn Mäusen an dem Tag betroffen. In Gruppe 2 starben vier von zehn Mäusen bzw. mussten getötet werden. In Gruppe 3 überlebten alle Mäuse bis auf eine.

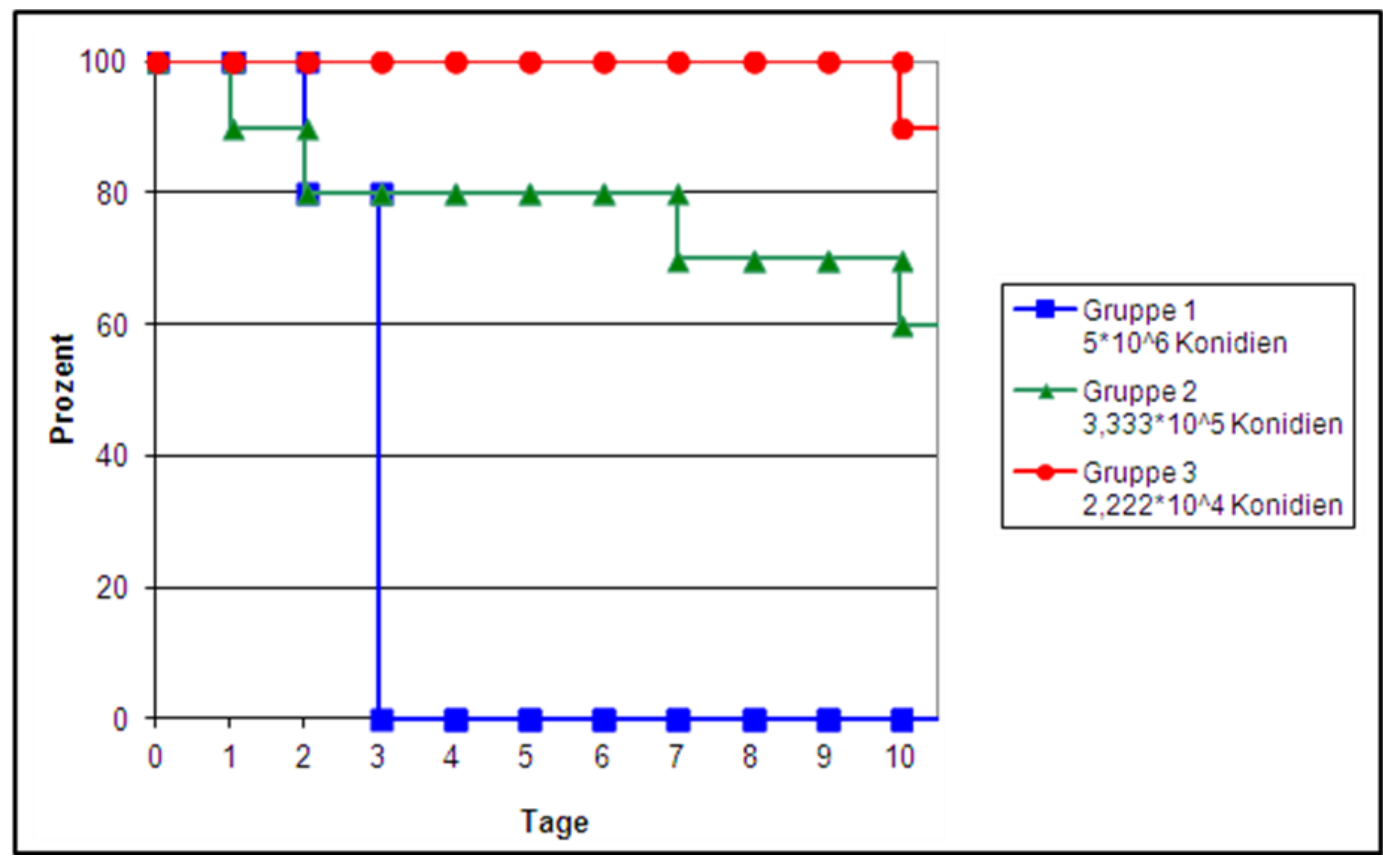

Abb. 25: Prozentualer Anteil überlebender Mäuse je Tag p.i. bei unterschiedlichen Dosen von Konidien in den einzelnen Gruppen bei der Durchführung des ersten Vorversuchs.

Nach dem ersten Vorversuch wurden einzelne Parameter geändert. Es wurden BALB/c Mäuse (Inzuchtmäuse) verwendet, und das Cortisonacetat wurde, um eine noch feinere Suspension zu erreichen, mit einem Stab-Ultraschallgerät behandelt. Die Mengen an 
Konidien beliefen sich bei dem zweiten Vorversuch auf $4 \times 10^{6}, 2 \times 10^{6}$ bzw. $1 \times 10^{6}$. Der Verlauf für den prozentualen Anteil überlebender Mäuse (Abb. 26) ist für die Gruppen 1 und 2 besser verteilt als für Gruppe 3, so wurde die Menge an Konidien auf 3x10 für alle nachfolgenden Versuche festgesetzt.

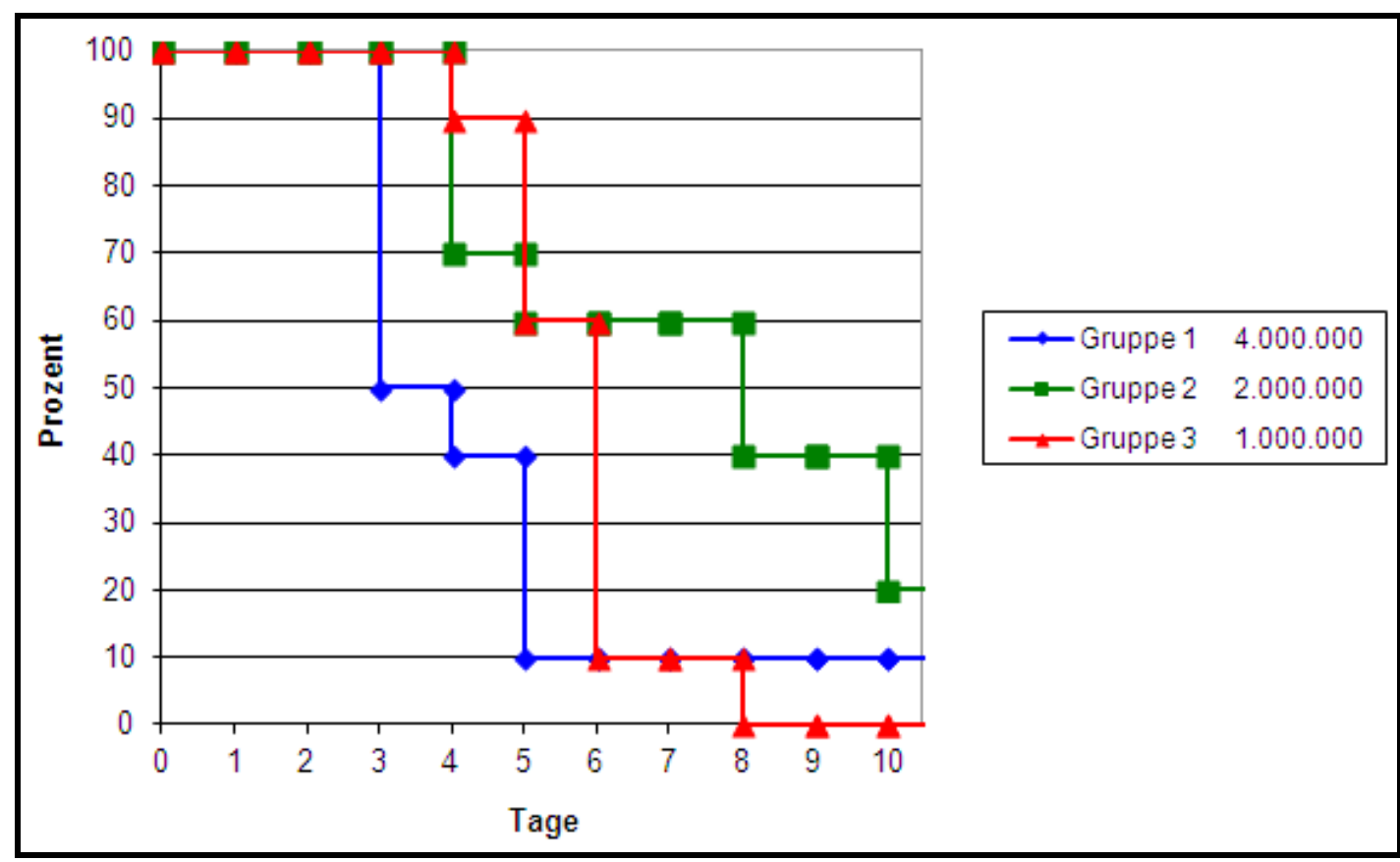

Abb. 26: Prozentualer Anteil überlebender Mäuse je Tag p.i. bei unterschiedlichen Dosen von Konidien in den einzelnen Gruppen bei der Durchführung des zweiten Vorversuchs.

\subsection{Immunisierung mit rekombinanten A.fumigatus-Proteinen im}

\section{Mausmodell}

Die rekombinant hergestellten Proteine wurden im Tierversuch auf ihre Potenz zur Induktion einer protektiven Immunantwort untersucht. Wegen der bekannten Streuung der Ergebnisse war das Mitführen einer Negativ-Kontrollgruppe bei jedem Versuch notwendig. Dieser Negativgruppe wurde nur das Adjuvans TiterMax ${ }^{\circledR}$ in PBS ohne Impfstoff injiziert. Alle Mäuse wurden regelmäßig zur Beurteilung des Allgemeinzustandes gewogen, wobei eventuelle Gewichtversänderungen erfasst wurden (nicht dargestellt). Nachfolgend genannte Proteine wurden vorwiegend teilexprimiert verwendet (s. Tab. 11). 


\section{Impfgruppe 1 (AAT, PG, PG3/4)}

Der Impfstoff für die Gruppe 1 bestand aus dem Protein Aspartat-Aminotransferase (AAT) und dem in zwei Teilen exprimierten Protein der Phosphoglucomutase PdcA (PG und PG3/4). Ein Vergleich der Überlebenskurven (Abb. 27) von Impf- und Kontrollgruppe erbrachte keine signifikante Protektion durch den Impfstoff ( $\mathrm{P}=0,7667)$.

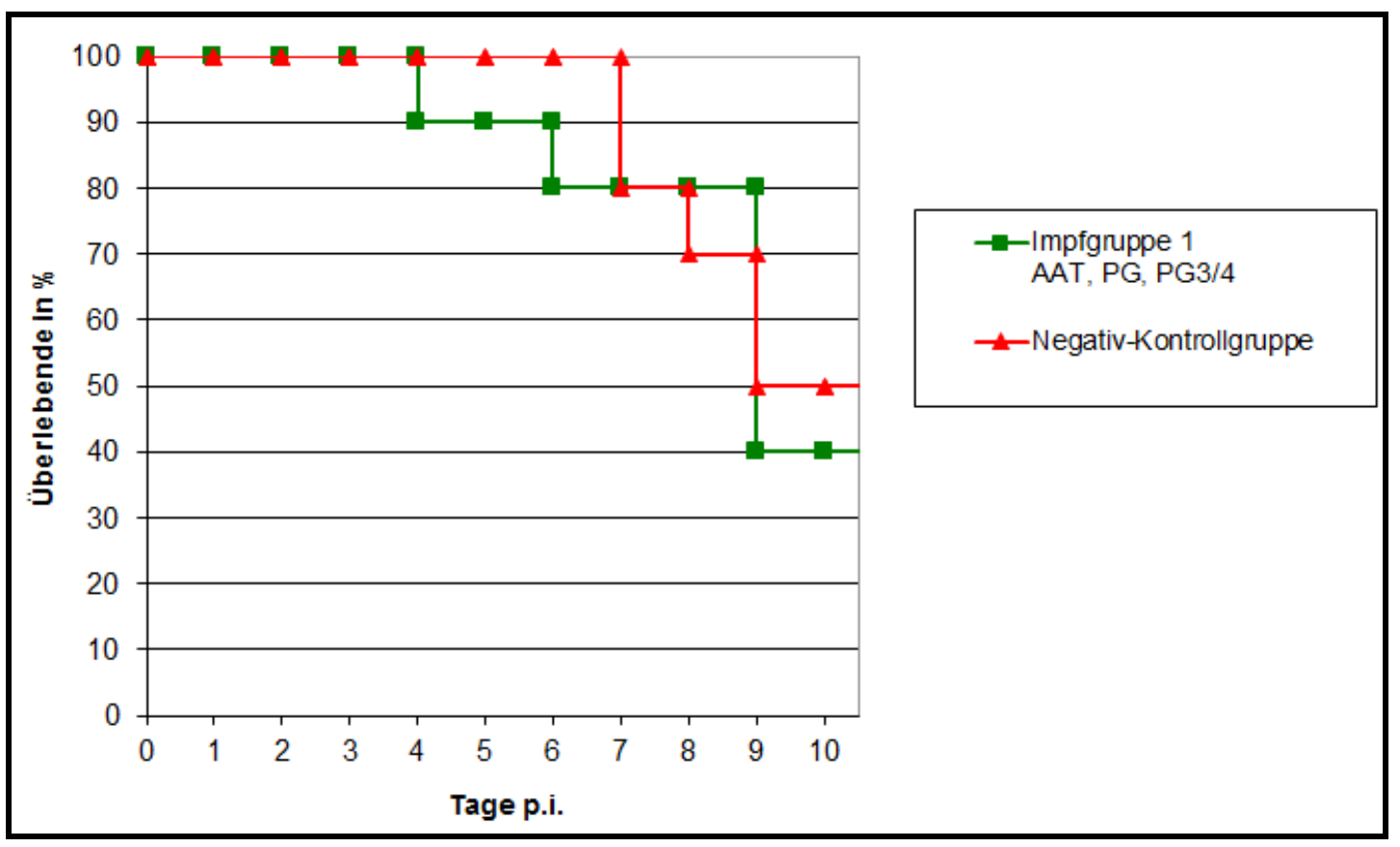

Abb. 27: Prozentualer Anteil an überlebenden Mäusen aufgeführt für jeden der zehn Beobachtungstage für die Impfgruppe 1 im Vergleich zu der Negativ-Kontrollgruppe.

Impfgruppe 2 (Aspf3) und Impfgruppe 3 (Enolase, HSP90, TBP)

Der Impfstoff für die Gruppe 2 bestand aus dem rekombinanten Protein Aspf3 (Peroxireduktase). Für die Impfgruppe 3 wurden die rekombinanten Proteine Enolase, HSP90 und Thiamin-Biosynthese Protein Nmt1 (TBP) verwendet. Ein Vergleich der Überlebenskurven erbrachte, dass in den beiden Impfgruppen weniger Mäuse als in der Negativ-Kontrollgruppe starben bzw. getötet werden mussten (Abb. 28). Sowohl für die Impfgruppe $2(* \mathrm{P}=0,0412)$ als auch für die Impfgruppe $3(* \mathrm{P}=0,0121)$ wurde ein signifikant protektiver Effekt durch Injektion des Impfstoffes erzielt. Nach Aufarbeitung der Lungen und dem sich anschließenden Vergleich des Ergebnisses der Kolonie formenden Units pro Maus pro Gruppe konnte festgestellt werden, dass bei der 
Impfgruppe 3 auch die Besiedelung mit A.fumigatus im Laufe der zehn Beobachtungstage abnahm (nicht dargestellt).

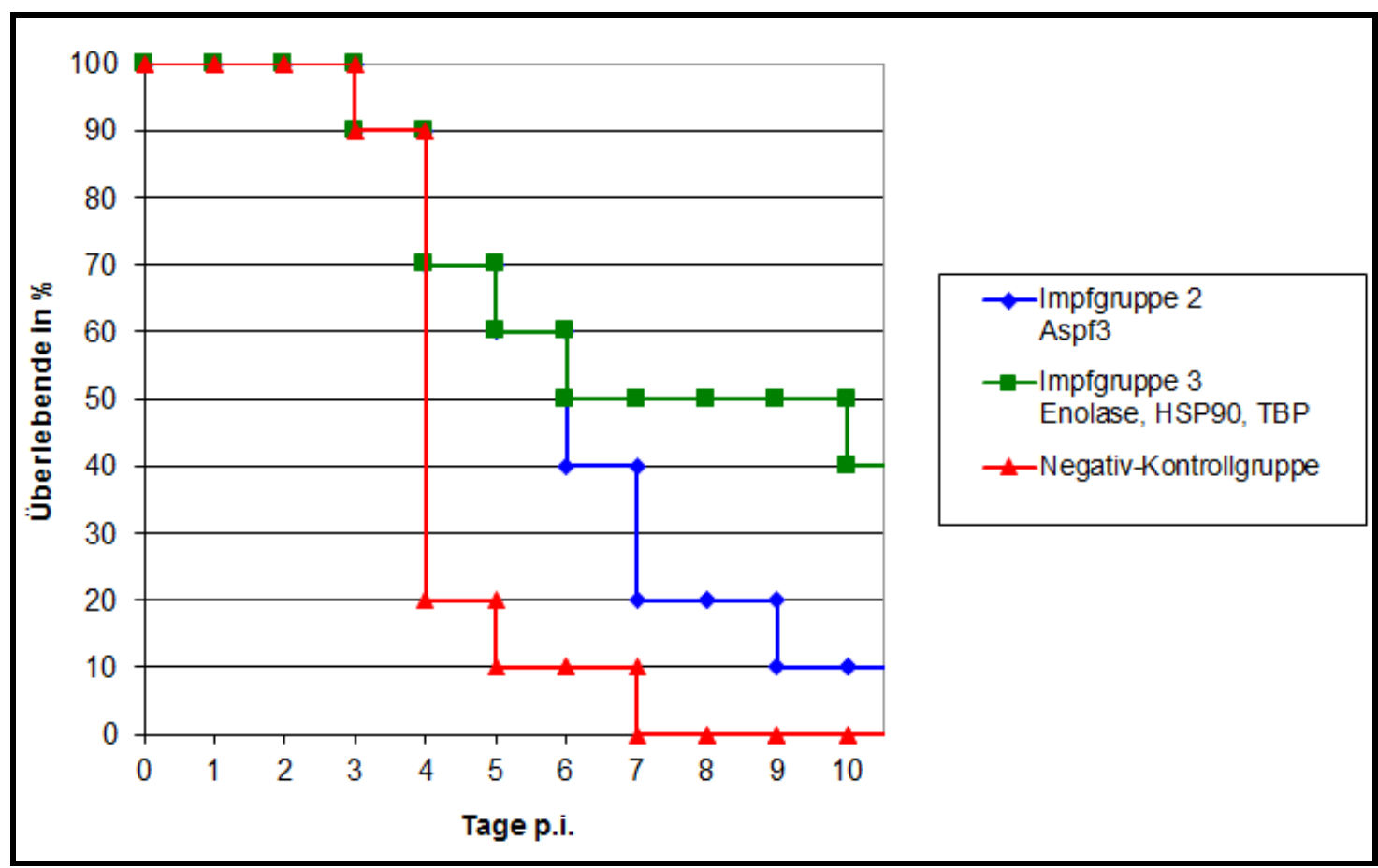

Abb. 28: Prozentualer Anteil an überlebenden Mäusen aufgeführt für jeden der zehn Beobachtungstage für die Impfgruppen 2 und 3 im Vergleich zu der Negativ-Kontrollgruppe.

Impfgruppe 4 (ADH, AP, AP5/6) und Impfgruppe 5 (COA, DI, DI3/4)

Der Impfstoff für die Gruppe 4 bestand aus dem Protein Alkohol-Dehydrogenase (ADH) und dem in zwei Teilen exprimierten Protein Aminopeptidase (AP und AP5/6). Für die Impfgruppe 5 wurden die rekombinanten Proteine Coatomer, Delta-Untereinheit (COA) und das in zwei Teilen exprimierte Protein Disulfid-Isomerase Pdi1 (DI und DI3/4) verwendet. Ein Vergleich der Überlebenskurven (Abb. 29) ergab, dass in der Impfgruppe 4 mehr Mäuse als in der Negativ-Kontrollgruppe starben bzw. getötet werden mussten. Auch ein Vergleich von Impfgruppe 5 und Kontrollgruppe erbrachte keine Protektion durch den Impfstoff $(\mathrm{P}=0,9677)$. 


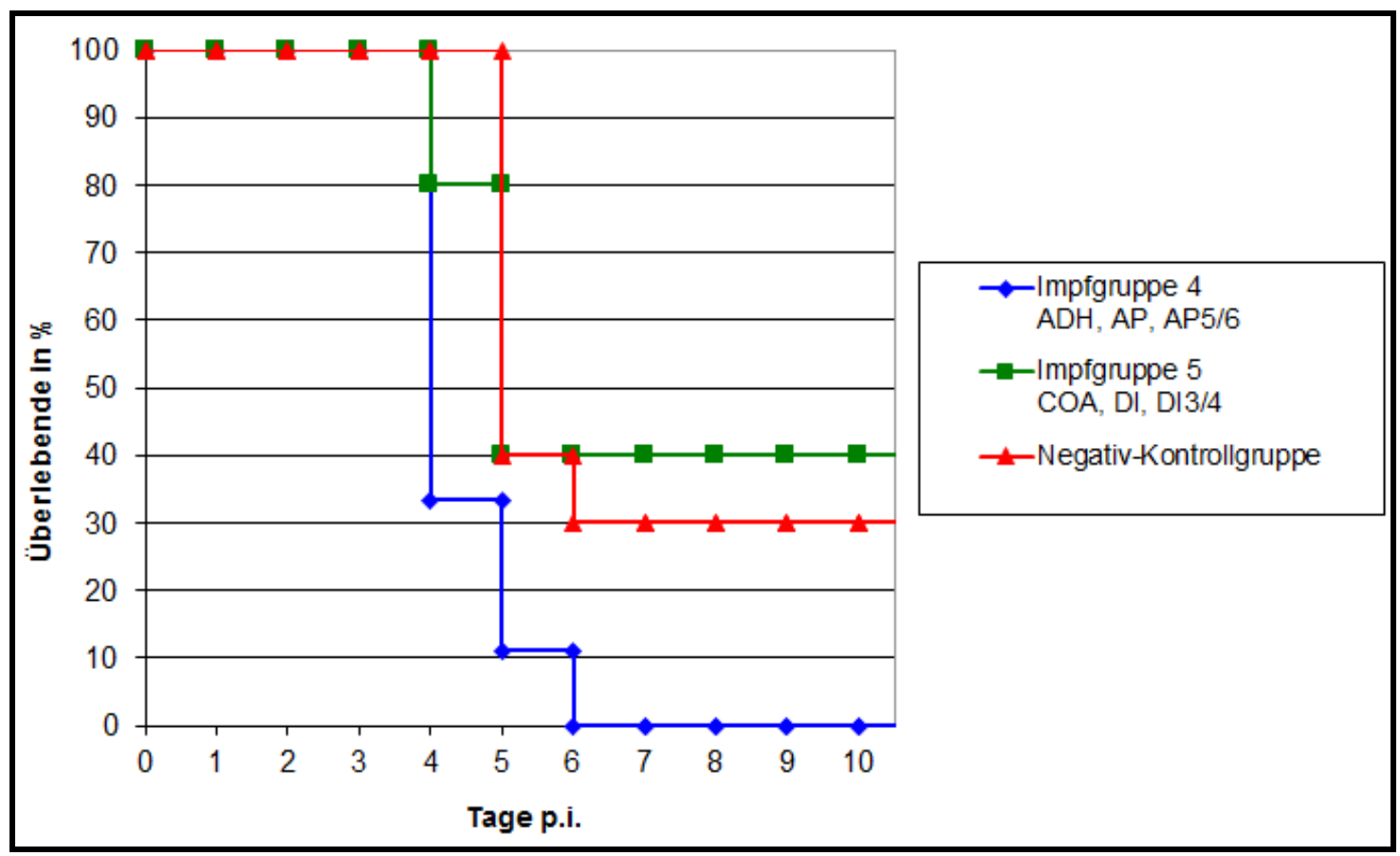

Abb. 29: Prozentualer Anteil an überlebenden Mäusen aufgeführt für jeden der zehn Beobachtungstage für die Impfgruppen 4 und 5 im Vergleich zur Negativ-Kontrollgruppe.

Impfgruppe 6 (INVO3/4, BGT, BGT3/4), Impfgruppe 7 (MIPS, PGM, PGM3/4) und Impfgruppe 8 (ALAD, TK, HP90)

Der Impfstoff für die Gruppe 6 bestand aus dem Involucrin-Repeat-Protein (INVO3/4) und dem in zwei Teilen exprimierten Protein 1,3-beta-Glucanosyltransferase (BGT und BGT3/4). Für die Impfgruppe 7 wurden das rekombinante Protein Myo-InositolPhosphat-Synthase (MIPS) und das in zwei Teilen exprimierte Protein Phosphoglyceratmutase (PGM und PGM3/4) verwendet. Der Impfstoff für die Gruppe 8 bestand aus dem Aldolase ClassII/ Adducin-Domain-Protein (ALAD), der Transketolase TktA (TK) und dem konservierten hypothetischen Protein Hp90 (HP90). In der Impfgruppe 7 starben weniger Mäuse als in der Negativ-Kontrollgruppe bzw. mussten getötet werden. Die Auswertung der Überlebenskurven (Abb. 30) der jeweiligen Impfgruppe und der Kontrollgruppe erbrachte jedoch keine Protektion durch einen der Impfstoffe (Impfgruppe 6: P=0,571; Impfgruppe 7: P=0,2788; Impfgruppe 8: $\mathrm{P}=0,5831$ ). 


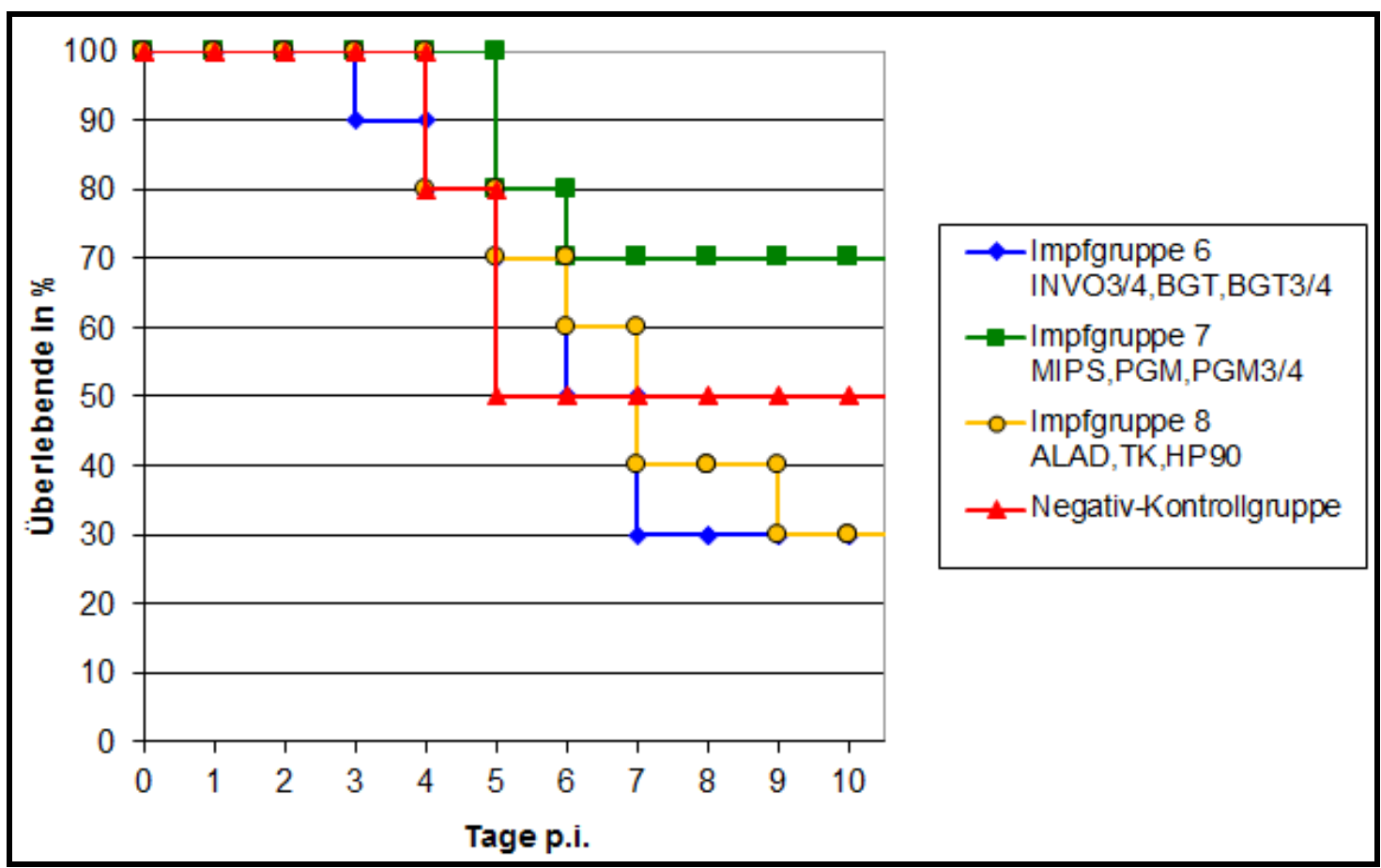

Abb. 30: Prozentualer Anteil an überlebenden Mäusen aufgeführt für jeden der zehn Beobachtungstage für die Impfgruppen 6, 7 und 8 im Vergleich zur Negativ-Kontrollgruppe.

Impfgruppe 9 (HP10, HSP30,GAPD), Impfgruppe 10 (HP70, SHMT, MPRO5/6) und Impfgruppe 11 (ADMA, NDGD, FBA)

Der Impfstoff für die Gruppe 9 bestand aus dem konservierten hypothetischen Protein Hp10 (HP10), dem Hitzeschockprotein Hsp30 (HSP30) und der Glyceraldehyd-3Phosphat-Dehydrogenase (GAPD). Für die Impfgruppe 10 wurden das hypothetische Protein Hp70 (HP70), die Serin-Hydroxymethyltransferase (SHMT) und das MRepeatprotein (MPRO5/6) verwendet. Der Impfstoff für die Gruppe 11 bestand aus der Metalloprotease ADM-A (ADMA), der NAD+-abhängigen Glutamat-Dehydrogenase (NDGD) und Fruktosebiphosphataldolase, classII (FBA). Ein Vergleich der Überlebenskurven (Abb. 31) der jeweiligen Impfgruppe und der Kontrollgruppe erbrachte keinen protektiven Effekt durch einen der Impfstoffe (Impfgruppe 9: $\mathrm{P}=0,8086$; Impfgruppe 10: $\mathrm{P}=0,5231$; Impfgruppe 11: $\mathrm{P}=0,6871$ ). 


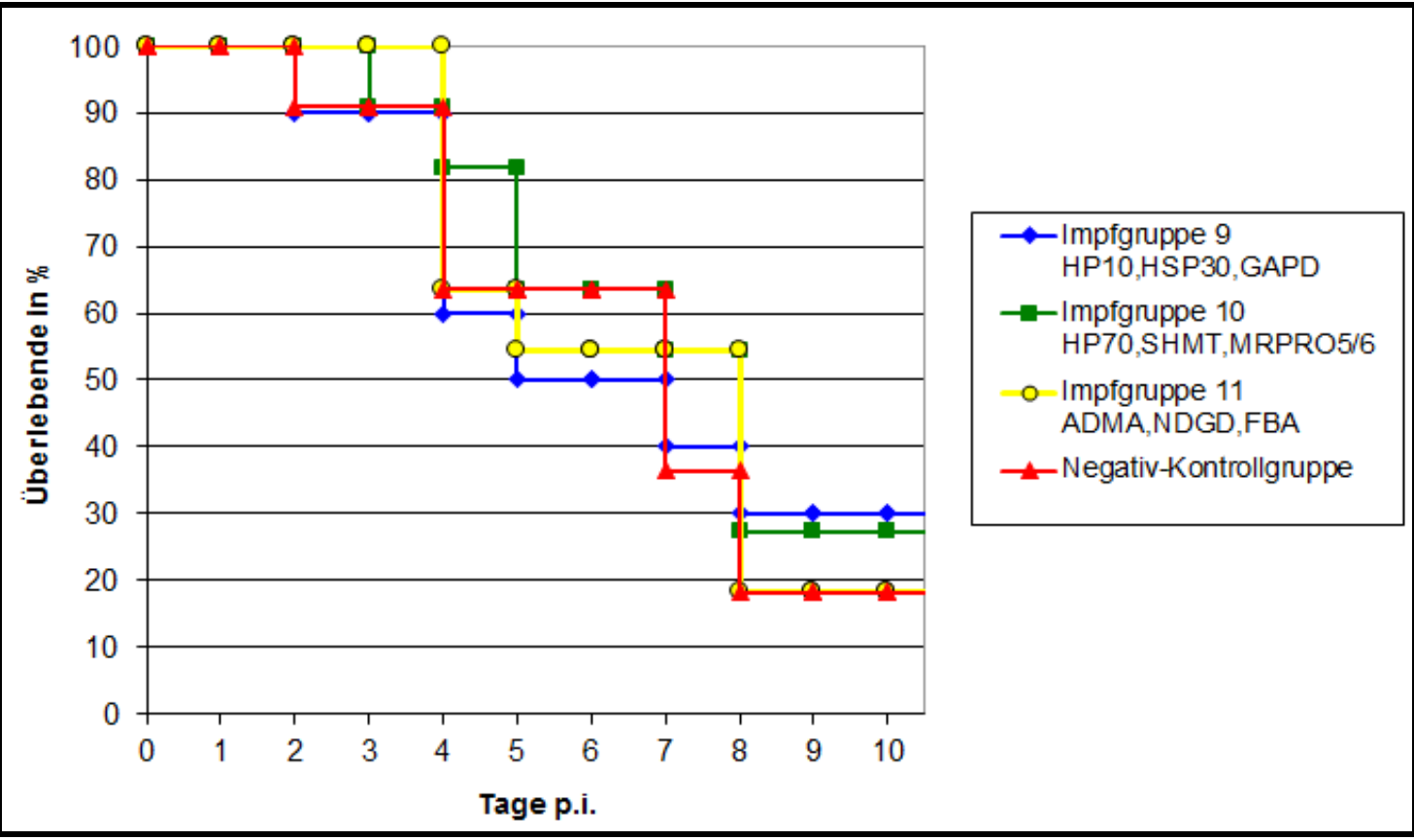

Abb. 31: Prozentualer Anteil an überlebenden Mäusen aufgeführt für jeden der zehn Beobachtungstage für die Impfgruppen 9, 10 und 11 im Vergleich zur Negativ-Kontrollgruppe.

Vereinzelte Verimpfung der Proteine des Impfstoffes 3 (Enolase, HSP90, TBP)

Der verabreichte Impfstoff 3 schien Erfolg versprechend (Abb. 28) und wurde daher, statt zu drei Proteinen in einem Kombinationsimpfstoff, verschiedenen Mausgruppe einzeln verimpft. So bekam eine Mausgruppe die Enolase verimpft, die Gruppe 2 HSP90, und der TBP wurde der Gruppe 3 verabreicht. Ein Vergleich der Kurvenverläufe (Abb. 32) ergab, dass mehr Mäuse in der Kontrollgruppe starben als in den jeweils anderen Gruppen. Doch die Auswertung der Überlebenskurven der jeweiligen Impfgruppe und der Kontrollgruppe erbrachte keine signifikante Protektion durch einen der einzelnen Impfstoffe (Enolase: P=0,4379; TBP: P=0,1450; HSP90: $\mathrm{P}=0,0848)$. 


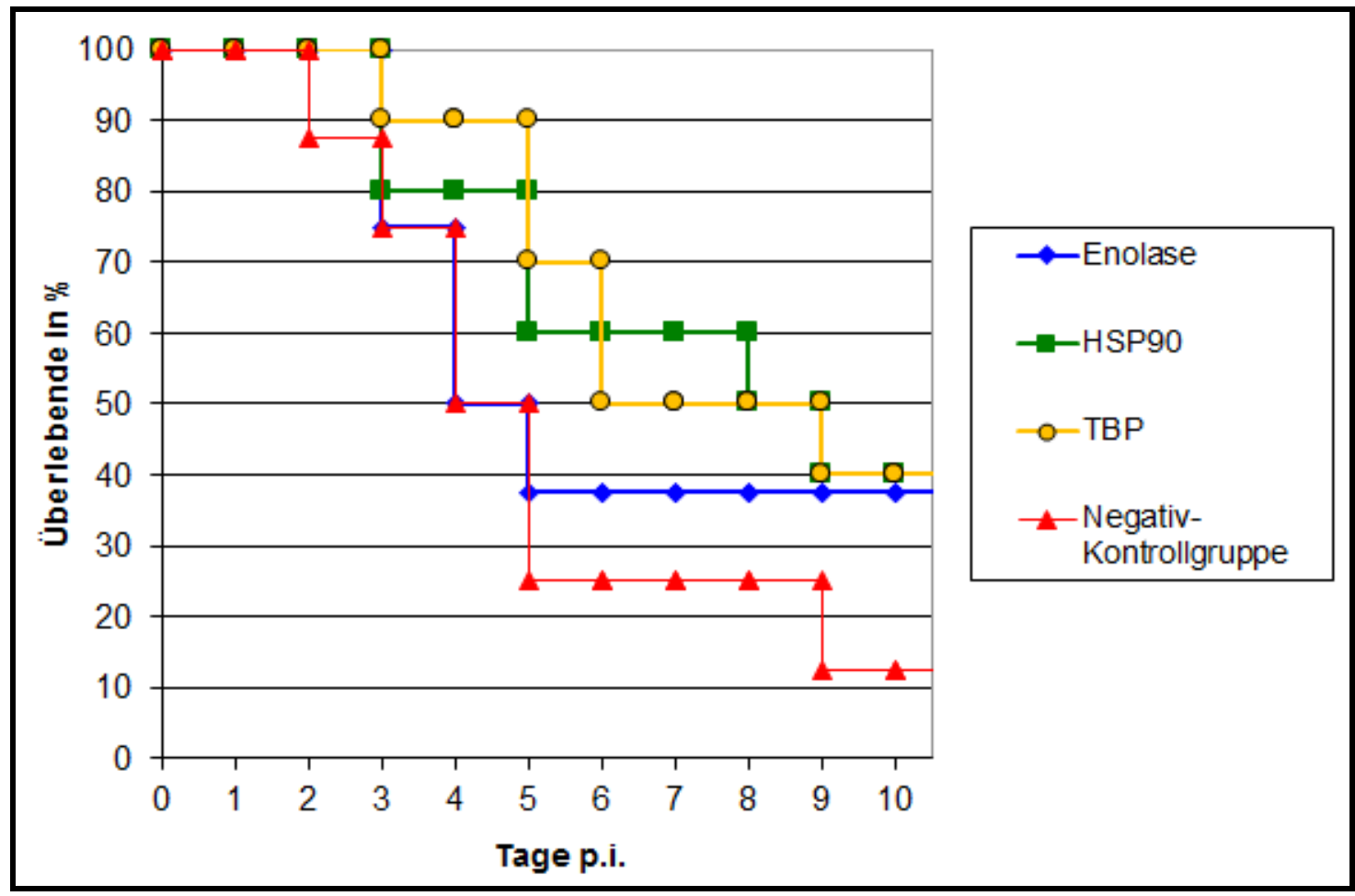

Abb. 32: Prozentualer Anteil an überlebenden Mäusen aufgeführt für jeden der zehn Beobachtungstage für drei verschiedene Gruppen, denen einzelne Impfproteine verabreicht wurden im Vergleich zur Negativ-Kontrollgruppe.

Wiederholung der Impfgruppe 3 (Enolase, HP90, TBP) und Impfgruppe 7 (MIPS, PGM, PGM3/4)

Die verabreichten Impfstoffe 3 und 7 sahen in Bezug auf den prozentualen Anteil überlebender Mäuse je Tag p.i. in den einzelnen Gruppen sehr vielversprechend aus (Abb. 28 und Abb. 30) und die Verimpfung dieser beiden Impfstoffe wurde zur Bestätigung ein zweites Mal durchgeführt. Ein Vergleich der Überlebenskurven (Abb. 33) von Impfgruppe 3 bzw. 7 und der Kontrollgruppe erbrachte keinen schützenden Effekt durch einer der jeweiligen Impfstoffe (Impfgruppe 3: $\mathrm{P}=0,2510$ und Impfgruppe 7: $\mathrm{P}=0,5785)$. 


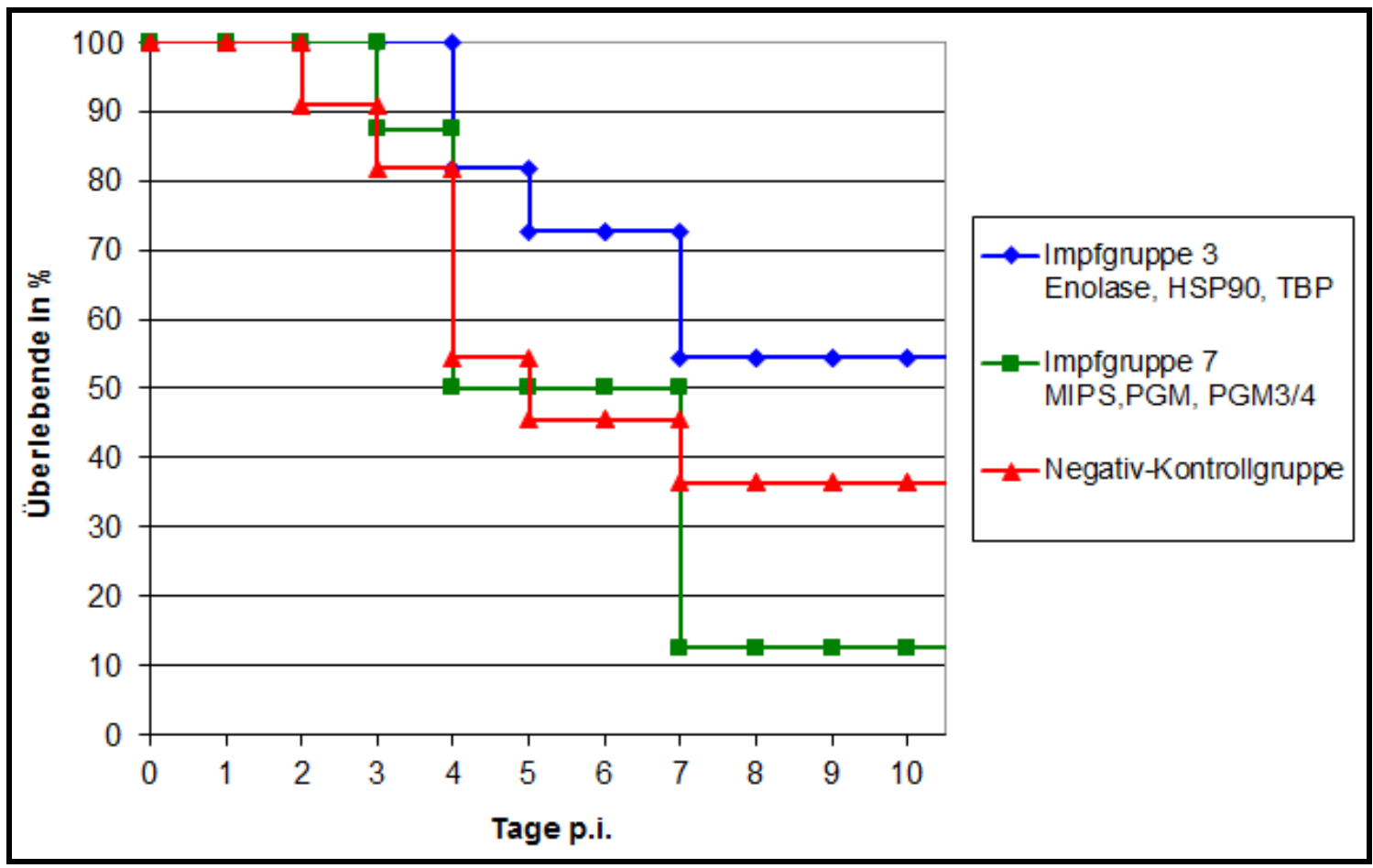

Abb. 33: Prozentualer Anteil an überlebenden Mäusen aufgeführt für jeden der zehn Beobachtungstage für die Impfgruppe 3 und 7 im Vergleich zur Negativ-Kontrollgruppe.

\subsection{Virulenztestung der A.fumigatus-Deletionsmutanten im Vergleich zu ihrer Komplementmutanten und dem Wildtyp D141}

Erste Testung: Deletionsmutante $\Delta$ HP16 im Vergleich zum Wildtyp D141

Zehn Mäuse wurden mit der Deletionsmutante $\Delta$ HP16 infiziert und mit einer Gruppe von zehn mit dem Wildtyp D141 infizierten Mäusen verglichen. In Abb. 34 sind die Ergebnisse nach einem Beobachtungszeitraum von 10 Tagen dargestellt. In der Gruppe, die den Wildtyp D141 verabreicht bekam, starben alle Mäuse bis auf eine in den ersten 7 Tagen. Im Gegensatz dazu starben in der Gruppe, die mit der Deletionsmutante infiziert wurde, nur vier von zehn Mäusen. Der Virulenzunterschied ist als signifikant anzusehen $(* \mathrm{P}=0,0115)$. 


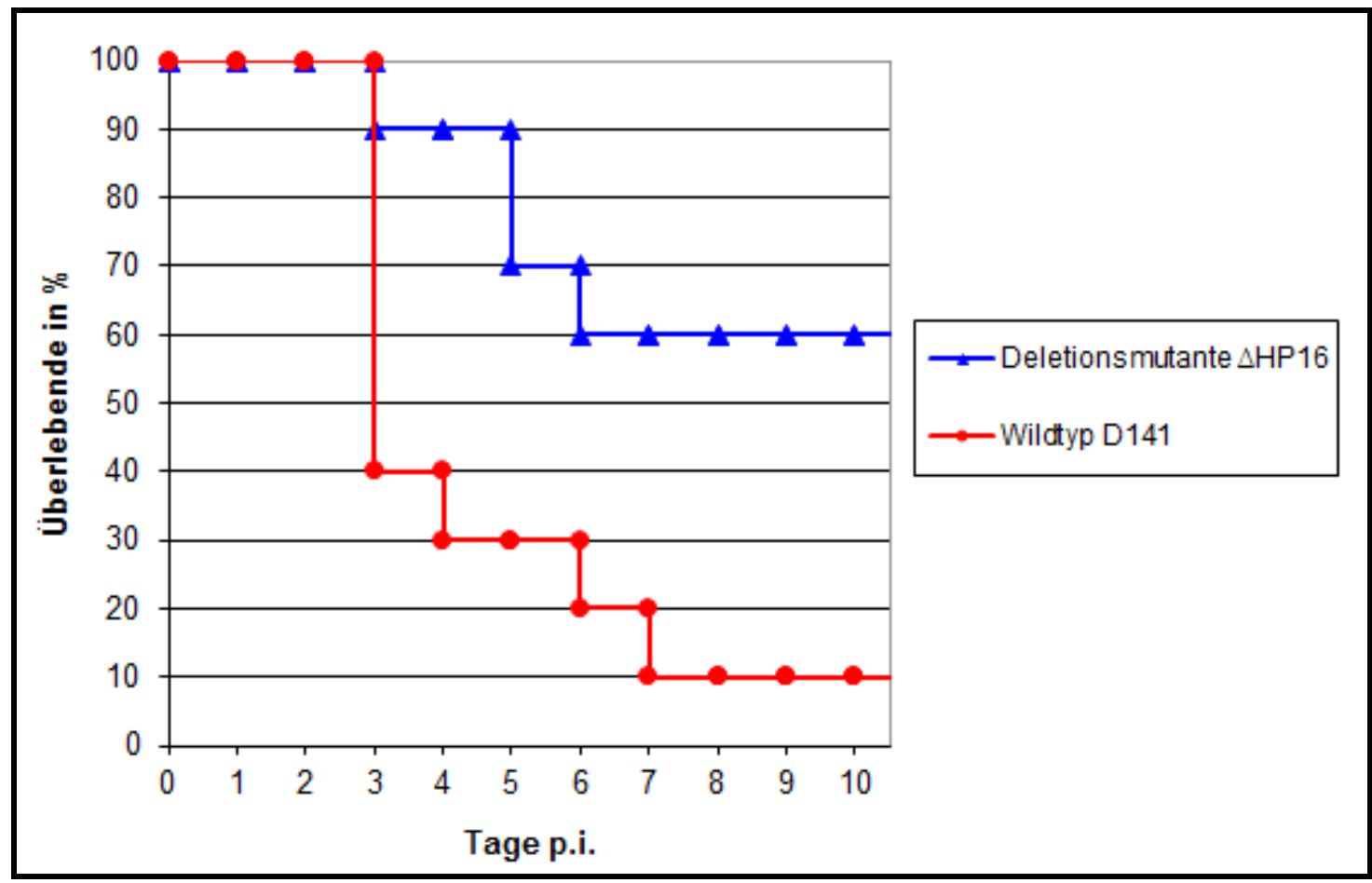

Abb. 34: Prozentualer Anteil an überlebenden Mäusen aufgeführt für jeden der zehn Beobachtungstage für die Infizierung mit der Deletionsmutante $\Delta$ HP16 im Vergleich zu Wildtyp D141.

\section{Zweite Testung: Deletionsmutante $\Delta \mathrm{HP} 16$, Komplementmutante $\Delta \mathrm{HP} 16^{\mathrm{K}}$ und Wildtyp}

Auf Grund der signifikanten Virulenzminderung der Deletionsmutante $\Delta$ HP16 wurde zur Bestätigung der molekularen Kausalität eine Komplementmutante $\Delta \mathrm{HP}^{\mathrm{K}}{ }^{\mathrm{K}} \mathrm{zu}$ dieser hergestellt (s. 3.1.2). Alle Mutanten und der Wildtyp D141 wurden anschließend im Vergleich von der kooperierenden Arbeitsgruppe unter der Leitung von Herrn Prof. Dr. Axel Brakhage am Leibniz-Institut für Naturstoff-Forschung und Infektionsbiologie, Hans Knöll Institut (HKI) in Jena, hinsichtlich ihrer Virulenz im Mausmodell getestet. Der Versuch wurde mit CD-1 Mäusen (Auszuchtstamm, 18-20g, 6-8 Wochen), die in individuell ventilierten Käfigen gehalten wurden, durchgeführt. Die Versuchsdurchführung entsprach ansonsten weitestgehend der unter 2.6.3 und 2.6.4 beschriebenen Vorgehensweise.

Je zehn Mäuse wurden mit der Deletionsmutante $\Delta \mathrm{HP} 16$, der Komplementmutante $\Delta \mathrm{HP} 16^{\mathrm{K}}$ und dem Wildtyp D141 infiziert. Außerdem wurde noch eine weitere Kontrollgruppe eingesetzt, die mit keinem der Aspergillus-Stämme infiziert wurde und stattdessen nur PBS verabreicht bekam. In Abb. 35 sind die Ergebnisse nach einem 
Beobachtungszeitraum von 14 Tagen dargestellt. In den Gruppen, die die Komplementmutante bzw. den Wildtyp D141 verabreicht bekamen, starben mehr Mäuse bzw. mussten mehr Mäuse getötet werden. Dies waren neun von zehn Mäusen für die Komplementmutante und alle Mäuse für den Wildtyp. Die bereits im ersten Versuch festgestellte signifikante Virulenzminderung ließ sich bestätigen. Es sind sowohl der Virulenzunterschied zwischen der Deletionsmutante $\Delta$ HP16 und dem Wildtyp D141 (**P=0,0019), als auch der Virulenzunterschied zwischen der Deletionsmutante $\Delta \mathrm{HP} 16$ und der Komplementmutante $\Delta \mathrm{HP} 16^{\mathrm{K}}(* * \mathrm{P}=0,0043)$ als hoch signifikant anzusehen. Die Komplementmutante zeigte sich hingegen mit nicht signifikanter Virulenzminderung gegenüber dem Wildtyp $(\mathrm{P}=0,4435)$.

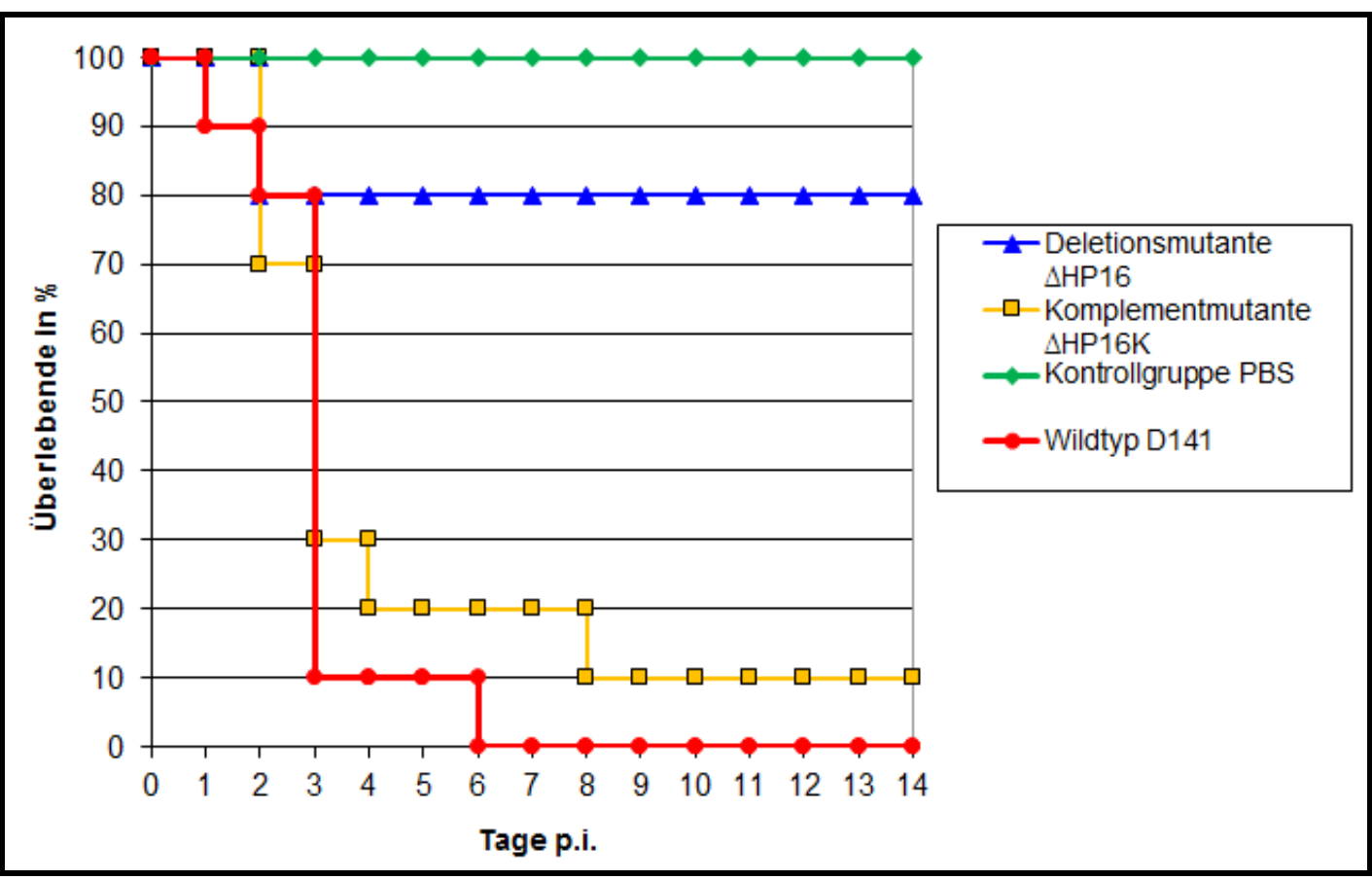

Abb. 35: Prozentualer Anteil an überlebenden Mäusen aufgeführt für jeden der 14 Beobachtungstage für die Infizierung mit der Deletionsmutante $\Delta H P 16$, der Komplementmutante $\Delta$ HP16 $^{\mathrm{K}}$, dem Wildtyp D141 und der Kontrollgruppe.

Deletionsmutante $\Delta$ Aspf3, Komplementmutante $\Delta$ Aspf $3^{\mathrm{K}}$ und Wildtyp D141

Elf Mäuse wurden mit der Deletionsmutante $\Delta$ Aspf3 bzw. der Komplementmutante $\Delta \mathrm{Aspf}^{\mathrm{K}}$ infiziert und mit einer Gruppe von elf mit dem Wildtyp D141 infizierten Mäusen verglichen. In Abb. 36 sind die Ergebnisse nach einem Beobachtungszeitraum von 10 Tagen dargestellt. In der Gruppe, die den Wildtyp D141 verabreicht bekam, 
starben alle Mäuse bis auf eine in den ersten 7 Tagen. Im Gegensatz dazu überlebten in der Gruppe, die mit der Deletionsmutante infiziert wurde, alle Mäuse. In der Gruppe, welche die Komplementmutante verabreicht bekam, starben vier von 11 Mäusen.

Der Virulenzunterschied zwischen der Deletionsmutante $\Delta$ Aspf3 und dem Wildtyp D141 ist höchst signifikant $(* * * \mathrm{P}=0,0001)$. Dahingegen zeigte sich der Virulenzunterschied zwischen der Deletionsmutante $\Delta$ Aspf3 und der Komplementmutante $\Delta \mathrm{Aspf}^{\mathrm{K}}$ nur als hoch signifikant (**P=0,0306). Somit konnte bei der Komplementmutante keine vollständige Restauration der Virulenz erzielt werden.

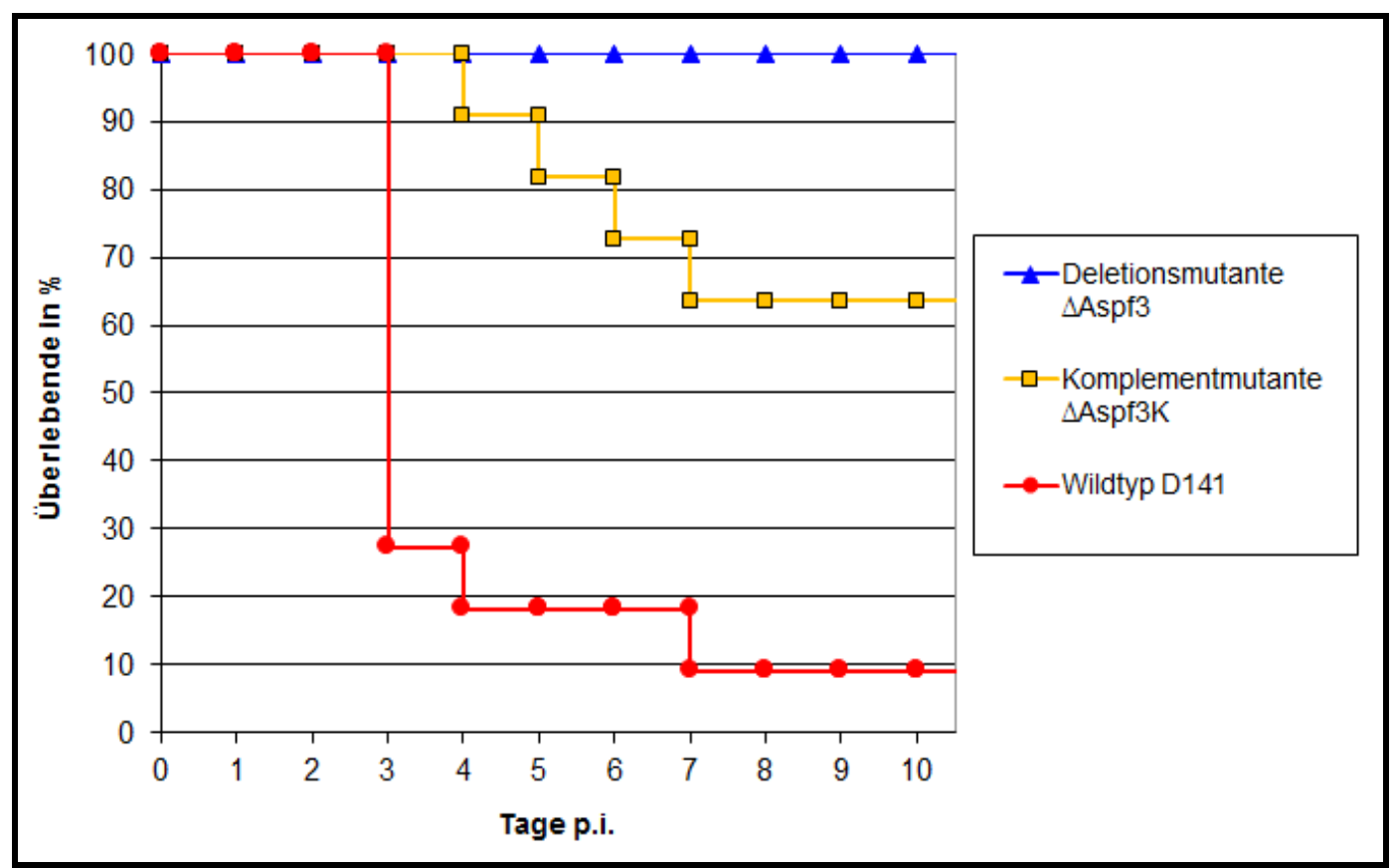

Abb. 36: Prozentualer Anteil an überlebenden Mäusen aufgeführt für jeden der zehn Beobachtungstage für die Infizierung mit der Deletionsmutante $\Delta$ Aspf 3 und der Komplementmutante $\Delta \operatorname{Aspf}^{\mathrm{K}}$ im Vergleich zu Wildtyp D141. 


\section{Diskussion}

\subsection{Deletionsmutante $\quad$ HHP16 eines ausgewählten}

\section{Konidienoberflächenproteins von A.fumigatus}

A.fumigatus ist als ein fakultativ pathogener Schimmelpilz anzusehen, denn beim gesunden immunkompetenten Menschen werden die eingeatmeten Konidien durch die angeborene Immunität abgetötet. Doch bei immunsupprimierten Menschen, z.B. organtransplantierten Patienten oder Patienten mit Leukämie, kann diese Resistenz versagen und eine invasive Infektion sich etablieren [70]. Dabei ist A.fumigatus der häufigste Erreger invasiver, meist tödlich verlaufender Schimmelpilzmykosen stark immunsupprimierter Patienten. Für das Verständnis der Pathogenese ist dabei die Suche nach den an ihr beteiligten Faktoren entscheidend. Dabei vermittelt die Konidienoberfläche den ersten Kontakt mit menschlichen Zellen und ist so in die primäre Phase der Infektion eingebunden [15]. Oberflächenproteine könnten in dieser initialen Phase der Infektion z.B. über eine Beeinflussung von Adhärenz und Phagozytose oder auch immunologische Modulationen (z.B. Antigenmaskierung) wirken und so gegebenenfalls als pharmakologische Targets oder auch Impfstoffkandidaten in Frage kommen.

In dieser Arbeit konnte im Tierversuch bewiesen werden, dass das hypothetische Konidienoberflächenprotein (HP) HP16 entscheidend an der Virulenz von A.fumigatus beteiligt ist. Das Protein HP16 wurde zur Untersuchung ausgewählt, da es zuvor in der Arbeitsgruppe von Herrn Prof. Dr. Utz Reichard (Göttingen) [15] mit Hilfe einer zweidimensionalen Gelektrophorese (2-D) als eines der dominanten Konidienoberflächenproteine dargestellt (Abb. 37) werden konnte. Für das 2-D-Gelbild wurden die Proteine eines Extraktes der Konidienoberfläche anhand ihres isoelektrischen Punktes und nach Größe getrennt. Die Proteine wurden anschließend massenspektrometrisch analysiert und mit Hilfe des Genomprojektes identifiziert [71]. Die Funktion einiger dieser Proteine ist unbekannt. Bei Betrachtung des 2-D-Gelbildes imponiert das Protein 18 (Abb. 37, durch grüne Pfeile markiert). Es handelt sich hierbei um ein bekanntes Protein, das RodA (AFUA_5G09580), das einen wichtigen Teil der konidialen Zellwand, die sogenannte Rodlet-Schicht, ausbildet [30]. Eine weitere prominente Spotgruppe konnte dem HP16 (Abb. 37, durch rote Markierungen 
gekennzeichnet) zugeordnet werden. Diese multiplen Spots könnten z.B. durch partielle Degradation oder verschiedene Glykolisierungszustände bedingt sein. Das für HP16 kodierende Gen wurde in dieser Arbeit durch ein Gen-Replacement selektiv aus dem Genom von A.fumigatus entfernt (Abb. 5).

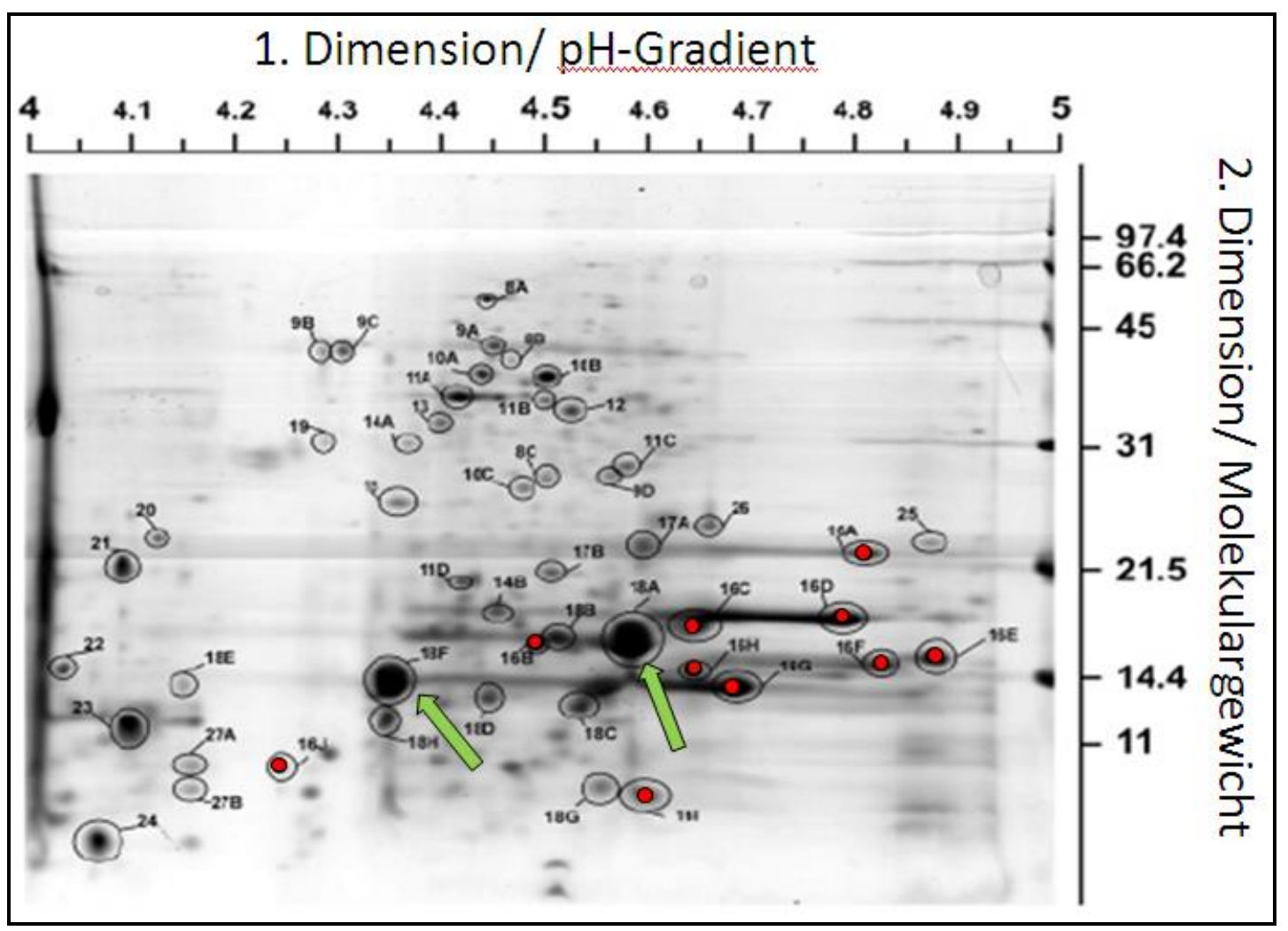

Abb. 37: 2-D-Gelbild von extrahierten A.fumigatus-Konidienoberflächenproteinen nach Auftrennung anhand ihres isoelektrischen Punktes und ihrem Molekulargewicht. Grüne Pfeile: RodA; rote Markierungen: HP16.

\subsection{Untersuchung des hypothetischen Proteins HP16}

Das Protein HP16 wurde zuvor als Konidienoberflächenprotein identifiziert [15]. Suh et al. untersuchten 2012 die Proteine des Konidien-Proteoms zu verschiedenen Zeitpunkten der Konidienentwicklung [72], wobei HP16 ausschließlich auf ruhenden Konidien gefunden wurde.

Das Protein HP16 ist somit kein „hypothetisches“ Protein mehr, sondern ein real existierendes Protein mit noch nicht vollständig bekannter Funktion (es wir hier aber weiter als HP16 bezeichnet). Da bei der de novo-Sequenzierung im Zusammenhang mit der Spotanalyse von Asif et al. [15] keine vollständige Sequenzierung des Proteins 
erfolgte, wurden die im Genomprojekt [71] anotierten und abgeleiteten Nukleotid- und Aminosäuresequenzen mit gängigen Onlinetools untersucht (Abb. 38). Die NukleotidSequenz umfasst 757 bp und beinhaltet ein hypothetisches Intron (16-64). Die ASSequenz umfasst 235 AS, wobei die errechnete Molekularmasse bei 25,5 kDa liegt. Das Protein besitzt sechs Cysteinreste, die theoretisch die Ausbildung von drei intramolekularen Disulfidbrücken zulassen.

\begin{tabular}{|c|c|c|c|c|c|c|c|c|c|c|c|c|c|c|c|c|c|c|c|c|c|c|}
\hline & CAT & $\mathrm{TAC}$ & $\mathrm{TCT}$ & $\mathrm{CAG}$ & $g^{t g}$ & & & at & oto & $t$ & $t 00$ & $a g 9$ & $a g c$ & $\operatorname{tg} g$ & $c c c$ & att & $\operatorname{sct}$ & gat & tat & $c c a$ & $g$ & TTC \\
\hline M & $\mathrm{H}$ & $\mathrm{Y}$ & 5 & $Q$ & & & & & & & & & & & & & & & & & & \\
\hline GTC & $\mathrm{ACC}$ & GTG & $G C \dot{A}$ & $\mathrm{TCA}$ & GCG & CTC & GCG & $\mathrm{CTG}$ & GCG & $\mathrm{CCT}$ & $\mathrm{ACC}$ & GCC & GTT & GTT & GCT & CGC & $\mathrm{CMG}$ & GGC & $\mathrm{GCC}$ & GCT & GCC & TTC \\
\hline V & $\mathrm{T}$ & $\mathrm{v}$ & A & $\mathrm{s}$ & A & L & A & L & A & P & $\mathrm{T}$ & A & $\mathrm{v}$ & $\mathrm{v}$ & A & R & $\mathrm{Q}$ & G & A & A & A & $\mathrm{F}$ \\
\hline GTC & $\mathrm{ACA}$ & GTG & $\mathrm{MiC}$ & TCG & ATM & $\mathrm{GMC}$ & GTT & TGT & $\mathrm{CCC}$ & $\mathrm{AAB}$ & $\mathrm{AMG}$ & GTG & $\mathrm{GCC}$ & $\mathrm{CAG}$ & GMM & $\operatorname{ATC}$ & $\mathrm{ATC}$ & $\mathrm{AMT}$ & CCG & GGA & CCG & $\mathrm{M} \mathrm{MG}$ \\
\hline $\mathrm{V}$ & $\mathrm{T}$ & $\mathrm{v}$ & $\mathrm{N}$ & $\mathrm{s}$ & I & D & $\mathrm{v}$ & C & $\mathrm{P}$ & $\mathrm{K}$ & $\mathrm{K}$ & $\mathrm{v}$ & $\hat{\mathbf{A}}$ & $Q$ & $\mathrm{E}$ & I & I & $\mathrm{N}$ & $\mathrm{P}$ & G & P & $\mathrm{K}$ \\
\hline GT & GTT & $\mathrm{ACC}$ & ACG & $\mathrm{CCC}$ & TAC & $\mathrm{ACT}$ & TGC & GMT & $\mathrm{CAM}$ & GTG & $\mathrm{AMG}$ & CTC & GGT & CAT & GGC & CTG & GAC & GTG & $\mathrm{TCC}$ & $\mathrm{TAC}$ & TAC & $\mathrm{AMC}$ \\
\hline $\mathrm{V}$ & $\mathrm{V}$ & $\mathrm{T}$ & $\mathrm{T}$ & $P$ & $\mathrm{Y}$ & $\mathrm{T}$ & C & D & $\mathrm{Q}$ & $\mathrm{V}$ & $\mathrm{K}$ & $\mathrm{L}$ & G & $\mathrm{H}$ & G & $\mathrm{L}$ & D & $\mathrm{V}$ & $\mathrm{s}$ & $\mathrm{Y}$ & $\mathrm{Y}$ & $\mathrm{N}$ \\
\hline TTC & GAC & ATC & $\mathrm{GMG}$ & $\operatorname{ccc}$ & СTC & $\mathrm{ACC}$ & $\mathrm{AMG}$ & $\mathrm{GAC}$ & $\mathrm{ACC}$ & TTT & $\mathrm{CCT}$ & $\mathrm{TACC}$ & TGC & AMG & GCT & CTC & $\triangle A M G$ & GTC & TTT & $\mathrm{GBC}$ & $\mathrm{AMC}$ & $\mathrm{GHA}$ \\
\hline $\mathrm{F}$ & D & I & $\mathrm{E}$ & P & $\mathrm{L}$ & $\mathrm{T}$ & $\mathrm{K}$ & D & $\mathrm{T}$ & $\mathrm{F}$ & P & $\mathrm{Y}$ & $\mathrm{C}$ & $\mathrm{K}$ & A & $\mathrm{L}$ & $\mathrm{K}$ & $\mathrm{V}$ & $\mathrm{F}$ & & $\mathrm{N}$ & E \\
\hline $\begin{array}{l}\text { GGT } \\
G\end{array}$ & TGC & CTG & GGC & TTC & CCT & $\mathrm{ACT}$ & TT & TGG & $\mathrm{ATC}$ & $\mathrm{CCC}$ & CTC & GMG & AGC & $\mathrm{CCA}$ & CTT & $\mathrm{GMG}$ & $\mathrm{GAC}$ & $\mathrm{AMG}$ & TGC & $\mathrm{ATC}$ & $\mathrm{CCT}$ & GA A \\
\hline $\mathrm{CAC}$ & TAC & TTC & $\mathrm{AGC}$ & GaC & GMS & GTG & $B M G$ & TCT & ITC & TCG & TTC & $\mathrm{CHG}$ & CTT & GAT & $T G C$ & CGC & GUG & GOC & $\mathrm{GCC}$ & $\mathrm{CCT}$ & GTC & $M G$ \\
\hline $\mathrm{H}$ & $\mathrm{Y}$ & $\mathrm{F}$ & 5 & D & $\mathrm{E}$ & $\mathrm{V}$ & $\mathrm{K}$ & 5 & I & 5 & $\mathrm{~F}$ & $Q$ & $\mathrm{~L}$ & D & C & $\mathrm{R}$ & $\mathrm{E}$ & D & A & $\mathrm{P}$ & $\mathrm{V}$ & $\mathrm{K}$ \\
\hline$M A G$ & $G \not G G$ & $\mathrm{CCA}$ & TÄT & GGC & $\mathrm{CCT}$ & $\mathrm{MHG}$ & $\mathrm{GAG}$ & GGG & GCT & GAM & $\mathrm{CH}$ & $\mathrm{TCT}$ & $G C A$ & $\mathrm{CCG}$ & $\mathrm{CMG}$ & $G \mathrm{CA}$ & $\mathrm{GHG}$ & CAT & $\hat{\mathrm{A} G T}$ & $\mathrm{ACT}$ & 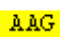 & $\mathrm{CAG}$ \\
\hline $\mathrm{K}$ & E & P & $\mathrm{Y}$ & G & P & $\mathrm{K}$ & $\mathrm{E}$ & G & A & E & $\mathrm{Q}$ & $\mathrm{s}$ & A & P & $Q$ & A & E & $\mathrm{H}$ & $\mathrm{s}$ & $\mathrm{T}$ & $\mathrm{K}$ & $Q$ \\
\hline GAC & GCT & CMg & $\mathrm{CAG}$ & GGT & TCT & $\mathrm{CAC}$ & CAG & GGA & $\mathrm{CAG}$ & $\mathrm{GMG}$ & GTG & $\mathrm{CAG}$ & $\mathrm{MAC}$ & $\mathrm{A} G \mathrm{C}$ & $\mathrm{CCT}$ & $\mathrm{MHG}$ & $\mathrm{CAG}$ & $\mathrm{GMG}$ & GCT & CGC & $\mathrm{CH}$ & GGT \\
\hline D & $\hat{\mathbf{A}}$ & $Q$ & $Q$ & G & s & $\mathrm{H}$ & $Q$ & G & $\mathrm{Q}$ & $\mathrm{E}$ & $\mathrm{V}$ & $Q$ & $\mathrm{~N}$ & 5 & P & $\mathrm{K}$ & $Q$ & $\mathrm{E}$ & $\grave{A}$ & $\mathrm{R}$ & $Q$ & G \\
\hline $\mathrm{TCC}$ & AGG & CCG & $G C A$ & $G M G$ & GCT & GCT & $\mathrm{CCT}$ & AMG & $\mathrm{CH} \mathrm{G}$ & $\mathrm{GMG}$ & $\mathrm{CAG}$ & GAM & $G C T$ & $\mathrm{GMG}$ & $\mathrm{CM}$ & $G C T$ & $\mathrm{TCT}$ & $\mathrm{GMG}$ & $G C A$ & GCG & $\mathrm{CCC}$ & $\mathrm{GMG}$ \\
\hline $\mathrm{s}$ & $\mathrm{R}$ & P & A & $\mathrm{E}$ & A & $\mathrm{A}$ & $P$ & $\mathrm{~K}$ & $Q$ & $\mathrm{E}$ & $Q$ & $\mathrm{E}$ & A & $\mathrm{E}$ & $Q$ & A & s & $\mathrm{E}$ & a & A & P & $\mathrm{E}$ \\
\hline MAM & $A M G$ & $\mathrm{GCC}$ & $\mathrm{TCM}$ & $\triangle A C$ & $\mathrm{CCT}$ & GCT & $\mathrm{GMC}$ & AGT & CTC & GGC & CTG & GGC & GMA & CTC & $\mathrm{ACA}$ & $M \mathrm{MG}$ & GTG & CTC & GGT & TTC & CGG & \\
\hline $\mathrm{K}$ & $\mathrm{K}$ & A & $\mathrm{s}$ & $\mathrm{N}$ & P & A & D & $\mathrm{s}$ & L & G & $\mathrm{L}$ & G & $\mathrm{E}$ & L & $\mathrm{T}$ & $\mathrm{K}$ & $\mathrm{V}$ & $\mathrm{L}$ & G & $\mathrm{F}$ & $\mathrm{R}$ & * \\
\hline
\end{tabular}

Abb. 38.: Nukleotid- und Proteinsequenz von HP16. Start- und Stoppcodon sind rot und die Cysteinreste grün markiert. Das Intron ist kursiv dargestellt und die wahrscheinliche Schnittstelle für die Signalpeptidase ist mit einem blauen Balken markiert (in Anlehnung an Aspergillus Genome Database; http://www.aspgd.org/).

Mit dem NCBI-BLAST-Programm (http://blast.ncbi.nlm.nih.gov) konnten deutliche Homologien mit konservierten, hypothetischen, nicht-charakterisierten Proteinen anderer Aspergillus-Arten gefunden werden. Die Proteine mit der größten Übereinstimmung gehören zu den folgenden Spezies: A.fischerianus (83 \%), A.clavatus (36\%) und A.nidulans (29\%). Der Kyte/Doolittle-Hydropathie-Plot von HP16 erbrachte ein hydrophobes Profil am N-Terminus von HP16 (ProtScale; http://web.expasy.org/protscale). Für die Abschätzung der Hydrophobizität einzelner Sequenzabschnitte wird häufig der GRAVY-Wert genutzt, der einen repräsentativen Hydrophobizitäts-Mittelwert der AS-Zusammensetzung angibt [73]. Ein positiver 
GRAVY-Wert entspricht dabei einem hydrophoben Protein, während ein negativer GRAVY-Wert für ein hydrophiles Protein steht. Der Protein-GRAVY für HP16 liegt bei -0,543 (GRAVY Calculator; http://www.gravy-calculator.de). HP16 wird wahrscheinlich sezerniert, eine hypothetische Schnittstelle für die Signalpeptidase findet sich nach AS 22 (SignalP 4.1 Server; http://www.cbs.dtu.dk/services/SignalP). Mit Hilfe des „GPI prediction Tool“ (http://mendel.imp.ac.at/gpi/cgibin/gpi_pred_fungi.cgi) konnte keine eindeutige GPI-Modifikationsstelle erkannt werden. Der beste Score fand sich für die AS 218.

\subsection{Mausmodell zur invasiven Aspergillose}

Das Mausmodell zur IA ist weltweit das gebräuchlichste und auch das einzige, an dem die intranasale Infektion mit A.fumigatus-Konidien standardisiert ist. Der Verlauf der Infektion kommt der Lungen-Aspergillose beim Menschen sehr nahe. In vitro-Versuche an Zelllinien hingegen lassen keinen Rückschluss auf komplexe Immunreaktionen zu. Aus ethischen Gründen verbieten sich, in der jetzigen Phase der Untersuchungen, Versuche am Menschen.

Primär entscheidend für die Abwehr von A.fumigatus-Infektionen sind unspezifische Mechanismen des angeborenen Immunsystems durch Granulozyten, Makrophagen und Komplementsystem [74]. Allerdings lässt sich im Tierversuch auch eine erworbene, schützende Immunität gegen die Infektion induzieren. So bildet sich diese im Tier aus, sowohl nach einer überlebten systemischen Infektion mit dem Pilz, als auch nach einer Verimpfung von A.fumigatus-Kulturüberstand. Bei dieser protektiven Immunreaktion sind besonders die Th1-Zellen mit ihren Zytokinen beteiligt [50-52].

Zur Etablierung eines Mausmodells zur IA wurden die ersten Vorversuche in Anlehnung an Veröffentlichungen anderer Arbeitsgruppen durchgeführt [41,64,75,76], und nach einigen Optimierungen konnte ein eigenes modifiziertes Mausmodell etabliert werden. Dabei musste die Frage nach der Verwendung eines leukopenischen oder nichtleukopenischen Mausmodells beantwortet werden. Für das leukopenische Mausmodell wird zur Immunsuppression sowohl Cortisonacetat als auch Cyclophosphamid verwendet $[75,77,78]$. Das nicht-leukopenische Mausmodell verwendet dahingegen nur Cortisonacetat zur Immunsuppression [41,77,79]. Im leukopenischen Modell ist eine zelluläre Immunantwort praktisch nicht vorhanden und die Entwicklung der IA ist 
gekennzeichnet durch umfangreiches invasives Pilzwachstum [80]. Es eignet sich zur Überprüfung von Virulenzfaktoren auf Pilzseite, allerdings nicht zur Beurteilung einer Immunreaktion auf Wirtsseite [77]. Im Gegensatz dazu ermöglicht das CortisonacetatModell die Rekrutierung von Leukozyten aller Art, die, trotz teilweise eingeschränkter Phagozytose, Pilzzellen angreifen und die schnelle Pilzverbreitung verhindern [81]. Erworbene Immunreaktionen können nach wie vor stattfinden. Das nicht-leukopenische Modell eignet sich deshalb sowohl zur Beurteilung einer Immunreaktion als auch für Virulenztestungen. In unserem Fall wurde deshalb dieses Modell etabliert.

Der erste Versuch zur Dosisfindungsstudie (s. 3.4) erfolgte zunächst mit NMRI-Mäusen (Auszuchtstamm). Da eine relativ weite Spreizung bei der Suche nach der optimalen Infektionsdosis beobachtet wurde, trafen wir dann die Entscheidung, auf Wirtsseite eine größere Uniformität durch die Verwendung von Inzuchtmäusen $(B A L B / c)$ zu gewährleisten.

In der Literatur sind die Mengenangaben verabreichter Konidien im Zuge der Infektion sehr verschieden. Die Infektionsdosen lagen bei $10^{5}, 10^{6}, 2 \times 10^{6}$ oder $3 \times 10^{6}$ Konidien, wobei auch unterschiedliche Mäusestämme verwendet wurden [60,63,64,76,82]. Die Dosisfindungsstudie (s. 3.4) war auch notwendig, da A.fumigatus-Wildstämme unterschiedliche natürliche Virulenzen aufweisen [83]. In jedem Fall musste die optimale Infektionsdosis in Abhängigkeit von den von uns verwendeten Bedingungen auf Wirts- und Pathogenseite eruiert werden. Der Verlauf des prozentualen Anteils überlebender Mäuse war für die Maus-Gruppe, die mit 3×10 $10^{6}$ Konidien infiziert wurde, am besten verteilt (Abb. 26). Die Infektion mit den Konidien erfolgte dabei intranasal, was dem natürlichen Infektionsweg entspricht.

\subsection{Virulenzversuche mit dem hypothetischen Protein HP16}

Je zehn Mäuse wurden mit der Deletionsmutante $\Delta$ HP16 infiziert und mit einer Gruppe von zehn mit dem Wildtyp D141 infizierten Mäusen verglichen (Abb. 34). In der Gruppe, die mit der Deletionsmutante infiziert wurde, starben weniger Mäuse. Der Virulenzunterschied ist als signifikant anzusehen $(* \mathrm{P}=0,0115)$. Somit liegt eine deutlich verminderte Virulenz der Deletionsmutante vor. Um dieses Ergebnis zu bestätigen, wurde die Deletionsmutante $\Delta \mathrm{HP} 16$ zusammen mit der Komplementmutante $\Delta \mathrm{HP} 16^{\mathrm{K}}$ in einem zweiten Versuch hinsichtlich ihrer Virulenz untersucht (Abb. 35). Beim 
Vergleich der Überlebenskurven wurde deutlich, dass der Virulenzunterschied zwischen der Deletionsmutante $\Delta$ HP16 und dem Wildtyp D141 dieses Mal sogar als hoch signifikant anzusehen ist $(* * \mathrm{P}=0,0019)$. Auch der Virulenzunterschied zwischen der Deletionsmutante $\triangle \mathrm{HP} 16$ und der Komplementmutante $\Delta \mathrm{HP} 16^{\mathrm{K}}$ erbrachte ein hoch signifikantes Ergebnis (**P=0,0043). Um den kausalen Einfluss von HP16 auf die Virulenz nachzuweisen, sollten die Kernkriterien, der sogenannten Henle-Koch'schenPostulate, auf molekularer Ebene erfüllt sein [84]. Hierbei sollte die Deletion des entsprechenden Gens (Deletionsmutante $\Delta$ HP16) einen attenuierten oder avirulenten Phänotyp herbeiführen. Die Wiederherstellung der Genfunktion hingegen sollte zur vollständigen Rückkehr der ursprünglichen Virulenzeigenschaften führen. Mit Hilfe des Versuchsergebnisses konnte eine solche restaurierte Virulenz der korrespondierenden Komplementmutante gezeigt werden.

Durch die HP16-assoziierte Virulenz bietet sich HP16 als mögliches neues TherapieTarget an. Da HP16 zumindest in vitro vorwiegend auf Konidien lokalisiert zu werden scheint [15,72], könnte sich hier ein Angriffspunkt insbesondere für eine präemptive Therapie bzw. für eine Prophylaxe ergeben. Vorstellbar wäre, dass ein entsprechendes Effektormolekül zielgerichtet eine Funktion des HP16 blockiert oder alternativ seine Struktur maskiert. Da im Menschen keine dem PHP16 eng verwandten Proteine vorhanden sind (s. 4.2), besteht hier die Hoffnung, dass potenzielle Pharmaka keine oder wenige kreuzreagierende menschliche Strukturen finden. Dieses erhöht, zumindest theoretisch, die Chance auf die Entwicklung eines nebenwirkungsarmen Medikaments.

\subsection{Rekombinant hergestelltes Protein HP16}

Kann einem Molekül eine Virulenz-vermittelnde Eigenschaft zugesprochen werden, könnte dieses eventuell auch als Impfstoff geeignet sein. Vorstellbar wäre hier zum Beispiel eine Blockierung seiner Funktion durch Antikörper. Da im Mausmodell eine HP16-assoziierte Virulenz bewiesen wurde, sollte HP16 auch als rekombinantes Protein hergestellt werden, um dieses später im Mausmodell zu verimpfen und auf die Eignung als Impfstoff zu untersuchen.

Die Herstellung des rekombinanten Proteins HP16 erwies sich als sehr komplex. Trotz erfolgreicher Klonierungen ließ sich HP16 nur unzureichend exprimieren. Daher wurde im weiteren Verlauf des Versuchs ein synthetisches Gen mit optimierter „Codon Usage“ 
für E.coli verwendet. Das synthetische Gen wurde dafür noch weiter verändert. So fehlt dem Gen der Bereich des Signalpeptids (AS 1-22). Mit Hilfe des „GPI prediction Tool“ konnte zwar keine eindeutige GPI-Modifikationsstelle für HP16 erkannt werden, aber der beste Score wurde für die AS 218 festgelegt. Um eventuelle Probleme bei der rekombinanten Expression des Proteins zu umgehen, wurde das Gen daher um diese Sequenz (AS 219-235) verkürzt. Die sogenannte lange Version umfasste somit den ASBereich von 23-218.

Ein Vergleich der AS-Sequenz von HP16 mit dem Hydrophobin RodA (Abb. 39) erbrachte eine interessante Auffälligkeit, die möglicherweise doch auf eine GPIVerankerung von HP16 deuten könnte. Die beiden Sequenzen stimmten in einem kleinen Bereich überein. So ist AS 180-183 von HP16 identisch mit den AS 135-138 von RodA.

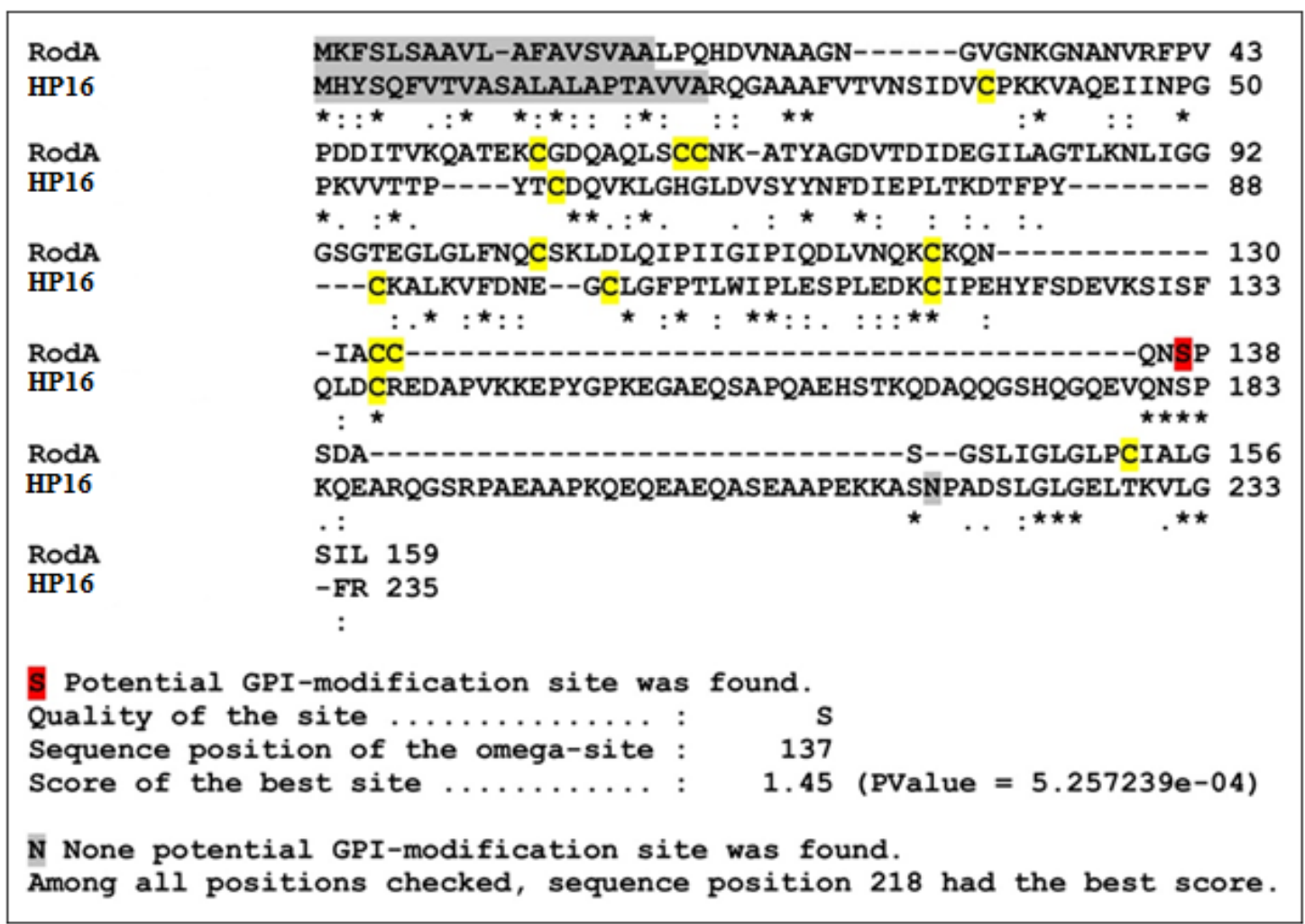

Abb. 39: Alignment der AS-Sequenz von HP16 mit RodA. Zur Verfügung gestellt von Dr. Peter Hortschansky, aus der Abteilung Molekulare und Angewandte Mikrobiologie am Leibniz-Institut für Naturstoff-Forschung und Infektionsbiologie, Hans Knöll Institut (HKI) in Jena (geringfügig modifiziert). Die Sequenzen wurden so gegenübergestellt, dass eine möglichst gute Übereinstimmung entsteht. Alle Cystein-Reste sind gelb unterlegt, alle weiteren identischen Aminosäuren mit einem Stern markiert. 
Das in der Abb. 39 rot markierte Serin (AS 137) charakterisiert bei RodA die GPIAnkersequenz. Dies war ausschlaggebend dafür, eine verkürzte Variante des synthetischen Gens herzustellen. Die sogenannte kurze Version umfasste somit den ASBereich von 23-182.

Viele Faktoren beeinflussen die Menge und Löslichkeit rekombinanter Proteine. Beispielhaft $\mathrm{zu}$ nennende Faktoren sind dabei die Art des Induktors, die Induktorkonzentration, die Lokalisierung des exprimierten Proteins und die gewählte Temperatur nach der Induktion $[85,86]$.

Die Aufreinigung von HP16 erfolgte über den His-Tag am N-Terminus mittels Ni-Sepharose. Bei der Herstellung des rekombinanten HP16 wurde die native Methode verwendet, bei der die Konformation des Proteins nicht zerstört wird. Die Aufreinigung des Proteins erfolgte nach dem Prinzip der Affinitätschromatographie durch das Histidin-Analogon Imidazol, wobei zur Elution des Proteins eine ansteigende Konzentration an Imidazol verwendet wurde.

Eine geringere Wachstumstemperatur (niedriger als $37^{\circ} \mathrm{C}$ ) $\mathrm{kann} \mathrm{zu}$ einem höheren Anteil an löslichem Protein führen [87]. So wurden die Hauptkulturen über Nacht bei $25^{\circ} \mathrm{C}$ inkubiert (s. 2.4.2). Eine besondere Form der Induktion des Proteins stellt die Verwendung eines Autoinduktionsmediums dar [88]. Das Medium besteht aus LBMedium mit Glukose, Glycerol, Laktose, Phosphatpuffer und $\mathrm{MgSO}_{4}$. Glukose ist das bevorzugte Substrat von E.coli und wird so zuerst verbraucht. Ist keine Glukose mehr vorhanden, stellt sich der Stoffwechsel auf Laktose um. In der Zwischenzeit dient Glycerol als Kohlenstoff-Quelle. Die Laktose wird zu Glukose und Galaktose verstoffwechselt, wobei letzteres die Proteinexpression induziert. Der Phosphatpuffer verhindert ein Absinken des $\mathrm{pH}$-Werts im Verlauf der Kultivierung, und das $\mathrm{MgSO}_{4}$ ist bei E.coli essenziell für das Erreichen höherer Zelldichten.

Im Gegensatz zur IPTG-Induktion, bei der in der Regel bei einer relativ niedrigen OD von 0,5 die Protein-Expression induziert wird, wachsen die Zellen bei der Verwendung eines Autoinduktionsmediums zunächst $\mathrm{zu}$ einer hohen Dichte an, bevor die Proteinexpression induziert wird. Dadurch kann eine insgesamt höhere Zelldichte erreicht werden. Die Hauptkultur wird mit einer Kolonie oder mit einer Vorkultur beimpft und kann nach ca. $16 \mathrm{~h}$ weiter bearbeitet werden, ohne dass man auf den richtigen Zeitpunkt, wie bei einer IPTG-basierten Induktion erforderlich, achten muss. 


\subsection{Versuche zu Aspf3}

Die Deletionsmutante $\Delta$ Aspf3 zeigte im Tierversuch eine stark verminderte Virulenz, und durch die Verwendung von Aspf3 als Impfstoff konnte sowohl in eigenen Versuchen als auch in Versuchen einer anderen Arbeitsgruppe [63] eine protektive Immunreaktion ausgelöst werden.

Alveolarmakrophagen sind die primären phagozytierenden Zellen innerhalb der Atemwege und somit eine wichtige Abwehrkomponente. An der Abtötung geschwollener Konidien durch Makrophagen sind unter anderem reaktive SauerstoffMetabolite (ROI) beteiligt [41]. Konidien, die den Alveolarmakrophagen entgangen sind, wachsen aus und werden durch Neutrophile angegriffen. Neutrophile heften sich an die Oberfläche der Hyphen. Dieser Kontakt zwischen Neutrophilen und Hyphen löst unter anderem die respiratorische Entladung und die Sekretion der ROI aus (zur Übersicht [89]). Mehrere Gene, die an der Abwehr gegen die ROI bei A.fumigatus beteiligt sind, konnten charakterisiert werden. Obwohl eine Deletion dieser Gene die Empfindlichkeit der jeweiligen Mutante gegenüber der ROI erhöht, konnte durch keine dieser Mutanten eine reduzierte Virulenz im Mausmodell herbeigeführt werden. Große Wichtigkeit wurde auch dem Schlüsseltranskriptionsregulator AfYap1 zugesprochen, der an der Regulation mehrerer Abwehrgene gegen ROI beteiligt ist [89]. Auch Aspf3 scheint zum Teil der AfYap1-Kontrolle zu unterliegen. Für dieses Molekül stand bislang jedoch eine genauere Untersuchung bezüglich seines Einflusses auf die Virulenz von Aspergillus aus.

Das Allergen Aspf3 wird von dem Pilz produziert [90], und es wird vermutet, dass es sich um ein peroxisomales Membranprotein handelt [91]. Es wurde jedoch auch in größerer Menge auf der Konidienoberfläche gefunden [15] und ruft sowohl bei einer experimentellen Infektion im Tier als auch nach einer invasiven Aspergillose im Menschen eine regelhafte Antikörperreaktion hervor [66]. Deshalb kann auch mit hoher Wahrscheinlichkeit von einer Produktion im Hyphenstadium ausgegangen werden.

\section{Wachstum unter oxidativem Stress}

Ausgehend von der hypothetischen Funktion von Aspf3 wurde von uns vermutet, dass es am Schutz der Pilze gegen oxidativen Stress durch Inaktivierung entsprechender Radikale beteiligt ist. Die Deletionsmutante $\Delta$ Aspf3 wies im Phänotyp eine starke Empfindlichkeit gegenüber Wasserstoffperoxid (Abb. 20) im Vergleich zu der 
Komplementmutante $\Delta \mathrm{Aspf}^{\mathrm{K}}$ oder dem Wildtyp D141 auf. Dies legt ebenfalls nahe, dass Aspf3 für eine Peroxireduktase kodiert. Da an der Abwehr von Sauerstoffradikalen eine Reihe weiterer Effektoren beteiligt sind [89], war eine so deutlich gesteigerte Empfindlichkeit gegenüber Wasserstoffperoxid (Abb. 20) nicht zwangsläufig zu erwarten. Dabei war zwar der Phänotyp der von uns generierten Komplementmutante $\Delta \mathrm{Aspf}^{\mathrm{K}}$ mit vollständig wieder hergestellter Resistenz des Hyphenwachstums unter Bedingungen des oxidativen Stresses ausgestattet. Jedoch fand sich bei den Wasserstoffperoxidkonzentrationen, bei denen die Deletionsmutante überhaupt kein Wachstum mehr zeigte, eine noch leicht eingeschränkte Sporulation (Abb. 21). Dieses könnte am ehesten darauf hinweisen, dass die erreichte Komplementierung funktionell nicht ganz vollständig gewesen ist, was auch die inkomplette Restauration der Virulenz im Tierversuch erklären könnte (s. unten).

\section{Virulenzversuche}

Mit den Aspf3-Mutanten wurde ein Virulenzversuch durchgeführt. Mäuse wurden mit der Deletionsmutante $\Delta \mathrm{Aspf3}$, der Komplementmutante $\Delta \mathrm{Aspf}^{\mathrm{K}}$ oder dem Wildtyp D141 infiziert (Abb. 36). Der Virulenzunterschied zwischen der Deletionsmutante $\Delta$ Aspf3 und dem Wildtyp D141 ist höchst signifikant (***P=0,0001), was einer drastischen Verminderung der Virulenz entspricht. Die Komplementmutante $\Delta \mathrm{Aspf}^{\mathrm{K}}$ zeigte allerdings nur eine teilweise wiederhergestellte Virulenz und somit keine vollständige Restauration.

Der aufgetretene Virulenzunterschied zwischen der Deletionsmutante $\Delta$ Aspf3 und der Komplementmutante $\Delta \mathrm{Aspf}^{\mathrm{K}}$ war eigentlich nicht zwangsläufig zu erwarten, denn eine Deletion des übergeordneten Schlüsseltranskriptionsregulators AfYap1 erbrachte keine Virulenzminderung im Mausmodell [89]. Es ist somit anzunehmen, dass sich Aspf3 in entscheidenden Situationen des Infektionsprozesses der übergeordneten Regulierung durch AfYap1 entzieht und autonom anders reguliert wird.

\section{$\underline{\text { Aspf3 als Impfstoff }}$}

Ito et al. [63] konnten durch Verimpfung von rekombinantem Aspf3 im Tierversuch eine protektive Immunreaktion auslösen. Der von uns durchgeführte Vakzinierungsversuch mit rekombinantem Aspf3 (Abb. 28, Impfgruppe 2) erbrachte ebenfalls einen signifikant protektiven Effekt durch den Impfstoff (*P=0,0412). Eine 
NCBI-BLAST-Suche (http://blast.ncbi.nlm.nih.gov) von Aspf3 erbrachte etliche Übereinstimmungen mit anderen Aspergillus-Arten. Die am stärksten homologen Proteine gehören zu den folgenden Spezies: A.fischerianus (99\%), A.clavatus (93\%) und A.terreus (92\%). Es ist daher möglich, dass ein Aspf3-basierter Impfstoff auch Schutz gegenüber verschiedenen Pilzpathogenen vermitteln könnte [63].

Da für die Komplementmutante $\Delta \mathrm{Aspf}^{\mathrm{K}}$ nur ein teilweise wieder hergestellter Phänotyp aufgezeigt werden konnte, wurde das entsprechende Komplementierungsplasmid (Abb. 16, pAspf3-del-komplementiert) im Bereich des Gens Aspf3 sequenziert. Durch einen Vergleich mit der Originalsequenz (Aspergillus Genome Database; http://www.aspgd.org/) wurde der Austausch von fünf Basen festgestellt. Es handelt sich hierbei eventuell um nicht kodierungsrelevante Unterschiede des von uns verwendeten Wildstamms D141 im Vergleich zum Sequenzierstamm. Allerdings ist es ebenfalls möglich, dass die Basenaustausche PCRbedingte Amplifikatfehler darstellen. Diese könnten z.B. zu einem insuffizienten Spleißen beitragen [92] und damit zu einer möglichen funktionellen Beeinträchtigung führen, die den unvollständig restaurierten Phänotyp erklären könnte.

Die stark verminderte Virulenz der Deletionsmutante $\Delta$ Aspf3, bei zumindest teilrestaurierter Virulenz durch die Komplementmutante $\Delta \mathrm{Aspf} 3^{\mathrm{K}}$, lässt vermuten, dass Aspf3 eine entscheidende Rolle während der Pathogenese spielt. Ohne den künstlichen Zusatz von Sauerstoffradikalen in vitro lässt sich zudem kein veränderter Phänotyp erkennen, so dass man es wagen kann, der Peroxireduktase eine spezifische Rolle während des Infektionsprozesses zuzuweisen und sie deshalb auch als „Virulenzfaktor“ $\mathrm{zu}$ bezeichnen. Eine spezifische Inhibition im Sinne einer pharmakologischen „Targetierung“ könnte deshalb alternative Therapieoptionen bieten. Sofern sich eine Therapiemöglichkeit bestätigt, dürfte die relativ geringe Homologie zu menschlichen Proteinen (ähnelt mit $31 \%$ am stärksten dem humanen Peroxiredoxin des Typs V) eine gute Chance dafür bieten, dass ein entsprechendes Therapeutikum wenige Kreuzreaktionen mit menschlichen Proteinen hat, was sich in einem günstigen Nebenwirkungsspektrum niederschlagen dürfte. 


\subsection{Immunisierung von Mäusen mit rekombinanten Proteinen}

Nach einer subletalen Infektion mit A.fumigatus lässt sich im Tierversuch eine protektive Immunreaktion gegenüber einer folgenden, an sich letalen Infektion nachweisen $[66,68]$. Somit sollten von A.fumigatus Antigene während einer Infektion exprimiert werden, die in der Lage sind, eine solche schützende Immunantwort zu induzieren. Die Identifizierung dieser Antigene könnte die Grundlage für die Entwicklung eines Impfstoffes darstellen. Bislang konnten durch andere Arbeitsgruppen vier verschiedene Einzelantigene gefunden werden, welche im Mäuseversuch eine solche Protektion vermitteln (s. 1.6) [61-63]. Unser Ziel war es, weitere erfolgversprechende Antigene zu identifizieren. Zur Immunisierung von Mäusen mit rekombinanten Proteinen standen entsprechende Protein-Kandidaten aus Vorarbeiten zur Verfügung bzw. wurden selbst hergestellt. Insgesamt wurden im Zuge dieser Arbeit 31 Proteine (s. Tab. 11) an Mäuse verimpft. Diese Proteine wurden in Vorarbeiten als entweder mengenmäßig oder immunologisch dominant exprimiert vorgefunden und deshalb von uns ausgewählt (s. 1.7) [2,15,66].

\section{Impfgruppe: Enolase, HSP90, TBP}

Vergleicht man die Überlebenskurven von Impf- und Kontrollgruppe, wird deutlich, dass für die meisten Impfgruppen keine protektive Immunreaktion induziert werden konnte (s. 3.5). Allerdings wurde für die Impfgruppe 3 (Enolase, HSP90, TBP) im Vergleich zu der Negativ-Impfgruppe (Abb. 28) eine signifikante Protektion durch den Impfstoff erzielt $(* \mathrm{P}=0,0121)$. In diesem Versuch wurde zusätzlich eine PositivKontrollgruppe mit Aspf3-Verimpfung mitgeführt. Mit Aspf3 ließ sich in einem analogen Versuchsaufbau von Ito et al. zuvor eine protektive Immunreaktion induzieren [63]. Diesen Effekt konnten wir auch in unserem Mausmodell bestätigen (*P=0,0412). Umso mehr wird dadurch die Wertigkeit der signifikant protektiven Immunreaktion der von uns getesteten Impfgruppe 3 betont, denn diese fiel im Gegensatz zu der Aspf3Impfgruppe stärker aus (s. oben).

Die drei Proteine aus Impfstoff 3 wurden an verschiedene Mausgruppen vereinzelt verimpft (Abb. 32). Doch die Auswertung der Überlebenskurven der jeweiligen Impfgruppe und der Kontrollgruppe erbrachte keine signifikante Protektion durch einen der Impfstoffe (Enolase: P=0,4379; TBP: P=0,1450; HSP90: $\mathrm{P}=0,0848$ ). Jedoch starben in der Kontrollgruppe mehr Mäuse als in jeder der anderen Gruppen. Somit lässt sich 
der signifikant protektive Effekt des Kombinationsimpfstoffes 3 keinem Einzelprotein dominierend zuordnen. Der Effekt der Protektion ist so nicht auf ein einzelnes Antigen zurückzuführen, sondern auf das Zusammenwirken von zwei oder vielleicht auch allen drei Impf-Antigenen des Kombinationsimpfstoffes. Bei einer abschließenden Wiederholung und Kontrolle des Kombinationsimpfstoffes 3 fand sich ebenfalls eine Protektion durch den Impfstoff. Diese war jedoch nicht mehr im Signifikanzbereich $(\mathrm{P}=0,2510)$. Jedoch imponiert diese fehlende Signifikanz möglicherweise durch statistische Ungenauigkeiten in der Negativ-Kontrollgruppe, die eine vergleichsweise geringe Sterblichkeit aufwies (Abb. 33).

\section{$\underline{\text { Enolase }}$}

Enolase ist in allen Geweben und Organismen vorhanden, die Glykolyse oder Fermentation betreiben. Das Enzym katalysiert dabei die Umwandlung von 2-Phosphoglycerat (2-PG) zu Phosphoenolpyruvat (PEP) [93]. Enolase kann aber auch die Rückreaktion katalysieren. Dies hängt von der Konzentrationen der Substrate in der Umgebung ab [94].

$\mathrm{Zu}$ der Aspergillus-Enolase existiert ein homologes Molekül in z.B. Coccidioides posadasii [95] und Candida albicans (C.albicans). Li et al. konnten durch Verimpfung dieser Candida-Enolase Mäuse wirksam vor einer invasiven Candidose schützen. Dieser Schutz stand in Zusammenhang mit einer reduzierten Pilzbelastung, Sekretion von inflammatorischen Zytokinen und einer effektiven Zerstörung phagozytierter Hefe durch Neutrophile [96]. Obwohl Enolase eine primäre intrazelluläre Lokalisation aufweist und ihrer Sequenz ein Signal zur Sekretion fehlt, kann Enolase-Aktivität auch auf der Zellwand von Pilzen und Bakterien nachgewiesen werden (zur Übersicht [66]). Nicht immer ist ein Signalpeptid für die Ausschleusung eines Proteins aus der Zelle notwendig. Es gibt eine wachsende Zahl von Hinweisen, dass einige Proteine mehr als eine Funktion und auch Lokalisation in einem Organismus innehaben [97]. Diese werden auch als „Mondschein-Proteine“ bezeichnet [98,99]. In einer Arbeit von Denikus et al. [66] wurden Aspergillus-Antigene im Kanincheninfektionsmodell identifiziert, die während der Infektion eine starke Immunreaktion ausgelöst haben. Viele der gefundenen Antigene haben ebenfalls kein Signalpeptid. Ihre Homologe bei anderen Pilzen konnten zum Teil aber ebenfalls als Mondschein-Proteine charakterisiert werden [100]. 


\section{$\underline{\text { HSP90 }}$}

Hitzeschockproteine (HSPs) sind hochkonserviert und kommen in allen Organismen und dabei in allen Zellen der Organismen vor. Ausgewählte HSPs, auch Chaperone genannt, spielen unter anderem eine entscheidende Rolle bei der Faltung bzw. Entfaltung von Proteinen, dem Aufbau von Multiproteinkomplexen und dem Transport bzw. der Sortierung von Proteinen in subzelluläre Kompartimente. Sie bilden eine große Familie von Proteinen, die oft, basierend auf ihrem Molekulargewicht, klassifiziert werden: z.B. HSP10, HSP40, HSP60, HSP70 und HSP90 [101]. Organismen reagieren stressbedingt auf erhöhte Temperaturen, sowie chemische und physiologische Einflüsse durch eine Erhöhung der Synthese von Hitzeschockproteinen [102].

HSP90 ist in allen Eukaryonten präsent [103]. In Pilzen wurde HSP90 vor allem in Hefen untersucht [104]. Bei Saccharomyces cerevisiae wurde HSP90 als wichtiger Bestandteil des Zellmetabolismus mit Einfluss auf zahlreiche Schlüssel- und Signalkaskaden-Proteine sowie Transkriptionsfaktoren gefunden. Diese HSP90abhängigen Proteine repräsentieren teilweise mehr als $10 \%$ des gesamten Proteoms unterschiedlicher Wachstumsstadien [105]. HSP90, welches hoch konserviert ist, existiert auch in C.albicans, wo es zusätzlich zu einer intrazellulären Lage auch in der Zellwand lokalisiert vorliegt (zur Übersicht [66]). Bei A.fumigatus erbrachten Untersuchungen mit dem Protein HSP90, dass dieses unter anderem für Konidienbildung und Zellwand-Integrität erforderlich ist [106].

\section{$\underline{\text { TBP }}$}

Thiamin (Vitamin B1) ist ein wasserlösliches Vitamin aus dem B-Komplex. Alle lebenden Organismen benötigen Thiamin, aber nur Bakterien, Pilze und Pflanzen können es selbst synthetisieren. Zu dem Thiamin-Biosyntheseprotein (TBP) existieren viele orthologe Moleküle in anderen Organismen, z.B. in den Pilzen N.crassa (nmt-1), S.cerevisiae (THI13) und C.albicans (THI13). Das TBP bei A.fumigatus ist möglicherweise involviert in das Hyphenwachstum und in den Thiamin-Stoffwechsel, wie es ebenfalls z.B. bei N.crassa der Fall ist [107]. 


\section{Weitere Testungen mit Teilerfolgen}

Ein weiterer Impferfolg konnte mit dem Impfstoff 7 (MIPS, PGM, PGM3/4) erzielt werden (Abb. 30). Auch die Verabreichung des Impfstoffs 7 wurde wiederholt (Abb. 33). Dabei erbrachte ein Vergleich der Überlebenskurven von Impfgruppe 7 und der Negativ-Kontrollgruppe keinen schützenden Effekt durch den Impfstoff ( $\mathrm{P}=0,5785)$. Nicht erklärbar erscheint der unterschiedliche Kurvenverlauf nach Verabreichen der Impfgruppe 7 (Abb. 30 undAbb. 33) bei jeweils identischem Versuchsaufbau.

\subsection{Einschränkungen und Verbesserungen bei der Impfstoffsuche}

Nach Verimpfung von Impfstoff 3 wurden unterschiedliche Signifikanzlevel erreicht (s. oben). So war nach einer Wiederholung und Kontrolle des Kombinationsimpfstoffes 3 kein weiteres Mal eine Protektion im Signifikanzbereich gegeben. Allerdings fanden sich gleichgerichtete Effekte, aber leider ohne Erreichen der Signifikanz. Es lassen sich Vermutungen anstellen, wie eine Verbesserung durch konstantere Versuchsbedingungen erzielt werden könnte. Zudem kann nach Anhaltspunkten bezüglich der Frage, weshalb die Versuchsergebnisse nicht reproduzierbar waren, gesucht werden.

\section{$\underline{\text { Unsichere Aufnahme der Infektionsdosis }}$}

Die Infektion mit den Konidien erfolgte intranasal, was dem natürlichen Infektionsweg entspricht. Allerdings beinhaltet diese Art der Verabreichung eine relativ große Fehlerbreite in der tatsächlichen wirksamen Infektionsdosis, denn ein Teil der Konidien wird von den Mäusen eventuell verschluckt. Somit ist die tatsächliche pulmonale Infektionsdosis gegebenenfalls sehr variabel. Infolgedessen kann dies eine breite Streuung im Schweregrad des Erkrankungsbildes verursachen, welche gegebenenfalls nur durch eine relativ hohe Anzahl von Versuchstieren statistisch ausgleichbar ist. Eine mögliche Modifikation der Versuchsbedingungen ist eine i.v.-Infektion der Mäuse mit den A.fumigatus-Konidien über die Schwanzvene. Bei dieser Art der Infektion sind auch bei kleineren Versuchsgruppen verlässlichere Ergebnisse möglich, da bei jeder Injektion eine definierte Konidienmenge sicher aufgenommen wird. Dies entspricht allerdings nicht dem natürlichen Infektionsweg, und sonst lokal in der Lunge agierende 
Immunmechanismen kommen bei einer i.v.-Infektion nicht in natürlicher Weise zum Tragen, deswegen wurde das i.v.-Modell von uns nicht favorisiert.

\section{Maskierung protektiver Immunreaktionen durch „Stille Feiung“6}

Im Verlauf der Versuche wurde deutlich, dass die fehlenden Signifikanz-Werte möglicherweise durch statistische Ungenauigkeiten in den Negativ-Kontrollgruppen, die zum Teil eine vergleichsweise geringe Sterblichkeit aufwiesen, entstanden sein können. Als „Stille Feiung“ bezeichnet man eine Immunantwort nach Infektion mit einem Krankheitserreger, die symptomlos verläuft [108]. Der Unterschied bezüglich der Protektion zwischen Impfgruppe und Negativ-Kontrollgruppe wurde eventuell dadurch maskiert. Bereits Corbel und Eades haben gezeigt, dass ältere Mäuse eine zunehmend protektive Immunreaktion gegenüber Aspergillen ausbilden [51]. Diese könnte die an sich eindeutigen protektiven Immunreaktionen der Impfstoffkandidaten maskieren und Ergebnisse entsprechend verfälschen.

Zudem sind zwei Häufigkeitsgipfel der invasiven Aspergillose beim Menschen nach Stammzelltransplantation bekannt [109]. Der erste Gipfel ist unmittelbar vor und nach der Transplantation. Ursächlich wird ein Versagen der primären, angeborenen Immunität bedingt durch einen Mangel an Leukozyten und Makrophagen hervorgerufen durch die herabgesetzte Knochenmarkfunktion. Trotz des Anwachsens neuer Stammzellen in der Regenerationsphase kommt es ca. 3 Monate nach der Transplantation zu einem zweiten Gipfel spät auftretender Infektionen. Obwohl die Granulozyten-Funktion wiederhergestellt ist, ist das Risiko für eine IA zu dieser Zeit erhöht. Der Grund dafür ist die verzögerte Regeneration der T- und B-Zellen. Dies macht deutlich, dass auch die Störungen im Bereich der erworbenen Immunität beim Menschen (in diesem Fall die erworbene Immunität des Spenders, welche im Anschluss an die Transplantation medikamentös unterdrückt wird, um eine Transplantatabstoßung zu verhindern) ein Risikofaktor für eine invasive Aspergillose darstellen. Erklärbar ist dieses Phänomen ebenfalls durch eine „Stille Feiung“ der Mäuse (s. oben).

Es ist erst mit fortschreitender Versuchsdurchführung der Verdacht aufgetreten, dass die Mäuse während der Zeit zwischen Immunisierung und Infizierung (5 Wochen) eventuell zu großen und letztlich individuell unkontrollierbaren Mengen an Konidien ausgesetzt waren. Dieses mag neben dem Alter der Mäuse aber auch z.B. lokale oder gar Jahreszeit-bedingte Ursachen haben, denn in wärmeren Monaten kommt es 
wahrscheinlich $\mathrm{zu}$ einer größeren Freisetzung an Aspergillen. In jedem Fall ist die Einatmung von Konidien und damit die „Stille Feiung“ eine unkontrollierte Beeinflussungsgröße.

Ein veränderter Ansatz wäre die Verwendung von individuell ventilierten Käfigen, die den Partikelaustausch zwischen Käfiginnerem und der Umgebung verhindert. Die Aufnahme von Konidien aus der Raumluft wäre auf diese Weise auch unterbunden. Der Gebrauch von ventilierten Käfigen könnte der Schlüssel für eine Verbesserung der Versuchsbedingungen sein, dies war uns im Vorfeld jedoch nicht bewusst und in der zu Rate gezogenen Literatur, welche sich mit Impfstoffentwicklung bei Aspergillen befasst, auch so nicht beschrieben $[41,64,75,76]$. 


\section{Zusammenfassung}

A.fumigatus ist der häufigste Erreger invasiver, meist tödlich verlaufender Aspergillosen bei stark immunsupprimierten Patienten. Eine natürliche Resistenz gegen den Pilz wird durch das angeborene Immunsystem vermittelt, jedoch wurde im Tierversuch auch eine erworbene Immunität nach einer überlebten systemischen Infektion festgestellt. Deshalb sollten Antigene, die im Verlauf der Erkrankung vom Pilz exprimiert werden, eine spezifische und protektive Immunantwort hervorrufen können. Für die Entwicklung eines Impfstoffes ist die Identifikation solcher Antigene Voraussetzung. Im Mausmodell wurden insgesamt 31 rekombinante Aspergillus-Antigene in Kombinationen getestet. Als besonders erfolgversprechend stellte sich ein trivalenter Impfstoff, bestehend aus Enolase, HSP90 und TBP (Thiamin-Biosyntheseprotein), dar. Im Vergleich zu einer ungeimpften Kontrollgruppe fand sich bei der Impfgruppe eine signifikante Protektion gegenüber einer an sich letalen Aspergillus-Infektion. Bei einer Wiederholung des Versuchs ließ sich der Schutz bestätigen, war jedoch nicht mehr im Signifikanzbereich. Mögliche Gründe hierfür sind die unsichere Aufnahme der Infektionsdosis durch nasale Verabreichung oder auch eine „Stille Feiung“ der Mäuse durch Einatmung von Konidien aus der Umgebung vor der eigentlichen Infektion. Eine Verbesserung der Versuchsbedingungen könnte durch die Verwendung individuell ventilierter Käfige (ohne Sporenbelastung aus der Raumluft) und/oder eine Vergrößerung der Versuchsgruppen erreicht werden.

Da die Konidienoberfläche den ersten Kontakt mit dem Wirt vermittelt, könnten Konidienoberflächenproteine sowohl vielversprechende Impfstoffkandidaten als auch Virulenzfaktoren sein. Im Tierversuch wurde hier nachgewiesen, dass das stark exprimierte Konidienoberflächenprotein HP16 entscheidend an der Virulenz von A.fumigatus beteiligt ist. Dabei stellte sich der Virulenzunterschied zwischen der Deletionsmutante $\Delta$ HP16 und dem Wildtyp D141 als hoch signifikant dar. Der Vergleich zwischen der Deletionsmutante $\Delta$ HP16 und der Komplementmutante $\Delta \mathrm{HP} 16^{\mathrm{K}}$ erbrachte eine komplett restaurierte Virulenz. Da HP16 zumindest in vitro vorwiegend auf Konidien lokalisiert ist, könnte sich hier ein Angriffspunkt für eine präemptive Therapie bzw. für eine Prophylaxe der invasiven Aspergillose ergeben. 
HP16 wurde auch als rekombinantes Protein hergestellt. Das rekombinante Antigen soll als Impfstoffkandidat in zukünftigen Projekten eingesetzt werden.

Letztlich wurde noch Aspf3, eine Peroxireduktase von A.fumigatus, als ein weiterer Target- und Impfstoffkandidat untersucht. Die stark verminderte Virulenz der Deletionsmutante $\Delta$ Aspf3 und eine zumindest teilrestaurierte Virulenz durch die hergestellte Komplementmutante $\Delta \mathrm{Aspf} 3^{\mathrm{K}}$ lassen vermuten, dass Aspf3 während der Pathogenese ebenfalls eine entscheidende Rolle spielt. 


\section{Literaturverzeichnis}

1. Latge JP: Aspergillus fumigatus and aspergillosis. Clin Microbiol Rev 1999, 12:310-350.

2. Asif AR, Oellerich M, Amstrong VW, Gross U, Reichard U: Analysis of the cellular Aspergillus fumigatus proteome that reacts with sera from rabbits developing an acquired immunity after experimental aspergillosis. Electrophoresis 2010, 31:1947-1958.

3. Rohde M, Schwienbacher M, Nikolaus T, Heesemann J, Ebel F: Detection of early phase specific surface appendages during germination of Aspergillus fumigatus conidia. FEMS Microbiol Lett 2002, 206:99-105.

4. Paoletti M, Rydholm C, Schwier EU, Anderson MJ, Szakacs G, Lutzoni F, Debeaupuis JP, Latge JP, Denning DW, Dyer PS: Evidence for sexuality in the opportunistic fungal pathogen Aspergillus fumigatus. Curr Biol 2005, 15:1242-1248.

5. Galagan JE, Calvo SE, Cuomo C, Ma LJ, Wortman JR, Batzoglou S, Lee SI, Basturkmen M, Spevak CC, Clutterbuck J, et al.: Sequencing of Aspergillus nidulans and comparative analysis with A.fumigatus and A.oryzae. Nature 2005, 438:1105-1115.

6. O'Gorman CM, Fuller H, Dyer PS: Discovery of a sexual cycle in the opportunistic fungal pathogen Aspergillus fumigatus. Nature 2009, 457:471-474.

7. Rhodes JC: Aspergillus fumigatus: growth and virulence. Med Mycol 2006, 44 Suppl 1:S77-81.

8. Schmitt HJ, Blevins A, Sobeck K, Armstrong D: Aspergillus species from hospital air and from patients. Mycoses 1990, 33:539-541.

9. Denning DW: Invasive aspergillosis. Clin Infect Dis 1998, 26:781-803; quiz 804785.

10. Latge JP: The pathobiology of Aspergillus fumigatus. Trends Microbiol 2001, 9:382-389.

11. Balloy V, Chignard M: The innate immune response to Aspergillus fumigatus. Microbes Infect 2009, 11:919-927.

12. Park SJ, Mehrad B: Innate immunity to Aspergillus species. Clin Microbiol Rev 2009, 22:535-551.

13. Ruchel R, Reichard U: Pathogenesis and clinical presentation of aspergillosis. Contrib Microbiol 1999, 2:21-43.

14. Pfaller MA, Diekema DJ: Rare and emerging opportunistic fungal pathogens: concern for resistance beyond Candida albicans and Aspergillus fumigatus. $J$ Clin Microbiol 2004, 42:4419-4431.

15. Asif AR, Oellerich M, Amstrong VW, Riemenschneider B, Monod M, Reichard U: Proteome of conidial surface associated proteins of Aspergillus fumigatus reflecting potential vaccine candidates and allergens. J Proteome Res 2006, 5:954-962.

16. Wald A, Leisenring W, van Burik JA, Bowden RA: Epidemiology of Aspergillus infections in a large cohort of patients undergoing bone marrow transplantation. $J$ Infect Dis 1997, 175:1459-1466.

17. Fridkin SK, Jarvis WR: Epidemiology of nosocomial fungal infections. Clin Microbiol Rev 1996, 9:499-511.

18. Binder U, Lass-Florl $\mathrm{C}$ : New insights into invasive aspergillosis--from the pathogen to the disease. Curr Pharm Des 2013, 19:3679-3688. 
19. Greenberger PA: Clinical aspects of allergic bronchopulmonary aspergillosis. Front Biosci 2003, 8:s119-127.

20. Guazzelli LS, Severo CB, Hoff LS, Pinto GL, Camargo JJ, Severo LC: Aspergillus fumigatus fungus ball in the pleural cavity. J Bras Pneumol 2012, 38:125132.

21. Soubani AO, Chandrasekar $\mathrm{PH}$ : The clinical spectrum of pulmonary aspergillosis. Chest 2002, 121:1988-1999.

22. Todea DA, Postolache P, Rosca LE, Coman AC: Pulmonary aspergilloma and pulmonary tuberculosis: is there a strong association? Chest 2014, 145:152A.

23. Abad A, Fernandez-Molina JV, Bikandi J, Ramirez A, Margareto J, Sendino J, Hernando FL, Ponton J, Garaizar J, Rementeria A: What makes Aspergillus fumigatus a successful pathogen? Genes and molecules involved in invasive aspergillosis. Rev Iberoam Micol 2010, 27:155-182.

24. Latge JP: The cell wall: a carbohydrate armour for the fungal cell. Mol Microbiol 2007, 66:279-290.

25. Fontaine T, Simenel C, Dubreucq G, Adam O, Delepierre M, Lemoine J, Vorgias CE, Diaquin M, Latge JP: Molecular organization of the alkali-insoluble fraction of aspergillus fumigatus cell wall. J Biol Chem 2000, 275:41528.

26. Bernard M, Latge JP: Aspergillus fumigatus cell wall: composition and biosynthesis. Med Mycol 2001, 39 Suppl 1:9-17.

27. Latge JP, Mouyna I, Tekaia F, Beauvais A, Debeaupuis JP, Nierman W: Specific molecular features in the organization and biosynthesis of the cell wall of Aspergillus fumigatus. Med Mycol 2005, 43 Suppl 1:S15-22.

28. Aimanianda V, Bayry J, Bozza S, Kniemeyer O, Perruccio K, Elluru SR, Clavaud C, Paris S, Brakhage AA, Kaveri SV, et al.: Surface hydrophobin prevents immune recognition of airborne fungal spores. Nature 2009, 460:1117-1121.

29. Paris S, Debeaupuis JP, Crameri R, Carey M, Charles F, Prevost MC, Schmitt C, Philippe B, Latge JP: Conidial hydrophobins of Aspergillus fumigatus. Appl Environ Microbiol 2003, 69:1581-1588.

30. Thau N, Monod M, Crestani B, Rolland C, Tronchin G, Latge JP, Paris S: rodletless mutants of Aspergillus fumigatus. Infect Immun 1994, 62:4380-4388.

31. Bruneau JM, Magnin T, Tagat E, Legrand R, Bernard M, Diaquin M, Fudali C, Latge JP: Proteome analysis of Aspergillus fumigatus identifies glycosylphosphatidylinositol-anchored proteins associated to the cell wall biosynthesis. Electrophoresis 2001, 22:2812-2823.

32. Li H, Zhou H, Luo Y, Ouyang H, Hu H, Jin C: Glycosylphosphatidylinositol (GPI) anchor is required in Aspergillus fumigatus for morphogenesis and virulence. Mol Microbiol 2007, 64:1014-1027.

33. Cao W, Maruyama J, Kitamoto K, Sumikoshi K, Terada T, Nakamura S, Shimizu $\mathrm{K}$ : Using a new GPI-anchored-protein identification system to mine the protein databases of Aspergillus fumigatus, Aspergillus nidulans, and Aspergillus oryzae. J Gen Appl Microbiol 2009, 55:381-393.

34. Lass-Florl C, Roilides E, Loffler J, Wilflingseder D, Romani L: Minireview: host defence in invasive aspergillosis. Mycoses 2013, 56:403-413.

35. Schaffner A: Macrophage-Aspergillus interactions. Immunol Ser 1994, 60:545552.

36. Dagenais TR, Keller NP: Pathogenesis of Aspergillus fumigatus in Invasive Aspergillosis. Clin Microbiol Rev 2009, 22:447-465. 
37. Netea MG, Warris A, Van der Meer JW, Fenton MJ, Verver-Janssen TJ, Jacobs LE, Andresen T, Verweij PE, Kullberg BJ: Aspergillus fumigatus evades immune recognition during germination through loss of toll-like receptor-4mediated signal transduction. J Infect Dis 2003, 188:320-326.

38. Gersuk GM, Underhill DM, Zhu L, Marr KA: Dectin-1 and TLRs permit macrophages to distinguish between different Aspergillus fumigatus cellular states. J Immunol 2006, 176:3717-3724.

39. Ibrahim-Granet O, Philippe B, Boleti H, Boisvieux-Ulrich E, Grenet D, Stern M, Latge JP: Phagocytosis and intracellular fate of Aspergillus fumigatus conidia in alveolar macrophages. Infect Immun 2003, 71:891-903.

40. Hohl TM, Feldmesser M: Aspergillus fumigatus: principles of pathogenesis and host defense. Eukaryot Cell 2007, 6:1953-1963.

41. Philippe B, Ibrahim-Granet O, Prevost MC, Gougerot-Pocidalo MA, Sanchez Perez M, Van der Meeren A, Latge JP: Killing of Aspergillus fumigatus by alveolar macrophages is mediated by reactive oxidant intermediates. Infect Immun 2003, 71:3034-3042.

42. Babior BM: The respiratory burst of phagocytes. J Clin Invest 1984, 73:599-601.

43. Urban CF, Ermert D, Schmid M, Abu-Abed U, Goosmann C, Nacken W, Brinkmann V, Jungblut PR, Zychlinsky A: Neutrophil extracellular traps contain calprotectin, a cytosolic protein complex involved in host defense against Candida albicans. PLoS Pathog 2009, 5:e1000639.

44. Brakhage AA, Bruns S, Thywissen A, Zipfel PF, Behnsen J: Interaction of phagocytes with filamentous fungi. Curr Opin Microbiol 2010, 13:409-415.

45. Zhang Y, Wallace DL, de Lara CM, Ghattas H, Asquith B, Worth A, Griffin GE, Taylor GP, Tough DF, Beverley PC, et al.: In vivo kinetics of human natural killer cells: the effects of ageing and acute and chronic viral infection. Immunology 2007, 121:258-265.

46. Gregoire C, Chasson L, Luci C, Tomasello E, Geissmann F, Vivier E, Walzer T: The trafficking of natural killer cells. Immunol Rev 2007, 220:169-182.

47. Weissler JC, Nicod LP, Lipscomb MF, Toews GB: Natural killer cell function in human lung is compartmentalized. Am Rev Respir Dis 1987, 135:941-949.

48. Bouzani M, Ok M, McCormick A, Ebel F, Kurzai O, Morton CO, Einsele H, Loeffler J: Human NK cells display important antifungal activity against Aspergillus fumigatus, which is directly mediated by IFN-gamma release. $J$ Immunol 2011, 187:1369-1376.

49. Polonelli L, Casadevall A, Han Y, Bernardis F, Kirkland TN, Matthews RC, Adriani D, Boccanera M, Burnie JP, Cassone A, et al.: The efficacy of acquired humoral and cellular immunity in the prevention and therapy of experimental fungal infections. Med Mycol 2000, 38 Suppl 1:281-292.

50. Lehmann PF, White LO: Acquired immunity to Aspergillus fumigatus. Infect Immun 1976, 13:1296-1298.

51. Corbel MJ, Eades SM: Examination of the effect of age and acquired immunity on the susceptibility of mice to infection with Aspergillus fumigatus. Mycopathologia 1977, 60:79-85.

52. Cenci E, Mencacci A, Bacci A, Bistoni F, Kurup VP, Romani L: T cell vaccination in mice with invasive pulmonary aspergillosis. J Immunol 2000, 165:381-388.

53. Gastebois A, Clavaud C, Aimanianda V, Latge JP: Aspergillus fumigatus: cell wall polysaccharides, their biosynthesis and organization. Future Microbiol 2009, 4:583-595. 
54. Bozza S, Gaziano R, Spreca A, Bacci A, Montagnoli C, di Francesco P, Romani L: Dendritic cells transport conidia and hyphae of Aspergillus fumigatus from the airways to the draining lymph nodes and initiate disparate $\mathrm{Th}$ responses to the fungus. J Immunol 2002, 168:1362-1371.

55. Ito JI: $\mathbf{T}$ cell immunity and vaccines against invasive fungal diseases. Immunol Invest 2011, 40:825-838.

56. Sun Z, Zhu P, Li L, Wan Z, Zhao Z, Li R: Adoptive immunity mediated by HLAA*0201 restricted Asp f16 peptides-specific CD8+ T cells against Aspergillus fumigatus infection. Eur J Clin Microbiol Infect Dis 2012, 31:3089-3096.

57. Taylor PR, Leal SM, Jr., Sun Y, Pearlman E: Aspergillus and Fusarium Corneal Infections Are Regulated by Th17 Cells and IL-17-Producing Neutrophils. $J$ Immunol 2014.

58. Reichard U, Herrmann, S., Asif, A. R.,: Vaccination Approaches Against Opportunistic Fungal Infections Caused by Aspergillus fumigatus. Current Protein and Peptide Science 2014, 15, in print.

59. de Repentigny L, Petitbois S, Boushira M, Michaliszyn E, Senechal S, Gendron N, Montplaisir S: Acquired immunity in experimental murine aspergillosis is mediated by macrophages. Infect Immun 1993, 61:3791-3802.

60. Ito JI, Lyons JM: Vaccination of corticosteroid immunosuppressed mice against invasive pulmonary aspergillosis. J Infect Dis 2002, 186:869-871.

61. Bozza S, Gaziano R, Lipford GB, Montagnoli C, Bacci A, Di Francesco P, Kurup VP, Wagner H, Romani L: Vaccination of mice against invasive aspergillosis with recombinant Aspergillus proteins and CpG oligodeoxynucleotides as adjuvants. Microbes Infect 2002, 4:1281-1290.

62. Bozza S, Clavaud C, Giovannini G, Fontaine T, Beauvais A, Sarfati J, D'Angelo C, Perruccio K, Bonifazi P, Zagarella S, et al.: Immune sensing of Aspergillus fumigatus proteins, glycolipids, and polysaccharides and the impact on Th immunity and vaccination. J Immunol 2009, 183:2407-2414.

63. Ito JI, Lyons JM, Hong TB, Tamae D, Liu YK, Wilczynski SP, Kalkum M: Vaccinations with recombinant variants of Aspergillus fumigatus allergen Asp f 3 protect mice against invasive aspergillosis. Infect Immun 2006, 74:5075-5084.

64. Diaz-Arevalo D, Bagramyan K, Hong TB, Ito JI, Kalkum M: CD4+ T cells mediate the protective effect of the recombinant Asp f3-based anti-aspergillosis vaccine. Infect Immun 2011, 79:2257-2266.

65. Ito JI, Lyons JM, Diaz-Arevalo D, Hong TB, Kalkum M: Vaccine progress. Med Mycol 2009, 47 Suppl 1:S394-400.

66. Denikus N, Orfaniotou F, Wulf G, Lehmann PF, Monod M, Reichard U: Fungal antigens expressed during invasive aspergillosis. Infect Immun 2005, 73:4704-4713.

67. Murphy K: Janeway's Immunobiology, vol Auflage: 8th edition.: Taylor \& Francis Ltd.; 2011.

68. Smith GR: Experimental aspergillosis in mice: aspects of resistance. J Hyg (Lond) 1972, 70:741-754.

69. Punt PJ, Oliver RP, Dingemanse MA, Pouwels PH, van den Hondel CA: Transformation of Aspergillus based on the hygromycin $B$ resistance marker from Escherichia coli. Gene 1987, 56:117-124.

70. Segal BH: Aspergillosis. N Engl J Med 2009, 360:1870-1884.

71. Nierman WC, Pain A, Anderson MJ, Wortman JR, Kim HS, Arroyo J, Berriman M, Abe $\mathrm{K}$, Archer DB, Bermejo $\mathrm{C}$, et al.: Genomic sequence of the pathogenic 
and allergenic filamentous fungus Aspergillus fumigatus. Nature 2005, 438:1151-1156.

72. Suh MJ, Fedorova ND, Cagas SE, Hastings S, Fleischmann RD, Peterson SN, Perlin DS, Nierman WC, Pieper R, Momany M: Development stage-specific proteomic profiling uncovers small, lineage specific proteins most abundant in the Aspergillus Fumigatus conidial proteome. Proteome Sci 2012, 10:30.

73. Kyte J, Doolittle RF: A simple method for displaying the hydropathic character of a protein. J Mol Biol 1982, 157:105-132.

74. Schneemann M, Schaffner A: Host defense mechanism in Aspergillus fumigatus infections. Contrib Microbiol 1999, 2:57-68.

75. Kupfahl C, Heinekamp T, Geginat G, Ruppert T, Hartl A, Hof H, Brakhage AA: Deletion of the gliP gene of Aspergillus fumigatus results in loss of gliotoxin production but has no effect on virulence of the fungus in a low-dose mouse infection model. Mol Microbiol 2006, 62:292-302.

76. Behnsen J, Lessing F, Schindler S, Wartenberg D, Jacobsen ID, Thoen M, Zipfel PF, Brakhage AA: Secreted Aspergillus fumigatus protease Alp1 degrades human complement proteins C3, C4, and C5. Infect Immun 2010, 78:35853594.

77. Schrettl M, Beckmann N, Varga J, Heinekamp T, Jacobsen ID, Jochl C, Moussa TA, Wang S, Gsaller F, Blatzer M, et al.: HapX-mediated adaption to iron starvation is crucial for virulence of Aspergillus fumigatus. PLoS Pathog 2010, 6:e1001124.

78. Liebmann B, Muhleisen TW, Muller M, Hecht M, Weidner G, Braun A, Brock M, Brakhage AA: Deletion of the Aspergillus fumigatus lysine biosynthesis gene lysF encoding homoaconitase leads to attenuated virulence in a low-dose mouse infection model of invasive aspergillosis. Arch Microbiol 2004, 181:378-383.

79. Schobel F, Jacobsen ID, Brock M: Evaluation of lysine biosynthesis as an antifungal drug target: biochemical characterization of Aspergillus fumigatus homocitrate synthase and virulence studies. Eukaryot Cell 2010, 9:878-893.

80. Stergiopoulou T, Meletiadis J, Roilides E, Kleiner DE, Schaufele R, Roden M, Harrington S, Dad L, Segal B, Walsh TJ: Host-dependent patterns of tissue injury in invasive pulmonary aspergillosis. Am J Clin Pathol 2007, 127:349355.

81. Balloy V, Huerre M, Latge JP, Chignard M: Differences in patterns of infection and inflammation for corticosteroid treatment and chemotherapy in experimental invasive pulmonary aspergillosis. Infect Immun 2005, 73:494503.

82. Ibrahim-Granet O, Jouvion G, Hohl TM, Droin-Bergere S, Philippart F, Kim OY, Adib-Conquy $\mathrm{M}$, Schwendener $\mathrm{R}$, Cavaillon JM, Brock $\mathrm{M}$ : In vivo bioluminescence imaging and histopathopathologic analysis reveal distinct roles for resident and recruited immune effector cells in defense against invasive aspergillosis. BMC Microbiol 2010, 10:105.

83. Mondon P, De Champs C, Donadille A, Ambroise-Thomas P, Grillot R: Variation in virulence of Aspergillus fumigatus strains in a murine model of invasive pulmonary aspergillosis. J Med Microbiol 1996, 45:186-191.

84. Falkow S: Molecular Koch's postulates applied to microbial pathogenicity. Rev Infect Dis 1988, 10 Suppl 2:S274-276. 
85. Jana S, Deb JK: Strategies for efficient production of heterologous proteins in Escherichia coli. Appl Microbiol Biotechnol 2005, 67:289-298.

86. Baneyx F: Recombinant protein expression in Escherichia coli. Curr Opin Biotechnol 1999, 10:411-421.

87. Schein C. H. NMHM: Formation of Soluble Recombinant Proteins in Escherichia Coli is Favored by Lower Growth Temperature. Nature Biotechnology 1988, 6:291-294.

88. Studier FW: Protein production by auto-induction in high density shaking cultures. Protein Expr Purif 2005, 41:207-234.

89. Lessing F, Kniemeyer O, Wozniok I, Loeffler J, Kurzai O, Haertl A, Brakhage AA: The Aspergillus fumigatus transcriptional regulator AfYap1 represents the major regulator for defense against reactive oxygen intermediates but is dispensable for pathogenicity in an intranasal mouse infection model. Eukaryot Cell 2007, 6:2290-2302.

90. Hemmann S, Blaser K, Crameri R: Allergens of Aspergillus fumigatus and Candida boidinii share IgE-binding epitopes. Am J Respir Crit Care Med 1997, 156:1956-1962.

91. Crameri R: Epidemiology and molecular basis of the involvement of Aspergillus fumigatus in allergic diseases. Contrib Microbiol 1999, 2:44-56.

92. Starokadomskyy PL: Protein Splicing. Molecular Biology 2007, 41: 278-293.

93. Diaz-Ramos A, Roig-Borrellas A, Garcia-Melero A, Lopez-Alemany R: alphaEnolase, a multifunctional protein: its role on pathophysiological situations. J Biomed Biotechnol 2012, 2012:156795.

94. Pancholi V: Multifunctional alpha-enolase: its role in diseases. Cell Mol Life Sci 2001, 58:902-920.

95. Champer J, Diaz-Arevalo D, Champer M, Hong TB, Wong M, Shannahoff M, Ito JI, Clemons KV, Stevens DA, Kalkum M: Protein targets for broad-spectrum mycosis vaccines: quantitative proteomic analysis of Aspergillus and Coccidioides and comparisons with other fungal pathogens. Ann N Y Acad Sci 2012, 1273:44-51.

96. Li W, Hu X, Zhang X, Ge Y, Zhao S, Hu Y, Ashman RB: Immunisation with the glycolytic enzyme enolase confers effective protection against Candida albicans infection in mice. Vaccine 2011, 29:5526-5533.

97. Urban C, Xiong X, Sohn K, Schroppel K, Brunner H, Rupp S: The moonlighting protein Tsa1p is implicated in oxidative stress response and in cell wall biogenesis in Candida albicans. Mol Microbiol 2005, 57:1318-1341.

98. Jeffery CJ: Moonlighting proteins. Trends Biochem Sci 1999, 24:8-11.

99. Jeffery CJ: Moonlighting proteins: old proteins learning new tricks. Trends Genet 2003, 19:415-417.

100. Urban C, Sohn K, Lottspeich F, Brunner H, Rupp S: Identification of cell surface determinants in Candida albicans reveals Tsa1p, a protein differentially localized in the cell. FEBS Lett 2003, 544:228-235.

101. Li Z, Srivastava P: Heat-shock proteins. Curr Protoc Immunol 2004, Appendix 1:Appendix 1T.

102. Wu C: Heat shock transcription factors: structure and regulation. Annu Rev Cell Dev Biol 1995, 11:441-469.

103. Whitesell L, Lindquist SL: HSP90 and the chaperoning of cancer. Nat Rev Cancer 2005, 5:761-772.

104. Burnie JP, Carter TL, Hodgetts SJ, Matthews RC: Fungal heat-shock proteins in human disease. FEMS Microbiol Rev 2006, 30:53-88. 
105. Zhao R, Davey M, Hsu YC, Kaplanek P, Tong A, Parsons AB, Krogan N, Cagney G, Mai D, Greenblatt J, et al.: Navigating the chaperone network: an integrative map of physical and genetic interactions mediated by the hsp90 chaperone. Cell 2005, 120:715-727.

106. Lamoth F, Juvvadi PR, Fortwendel JR, Steinbach WJ: Heat shock protein 90 is required for conidiation and cell wall integrity in Aspergillus fumigatus. Eukaryot Cell 2012, 11:1324-1332.

107. McColl D, Valencia CA, Vierula PJ: Characterization and expression of the Neurospora crassa nmt-1 gene. Curr Genet 2003, 44:216-223.

108. Hahn H. FD, Kaufmann S. H. E., Ulimann U. (Hrsg.): Medizinische Mikrobiologie und Infektiologie, Abschnitt 3.5 Lebendimpfstoffe. Springer, Berlin/ Heidelberg 2005, 5. Auflage,:467.

109. Tomblyn M, Chiller T, Einsele H, Gress R, Sepkowitz K, Storek J, Wingard JR, Young JA, Boeckh MJ, Center for International B, et al.: Guidelines for preventing infectious complications among hematopoietic cell transplantation recipients: a global perspective. Biol Blood Marrow Transplant 2009, 15:1143-1238. 


\section{Anhang}

\subsection{Molekulargewichtsmarker}

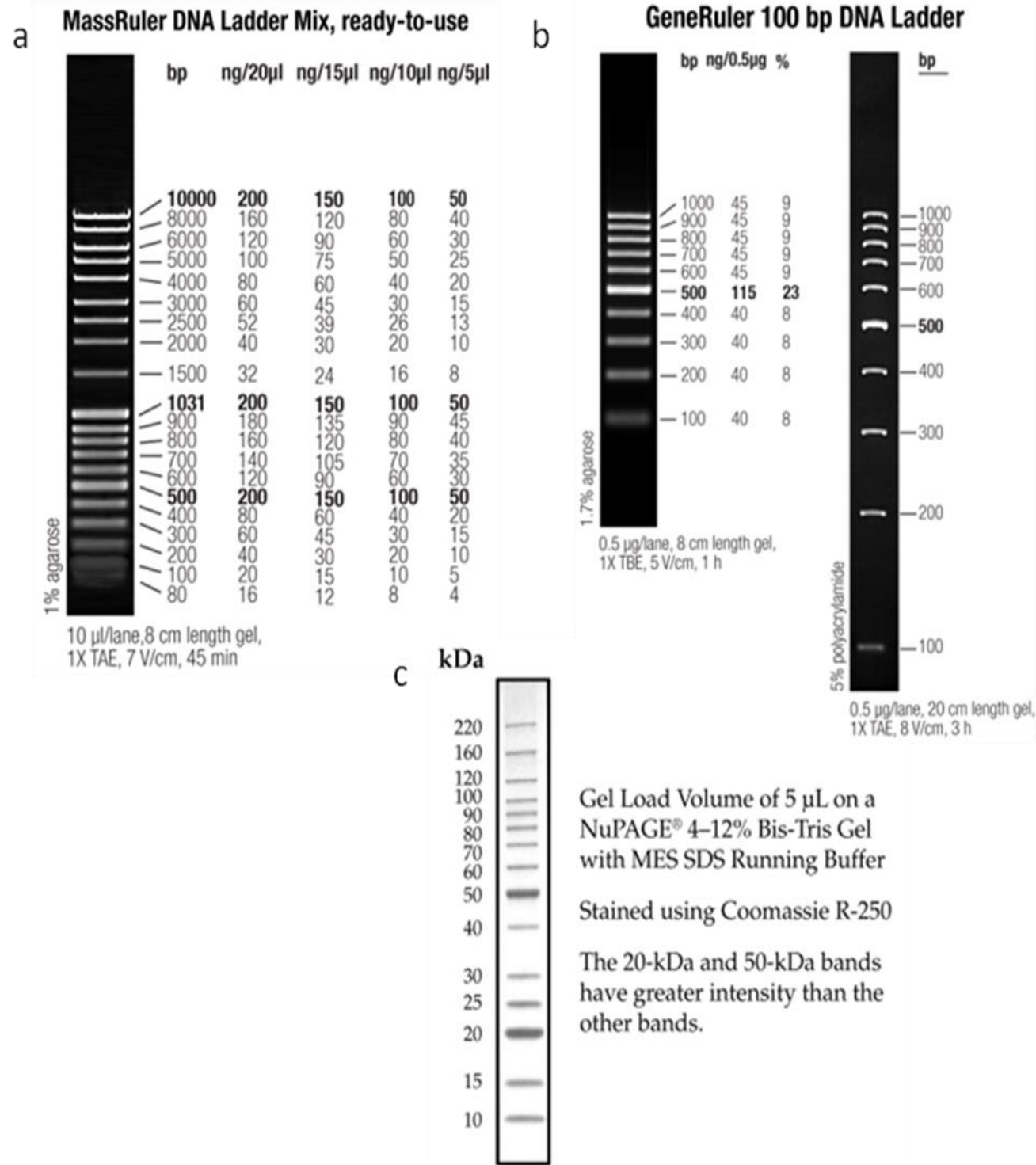

Abb. 40: a) MassRuler ${ }^{\mathrm{TM}}$ DNA ladder mix. b) GeneRuler ${ }^{\mathrm{TM}}$ 100bp DNA ladder. c) Bench Mark. 


\subsection{Vektoren}

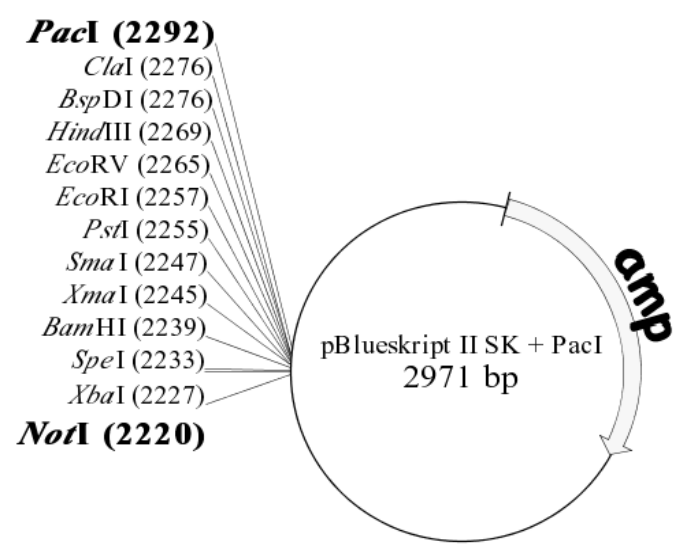

Abb. 41: pBlueskript II SK+PacI-Vektor.

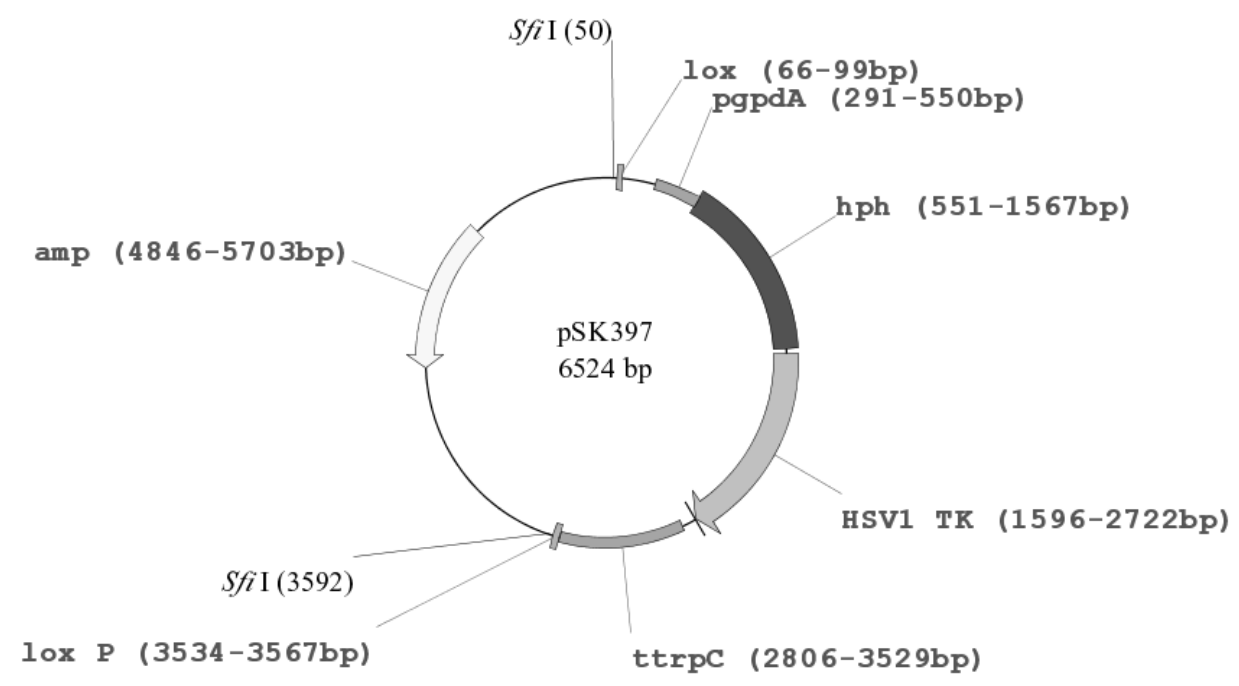

Abb. 42: Plasmid psk397; Resistenz-lieferndes Insert der Deletionsplasmide.

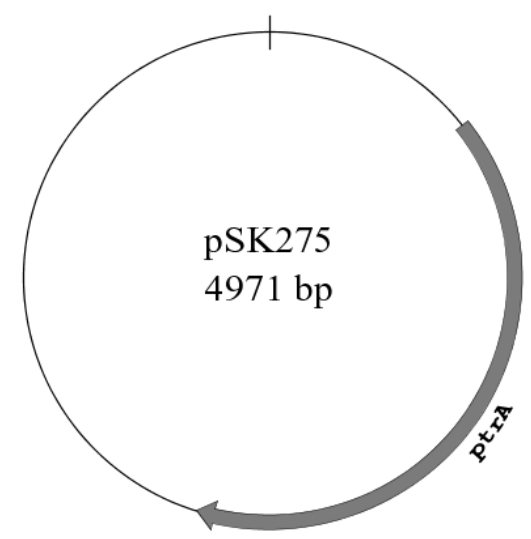

Abb. 43: Plasmid psk275; Resistenz-lieferndes Insert der Komplementierunsplasmide. 


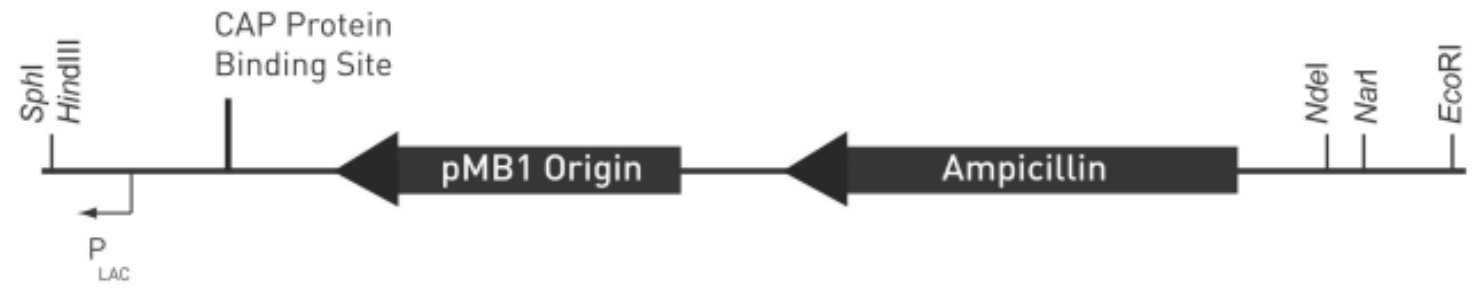

Abb. 44: Linearisierter pUC19-Vektor zur Herstellung der Komplementierungsplasmide.
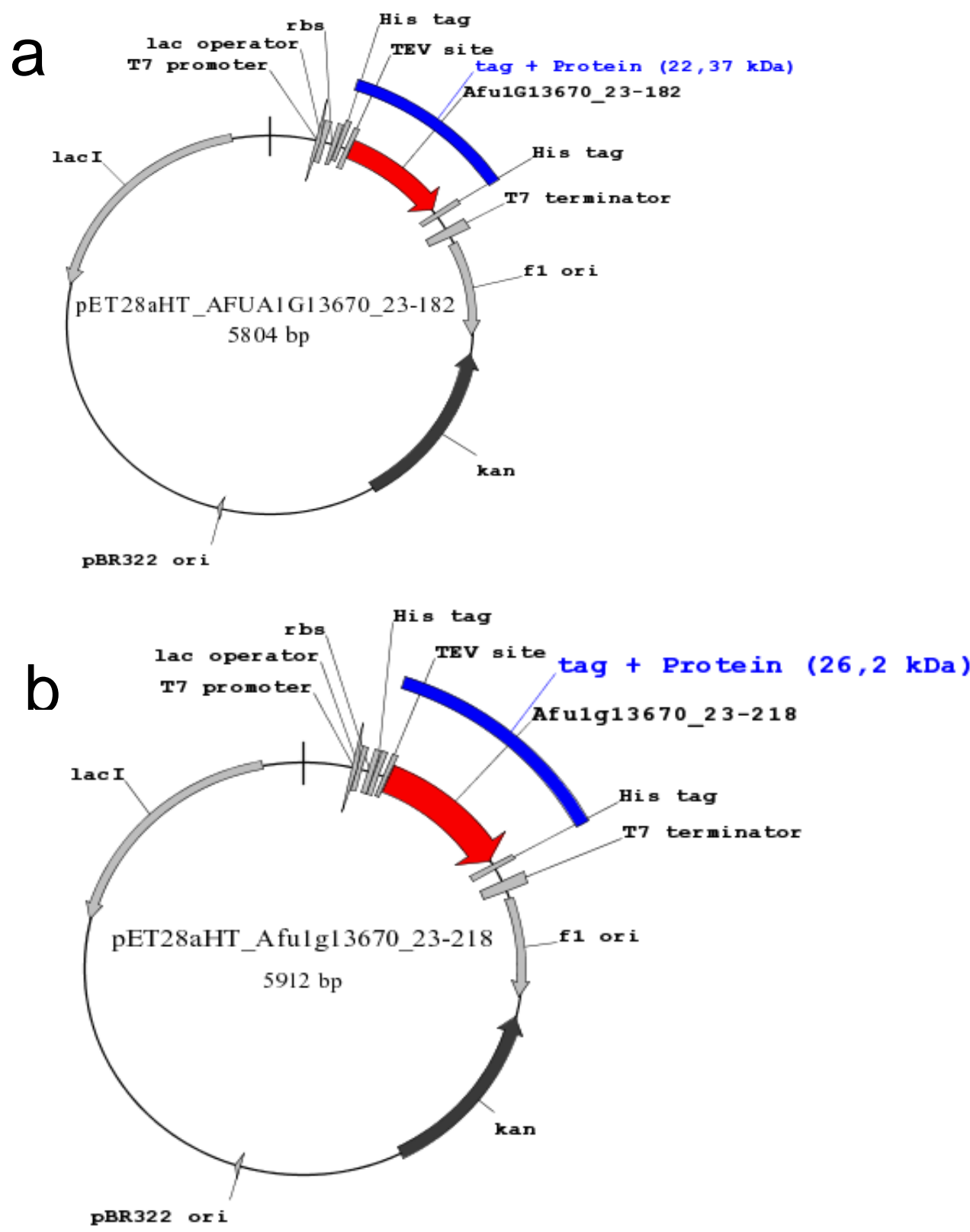

Abb. 45: Expressionsplasmid pET28aHT_Afu1g13670 mit a) kurzer Version des Proteins (AS 23182) und b) langer Version des Proteins (AS 23-218) und der erwarteten Größe für das Protein einschließlich Tag. 


\section{Lebenslauf}

$\begin{array}{ll}\text { Name } & : \text { Sahra Herrmann } \\ \text { Geburtsdatum } & : \text { 20. November } 1984 \\ \text { Geburtsort } & : \text { Uslar } \\ \text { Staatsangehörigkeit } & : \text { deutsch }\end{array}$

Schulbildung

08/91-06/95 Grundschule Schönhagen/ Sohlingen

06/95-07/97 Orientierungsstufe Uslar

07/97-06/04 Gymnasium Uslar,

Abschluss: Abitur

\section{Studium}

$10 / 04-09 / 10$

Diplom- Biologie,

Georg-August-Universität Göttingen

$01-10-09 / 10$

Diplomarbeit am Institut für Medizinische Mikrobiologie, Universitätsklinikum Göttingen

Thema der Diplomarbeit: Der Einfluss der Wirtsadaptation von Campylobacter jejuni auf dessen Zellinvasivität

\section{Auslandszeiten}

08/07-06/08

Stipendium-Auslandssemester an der Lund University

Department of Undergraduate Studies in Biologie,

Lund/ Schweden

\section{Arbeitsverhältnisse/ Promotion}

01/11-12/13

Institut für Medizinische Mikrobiologie, Universitätsklinikum Göttingen

01/14-03/14

Leibniz Institut für Naturstoff-Forschung und Infektionsbiologie e.V., Hans-Knöll-Institut in Jena 
Thema der Doktorarbeit: Identifizierung

schutzvermittelnder Antigene von Aspergillus fumigatus für eine Impfstoffentwicklung zur Verhütung invasiver Aspergillosen bei Leukämie-Patienten

\section{Publikation}

Utz Reichard, Sahra Herrmann and Abdul R. Asif, Vaccination Approaches Against Opportunistic Fungal Infections Caused by Aspergillus fumigatus, Current Protein and Peptide Science, 2014, 15(5):424-9

\section{Kongressbeiträge}

Herrmann S., Iben I., Groß U., Reichard U., Untersuchung neuer Impfstoffkandidaten bei Aspergillus fumigatus, 45. Wissenschaftliche Tagung der Deutschsprachigen Mykologischen Gesellschaft e.V., 1.-3.9.2011 in Kiel, Posterpräsentation

Virulenztestung von Aspergillus fumigatus Mutanten nach Knock-out von Konidienoberflächenproteinen, 44. Jahrestagung der Arbeitsgruppe „Klinische Mykologie“ der Deutschsprachigen Mykologischen Gesellschaft, 10.-11.2.2012 in Göttingen, Vortrag

Herrmann S., Iben I., Groß U., Reichard U., Reduced virulence of Aspergillus fumigatus mutants after knock-out of conidial surface proteins, 18th Congress of the International Society for Human and Animal Mycology, 11.-15.6.2012 in Berlin, Vortrag

Herrmann S., Iben I., Groß U., Reichard U., Testing the protective properties of vaccine candidates against Aspergillus fumigatus in animal trials, 64. Jahrestagung der Deutschen Gesellschaft für Hygiene und Mikrobiologie e. V., 30.09.-3.10.2012 in Hamburg, Posterpräsentation 